Andrews University

Digital Commons @ Andrews University

\title{
Empirical Development of an Instructional Product and its Impact on Mastery of Geometry Concepts
}

Donaldson Williams

Andrews University, williams@andrews.edu

Follow this and additional works at: https://digitalcommons.andrews.edu/dissertations

Part of the Education Commons, and the Geometry and Topology Commons

\section{Recommended Citation}

Williams, Donaldson, "Empirical Development of an Instructional Product and its Impact on Mastery of Geometry Concepts" (2009). Dissertations. 1724.

https://digitalcommons.andrews.edu/dissertations/1724

https://dx.doi.org/10.32597/dissertations/1724

This Dissertation is brought to you for free and open access by the Graduate Research at Digital Commons @ Andrews University. It has been accepted for inclusion in Dissertations by an authorized administrator of Digital Commons@ Andrews University. For more information, please contact repository@andrews.edu. 


\title{
ABSTRACT \\ EMPIRICAL DEVELOPMENT OF AN INSTRUCTIONAL PRODUCT AND ITS IMPACT ON MASTERY OF GEOMETRY CONCEPTS
}

\author{
by
}

Donaldson Washington Williams

Chair: Larry D. Burton 


\title{
ABSTRACT OF GRADUATE STUDENT RESEARCH
}

Dissertation

\author{
Andrews University \\ School of Education
}

\begin{abstract}
Title: EMPIRICAL DEVELOPMENT OF AN INSTRUCTIONAL PRODUCT AND ITS IMPACT ON MASTERY OF GEOMETRY CONCEPTS

Name of researcher: Donaldson Washington Williams

Name and degree of faculty chair: Larry D. Burton, Ph.D.

Date completed: March 2009
\end{abstract}

\section{Problem}

Relatively poor levels of mathematical thinking among American school children have been identified as a major issue over the past half century. Many efforts have been made to increase the mathematics performance of children in schools. Additionally, out-of-school-time programs have attempted to address this issue as well. Holistic development is one of the distinguishing features of Seventhday Adventist instructional programs. Yet, as of 2007, the Pathfinder program, an informal educational program operated by the world-wide Seventh-day Adventist church, had no instructional product designed to foster participants' cognitive development in mathematics. This study focused on the empirical development of 
an out-of-school-time geometry curriculum and looked at its impact on mastery of geometric concepts. This program was entitled Geometry in Real-life Application Curriculum Experiences (G.R.A.C.E.).

\section{Method}

The instructional product development procedure of Baker and Schutz was employed in this study. First the need for an empirically developed geometry education product for Pathfinders was established. Then behavioral objectives were written, based on the standards developed by the National Council of Teachers of Mathematics and geometry education literature.

Instructional activities were prepared to help meet each objective and organized in logical sequence. Bloom's Revised Taxonomy served as a resource during initial instructional development. The Baker and Schutz process stipulated that the instructional product undergo repeated tryouts with members of the target population. The development process would be considered complete when a minimum of $80 \%$ of G.R.A.C.E. Project participants scored at least $80 \%$ on each of the stated objectives. Accordingly, the instructional product was subjected to repeated revision during its developmental stages. Appropriate adjustments were made to eliminate specific weaknesses. Both developer's and participant's manuals were created in their final forms.

\section{Results}

The completed G.R.A.C.E. Project consists of a developer's manual, pre- and post-tests for participants, and a participant's manual. The developer's manual 
covers both relevant content and detailed procedures for project presentation and test administration. The participants' manual presents mathematics content to be mastered by participants. In addition, review questions and answers, diagrams, and charts are included to facilitate mastery of project contents. The pre-/post-test inventory consists of a 25-item cognitive instrument combined with a 20-item affective instrument. After three field trials and revisions of the curriculum, the product was delivered to 25 subjects. These subjects were able to achieve cognitive mastery at the level specified for the 25 objectives.

Based on the assumptions of the Baker and Schutz model the percentage difference between affective post- and pre-test scores was expected to be positive, yielding a moderate effect size. However, the average effect size for all four groups was .868, indicating a high impact of program on subjects' interest in and appreciation of geometry concepts.

\section{Conclusions}

This study provided insight into the role of curriculum developers as they engage in the process of empirical development. It also provided a resource for instructors in Pathfinder instructional programs in the Lake Union Conference of Seventh-day Adventists. Other Seventh-day Adventist audiences may also utilize a modified version of the instrument in their instructional programs for Pathfinders. 
Andrews University

School of Education

\title{
EMPIRICAL DEVELOPMENT OF AN INSTRUCTIONAL PRODUCT AND ITS IMPACT ON MASTERY OF GEOMETRY CONCEPTS
}

\author{
A Dissertation \\ Presented in Partial Fulfillment \\ of the Requirements for the Degree \\ Doctor of Philosophy
}

by

Donaldson Williams

March 2009 
(C)Copyright by Donaldson Williams 2008 All Rights Reserved 


\title{
EMPIRICAL DEVELOPMENT OF AN INSTRUCTIONAL PRODUCT AND ITS IMPACT ON MASTERY OF GEOMETRY CONCEPTS
}

\author{
A dissertation \\ presented in partial fulfillment \\ of the requirements for the degree \\ Doctor of Philosophy
}

by

Donaldson Williams

APPROVAL BY THE COMMITTEE:

Chair: Larry D. Burton

Dean, School of Education

James Jeffery

Member: R. Lee Davidson

Member: Lionel Matthews

External: Lynelle Weldon

Date approved 
To Pastor Phillip N. Hosten, Kenneth Palmer, and Dr. Adrian Westney, distinguished veteran leaders in the Seventh-day Adventist Church Organization, my mentors and brothers in Christ 


\section{TABLE OF CONTENTS}

LIST OF TABLES .......................................................................................................... vii

ACKNOWLEDGMENTS ………………...................................................................... viii

Chapter

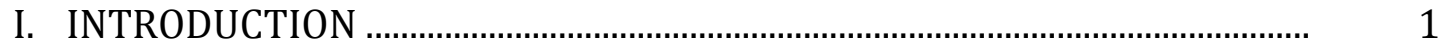

Background to the Problem ....................................................................... 1

Statement of the Problem ......................................................................... 3

Purpose of the Study .................................................................................

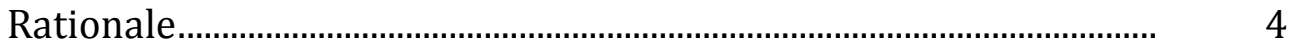

Theoretical Framework of the Study................................................... 5

Overview of Method.................................................................................... 9

Delimitations of the Study ........................................................................ 11

Limitations of the Study ....................................................................... 12

Definition of Terms................................................................................ 12

Organization of the Study …………………………………………….... 14

II. REVIEW OF RELATED LITERATURE............................................................... 16

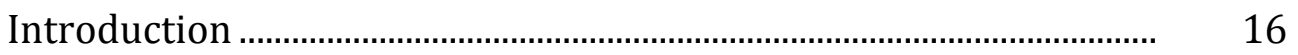

Math Related Issues in the U.S.: Highlights ......................................... 17

Curriculum: Theoretical Considerations................................................. 19

Curriculum Approaches......................................................................... 23

Curriculum Ideas ................................................................................... 27

Four Theorists and Their Implications for

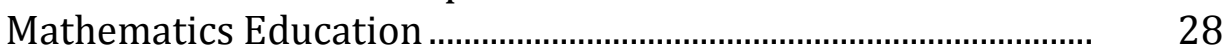

Piaget ............................................................................................... 29

Sensory-motor Stage ………………………………………..... 29

Preoperational Stage ................................................................. 30

Concrete-Operational Stage...................................................... 30

Formal Operational Stage ........................................................... 31

Bruner …………………………………………………….... 31

Vygotsky …………………………………………………....

White.......................................................................................... 33

International Studies on Mathematics Achievement ......................... $\quad 36$

Mathematics Standards and Focal Points.............................................. $\quad 42$

Geometry in the Middle Grades ................................................................. 
The Van Hiele's Hierarchy .......................................................................... 47

Out-of-School Time Programs................................................................ $\quad 50$

Out-of-School Time Program Design ..................................................... 55

Project Based Learning...................................................................... 55

Research-Based Learning ............................................................... 57

Examples of Successful Mathematics Programs .......................... 58

III. METHODOLOGY …………………...................................................................

Introduction .........................................................................................

Baker and Schutz Product Development Model's

Relevance for the $21^{\text {st }}$ Century........................................................... 62

Population and Sample ......................................................................... 66

Steps in Developing the Instructional Product..................................... 67

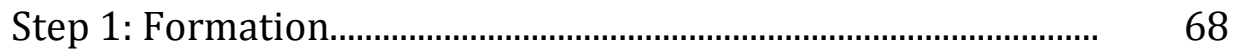

Step 2: Developing Behavioral Specifications................................. 68

Step 3: Item Tryout........................................................................... 68

Step 4: Initial Product Development, Group of 2 ……………...... 69

Step 5: Product Tryout, Group of 4 ................................................. 69

Step 6: Product Revision, Group of 8……………………………... $\quad 70$

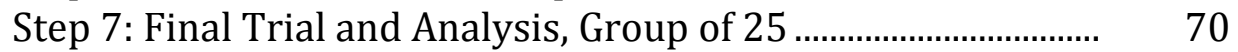

Modification of Affect ............................................................................. $\quad 70$

Statistical Analysis .................................................................................

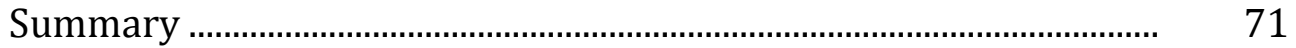

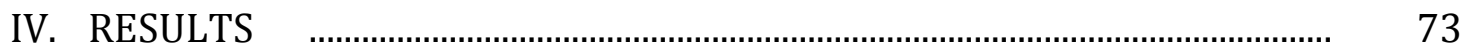

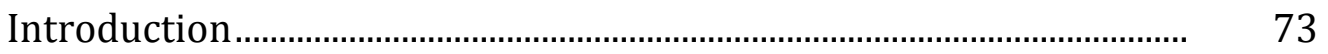

Empirical Development of the Instructional Product.......................... $\quad 74$

Step 1: Formulation............................................................................

Step 2: Developing Instructional Specifications ........................... $\quad 74$

Section One: Foundations of Geometry-

Six Behavioral Objectives .................................................. $\quad 75$

Section Two: Geometry All Around Us-

Five Behavioral Objectives............................................... $\quad 75$

Section Three: Understanding Key Principles in Geometry-

Five Behavioral Objectives.................................................. 76

Section Four: Constructing Meaning in Geometry-

Five Behavioral Objectives.............................................. 76

Section Five: Using Geometry to Solve Problems-

Four Behavioral Objectives................................................... $\quad 77$

Step 3: Item Tryout............................................................................

The Affective Instrument........................................................... 80

Step 4: Initial Product Development, Group of 2 ………………... 81

Modification of Affect, Group of 2........................................... 86

Step 5: Product Tryout, Group of 4 ………………………………... 87 
Modification of Affect, Group of 4 …………………………... 88

Step 6: Product Revision, Group of 8 ……………………………... 91

Modification of Affect, Group of 8.......................................... 95

Step 7: Final Tryout and Analysis, Group of 25 …………………. $\quad 95$

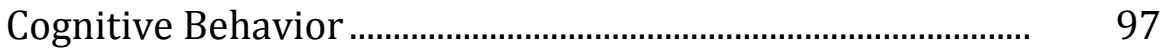

Modification of Affect, Group of 25, Affective Behavior........ 108

Summary ......................................................................................... 112

V. SUMMARY, CONCLUSIONS, AND RECOMMENDATIONS ............................... 113

Literature Review Summary ............................................................ 115

Mathematics Standards and Focal Points...................................... 117

Theorists: Their Influence on Math Education.............................. 118

Mathematics Achievement .............................................................. 119

Seventh- to Eighth-Grade-Level Geometry Achievement............ 121

Curriculum Design: Relevance for the 21 ${ }^{\text {st }}$ Century ..................... 122

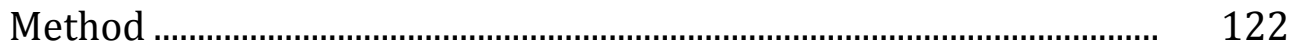

Findings ………………………………………………………….. 124

Discussion .................................................................................... 127

Recommendations ............................................................................ 131

Suggestions for Further Study ……………………………………... 133

Appendix

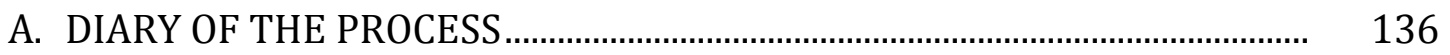

B. ALIGNMENT OF OBJECTIVES, STANDARDS AND CONTENT ........................ 146

C. COGNITIVE INSTRUMENT ................................................................................ 148

D. CRITERIA FOR COGNITIVE INSTRUMENT ...................................................... 164

E. INSTRUMENT FOR MODIFICATION OF AFFECT …………………………..... 181

F. PARTICIPANT'S MANUAL.............................................................................. 184

G. DEVELOPER'S MANUAL ............................................................................. 219

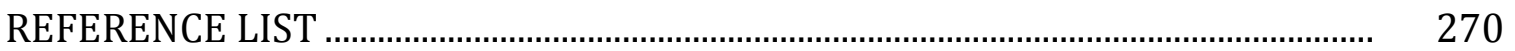

VITA 


\section{LIST OF TABLES}

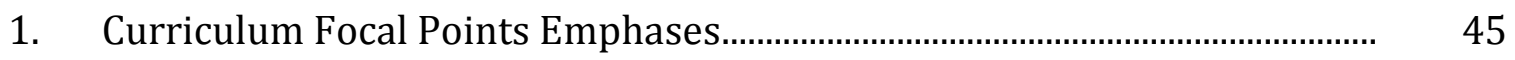

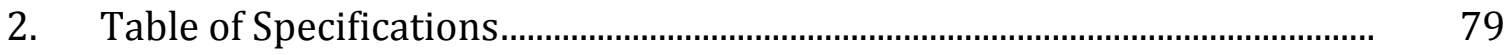

3. Cognitive Pre/Post-Test Results of 2 Participants .......................................... 84

4. Affective Test Scores of 2 Participants.................................................................. 86

5. Cognitive Pre/Post-Test Scores for 4 Participants............................................ 89

6. Affective Test Scores of 4 Participants............................................................. 91

7. Cognitive Pre/Post-Test Score for 8 Participants........................................... 92

8. Affective Test Scores of 8 Participants............................................................ 96

9. Cognitive Pre- and Post-Test Results of 25 Participants.................................. 99

10. Affective Test Scores of 25 Participants ............................................................ 109 


\section{ACKNOWLEDGMENTS}

To Dr. Larry Burton, my dissertation chair and advisor, to whom I feel greatly indebted, I am extremely grateful.

To Dr. Lionel Matthews and Dr. Lee Davidson, who also provided insights and direction in the capacity of dissertation committee members, I express much appreciation.

To other resource persons such as Dr. Barbara Reid, Dr. Randy Seibold, Dr. Kijai, course instructor, Dr. Elvin Gabriel, Dr. Candice Hollingsead, Ginny Lonser, dissertation support and editor, and Members of the Andrews University Library staff, I am very thankful.

To all of my colleagues who have completed or are still in the process of pursuing doctoral studies at Andrews University (especially Dr. Donna Brown, Dr. Virginia Romer, and Dr. Hyacinth Rose), I am unable to thank you enough for your contribution to my success.

To members of my immediate family, close friends, relatives, and wellwishers, I am especially grateful for your encouragement, prayers, and support during the years of my engagement in such a challenging undertaking.

To Mr. Kenneth Palmer, former Superintendent of Allegheny East

Conference, Dr. Adrian Westney, former Associate Director of Education at Columbia Union, and Elder James Lewis, President of Allegheny West Conference, I 
acknowledge the sacrifices made on my behalf during my tenure under your supervision.

I am also grateful to other officials associated with the following local and regional Seventh-day Adventist conferences: Allegheny East Conference, New Jersey Conference, Allegheny West Conference, Lake Region Conference, Columbia Union Conference, and Lake Union Conference.

And last but most important, to God, in whom alone "we live and move and have our being," I am and shall be eternally grateful for another opportunity to prepare to serve. 


\section{CHAPTER 1}

\section{INTRODUCTION}

\section{Background to the Problem}

Math application is required in almost every aspect of our existence; therefore mathematics is critical to our survival (Kanter, 1992; Lucas, 2005). Why? Experts in educational research give several reasons why children and youth need to have a solid foundation in mathematics. First, they recognize that the sustained, rapid advances in science and technology demand math application beyond the most basic level for successful performance in the $21^{\text {st }}$ century workplace (Imel, 1988). Universities and colleges are often unwilling to admit individuals into various programs without evidences of adequate linguistic proficiency and substantial numeracy skills. Consequently, students' career options may be hindered greatly without an adequate foundation in mathematics (Earls, 2007). Proficiency in mathematics may also be related to individuals' successful on-the-job performance (Imel, 1988). As a result, individuals' salaries as well as their quality of life may be enhanced by an early successful math experience (Horn \& Nunez, 2000; Horowitz, 2005).

Besides, students develop confidence among the countless benefits they reap from reasoning mathematically (Whitenack \& Yackel, 2002). They often develop or refine ideas as they develop and justify their thinking. In an age of rapid 
technological and scientific advances, there seems to be an ever-increasing demand for more advanced math applications (Lucas, 2005).

Despite the critical need for a more numerate workforce, current mathematics achievement is below standard nationally when compared with other developed nations (Silver, 1998). Reports on both the Second and Third International Mathematics and Science Study (Program for International Student Assessment [PISA], 2003/2006; Crosswhite, 1985; TIMSS, 1995) indicated overall poor performance in geometry and measurement. The difference in U.S. mean math performance between 2003 and 2006 (483 vs. 474) is not statistically significant (Baldi, Jin, Skemer, Green, Herget, \& Xi, 2007). Undoubtedly, the need for individuals to acquire an adequate math background poses a legitimate challenge for curriculum specialists and educators alike (Leath, 2003; National Science Foundation $[\mathrm{NSF}], 2006)$. This explains in part the reason for the increasing number of recommendations for continuing research in mathematics (Richards, 2002).

There was a specific need for a new type of geometry curriculum at the Grade 7-8 level (Silver, 1986, 1987). The lack of progress in 7-8 level geometry for more than decades suggests that the need still exists for a new type of geometry curriculum. This need for a new approach to the study of geometry fits well within my research interest. Based on claims made by many researchers that the U.S. Public School System has failed in its attempt to address this math emergency (NSF, 2000), some have called for adequate supplemental educational machinery—out-of-school time (OST) programs that are specifically designed to reinforce in-school learning (American Youth Policy Forum [AYPF], 2004; Fabiano, 2004). It is hoped that OST 
programs would help accomplish that which schools "either cannot or choose not to provide" (AYPF, 2004). Several OST program models exist, but policymakers fail to provide the support needed to ensure the effective functioning of the system (AYPF, 2006; Driscoll, Woodruff, Christensen, \& Houlihan, 2005).

\section{Statement of the Problem}

Like many other OST programs such as Boy Scouts, YMCA/YWCA, Boy's Brigade, and American Youth Policy Forum, the Pathfinder Club seeks to identify and address specific needs of youth and children. Seventh-day Adventist (SDA) instructional programs everywhere seek to maintain their distinctiveness by providing a bifocal mission: the "preparation for the joy of service in this life, as well as the higher joy of wider service in the life to come" (White, 1952, p. 13). In order to achieve these noble aspirations, particular emphasis is placed on participants' efforts to “develop their power to think and not be mere reflectors of other men's thoughts" (White, 1903, p. 18).

My initial inquiry revealed that the Pathfinder Club had no instructional product that is deliberately designed to foster cognitive development in mathematics. Without an appropriate and available resource, the existing need among club members is likely to remain unaddressed. This study is intended to supplement the effort of schools in attempting to provide students with an adequate foundation in mathematics. Therefore, whether the development of a relevant geometry curriculum will effectively aid children in the acquisition of useful understandings (that is, being able to apply theory in solving real-life problems) in geometry is the major concern of this research project. 


\section{Purpose of the Study}

The purpose of this study was to empirically develop and test an intensive, 7hour out-of-school time (OST) geometry curriculum. Participant's and developer's manuals were prepared using the Baker and Schutz's (1971) Seven-Step Model. I also developed a 25 -item criterion-referenced test and used it to measure participants' mastery of geometric concepts. Mastery was set at a minimum score of $80 \%$ on each objective by at least $80 \%$ of those participating in the program. Each succeeding group of participants consisted of an increasingly larger number of participants. The emerging curriculum was used for separate tryouts with the different groups of participants. Revisions were completed based on data from each tryout to finally result in a field-ready curriculum product.

\section{Rationale}

Many curriculum specialists agree that if the curriculum is to be effective, it must target an identified need. International comparison reports (International Association for the Evaluation of Educational Achievement, 1967; SIMSS, 1981; TIMSS, 2003) for three decades confirmed low overall mathematics achievement among U.S. students. This problem indicates the need for corrective measures. Follow-up analyses of recent International Trend reports suggest a chronic deficiency in geometric knowledge among U.S. students that is impeding progress in overall math achievement (Ginsburg, Leinwand, Anstrom, \& Pollock, 2005). Clearly, the products that exist are not adequately meeting the needs of the developers' intended audiences. 
Hence, many educators and researchers are strong advocates for the development of a modified, integrated, supplemental curriculum that will support school efforts (Holland \& Andre, 1987; Braddock et al., 1991; Nettles, 1991; Jordan \& Nettles, 1999; AYPF, 2006). Some focus on knowledge and skills application in real-world settings (AYPF, 2006; Peters, 2002). However, the American Institute for Research report by Ginsburg et al. (2005) presents further international math comparison results that "call attention to the United States' relatively poor performance on measurement and geometry and comparatively strong performance in statistics." They suggest that middle school performance in geometry is likely to determine later results in this content area (p. 16).

\section{Theoretical Framework of the Study}

Baker and Schutz (1971) require an empirical/technical type of inquiry for more accurate interpretation of their behavioral, technical production model. The methodology employed in the development of this model is now over 35 years old. This model of instructional product development is being interpreted, in this research, in terms of the progression of four historical curriculum development methodologies that influenced the Baker and Schutz (1971) methodology.

The first foundational methodology is Franklin Bobbitt's (1918) scientific management theory. Principles from industrial production management were incorporated into educational product management. Specifically, the scientific management theory focused on the development of specific objectives as a basis for curriculum development. Seguel (1966) believes that the idea of bringing the new specialization of curriculum making to professional awareness was Bobbitt's main 
contribution. This attempt to employ scientific rigor to facilitate a more accurate measurement of learning brought about a revolution in the field of education. The Baker and Schutz (1971) model utilizes the development of specific objectives to guide the learning process. The model also incorporates a scientific approach by using a pre-instructional inventory to determine what is known about the subject. In addition, it highlights sensitivity to all questions raised, during a subject presentation, to determine learning that is formulated into learning objectives.

The second foundational methodology is concerned with certain objective experiences as advocated by John Tyler (1949). This theory focuses on learning and the learning process. It considers a wide range of factors that affect learning. For example, it involved the design of the course of study, instructional materials, and assessment of achievement. The concept of learning as a production system and individual learning outcomes as the principal product of such a system, as advocated by Tyler (1949), was also adopted by Baker and Schutz (1971) in the formation of their instructional product development methodology. Specifically, the pre- and post-test comparison which indicates measurable learning outcome is an essential feature that is common to both theories.

The Baker and Schutz (1971) methodology is concerned with formulation of behavioral objectives, the organized planning and delivery of need-specific instruction, and established procedure for assessment. These features of the model conform to the following four fundamental questions which focused the work of Tyler (1949/1986): What educational purpose should the school seek to attain? What educational experiences can be provided that are likely to attain these 
purposes? How can these educational experiences be organized? And, how can we determine whether these purposes are being attained?

The third foundational methodology that influenced the development of the Baker and Schutz (1971) model was formulated by Frederick Shaw (1966). It consists of features which were incorporated into the Baker and Schutz instructional product development model. His theory focused on the structure of learning through specific teaching strategies. This approach supports the Baker and Schutz methodology that suggests a prescription for instructional content delivery. Shaw's theory was developed during the mid-1960s--a time of prevailing consciousness of the need for a more relevant curriculum--among educators, administrators, and government alike. Shaw's theory synthesizes ideas from several of his contemporaries including: Ianni and Josephs (1964) who identified the renewed involvement of the U.S. government in the field-testing and development of curriculum and curriculum materials. Watson (1963) expresses concern for the need of a new curriculum, emphasizing students' active involvement, the use of concrete objects, and practical applications. Other contemporaries of Watson focused on the national War on Poverty by highlighting the long-term socioeconomic crisis that is likely to be experienced by those who lack the minimum of a high-school education. This was confirmed by President Johnson (1964) in his declaration that "science and technology have moved so swiftly that advanced education is no longer a luxury; it is a necessity" (p.138). Shaw (1966) was primarily concerned with the depressed condition of the urban youth and the changes in curriculum that would provide a remedy. 
My claim that the foundational methodology of Charles Silberman (1970) also influenced the Baker and Schutz (1971) Instructional Product Development model is justifiable in terms of a prominent feature that is common to both models. The learner's theory--the theoretical and practical regard for individual understanding and personal interests--implemented by Baker and Schutz (1971) constitutes the essence of the Silberman (1970) approach. His work as published in Crisis in the Classroom was done in response to the controversy among college educators regarding the criterion for measurement of success. As a journalist and scholar, Silberman's critique gained the attention of individuals from a wide crosssection of the American society, and many were forced to reevaluate the problem of achievement disparities in institutions of higher learning. As a result of Silberman's (1970) contribution to the on-going debate, educators began to evaluate the success of the educational systems in terms of program impact on individuals' achievement rather than group failure or success. The flexibility feature of the Baker and Schutz (1971) model makes provision for the situational implementation of need-specific instructional product.

The Baker and Schutz (1971) curriculum development model, to a great extent, reflects my passion and therefore meets my expectations as a potential curriculum developer. This model addresses what may be considered the most significant perspective related to the education of learners--the type of resources that learners need, and what the learner can now do with these resources. 


\section{Overview of Method}

The Baker and Schutz (1971) Instructional Product Development Model, which was used in the curriculum development process for this study, prescribes the following seven steps to complete the development process:

Formulation is the first step. The purpose of this initial step is to determine whether there is a genuine need for a new product within a clearly defined population. For example, following interviews with Pathfinder leaders, conference officials, and Pathfinder club members, I determined that the need for a geometry curriculum existed within a selected age group of Pathfinders before attempting to undertake this study.

The second step of the Baker and Schutz (1971) Model requires the formulation of clearly defined performance objectives. These outcomes specify performance at different levels of the cognition continuum as outlined in Bloom's Taxonomy. Based on specific geometric skills needed for Pathfinders to function, recommendations found in the literature, and guidelines from the National Council of Teachers of Mathematics (NCTM), 25 behavioral objectives were developed to guide the instructional process. These objectives were aligned with selected NCTM Standards and project contents (Appendix B) of the cognitive instrument, and criteria for the instrument, along with specific instructional strategies for seventhand eighth-grade-level geometry were guided by the objectives. This was followed by the preparation or selection of relevant instructional materials. The material is then organized and presented in both a developer's and participant's manuals. 
The third step of the developmental process is concerned with preparation of the cognitive pre- and post-test with criteria for evaluation. Bloom's Taxonomy provides the framework for the generation of objectives used to facilitate both instruction and outcomes of instruction.

The aforementioned components constitute the curriculum at its initial stage. The fourth step involves experiment with a small group of two or three subjects from the target audience. Following administration of the pre-test, the curriculum is delivered with special care; then, suggestions from the subjects are sought during full exposure to the curriculum. These suggestions, the instructor's observations, and the pre- and post-test comparison outcomes are used in the revision and modification of the developer's manual in preparation for the next session.

Step 5 is the second tryout. It is similar to stage 4 except that a larger group of four to six subjects from the target audience provide suggestions, which are used along with pre- and post test comparison outcomes, in the second round of revisions of the administrator's manual.

The sixth step utilizes 8 to 12 subjects who are exposed to the full curriculum. Mastery is set at the $80 / 80$ level as in the previous sessions. Feedback from this comparatively larger group is critical to this final revision; the product is now sufficiently refined for use with a very large group of subjects.

The seventh and final step follows similar procedures of earlier tryouts. However, there is a heavy focus on complete mastery of contents at this stage. A large group of at least 25 subjects engages the curriculum with the expectation of a 
minimum score of $80 \%$ on each of the stated objectives. When $80 \%$ or more of the subjects demonstrate mastery of test contents, this gives the indication that the curriculum is empirically developed.

The Baker and Schutz (1971) instructional product development procedure stipulates a repeat of all steps, in the entire process, should the stated requirement for mastery be still unmet after the seventh step.

\section{Delimitations of the Study}

1. This study was designed primarily to develop an instructional product to facilitate the cognitive development of seventh- and eighth-grade-level active Pathfinder club members.

2. This instructional product is focused on selected geometry concepts, and is therefore not an exhaustive curriculum in the study of geometry.

3. The instructional product in this study was designed for English readers only. Therefore, references associated with geometric understanding in other languages were not included.

4. Given that some items (example, procedure used in finding volume and or perimeter of irregular shapes) used to both teach and assess the learners were identical, it is possible that post-test outcomes (for these items) have measured simple recall rather than conceptual understanding.

5. The wording of the pre-test instructions may have introduced some bias towards improvement in the cognitive scores (emphasis on the no penalty for not being able to answer questions and that the purpose is to see how much help you 
will need). It is not clear that the zeros on the pre-test reflected complete lack of understanding rather than a lack of interest in exerting greater effort.

\section{Limitations of the Study}

1. The target population for this study is specific to the Adventist Church Pathfinder Program and may not generalize to other OST Programs.

2. From a purposive sampling of subjects, from five Pathfinder groups, the female to male participants' ratio was 8:5.

3. The Seventh-day Adventist organization is almost as diverse as the world. However, the composition of the sample frame for this study consisted mainly of subjects from two to three ethnic groups.

4. Control for a multiplicity of extraneous and interacting factors was beyond the scope of this project.

5. In a single paragraph, only compatible features (of 5 programs mentioned on pp. 55-6) were described; detailed descriptions of all aspects of each program were not presented.

\section{Definition of Terms}

The following terms are defined as used in the study:

Seventh-day Adventists: A conservative Protestant religious group that is engaged in various ministries worldwide, including education, for the distinct purpose of preparing its members for service to humanity while preparing for the hereafter. 
Behavioral objective: A statement of performance that pinpoints learning outcomes under specified conditions. These constructs are used to determine the contents of an evaluation.

Mastery: Attaining to and maintaining the level of competence prescribed by the instructional program. For the purpose of my study, mastery occurs when at least four out of every five participants score a minimum of $80 \%$ on the postcriterion-referenced test.

Empirical instructional product development: A process that leads to the development of a product in a real-life setting but is strictly grounded in theory. For example, Baker and Schutz (1971) advanced a seven-step model that involves delivery of curriculum to increasingly larger groups of subjects for their input. These subject responses are then used in the repeated modification of the curriculum at each stage. Finally, the curriculum in its polished form is administered to a sufficiently large group of subjects for mastery of the contents, before the empirical development process is completed. The model specifies criteria for mastery at $80 \%$ minimum on all of the stated behavioral objectives by at least $80 \%$ of the participants. White (1952) supports the need to give attention to the individual. She also supports clarity in describing performances/tasks to be completed by the learner. Thus, she underscores several features of the Baker and Schutz (1971) model which was used to develop the instructional product herein identified. 
The G.R.A.C.E. Program: A 7-hour, flexible instructional plan designed to promote Geometry for Real-Life Application Curriculum Experience for Grade 7-8level Pathfinder participants.

Pathfinders: A club for boys and girls between the ages of 10 and 16 operated by the Seventh-day Adventist Church, which directs its resources toward training of youth for service to humanity and devotion to God and fun fellowship with each other. Participants' cognitive development is an integral component of the training.

Out-of-school time program: Any needs-based training program that is not conducted within a formal school, and engages young people in meaningful training for personal enhancements (AYPF, 2006).

Project-based Learning (PBL): An instructional strategy that begins with clearly stated outcome and project activities that are structured and engaged toward accomplishing those goals.

Research-based instruction: Innovative ways of teaching that incorporate non-traditional approaches that have been found to be effective.

Developmentally appropriate mathematics: Modified content in mathematics that is best suited for the learner in terms of his/her developmental stage rather than age.

\section{Organization of the Study}

This study is divided into five chapters. Chapter 1 provides an introductory overview, including the purpose and rationale for this study. Chapter 2 is the organization, analysis, and discussion of selected literature related to OST geometry curriculum development. Chapter 3 outlines the methodology used in this study; a 
seven-step process based on Baker and Schutz (1971) provides a description of how the instrument is used. In addition, procedures for data collection and analysis are included. Chapter 4 presents results of the empirical development of the instrument along with pre- and post-test comparisons. Chapter 5 gives the summary, conclusion, implications, and recommendations for further research. The appendices contain the cognitive instrument, pre- and post-test, criteria for development of objectives, a record of the developmental process, and a developer's and participant's manuals.

This study was guided by its purpose rather than by research questions. 


\section{CHAPTER 2}

\section{REVIEW OF RELATED LITERATURE}

\section{Introduction}

Review of the literature for this chapter was organized and focused on five main themes. The first provides a highlight on math-related issues in the U.S. The second looks at some theoretical ideas as well as core concepts advocated by selected learning theorists. The third details the process involved in the Baker and Schutz (1971) Instructional Product Development model. The fourth focuses on math achievement and standards; and the fifth looks on design, implementation, and outcomes of a typical Out-of-School Time (OST) program. The chapter concludes with core features of mathematics programs that have been successful.

Basic strategies for conducting this literature review included identifying, accessing, organizing, filtering, and utilizing available resources. The James White Library at Andrews University provided ready access to a variety of rich sources of information. Some examples of its electronic databases include Academic Search File, PsycLIT, JSTOR, FirstSearch (OCLC), Dissertation Abstracts and Full Text, and E. G. White Resources. In addition, a wide variety of books, dissertations, and current journals/periodicals constitute important primary and secondary sources of information. The World Wide Web and Internet resources, such as ERIC DATABASE, along with the Google and Yahoo search engines, were found to be very useful. 
These wide choices of search options allowed for greater flexibility. Some examples of search terms that were used included: math foundation for high school, junior high mathematics achievement, middle school mathematics achievement, or math achievement in the middle grades, geometry achievement, Junior high level geometry, developing geometry curriculum, and math/geometry standards for middle grades (Glatthorn \& Joyner, 2005). Narrowing of the search by year was particularly helpful in pinpointing the most current/relevant literature for this study.

\section{Math-Related Issues in the U.S.: Highlights}

The cry for greater mathematics achievement among American students can be traced to the launch of Sputnik by the Russians in 1957 (Herrera \& Owens, 2001, p. 2). This event signaled a new era of scientific and technological advancement that demanded mathematics applications beyond the most basic level (Schoen, 1993). The increasing complexity of daily life requires a citizenry that is scientifically literate, and increasing the quality of math and science is an important first step (Leath, 2003). Despite renewed awareness of the need for equity in math curriculum in K-12 education in the United States, the system fails to guarantee equal access to quality education for every child (Malhoit, 2005, p. 19). In fact, after 130 years of K-12 performance history, schools are facing enormous problems which they cannot fix alone and that the best effort of any school is still inadequate (Campbell, 2006; Enderle, Liebler, Haapala, Hart, Thonakkaraparayil, Romonosky, Rodriquez, \& Trumbower, 2004; Fullan, 1993). The most recent study of the 
Program for International Student Assessment (PISA) has highlighted once again the continuing failures of American school math education (Ralston, 2005).

As a result, several corrective measures have been attempted by the U.S. government over the past several years. For example, it was projected that by the year 2000 every child in the public school system should be performing at standard in reading and mathematics (Schlafty, 2000). The 2001 modification of the Elementary and Secondary Education Act (ESEA) into the No Child Left Behind Act (NCLB), by the U.S. Congress, was signed into law by George W. Bush on January 8, 2002 (U.S Congress, 2002). The gesture was a response to two main conditions: (a) the chronic failure of the U.S. educational system to provide an adequate educational experience for every child (Ralston, 2005), and (b) poor performance among American students when compared with students from other developed nations (Silver \& Kenny, 2000). The architects of this Act acknowledged that in the past a significant number of students have not achieved an acceptable level of competence in mathematics. They also challenged public schools to ensure proficiency in reading and mathematics for all students by 2003 and 2004 (Kim, 2006, p. 9).

However, the 2005 National Educational Assessment Progress math results for eighth-graders were described as being "illusive and alarming with less than one-third of the students and 13 percent of low-income eighth-graders scoring at the proficiency level or above" (Bush, 2005, p. 1). Her analysis of national standards for all 50 states revealed that not much has changed for students in the $8^{\text {th }}$ and $12^{\text {th }}$ grades. Further, most states claim that large majorities of students in $4^{\text {th }}$ and $8^{\text {th }}$ grades are proficient in mathematics and reading but these claims are not reflected 
in NEAP results (Ravitch, 2006). The learning of mathematics in the middle school is a critical component in the education of our nation's youth (Mathematical Science Education Board [MSEB], 2002). The foundation laid during these years prepares students with the skills and knowledge necessary to study higher level mathematics during high school. On a broader note,

Success in mathematics education matters at the level of individual citizens because it opens options for college and career and increases prospects for future income. The probability that students will enroll in 4-year college correlates substantially with completion of high school mathematics programs. (National Center for Educational Statistics [NCES], 2007, p. 17)

\section{Curriculum: Theoretical Considerations}

Curriculum lies at the heart of an educator's desire to make a difference in human lives. To ask meaningful questions about what should be taught and learned invokes basic assumptions about what it means to enable the growth of human beings and society (Marshall et al., 2000, p. 2). In The Curriculum Reader, Flinders and Thornton (2004) identified a series of questions around which curriculum scholars have organized theory. These questions raise issues regarding values, purpose, and outcome of education from the collective perspective of curriculum scholars.

Curriculum issues were addressed during the late $19^{\text {th }}$ century and early $20^{\text {th }}$ century by national committees which were appointed to formulate, prescribe, and mandate the implementation of curricula (Richards, 1892). For example, the 1893 report of the Committee of Ten on Secondary School Studies stipulated that: All secondary school students were to study a common curriculum of nine subjects. 
Detailed programs of study were developed with weekly time allotment for each subject. The 1918 report of the Commission on Reorganization of Secondary Education (appointed by the NEA in 1913) indicated that secondary education should be determined by the needs of the society to be served, the character of the individuals to be educated, and the knowledge of educational theory and practice available (Commission on Reorganization of Secondary Education, 1918, p. 7).

On the contrary, Rugg (1926) indicated that every subject that is taught in the secondary school should be taught in the same way and to the same extent to each pupil so long as he pursues it, no matter what the probable destination of the pupil may be and at what point his education is to cease (p. 40). This contrast indicated the beginning of another era in which the curriculum field in America was now about to be fully launched by the informed works of emerging scholars everywhere (Pratt, 1980).

The principle of scientific management has had its impact on curriculum development in the U.S. over the years. Through the work of Franklin Bobbitt (1918), the popular scientific-management theory was converted for the formation of the curriculum theory (Bailey, 1997). Specifically, the design was for the continuation and management of national progress in industry and technology (Apple \& King, 1977). It was based on the proposition that

if schools were to become as efficient as factories, waste in the curriculum needed to be eliminated. This process resulted in the identification of numerous discrete skills and other learnings, and the emergence of specific detailed objectives as the first and most important decision in curriculum development. (Apple \& King, 1977, p. 2) 
Harold Rugg, W. Charters, and their contemporaries shared the faith of Bobbitt; most of them emphasized the education that would enable children to grapple with the problems of the future in a changing society. In Bobbitt's curriculum writing, he stressed the need for a common vocabulary and the importance of cooperation among specialists and professionals from different areas, including classroom teachers, materials developers, measurement experts, administrators, psychologists, sociologists, and subject specialists (Pratt, 1980).

The contribution of Ralph Tyler (1949/1986) to the field of curriculum studies is principally known through his Basic Principles of Curriculum (1949/1986). "This may have had more influence on world-wide curriculum design and practice than any other" (Cordero \& Garcia Garduno, 2004, p. 3). It is impossible to ignore the fact that Tyler was influenced by his contemporaries who focused on curriculum behaviorism: Franklin Bobbitt and Werrett W. Charters, both of whom were Tyler's teachers at the University of Chicago (Garcia Garduno, 1995). In fact, even though Tyler was undoubtedly a behaviorist, his Theory was formulated as a result of his attempt at synthesizing the works of theorists from a variety of philosophical camps. For example, Tyler's work included an evaluation of the effect of Dewey's progressive education on university students by comparison with traditional education (Ridings, 1981). Following are four fundamental questions asked by Tyler:

1. What educational purposes should the school seek to attain?

2. What experiences can be provided that is likely to attain these purposes?

3. How can these educational experiences be effectively organized? 
4. How can we determine whether these purposes are being attained? These questions, according to Tyler, "must be answered in developing any curriculum and plan of instruction" (Tyler, 1949/1986, p. 1). Essentially, these questions brought into focus the major curricular issues with which Tyler was most concerned.

Several later theorists have attempted to make improvements in clarity and design of specialized instructional products. These include Taber (1962), Popham and Baker (1970), Baker and Schutz (1971), and Gagne and Briggs (1974). More recently, Naden (1992), Gregor (1996), Selmanovic (1996), and Bailey (1997) have utilized the Baker and Schutz model to develop curriculum products for specific content and context.

Curriculum theory research has developed a new understanding of culture, gender, and class bias that has led to various attempts to construct a curriculum that is more sensitive to cultural, gender, and language differences among students (Sergiovanni \& Starratt, 1998). Culturally pluralistic curricula are viewed by many educators as strategies for improving academic programs and enhancing selfesteem among students whose racial, ethnic, or language heritage differs from that of the Anglo-European population (Association for the Advancement of Health Education, 1994; McCarthy, 1994). A corollary to this perspective is the belief that an inclusive curriculum can help promote intergroup harmony and reduce conflict between ethnic groups (Heller \& Hawkins, 1994). 


\section{Curriculum Approaches}

Conceptualizations of the curriculum fall within two broad categories. First, the curriculum should be treated as a body of content with emphasis on what should be taught. Products or certain achievement levels are the outcomes (Baker \& Schutz, 1971). The second idea is to regard curriculum as a process that focuses on the learner and the needs of the learner. Clearly, the organizational framework for curriculum is preceded by its conceptualization. Below are five variations of the subject-centered curriculum presented in the literature. These are primarily concerned with the curriculum as planned.

1. Subject-area curriculum design has its roots in the seven liberal arts of Greece and Rome (Tanner \& Tanner, 1990). Some believed that the modern history of the curriculum design started in the St. Louis school system in the 1870s under William Harris. This design has dominated the U.S. curriculum from that time to the present. In this design curriculum is treated as subject matter that is a specialized and largely autonomous body of knowledge.

2. One of two conservative philosophies of education specifies what the curriculum should look like. Perennialism holds that curriculum should consist of the three R's, Latin, and logics at the elementary level, with the classics added at the secondary level. Hutchins (1936) believes that the classics (or what he terms "Permanent studies") are enduring and are therefore equally valid for the present.

3. The second conservative philosophy specifies a similar approach to curriculum design, in terms of its resilience. It focuses on the following subject areas: English, math, the sciences, history, and foreign languages (Bestor, 1956). It is 
suggested that delivery of these subject matters is the most effective way to develop a system that will keep up with the explosion of knowledge.

4. During the 1950s and 1960s, the federal government funded several projects designed to improve English and math curriculum. This resulted in new curricula organized around the structure of each distinct subject or discipline. Structure implies unifying concepts, rules, and principles that define how one thinks about the subject or area of inquiry (Anderson, 2004). Individuals who follow this model regard curriculum as a process of continuing inquiry within the boundaries of a subject rather than being fixed or permanent (Phenix, 1962). The essential difference between this design and that of the earliest subject-centered design is the method of inquiry which clearly indicated a shift from a rigid to a more dynamic approach.

5. The back-to-basics movement produces a core subject curriculum design. It is another subject-centered approach that places emphasis on solid subjectsEnglish, history, science, and math. Music and art may also be allowed as supplements but are not considered basic (Jarrett, 1977). It arose out of the general laxness of the 60s and 70s which resulted in a general decline in achievement test scores.

The process-driven conceptualization of curriculum has been the focus of interactionists such as Dewey, Borton, Montessori, and Vygotsky. These theorists are concerned primarily with learning as a function of the many self-directed activities engaged in by learners as they interact within the learning environment. These five conceptualizations are as follows: 
1. The Student-Centered Approach: The student-centered approach to curriculum design arises out of the philosophy of Jean Jacques Rousseau, who believed that a child should be allowed to develop and create freely without adult impositions in the form of structured curriculum. In the United States John Dewey advocated a version of a child-centered curriculum experience that sought to balance subject matter with the needs and interests of students. Some variations of the student-centered curricula include:

2. The Child-Centered Approach: Child-centered schools were a reaction to the traditional subject-matter-dominated curriculum and trace their beginnings to Rosseau's publication of Emile in 1762. Other theorists followed and built upon his ideas. Pestalozzi in Switzerland and Frobel in Germany introduced child-centered practices in schools during the $19^{\text {th }}$ century. Early in the $20^{\text {th }}$ century Maria Montessori developed a series of learning activities that incorporated play and work with young children. Progressive educators in the United States used Dewey's ideas to develop what he called organic schools (1915) organized around student interests and needs. Dewey advocated a somewhat radical approach to learning. He was among the first theorists to demonstrate that children learn effectively when they are allowed to construct meaning during informal play.

3. The Activity-Centered Approach: The activity-centered curriculum was advocated by William Kirkpatrick, a student of Dewey. The model tied purposeful activities to a child's interests and needs. His project method (1918) was further developed by Elisworth Collings (1923), one of Kirkpatrick's students. He based his 
curriculum on various real-life experiences. Field trips, dramatization, interest centers, and other activity-based curriculum came out of this.

4. The Humanist Approach: The humanistic point of view was another major philosophy concerning education. The rise of humanistic education during the 1960s and 70s was in part a reaction to the emphasis on cognitive learning of the 50s and 60s. Terry Borton (1970) believed that curriculum ought to be related to the personal growth of values, feelings, and a happy life. He believed that a student's social and personal needs should be taken in consideration in designing curriculum. Carl Rogers and Abraham Maslow are also among modern humanistic theorists who have emphasized process and development of self.

5. The Constructivist Approach: The constructivist approach to curriculum development is based on the assumption that learning is an active process that requires a change in the learner (Vygotsky, 1987). Therefore, as people solve problems and discover the consequences of their actions--through reflecting on past and immediate experiences--they construct their own understanding (Vygotsky, 1987). Vygotsky believed that the child gradually internalizes external and social activities, including communication, with more competent others. On the other hand, Dewey argues that cognitive conflict or puzzlement is the stimulus for learning, and that it determines the organization and nature of what is being learned. In his experiments, Vygotsky studied the difference between the child's reasoning when working independently versus reasoning when working with a more competent person. Vygotsky's findings suggested that learning environments should involve guided interactions that permit children to reflect on inconsistency 
and to change their conceptions through communication. Vygotsky's and Piaget's theories are often contrasted to each other in terms of individual cognitive constructivism (Piaget) and social constructivism (Vygotsky). Some researchers have tried to develop a synthesis of these approaches, and some, such as Michael Cole and James Wertsch, argue that the individual versus social orientation debate is over-emphasized.

\section{Curriculum Ideas}

Curriculum ideas were also advanced by critics over the years. For example, the relevant curriculum has been a recent development. It seems axiomatic that curriculum should reflect social change. A classic work done in satiric style regarding this idea is the Saber-Toothed Curriculum (Benjamin, 1939). The idea is that curriculum must change. The emphasis today within this movement is to tie curriculum to the needs of students and their real-life experiences. On a similar note, one of the first educators to describe the hidden curriculum was Wayne Gordon (1957). He believed that the value of the student peer group was ignored when formal curriculum was designed. He also believed that students' behavior and achievement were affected by their status and roles in schools and that these roles often conflict with the formal school curricula. The need was to develop a curriculum that emphasized personal freedom and cooperative group learning.

Anderson (2004) concluded that the two methods of organizing curriculum (subject-centered and student-centered) represent the "ends of a continuum." Further, she observed that "most curricula today seek a balance between these two 
extremes" (p. 7). However, what has been omitted from the discussion is the theistic view-a view that emerges from the basic assumption of God as creator/redeemer of humankind. Seventh-day Adventists use such a theistic approach which places emphasis on students' balanced, holistic development. By way of scriptural authority and the works of White (1952), a curriculum model aligned to theistic assumptions was established with particular emphasis on (a) the inestimable value/worth of the learner (who should be taught?), (b) the essential curriculum content (what should be taught?), (c) the effective methods for instructional delivery (how should it be taught?), and (d) an atmosphere of love and affirmation (where should it be taught?).

\section{Four Theorists and Their Implications on Mathematics Education}

Since the acquisition of mathematical skills/competencies is a cognitive process, principles from the works of reputable theorists have been analyzed, summarized, and used as a guide to curricular content planning, structure, and delivery. Notwithstanding, I recognize that though helpful, the combined effort of these theorists is still inadequate for the purpose of this study as they do not consider implications of concern for theistic educators. The intent is to assume a more inclusive stance so that the voices of theorists from other perspectives may also be given some attention. Therefore, its theoretical framework consists of a combination of major elements from these with special emphasis on E.G. White's perspective on curriculum development. 


\section{Piaget}

Swiss scholar Jean Piaget (1896-1980) began to study intellectual development during the 1920s. His research integrated two fields-biology and epistemology—in his structural-functional approach to children's cognitive development. His notion that a baby's thoughts and learning were radically different from those of adults was revolutionary (Ginsburgh \& Opper, 1988). It is believed among reputable scholars that Piaget's work is still the most detailed and systematic statement on human intellectual growth available today (Beilin \& Pufall, 1992; Seigler, 1991; Sutherland, 1992). Piaget viewed children as curious, active explorers who, in response to their environment, create understandings or construct their own meanings (Piaget, 1950). Stages of Piaget's cognitive developmental sequence are summarized below.

\section{Sensory-motor Stage}

This is the initial cognitive developmental stage from 0-2 years. Behavioral schemata evolving from the child's coordination of sensory input and motor responses are the dominant cognitive structures of this stage. Piaget identified six sub-stages in the child's gradual transitioning from a reflexive to a reflective organism. It is during this process that the child develops the ability to distinguish self from environment and learns about properties of various objects and their relationship to each other. 


\section{Preoperational Stage}

This period focuses on limitations and deficiencies of children's thought processes. It is divided into two stages: the preconceptual period (2-4 years) and the intuitive period (4-7 years). The preconceptual period is characterized by symbolic representations. The child develops a schema for comparing missing objects even though it becomes difficult to distinguish between the real and the imaginary. Piaget claimed that young children often fail to make accurate judgments about people's motives, desires, and intentions because they tend to rely on their own perceptions. The child during the intuitive period is less egocentric in his/her thinking than the preconceptual child and is more proficient in classifying objects. However, he or she still tends to focus on the appearance of an object rather than its detailed, logical description.

\section{Concrete-Operational Stage}

The centered thinking of the preoperational stage (7-11 years) has been replaced by more sophisticated thought processes. Piaget maintained that a concrete-operational child is capable of producing cognitive maps and constructing accurate mental representations of a complex series of actions and that those operational abilities evolve gradually and sequentially. He further noted that a concrete operational child finds it impossible to think about abstractions that violate his/her conceptions of reality. 


\section{Formal Operational Stage}

During the formal operational period (11 years and older), children have entered a developmental stage in which they are able to perform mental operations on ideas and propositions. Their approach to problem solving becomes increasingly systematic and abstract and resembles the hypothetical deductive reasoning of a scientist. For example, unlike the concrete-operational child, who uses a trial-anderror approach to solve problems and is inclined to accept the first solution, the formal operational child uses a systematic approach to finding multiple solutions to problems.

\section{Bruner}

Jerome Bruner, like Jean Piaget, demonstrated how thought processes could be subdivided into three distinct modes of reasoning. While Piaget related each mode to a specific period of childhood development, Bruner saw each mode as dominant during each developmental phase but present and accessible throughout. Bruner's mode of human development as a combination of enactive skills (manipulating objects, spatial awareness), iconic skills (visual recognition, ability to compare and contrast), and symbolic skills (abstract reasoning) has influenced psychological and educational thought over the past 50 years (Hollyman, 2007).

At a time when psychological thought was dominated by behaviorism, Bruner was able to apply a similar scientific rigor to unobserved mental processes, as was done to observable, measurable responses by behaviorists. Bruner was instrumental in the move from behaviorism to cognitivism in the 1950s and 1960s 
mainstream psychology. An important work in the early days of the cognitive movement was a study in thinking that Bruner published in 1956 with Jacqueline Goodnow and George Austin, and where they defined cognitive process as "the means whereby organisms achieve, retain and transform information" (Bruner, Goodnow, \& Austin, 1956, p. 314).

Bruner believed that information or knowledge is most effectively gained by personal discovery. As a result, he proposed that developmental growth involves mastering each of the increasingly more complex modes-enactive, to iconic, to symbolic. He implied that children should be provided with study materials, activities, and tools that match to and capitalize on their developing cognitive capabilities. For example, a teacher wanting to help children learn about dinosaurs could use all three modes. Students could be asked to construct models of dinosaurs (enactive), they might watch a film about or involving dinosaurs (iconic), or they could consult reference texts and then discuss their findings (symbolic).

Bruner suggested that a person's memory is best facilitated with a view toward meaning and signification and not toward the presentation of facts by someone else. The view of knowledge and memory as a constructed entity is consistent with constructivism, with which Bruner is also closely associated.

\section{Vygotsky}

Vygotsky's (1978) constructivist framework can be a key to the teaching and learning of mathematics (Kim, 2006). A fundamental principle of this theory holds that students need to understand certain basic concepts before proceeding to new 
and more advanced ones. This is especially important since the learning of mathematics progresses in stages. In other words, acquisition of higher-level math skills requires mastery of prerequisite skills. This learning theory seems to reasonably describe what fails to happen for the vast majority of middle-school students who struggle with mathematics. If previously learned concepts were not properly mastered, then the resources needed to pursue further learning in the subject area are lacking. Vygotsky's constructivism is also supported by Bruner's (1960) inquiry process, which connects newly acquired knowledge to previously gained knowledge and Piaget's (1970) process of cognitive interpretation, reevaluation, and connectional reorganization. It also seems safe to assume that Dewey's (1997) guidelines for problem-based instruction, in which children are allowed to learn by actively interacting with their environment, form the basis of later constructivist models.

Novak's (1986) definition of constructivism seems consistent with Bruner's and Vygotsky's ideas of what constitutes wholesome learning. In their attempt to explain how learners gain new knowledge, Eggen and Kauchak (2001) describe constructivism as "views of learning in which learners use their own experiences to create understanding of knowledge that makes sense to them rather than having understanding delivered to them" (p. 246).

\section{White}

Ellen White brings to the discourse a new dimension of thinking and practice based on the authority of the Bible and the inspiration of the Holy Spirit. It was 
during the early 1870s that Ellen White joined the American educational reform movement and began the process that would later establish the Seventh-day Adventist Christian Education model (Schwarz, 1979). Unlike most respected theorists, Ellen White could claim no reasonable pedagogical basis for her insights that have impacted educational thought, primarily in the schools operated by the Seventh-day Adventist church, for well over a century. However, her works provide evidences of the legitimacy of her dual claim: the authority of the Holy Scriptures (White, 1911, p. vii), and the inspiration of the Holy Spirit (White, 1882, p. 13). Ellen White addressed curriculum issues from a purely theistic perspective. Her eclectic approach underscores essential curricula features of other reputable curriculum theorists. For example, Tyler's (1949/1986) and Taba's (1962) definitions of curriculum resonate with Ellen White's instruction that "Before attempting to teach a subject, he [the teacher] should have a direct plan in mind and should know just what he desires to accomplish" (White, 1903, p. 233).

Also, Bobbitt (1918) defines curriculum as an experience designed to foster disciplined thinking. This underscored White's (1903) idea of curriculum function as it relates to students' cognitive development. She believed that educational experiences should be designed to develop the learner's power to think rather than to be "mere reflectors of other men's thought" (White, 1903, p. 18). Ellen White saw the learner (who should be taught?) as having inestimable worth endowed by the Creator in whose image he/she was created, and regarded the curriculum (what should be taught?) as the acquisition of relevant knowledge that prepares the 
learner for "the joy of service in this life and the higher joy of wider service in the life to come" (White, 1903, p. 13).

Ellen White's instructions regarding procedure for curriculum delivery (how should it be taught?) call for modeling of the Master Teacher by highlighting the necessity for Christian teachers to emulate specific personal characteristics of Jesus' teaching. For example, she observed that "In all true teaching the personal element is essential. Christ in his teaching dealt with men individually" (White, 1952, p. 231). In addition, she recommended that the teacher should constantly aim at simplicity and effectiveness, teach largely by illustration, and be careful to make every instruction plain and clear (White, 1903, p. 233).

Ellen White advocated a holistic approach to curriculum, which would enable delivery of "true education" which promotes "the harmonious development of the mental, physical and spiritual powers" (White, 1903, p. 7). She advocated that the body, mind, and soul are inseparable. As a result, her recommended strategy for mental/intellectual vigor includes systematic study of God's word (White, 1930, p. 254), preservation of physical health through exercise (White, 1977, vol. 2, p. 406), and exercise of the mental capabilities through practical applications in various trades and/or occupations with one's future career in mind (White, 1985, p. 148). From the same worldview, Habenicht and Burton (2004) capture what could be regarded as Ellen White's passion for instruction in all subject areas. They believe that if we are serious about helping children become thinkers, rather than mere imitators of the thoughts of others, we must promote learning beyond the lower levels of understanding. For example, being able to recall facts is simply inadequate. 
Therefore, we must encourage cognitive exercises which allow children to come up with original ideas, designs, and interpretations. Consequently, we need to teach them how to think at higher levels (p. 190), such as those described in Bloom's taxonomy.

\section{International Studies on Mathematics Achievement}

Today's global economy is driven by scientific and technological processes which require advanced math applications (Quesinberry, 2002). The need for all students to acquire math competence is strongly emphasized among researchers and educators alike. They believe that this knowledge is necessary for survival in a complex world. Van Hiele (1986) suggested that a good foundation in geometry will have a positive impact on overall math achievement. As a result he recommended systematic geometry instruction for students, even before the transitional period is reached. Therefore, more and more researchers are directing their energies toward better understanding of the math phenomenon that has long-term, positive implications for 21st-century survival (Lappan, 2000). Indications are that K-12 education has taken on a more definitive role, especially since the past decade or so. Gateway curricula such as math and science must be developed in order to meet new demand for higher competence in math. Earls (2007) identified gateway courses as those that are important predictors of success in college, careers, and citizenship. The necessity for higher math achievement has been identified as (a) a requirement for entrance into university, and (b) a requirement for on-the-job performance (Sergiovanni \& Starratt, 1998). 
Future economic implications of adequate math achievement, at the highschool level, are highlighted by Rose and Betts (2004). They recognize that there is a fundamental link between earlier preparation in mathematics and future levels of success, both in academics and economics (Rose \& Betts, 2001). Although they did not explicitly mention junior-high-level preparation, the levels of competence leading to college graduation and higher earnings inevitably begin at the foundation level for high-school success--the elementary grades. Lappan (1998) and Ma and Xu (2004) focus their research on the fundamental question regarding what constitutes adequacy of math achievement among K-12 students, and what developmental stage constitutes the most "teachable moment" for satisfactory progress.

Major studies related to math achievement at the seventh- and eighth-grade level were conducted by the International Association for the Evaluation of Educational Achievement (IEA). As part of the reform in mathematics education, the first International Mathematics Study was conducted during 1963-1967. Eleven countries participated, based on consensus reached regarding what essential new materials should be included in the curriculum. The target population was mainly 13-year-old students, 13-year-old grade level students, and pre-university students. The project focused on curriculum organization and methods of teaching. Mathematics teaching and learning were also examined in terms of societal, scientific, and technological changes. Several follow-up studies also focused on junior high-school-level mathematics and science achievement. Findings of the study reported by Husen (1967) and Postlethwaite (1967) included the following: 
1. Students who had taken courses in "New Mathematics" achieved higher scores than other students on items in traditional mathematics.

2. At the lower secondary school level in most countries, achievement in mathematics was positively correlated with students' view that that mathematics learning is an open and inquiry-centered process.

3. At all levels of schooling students' expressed interest in mathematics was positively correlated with achievement; gender difference in interest in mathematics was found only in co-educational schools in favor of boys.

4. Only in two countries, Japan and the United States, was there evidence of differences in mathematics achievement between urban and rural communities.

5. On average, parents of students at the pre-university level had 1.7 more years of formal schooling. The difference varied from 0.5 years in the United States to 3.6 years in the Federal Republic of Germany.

The Second International Mathematics Study (SIMS) was conducted in 1981 (Crosswhite, 1985). Target population for SIMS consisted of students who were enrolled in the $8^{\text {th }}$ and $12^{\text {th }}$ grades. The purpose was to provide detailed information from participatory countries regarding content of the mathematics curriculum, how mathematics is taught, and how much students learn. For policymakers and educators to analyze progress in mathematics, determine strength and weaknesses, and make plans for the future, results from this and other studies are extremely important.

These findings were to be further investigated by another series of widescale investigations. Trends in International Mathematics and Science Study 
(TIMSS) provide reliable and timely data on the mathematics and science achievement of U.S. students compared to that of students in other countries. TIMSS data have been collected in 1995, 1999, 2003, and 2007.

The Third International Mathematics and Science Studies (TIMSS) were done in 1995. The study assessed the mathematics and science performance of U.S. students in comparison to their peers in other nations at $4^{\text {th- }}, 8^{\text {th-, }}$ and $12^{\text {th }}$-grade levels. Fourth-graders performed well in both mathematics and science in comparison to students in other nations. U.S. $8^{\text {th }}$-grade students performed near the international average in both mathematics and science, and U.S. 12th-graders scored below the international average and among the lowest of the TIMSS nations in mathematics and science general knowledge, as well as in physics and advanced mathematics.

Silver (1998) suggested that TIMSS was a particularly rich data source about middle grades' math achievement and curriculum. He also reminded us that those results from these major studies of international comparison confirm critically poor performance in geometry and measurement. Further, he directed the following appeal to stakeholders:

Teachers, principals, parents, policy makers, and others wishing to improve math education in the middle grades can learn much from TIMSS by: reviewing some major TIMSS findings related to grades 7 and 8; considering these findings in light of other relevant research on mathematics curriculum content, classroom instruction, and student achievement; and then pondering the lessons from TIMSS and related research about what must be done to ensure that U.S. students have access to better mathematics education that will prepare them for the challenges of tomorrow. (p. 1) 
TIMSS also assessed the mathematics and science performance of U.S. students in comparison to their peers in other nations at Grade 8 in 1999. TIMSS collected information on schools, curricula, instruction, lessons, and the lives of teachers and students to understand the educational context in which mathematics and science learning takes place. Thirty-eight nations chose to compare the mathematics and science performance of their students in 1999. TIMSS-R allows the United States to compare the achievement of its eighth-grade participants in the original TIMSS to the achievement of its eighth-graders 4 years later. It also provides an opportunity to compare the relative performance of U.S. fourth-graders in 1995 to the relative performance of U.S. eighth-graders 4 years later in 1999.

The Trends in International Mathematics and Science Study (TIMSS, 2003) is the third comparison of mathematics and science achievement carried out since 1995 by the International Association for the Evaluation of Educational Achievement (IEA), an international organization of national research institutions and governmental research agencies. In 2003, some 46 countries participated in TIMSS, at either the fourth- or eighth-grade level, or both. Some of the TIMSS results for the United States mirror similar findings in the 2003 NAEP mathematics assessment (Braswell, Daane, \& Grigg, 2003). For example, as in TIMSS eighth grade, the national mathematics average of eighth-graders in NAEP increased from 1996. However, some of the TIMSS results, particularly at fourth grade, do not mirror the findings in NAEP. Both TIMSS and NAEP are curriculum-based studies.

PISA is concerned mostly with the international assessment of the reading, mathematics, and science literacy skills and abilities of 15 -year-olds in the 30 - 
member countries of the Organization for Economic Cooperation and Development (OECD). PISA 2003 results indicate U.S. 15-year-olds performed relatively poorly in mathematical literacy when compared to their peers in other OECD-member nations (Lemke et al., 2005). In 2003, 15-year-olds in the United States scored below the international average in mathematical literacy and below their peers in 20 of the 28 other OECD-member countries. Comparisons of the mathematics and science achievement of eighth-graders between 1995 and 2003 are made for the 35 countries that collected data in 2003 and at least one prior year, either 1995 or 1999.

U.S. eighth-graders improved their average mathematics and science performances in 2003 compared to 1995. Moreover, the data suggest that the performance of U.S. eighth-graders in both mathematics and science was higher in 2003 than it was in 1995, relative to the 21 other countries that participated in the studies. U.S. eighth-grade boys and girls, and U.S. eighthgrade Blacks and Hispanics improved their mathematics and science performances from 1995. As a result, the gap in achievement between White and Black eighth-graders narrowed in both mathematics and science over this time period. (TIMSS, 2003, p. 12)

In mathematics at the upper grades, PISA 2006 shows that statistically there is no change in the scores of U.S. 15-year-olds since 2003. On PISA 2006, the U.S. score for mathematics literacy is below the average for all OECD countries.

The most recent in the series of international comparison reports is TIMSS 2007. Content and cognitive domains are the foundation of the TIMSS 2007 fourthand eighth-grade assessments. The mathematics assessment framework for TIMSS 2007 is organized around subject matter to be assessed within mathematics (for example, number, algebra, geometry, and data and chance at the eighth grade) and a thinking process to be assessed (that is, knowing, applying, and reasoning). The 
cognitive domains describe the sets of behaviors expected of students as they engage with the mathematics content.

\section{Mathematics Standards and Focal Points}

The effort made by educators, researchers, and government and private agencies to improve mathematics achievement in the U.S. has been on-going. As the demand for a more advanced mathematics curriculum arises, deliberate actions to meet this demand follow. A brief account of events that led to the development and implementation of curriculum Standards and Focal Points follow.

The National Council of Teachers of Mathematics (NCTM) developed and published Curriculum and Evaluation Standards for School Mathematics, their first set of guidelines for instruction and assessment of K-12 curricula, in 1989 (NCTM, 1989). The standards were developed primarily in response to the equity crisis that led to the signing into law of the No Child Left Behind Act. The mathematics reform movement began when NCTM solicited input from professional math organizations including: American Mathematical Society (AMS), American Statistical Association (ASA), Association for Computing Machinery (ACM), Mathematical Association of America (MAA), and Society for Industrial and Applied Mathematics (SIAM). Their responses brought into existence the Associates Resource Group, which provided needed support to the NCTM writing group. This initiative facilitated revision of the original standards and the publication of Standards 2000 (Howe, 1998). Expected performances in mathematics were presented in the form of standards and benchmarks that specify the acquisition of mathematics knowledge beyond mere 
surface understanding. According to Suydan (1990) there are 13 standards for Grades 5-8 mathematics content; 7 standards pertain to general assessment; 7 standards concern student assessment, and 4 standards are used for program evaluation. The standards place considerable emphasis on problem solving, use of manipulatives, spatial visualization, and real-life application of math principles, instead of computational algorithms, paper-and-pencil drills, and manipulation of expressions which previously dominated the math curriculum (Pascopella, 2007).

President Bush created the National Mathematics Advisory Panel in April 2006 to advise himself and the U.S. Secretary of Education on the best use of scientifically backed research to the teaching and learning of mathematics. In response to this demand, the NCTM released its Curriculum Focal Points (for prekindergarten to 8th grade) which was developed to supplement Standards 1989 and 2000. In addressing questions regarding these new curriculum constructs, the NCTM president, Skip Fennell, indicated that mathematics educators have been engaged in varying levels of reform ever since Sputnik. He also indicated that the Council's Curriculum Focal Points is another example of reform (Fennell, 2007). Focal points give descriptions of concepts that the authors regard as essential. The intent is to facilitate students' mastery of content by objectives while covering fewer topics in greater depth. A noteworthy feature of curriculum focal points is the potential to ease learning difficulties for students who struggle with important math content by helping them develop key problem-solving, reasoning, and criticalthinking skills. Focal points assume that mathematics is cumulative; therefore, skills learned in later grades depend on what students have learned in earlier grades. 
The three curriculum focal points may be investigated in terms of a connection to geometry at the seventh- and eighth-grade levels. These are listed in the form of recommended content emphases as shown in Table 1. Problem solving, reasoning, communication, making connections, and designing and analyzing representations are skills that have been specified for each academic level from kindergarten to the eighth grade. The mode of enquiry recommended by reformers of the NCTM Standards is consistent with the Vygotsky (1978) principle which is based on the assumption that learning is cumulative. Skills learned during the earlier elementary grades are built upon during the middle- and high-school years. These same skills are perfected and utilized throughout life as individuals engage in career pursuits or profitable pastime activities. Hence, there is need for students to acquire foundation skills in preparation for the pursuit of more advanced levels of learning. Vygotsky's approach to learning may best be facilitated by the teaching of geometry, since geometry applications often require active student involvement, the use of concrete

objects, and reference to real-world objects that are visibly displayed. Consequently, learners develop useful skills that they will find helpful as they advance up the academic ladder or engage in regular everyday activities at home or in the community.

\section{Geometry in the Middle Grades}

Studies show that students who take gateway courses such as algebra and geometry are more than twice as likely to advance to higher education as those who do not (NCTM, 1989). Curriculum and Evaluation Standards for School Mathematics 
Table 1

Curriculum Focal Points Emphases

Grade 7 Curriculum Focal Points

Grade 8 Curriculum Focal Points

Number and operation and algebra and geometry

Algebra

Measurement and geometry and algebra

Geometry and measurement

Number and operations and algebra

Number and operation

emphasizes problem solving for all levels of mathematics instruction. Grades 5-8 geometry and measurement have been earmarked to be given much attention whereas formulas and memorization of facts received less attention (pp. 70-73). NCTM Standard 13 emphasizes the choice of appropriate units and use of measurement tools, as well as the development of student understanding of the concepts of area and volume. During the junior-high-school years, students continue to benefit from concrete objects to aid in their learning when new or highly abstract concepts are about to be learned.

Among low income students who take algebra and geometry, $71 \%$ pursue higher education compared to $27 \%$ of those who do not take such challenging courses (US Department of Education, 1997). In fact, junior-high students should have considerable experiences in making data tables, graphs, and geometric sketches and using them along with symbols and clear English to describe a wide variety of patterns and relationships (American Association for the Advancement of Science [AAAS], 1993). 
Boudreau (1999) attempted to reverse geometry deficiencies in a group of eighth-grade algebra students. The curriculum was supplemented with geometry content in order to increase competency in geometry skill while maintaining algebra competency. Geometry concepts were presented to students through exploration, discussion, and integration. It was found that the measurable difference between control and experimental groups was insignificant. However, when the experimental group matched pairs were tested, there was significant growth.

During an action research project with pre-service teachers, Burton (2003) highlighted the importance of manipulative/geometric models in the teaching and learning of math concepts. He asserted that the appropriate selection and use of manipulatives may be the key to bridging the gap between "meaningless vocabulary and rules to remember," and what he terms "a readily accessible component of a conceptual understanding of mathematics" (p. 19).

According to the NCTM (1992) Math Framework for California Public Schools, Grades 5-8 curriculum should include the study of geometry. Students need to be able to identify, describe, compare, and classify one-, two-, and three-dimensional geometric figures in a variety of spatial senses, solve problems using geometric models, and be able to understand and apply geometric properties and relationships. Standard 12 outlines what students need to know and be able to do in geometry, and offers a math benchmark from which to examine curriculum for middle-school students' educational ventures. Curriculum development and instruction must consider the geometric hierarchy of learning. Although learning 
can occur at several levels simultaneously, the learning of more complex concepts and strategies requires a firm foundation of basic skills (NCTM, 1997).

Grades 5-8 geometry should link the informal explorations that were begun in kindergarten to fourth grade. This continuity is vital to the acquisition of higherlevel mathematics skills. Evidences suggest that the development of geometric ideas progresses through a hierarchy of levels (Van Hiele, 1986). Geometry uniquely enables ideas from other areas of math to be visualized. For example, the use of models and a host of real-world applications helps students to construct meaning. This is particularly helpful to kinesthetic learners who learn best through hands-on activities. Students also need geometry to make sense of statistics, linear algebra, functions and calculus, and graph theory. In other words, geometry enables students to utilize the practical applications of mathematics in fostering their understanding. Geometry uniquely connects math with the real physical world and provides an example of a mathematical system (Usiskin, 1995).

\section{The Van Hiele's Hierarchy}

In his second edition of Elementary and Middle School Mathematics: Teaching Developmentally, John A. Van de Walle (2004) presented the Van Hiele work which began in the Soviet Union in the late 1950s but has become a most influential factor in American geometry curriculum. The most prominent feature of the model is a five-level hierarchy of ways of understanding spatial ideas. Each of the five levels describes the thinking process used in geometric contexts. The levels describe how 
we think, rather than how much knowledge we have. Each level is distinctly different from the next, yet it is the foundation upon which the next level is built.

Summary of the levels of the Van Hiele hierarchy of geometric understandings includes the following:

1. Level 0-Visualization: Recognition of figures/shapes based on appearance. For example, a rectangle may be rotated to form an oblong or a square to form a diamond. Students at this level can create and begin to understand how shapes are classified.

2. Level 1-Analysis: This stage represents a shift from a single shape idea to all shapes within a class. For example, oblong, square, and rectangle all have four right angles, a pair of parallel sides, four sides, congruent diagonals, etc. This level may also recognize properties of classes of shapes, but fails to recognize subclasses such as indicated by the fact that squares are rectangles and rectangles are parallelograms.

3. Level 2-Informal Deduction: The objects of thought at this level are the properties of shapes. Students at this level are not only able to recognize properties, but also the relationships among these properties. For example, if all four angles are right angles, the shape must be a rectangle; however, if in addition to four right angles the sides are congruent, then the shape must be a square. This kind of informal deduction argument is characteristic of level 2.

4. Level 3-Deduction: The objects of thought at level 3 are relationships among properties of geometric shapes. At this level, students are able to examine more than just properties of shapes and are able to produce and examine 
conjectures. This analysis of informal arguments leads to the structure of a system complete with axioms, corollaries, definitions, theorems, and postulates. Students at this level are able to work with abstract statements about geometric properties and make conclusions based more on logic than intuition.

5. Level 4-Rigor: The objects of thought for this level are deductive axiomatic systems for geometry. For example, spherical geometry is based on lines drawn on the sphere rather than in a plane. This level of comparison is beyond the scope of this research and will, therefore, not be further expanded.

The Van Hiele theory provides a framework in which to conduct geometric activities, but does not tell us what content to teach. However, the guidelines provided do help in the selection of content. This model also promotes developmentally appropriate, rather than age-appropriate, practices, which is congruent with the idea of my research focus.

For example, junior-high-school-level learners are expected to solve geometric problems which involve fairly abstract concepts, even though they may not have had the exposure to a formal class. In such a circumstance, the instructor may focus on geometry concepts on a continuum from two or even three grade levels below in order to ensure that the foundation is properly laid. In other words, it would be frustrating for any learner if he or she is asked to find the area and/or circumference of a circle before an understanding of the relationship between diameter and circumference (pi) is gained. Similarly, it becomes helpful to address understanding of the concept of area of plane shapes prior to the introduction of volume of solids. 
The Van Hiele model is consistent with research-based practices including differentiated classroom instruction, which encourages developmentally appropriate learning. The focus is on a mathematics experience which addresses learners' needs where they are rather than where they should be (Tomlinson, 2000).

\section{Out-of-School-Time Programs}

Research shows that out-of-school time (OST) programs can increase educational equity by (a) providing socio-economically disadvantaged youth with comparable experiences to their more affluent peers, (b) fostering high expectations from adults other than school teachers, and (c) enabling participants to develop "new basic skills" such as literacy, numeracy, teamwork, and problem solving (AYPF, 2004).

Newman, Fox, and Flynn (2000) observed that it is during their free time that youth without after-school opportunities are at risk for a host of negative behaviors such as drugs and alcohol use, sexual activity, and participation in crime. Larson (2002) confirmed that U.S. children and adolescents spent dramatically less time on school work, and what he referred to as productive activities, than teens in other industrialized countries. Consequently, they spend more time on discretionary activities such as playing sports, viewing television, playing and hobbies, and attending church. Despite so much discretionary time on their hands, their mathematics achievement ranks lower than that of their peers in other industrialized countries (Silver, 1998; SIMSS, 1982; TIMSS, 1995). For example, East 
Asian students spend much more time and money during out-of-school time on school subjects than their counterparts in the U.S. (Zhao, 2005).

Social scientists regarded this as an emergency that needed to be addressed expeditiously (Leath, 2005). As a result, they have taken a critical look at the performance status of the U.S. K-12 system of education and have determined that it has failed miserably in that it has not delivered high content learning opportunities to every child. Plank and Jordan (1997) believed that far too many children, especially those from minority families, are placed at risk by school practices that are based on a sorting paradigm in which some students receive high expectation instruction while others are neglected. From this perspective Bell and Heath (1993) declared that

school has been an environment of frustration and failure for many youth, so association with schools can lead to unproductive experiences. In addition, school bureaucratic structures as well as norms may "invade" after school clubs they host undermining otherwise positive possibilities. (p. 69) Consequently, an alternative plan has been proposed-to utilize supplemental programs that have proven to enhance the achievement of middle- and high-school students (Piha, 2004).

The American Youth Policy Forum clarified that the term out-of-school time encompasses both traditional programs operating during afternoon hours and more comprehensive efforts that respond to the needs of children, youth, and their parents during evenings, weekends, summers, and holidays, by offering activities that help youth grow, learn, and develop (AYPF, 2005). A meta-analysis of 73 afterschool programs conducted by Durlak and Weissberg (2005) underscored findings 
of several other researchers that after-school programs not only impact achievement in reading and mathematics, but also promote important personal skills. Further, they proposed the following list of additional benefits: (a) improving youths' feeling of self-confidence and self-esteem, (b) school bonding (positive feelings and attitude toward school), (c) positive social behaviors, (d) improving school grades, and (e) increasing achievement test scores. Durlak and Weissberg (2005) also observed that the level of success of OST programs is associated with structure and that they produce twice the benefits of unstructured programs.

In a survey commissioned by the YMCA of the USA (2001), it was found that OST program participants are higher achievers than non-participants. This is evidenced by three out of four teens under supervision in after-school programs who are A and B students, compared with only $58 \%$ of students left unsupervised 4 out of 5 days who achieve such high marks. Warren, Brown, and Freudenburg (1999) observed that more and more after-school programs are being charged with extending and enhancing the educational goals of the traditional school day and with providing academically enriching experiences for the youth in their care. Fabiano (2004), in her Fact Sheet Report, provided a classic example of how OST programs may augment the efforts of the K-12 school system. She indicated that more than $50 \%$ of students on the MLK Honor Roll were participants in the After School Program. For the past 4 years, all MLK Posse Scholarship winners have been After School Program participants; for the past three years, the class valedictorian has been After School Program member. (p. ii) Laver et al. (2006) indicated that schools and districts are adopting out-ofschool time programs to supplement the education of low-achieving students. They 
also indicated that research paints a mixed picture of the effectiveness of OST programs. So, in order to clarify OST impact, they examined 35 studies on OST programs that assist at-risk students in reading and mathematics. The studies employed control or comparison groups and met other inclusion criteria. Metaanalysis indicated substantially significant positive effects of OST programs on both reading and mathematics achievement. The time that each program was conducted did not make a difference. Jordon and Nettles (1999) focused their study on the influence of various kinds of OST programs on student learning and achievement. They express this new trend as follows:

Educators, policymakers, and social scientists are looking beyond the constraints imposed by the limits of the typical school day trying to find creative ways to foster student learning, school engagement, and commitment to ongoing self-improvement. Unfortunately, not much is known about the real benefits of experiences such as after-school programs or how the ways in which students make personal investments in activities outside of school influence their educational success and perception of personal fulfillment in their lives as adults. (p. 1)

Recurring in the body of literature on OST programs are the following features:

1. They support strong American schools by giving youths more time and support for learning (Farbman, 2003; McLaughlin, Hill, Donahue, Malone, \& Bell 2007; Sarita, 2005).

2. They either focus on a specific topic such as math and science or a broad selection of activities including academic enrichment, cultural awareness, and community service (Peter, 2002). 
3. They provide interaction with positive adult role models and peers who share similar goals and aspirations (Galbo, 1989).

4. They are linked to higher academic performance and attainment (Braddock, Royster, Winfield, \& Hawkins, 1991; Townsend, 2003).

5. They are associated with an increase in academic achievement, school attendance, time spent on homework and extracurricular activities, enjoyment and effort in school, and better student behavior (Anderson-Butcher, Newsome, \& Ferrari, 2003).

Boy Scouts and YMCA are examples of traditional OST programs that seek to address a wide range of needs including behaviors, attitude, academic performance, and self-esteem. Over the years, religious clubs have also played a significant role in meeting the social, spiritual, and some academic needs of young people in their organization as well as in the community. The Pathfinders Club is a religious club that is sponsored by the Seventh-day Adventist church. It was organized for the distinct purpose of developing and demonstrating faith through service to God and humanity. Unlike other secular OST programs the Pathfinder Club places special emphasis on youths' spiritual development. It also focuses on interaction among participants as a means of mutual learning and fun engagements. However, the cognitive development of its members remains a central focus (White, 1952). This is facilitated by an ongoing instructional program, which this study seeks to enhance by providing a resource that will enable Pathfinders to improve their understanding important concepts in geometry. 


\section{Out-of-School-Time Program Design}

Peter (2002) observes that some out-of-school time (OST) programs are topic-specific and focus on categories such as arts and crafts, tennis or basketball, singing and dancing, or math and science. These programs are often labeled "quality program" when they are well organized and are able to draw and retain students. "In a culture that expects profound benefits from out-of-school participation, OST programs should be designed to achieve desired and articulated outcomes" (p. 5). This approach provides some flexibility in selecting strategies, techniques, approaches, and activities that are likely to produce satisfactory results for participants and their families. The importance of a research-based OST-designed curriculum is hereby underscored by the following statements:

In the field of out-of-school time (OST) programming, research helps link successful strategies to desired results. The type of research takes on many shapes. Analysts may look at the increase or decrease in participant behavior over the duration of a particular initiative, or they may measure the combined impact of several programs. They may analyze entire programs or specific program components. They may or may not incorporate qualitative evaluations of participants, teachers, parents, and community members. Whatever the process, the results are that specific techniques can often be linked to articulated outcomes. (Peter, 2002, p. 5)

\section{Project-Based Learning}

Most quality OST programs include project-based learning or varied combinations of activities. The combinations vary depending on the program, the age level, the audience, and desired outcomes. Whether it is a specific program framework or customized set of activities, research-based Best Practices can help to shape, refine, and authenticate quality. 
Project-Based Learning (PBL) has a long history (Grant, 2002). For over 100 years, educators such as John Dewey have reported on the benefits of experiential, hands-on, student-directed learning. Many educators, knowing the value of engaging, challenging projects for students, have planned field trips, laboratory investigations, and interdisciplinary activities that enrich and extend the curriculum. PBL approach engages learners in exploring important and meaningful questions through a process of investigation and collaboration. Students ask questions, make predictions, design investigations, collect and analyze data, use technology, make products, and share ideas. Krajcik, Czerniak, and Berger (1999) also try to define this approach, and emphasizes that in the typical PBL environment, students are, in fact, investigating solutions to a problem. They build their own knowledge by active learning, interacting with the environment as suggested by the constructivist approach, working independently or collaborating in teams, while the teacher directs and guides. They make a real product (Thomas \& Mergendoller, 2000). He also classified the investigation processes as design, decision-making, problem-finding, problem-solving, discovery, or model building. Thus, central activities for the project are transformation and knowledge construction. New understandings and new skills are extended in terms of making connections with prior knowledge. For instance, planting a garden or cleaning a stream bed are projects, but not PBL projects.

Krajcik et al. (1999) suggest four benefits for the student. First, learners develop deep, integrated understanding of content and process. Second, students learn to work together to solve problems. Collaboration involves sharing ideas to 
find answers to questions. In order to succeed in the real world, students need to know how to work with people from different backgrounds. Third, this approach promotes responsibility and independent learning. As a final benefit, this approach actively engages students in various types of tasks, thereby meeting the learning needs of many different types of learners.

\section{Research-Based Learning}

A research-based program in mathematics is built on the idea that all students can succeed in mathematics, when given a program that provides best practices in assessment, instruction, and professional development (Hillman, 2007). The balanced pedagogical approach of any research-based program is founded on several core beliefs such as:

1. Students perform best when challenged to meet high expectations (Brook, Nomura, \& Cohen, 1989; Edmonds, 1986; Howard, 1990; Levin \& Lezotte, 1990; Rutter, Maughan, Mortimore, Ouston, \& Smith, 1979; Slavin, Karweit, \& Madden, 1989).

2. Students learn best through a variety of modalities, including auditory, visual, tactile, and kinesthetic (Bransford, Brown, \& Cocking, 2000; Gardner, 1993; Silver, Strong, \& Perini, 2000).

3. Underprepared students benefit from scaffolding, a process by which they are supported until they can apply new skills and strategies independently (Kame'enui, Carnine, Dixion, Simmons, \& Coyne, 2002; Rosenshine \& Meister, 1992). 
4. Underprepared students need both guided instruction and challenging activities that demand critical thinking, problem-solving skills, creativity, and reflection (Stronge, 2002).

To accomplish these ideals, activities are planned that allow students to discover, explore, discuss, practice, and reflect on the foundational mathematics concepts, skills, and problem-solving strategies for their grade levels. This strategy ensures optimal student engagement, thus supporting student performance.

Engaging students in active learning requires that they practice the objectives to be mastered through a variety of activities and levels of activities (Chickering \& Gamson, 1987). In addition, students are provided with opportunities to reflect upon what they did throughout the lesson. In fact, there is widespread support for the potency of reflection in the learning process (Perrone, 1994). These features give the distinction between research-based practices in education and the traditional (that is the perennialist and/idealist model) program design.

\section{Examples of Successful Mathematics Programs}

Clewell, Consentino de Cohen, Campbell, and Perlman (2005) used evaluation study results to identify a number of math and science curricula, at the middle- and high-school levels, that have successfully increased student achievement. I closely examined several of these curricula, selected essential features that are compatible with this study, and present these below. The Integrated Mathematics, Science, and Technology program (IMaST) promotes hands-on learning and implements the constructivist theory with active student 
participation. In Direct Instruction (DI), each skill is broken down into its component parts and each component of the skill is taught to mastery. Saxon Math: An Incremental Development (SM) leads students toward a deeper understanding of mathematical concepts by building a foundation on increments while implementing a mastery paradigm. Similar to Math in Context (MIC), the Interactive Mathematics Program (IMP) is a 4-year, problem-based curriculum that incorporates traditional branches of math (algebra, geometry, and trigonometry) with additional topics recommended by the National Council of Teacher of Mathematics. The NCTM standards place considerable emphasis on conceptual understanding, problem solving, and the constructivist pedagogy. Students are encouraged to experiment, investigate, ask questions, reflect, and accurately communicate their ideas and conclusions.

The extant body of literature related to OST curriculum development is growing. It is a result of the continuation of the works of reputable theorists such as Bobbitt, Tyler, Baker and Schutz, Dewey, Piaget, Bruner, and Montessori. These have engaged in a progression of curriculum works toward the establishment of curriculum as a field of study. The attention given to development of the math curriculum in the U.S. since the year 2000 is significant. Stakeholders at all levels became better aware of the importance of mathematics, as a result of the growing

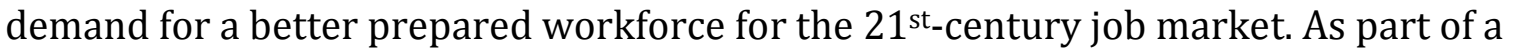
global educational community, performance among U.S. students was repeatedly found to be non-competitive. This condition had implications for the K-12 education, which led to the acknowledgment of OST programs as supplement. In 
particular, educators are called upon to do their part to ensure that every child receives an adequate mathematics experience. Any curriculum development model that establishes partnership, by active learners' involvement and systematic feedback, has the potential to produce a more student-friendly product.

In developing this project, I found strong support and encouragement in the literature. For example, I discovered that the continuing use of objectives, in curriculum development, constitutes an important link between the traditional and non-traditional curricula. Hence, the dynamism of educational design research facilitates one's effort in the development of a more relevant curriculum. The educator's passion to improve student achievement can certainly lead to actions that make a positive impact toward the acquisition of useful knowledge and skills. Curriculum conceptualizations in the U.S. have evolved for more than two centuries from the rigid, perennialists' industrial model to a liberal model which is accommodating to a more culturally pluralistic, $21^{\text {st-century audience. Features of }}$ the G.R.A.CE Project mirror several innovations of current educational research designs. These include: (a) clear description of outcomes in the form of behavioral objectives, (b) learner-and activity-centered exercises, and (c) learner-instructor collaboration in product content modification.

The undertaking of this research project was encouraged largely by the following reports: (a) legislation by the federal government to implement corrective measures, (b) national assessment of the status of K-12 mathematics achievement, and (c) international comparison of mathematics achievement between the U.S. and other developed nations. These reports brought to light the truth regarding where 
we were and where we should aspire to be. In other words, math achievement need among U.S. children became a top priority. In response I chose to develop a geometry curriculum-a resource that can be adopted to meet the needs of different audiences.

Recent proliferation of the literature on OST program-related issues has also been a response to the need for supplement to the U.S. K-12 education system. OST programs often implement demarginalization initiatives toward the realization of greater achievement in various areas of need including reading and mathematics. The G.RACE Project is grounded in a variety of recent empirical research findings. For example, research-based instruction, project-based learning, and a variety of student-centered activities were included in the project. In addition established theoretical "mandates" in the curriculum field were reviewed and used as a guide throughout the process. 


\section{CHAPTER 3}

\section{METHODOLOGY}

\section{Introduction}

The purpose of this study was to develop and test an out-of-school time (OST) geometry curriculum. The Baker and Schutz (1971) Instructional Product Development Model was utilized in the empirical development process. Other researchers such as Bailey (1997), Selmanovic (1996), and Gregor (1996) have found the Baker and Schutz (1971) model useful in their curriculum development initiatives. The model is flexible and therefore makes provision for curriculum developers to incorporate current research-based practices as part of their final product. The accountability feature of this model allows researchers to pinpoint the status of change in measurable terms (Popham \& Baker, 1970).

\section{The Baker and Schutz Product Development Model's Relevance for the 21 st Century}

Curriculum design is the organizational plan used in the development of a specific curriculum. This mixed-method study used the Baker and Schutz (1971) model in its organization. This seven-step design model features the core components associated with the empirical developmental process of an instructional product. Whether this 36-year-old model is still appropriate for the 
organization, construction, delivery, and assessment of a specialized out-of-school time (OST) geometry curriculum is a legitimate concern.

Bailey (1997) developed a compelling argument in favor of the relevance of the Baker and Schutz (1971) curriculum development methodology one decade ago. She recounted the complex combination of theoretical perspectives interwoven into one "master" theory. Among these are: (a) Bobbitt's (1918) Scientific Management theory, (b) Tyler's (1949/1986) Theory regarding the use specific objectives in curriculum construction and evaluation, (c) the National Committee of the National Educational Project on Instruction's (1963) concept of unification of theory through clearly stated rationale, (d) Fredrick Shaw's educational design framework that focuses on beneficial changes through educational guidance and teaching strategies, (e) Carter's (1969) theory of accountability in a systems approach, in his specific plan to represent specific curriculum and student learning based on this curriculum, and (f) Charles Silberman's (1970) theory regarding students' creativity, understanding, and basic interest as the essence of education. Lagemann (1997) takes a retrospective view of the past century of activities in the educational research arena. She refers to these activities as "continuing contests" among different groups--especially scholars.

According to Bailey (1997), the fundamental principle of the Baker and Schutz (1971) model--specificity of desired outcomes as a central component of curriculum design--resonates with the innovations in design among researchers and practitioners during the period 1971-1997. The model was therefore relevant in 1997 and possibly beyond. 
Fauser, Henry, and Norman (2006) compare alternative instructional design models, one for each of three design models classified by Gustafson and Branch (2002) as classroom, product, and system. The Classroom-Oriented Model such as the Gerlach and Ely Model recognizes that most curricula will be designed around the concepts to be taught in each subject matter (Braxton, Bronico, \& Looms, 1995). The first step in this model is to specify objectives and content simultaneously; and following allotment of resource to accomplish the task stated in the objectives, the performance is then evaluated. Bates's (1995) Product-Oriented Model focuses on material production and course delivery which is most suitable for distance learning. Its focus on computer material production represents a dramatic shift from the basic component of the Baker and Schutz (1971) Model. However, it is to be noted that this design is best suited within a technology-focused context and may not be suitable for curricula with other emphases. The System-Oriented Model developed by Gentry (1994) focuses mainly on needs assessment, instructional design featuring specific objectives, strategies and techniques, pilot testing for new instructional products, and ongoing application and evaluation.

Although a dramatic revolution in educational design research (between 1977 and 2007) seems to make the Baker and Schutz (1971) model obsolete, the fundamental principle of this model (objective-based) is still widely utilized. Therefore, its continuing relevance stands uncontested. Fauser et al. (2006) propose that

Instructional Designers cannot be effective if they are familiar with only one model. The designer must be able to fit the design to the situation and familiarity with various models demonstrates that although the models had 
differences, combined steps in various ways, or used different vocabulary, they share a fundamental principle of attempting to deliver effective learning. (p. 5)

In his attempt to build a broader definition than that of the traditional curriculum, Akker (2003) proposes a model that shows the connectedness between

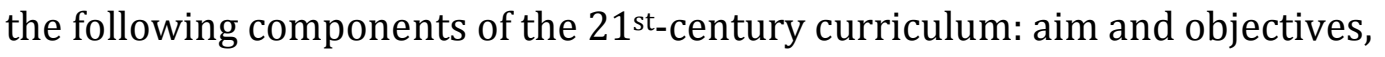
content, learning activities, teacher role, materials and resources, grouping, location, time, and assessment. In Educational Design Research, Akker, Gravemeijer, McKenney, and Nieveen (2007) describe a relevant curriculum as one that is carefully examined and tailored for the context and culture in which it is implemented. However, such effort must consider the target setting (context), current research, and a natural ecology in which development activities take place. From a learning design perspective, Akker et al. (2007) detail three stages: preparation for experiment, experimenting in the classroom, and conducting retrospective analyses. Again, the singular intent to improve learning and the implementation of goals/objectives formulation, rallying resources to accomplish the desired outcomes, and seeking to ascertain the effectiveness of the experiment have been reordered somewhat but form the basis of the most current practices associated with educational design research.

The U. S. K-12 education is strongly influenced by Standards 2000 and Curriculum Focal Points--a recent innovation of the NCTM. This upgrade attempt was part of the standard-driven mandate of the NCLB Act which demanded a high standard of accountability. Compliance practices include: establishing of clear direction for instruction, selecting appropriate standards and benchmarks, utilizing 
resources that are either made available (for the task) or suggested, and administering standardized tests. These practices were engaged in as educators "assert the fundamental importance of striving toward excellence in mathematics education. They set high expectations for all students and provide strong support for students to meet them" (Silver, 2002, p. 75).

Current educational design research is promoting curriculum models that focus on a more thorough account of all aspects of the learning process. For example, audio recording of group meetings and classroom sessions, conducting and recording pre- and post-interviews, making copies of students' work, and assembling field notes are part of the process (Rebello, Cui, Bennett, Zollman, \& Ozimek, 2007). These design features may be intended to provide support for Dewey's complexity of the learning process theory or to justify the criticism that the traditional curriculum is more production-oriented than people-friendly. This may hold true for the cognitive component of the Baker and Schutz Model. However, it is this same model that highlights the importance of the affective component of the learning process. The affective component is sensitive to participants' feelings; it values their perspectives, and utilizes participants' input in the development of the instructional product.

\section{Population and Sample}

The population for this study consisted of Pathfinder Club participants and their eligible guests within the Lake Union Conference of Seventh-day Adventists. These individuals were located in local conferences within the states of Michigan, Indiana, Illinois, and Wisconsin. The participants for this study were selected based 
on the following criteria: (a) must fall within the 12-14 age group and (b) currently an active member of a LUC club. Pathfinder members who met the selection criteria were invited to volunteer to participate in the G.R.A.C.E. Program.

The first two participants were members of the All Nations Pathfinder club located in Berrien Springs, Michigan. Four subjects from the South Bend Seekers Seventh-day Adventist Pathfinders Club located in Gary, Indiana, participated in the second session. A third group of eight club members from the South Bend-area Seventh-day Adventist churches Pathfinder clubs was invited to participate in the third session.

The fourth group of 25 subjects was assembled from club members who were available at the time scheduled for the tryout session. These participants were selected from the SDA Pathfinder clubs from the following four locations: Eau Claire, Michigan; Ypsilanti, Michigan; Gary, Indiana; and Shiloh, Illinois.

Even though the selection of subjects was done through a non-random sampling procedure, an effort was made to ensure that the sample was representative of the population. Consequently, an ethnically diverse group of seventh- to eighth-grade-level Pathfinders consisting of males and females, inner city, suburban and rural youth volunteered to participate in the G.R.A.C.E. Project.

\section{Steps in Developing the Instructional Product}

The Baker and Schutz Model includes the following seven steps for the empirical development of an instructional product: 


\section{Step 1: Formulation}

The question of whether a new or improved product is justifiable in terms of its need is addressed in this step. Baker and Schutz (1971) pointed out that the value of developing an instructional product is in direct proportion to its need. The purpose of this phase of the process is to determine the need for a new instructional product.

\section{Step 2: Developing Behavioral Specifications}

The second step of the process requires the development of clearly stated behavioral objectives. Acceptable levels of performance and any criteria-qualifying objectives must be specified (Baker \& Schutz, 1971). According to Gronlund (2006), the most recent revision of Bloom's taxonomy as presented by Anderson et al. (2001) provides a useful framework for identifying and presenting instructional objectives, instructional activities, and assessment methods.

\section{Step 3: Item Tryout}

During Step 3 a cognitive pre-test/post-test instrument (Appendix A) and criteria for evaluating mastery (Appendix B) are designed, based on the stated behavioral objectives and guidelines gathered from the literature. The objectives are classified using six levels of Bloom's most recent taxonomy (remember, understand, apply, analyze, evaluate, and create). To ensure balance in levels of cognition in the evaluation process, for the six levels of performance, points are assigned in ascending order of complexity, ranging from "remember," 1.0 point, to "create," 6.0 points. The numeric value assigned to each level of the taxonomy is intended for 
proper communication in this model. This is consistent with Bloom's primary purpose for the establishment of his Taxonomy (Bloom, Max, Furst, Jill, \& Krathwohl, 1956).

Step 4: Initial Product Development, Group of 2

At this stage, the curriculum is delivered to a small group of two members of the target population. Special attention is given to details regarding content, organization and interest-building strategies. The information presented at the seminar is delivered in a positive manner, while seeking suggestion for improvement. Feedback obtained in the form of written or verbal suggestions from subjects along with comparison of the pre-test and post-test scores become helpful in the development of the instructional product.

At the conclusion of the first tryout, the cognitive pre/post-test, criteria for the test, participants' and developer's manuals are all revised to reflect suggested changes. The newly revised product is now ready to be used with the second group of subjects in the next tryout.

\section{Step 5: Product Tryout, Group of 4}

Following administration of the pre-test, the curriculum is delivered to a larger group consisting of four individuals from the target population. During this phase of the developmental process, a word-for-word presentation is made using the revised developer's manual. During this tryout stage, special attention was given to content, clarity, and the efficiency in communicating the instructional contents of 
the seminar. Post-test results along with evaluative comments elicited from the group are again used in further revisions and modifications of the product.

Step 6: Product Revision, Group of 8

Eight members of the target population are selected and exposed to the product in its complete form, and mastery from pre-test and post-test comparison was documented. Using this valuable information on record, along with more feedback from the subjects the product is again revised.

Step 7: Final Trial and Analysis, Group of 25

A group consisting of 25 individuals is used in this final stage of the instructional product development. Mastery of at least $80 \%$ of the objectives by at least $80 \%$ of the participants provides as indication that the empirical development process is complete.

\section{Modification of Affect}

Baker and Schutz (1971) and Naden (1992) reason that since learning is both a cognitive and an affective process, modification in the affective domain should also be measured. Gregor (1996) states the following criteria regarding modification of effect: (a) It should be examined through the affective instrument, (b) the instrument should be administered at the beginning and conclusion of the lecture presentations, and (c) items of the questionnaire should be related to the lecture material and randomly ordered with Likert-scale questions ranging from 1 (strongly disagree) to 5 (strongly agree). Modification of affect among learners was measured 
through a Likert-type instrument. This instrument, along with the cognitive pre/post-test, made up the complete testing instrument for the G.R.A.C.E. Project.

\section{Data Analysis}

Modification of affect was measured by comparing participants' pre- and post-test scores on the affective exams. Test scores from each group involved in the developmental process were compared (Anderson, Klein, Davidson, \& O’Malley, 1991; Bailey, 1997; Ferguson \& Takane, 1989). Descriptive statistics procedures were used in converting test scores to percentages and calculating pre-and post-test means for comparison at each developmental stage of the instructional product. Effect size was calculated using the formula $n^{2}=t^{2} /\left(t^{2}+d f\right)$.

\section{Summary}

This study focused on the development of an out-of-school time geometry curriculum, using the Baker and Schutz (1971) Instructional Product Developmental Model. This model is flexible and assumes a step-by-step approach that walks the researcher through the entire empirical development process. Many recent researchers also utilized the Baker and Schutz Model in their curriculum research projects.

The population for this study consisted of Pathfinder Club participants and their eligible guests within the Lake Union Conference of Seventh-day Adventists. These individuals were located in local conferences within the states of Michigan, Indiana, Illinois, and Wisconsin. Four groups totaling 39 subjects were selected 
using purposive sampling based on the following criteria: (a) must fall within the 12-14 age group and (b) currently an active member of a LUC club.

Tryout sessions, which engage progressively larger groups of participants in interactive learning sessions, are an integral part of the seven-step process prescribed by Baker and Schutz (1971) for the empirical development of an instructional product. Minimum acceptable performance on the cognitive pre-/posttest was set at the $80 / 80$ level. In other words, $80 \%$ of the participants had to score a minimum of $80 \%$ on each of the 25 behavioral objectives in order to achieve mastery of content. A 20-item Likert-type instrument is used to measure participants' modification of effect; that is, the extent to which appreciation for and interest in the new learning may be sustained over time. 


\section{CHAPTER 4}

\section{RESULTS}

\section{Introduction}

The Pathfinder Program currently implements curricula that foster social, spiritual, and physical development of its members, in keeping with its holistic approach; yet, no instructional product has been used to deliberately address participants' intellectual development in mathematics. In an attempt to address this existing need, I implemented the Baker and Schutz (1971) Instructional Product Development Model in developing an out-of-school (OST) time geometry curriculum.

This chapter reports results obtained throughout the developmental process of the Geometry in Real-life Application Curriculum Experiences (G.R.A.C.E.) Project-making meaning and application in geometry. This chapter is organized based on the following seven steps used by Baker and Schutz (1971) in their Instructional Product Development Model. The sequencing of these results is based on the performance of three tryout sessions followed by a full-scale implementation with the largest group of 25 subjects. 


\section{Empirical Development of the Instructional Product}

Step 1: Formulation

Active seventh- and eighth-grade-level members of Pathfinder clubs constituted the target audience for this study. Individuals at this cognitive developmental stage are ready for more challenging mathematics experiences (Ma $\& \mathrm{Xu}, 2004)$. Yet no instructional product that deliberately addresses the mathematical cognitive development of Pathfinder Club members was found. Justification for a new instructional product to enhance Pathfinders' cognitive development in math was established by means of informal interviews with club members and Pathfinder club officials who confirmed the non-existence of such a product. In addition, review of the limited literature on specialized curricula pieces currently used in the training program provided additional confirmation.

Step 2: Development of Behavioral Specification

Twenty-five behavioral objectives were formulated based on guidelines presented in the literature (on instructional product development) as well as repeated peer and expert reviews. Bloom's revised taxonomy was used to classify objectives in terms of levels of difficulty ranging from 1 to 6 . Objectives were also classified under five main headings and were stated in measurable terms.

Minimum acceptable performance for mastery is set at $80 / 80$; that is, at least $80 \%$ of the participants must master at least $80 \%$ of the objectives. The 25 behavioral objectives described below have been processed through extensive peer and expert review. In addition, each has been compared to a Standard and recent 
Focal Points established by the National Council of Teachers of Mathematics

(NCTM).

\section{Section One: Foundations of Geometry- Six Behavioral Objectives}

1. The learner will select correct descriptions for geometry, Euclidian geometry, and non-Euclidian geometry, given five choices.

2. The learner will match ten geometric symbols with their appropriate names.

3. The learner will accurately translate into English a statement expressed in geometric symbols.

4. The learner will correctly use five geometry terms (supplementary, symmetry, postulate, similar, and sector), given descriptions.

5. The learner will prepare fairly accurate sketches of graduated cylinder, triple beam balance, and cylinder.

6. The learner will use definitions of congruency and similarity to write correct statements of equality.

\section{Section Two: Geometry All Around Us- Five Behavioral Objectives}

7. The learner will identify five geometric shapes that are visible in nature, given clear descriptions of each.

8. The learner will differentiate between basketball and circle (in terms of their unique properties) in 15 words or less. 
9. The learner will choose the best estimates of area and perimeter of a trapezium, given four choices.

10. The learner will determine a pair of possible dimensions of a cuboid whose volume is given.

11. The learner will identify a transformation out of six choices, given a diagram of the transformation of a shape in the Cartesian plane.

\section{Section Three: Understanding Key Principles in Geometry-Five Behavioral Objectives}

12. The learner will determine equivalent estimates of pi by comparing diameter and circumference of a circle.

13. The learner will write true statements leading to the conclusion that for any triangle RPQ, the sum of the interior angles equals the exterior angle.

14. The learner will answer six questions related to the formula " $D=m / v$ " correctly.

15. The learner will apply the Pythagorean Theorem by selecting the appropriate anchor position of the rope when a pole is erected at 90 degrees with the ground, given a diagram showing the various positions and the rope.

16. The learner will explain in five steps how to determine perimeter of an irregular plane shape with a string and ruler.

\section{Section Four: Constructing Meaning in Geometry- Five Behavioral Objectives}

17. The learner will create a tessellation with exactly 20 congruent shapes. 
18. The learner will rearrange segments of a design to create a new symmetric pattern.

19. The learner will position an image to show the effect of transformations by reflection through the $x$ and $y$ axes.

20. The learner will classify coordinates in their appropriate quadrant or axis category.

21. The learner will sketch a net for a similar cylinder, given scale factor and model.

\section{Section Five: Using Geometry to Solve Problems-Four Behavioral Objectives}

22. The learner will apply the proportion principle in calculating total investment and expected yield per hectare.

23. The learner will calculate the number of boxes of tiles needed to tile a parallelogram, given a job description.

24. The learner will give a rationale for their selected travel route, given a written scenario.

25. The learner will explain in five steps how to determine the volume of an irregular solid using a graduated cylinder.

\section{Step 3: Item Tryout}

An objective-based cognitive pre- and post-test (Appendix A) with specific criteria for evaluating mastery (Appendix B) were prepared and used to assess participants' achievement at both entry and post-instruction levels, to determine the 
effect produced by the instruction. Six levels of objectives (remember, understand, apply, analyze, evaluate, and create) were classified under the following main headings: Foundations of Geometry: items 1-6; Geometry All Around Us: items 7-11; Understanding Key Principles in Geometry: items 12-16; Constructing Meaning in Geometry: items 17-21, and Using Geometry to Solve Problems: items 21-25. Test items used to measure the educational objectives were constructed in a variety of forms including matching, multiple choice, completions, essay-type, and shortanswer questions. Test items were also included that required practical demonstration of selected principles taught during the G.R.A.C.E. Project. McMillan and Schumacher (2001) confirm that "authentic or alternative assessments are measures of performance that require demonstration of skill or proficiency by having the respondent create, produce, or do something" (p. 41).

In addition to the criteria established for the cognitive instrument, for this study, a Table of Specifications (Table 2) was used to specify point allotments for test items. In Assessment of Student Achievement, Gronlund (2006) confirms that "the table of specifications serves the test maker like a blueprint; it weighs the learning outcomes and content areas in terms of their relative importance" (p. 60). The level of performance specified for each topic is indicated by the points allotted. For example, three responses to questions on Definition of Geometry were classified at the Understand level of Bloom's Taxonomy, and the topic is given a relative emphasis of 3\%. For the topic Understanding Symbols, the learner received full points only if he/she responded correctly to 10 items at the Remember level, 2 items at the Understand level, and 3 items at the Apply level. 


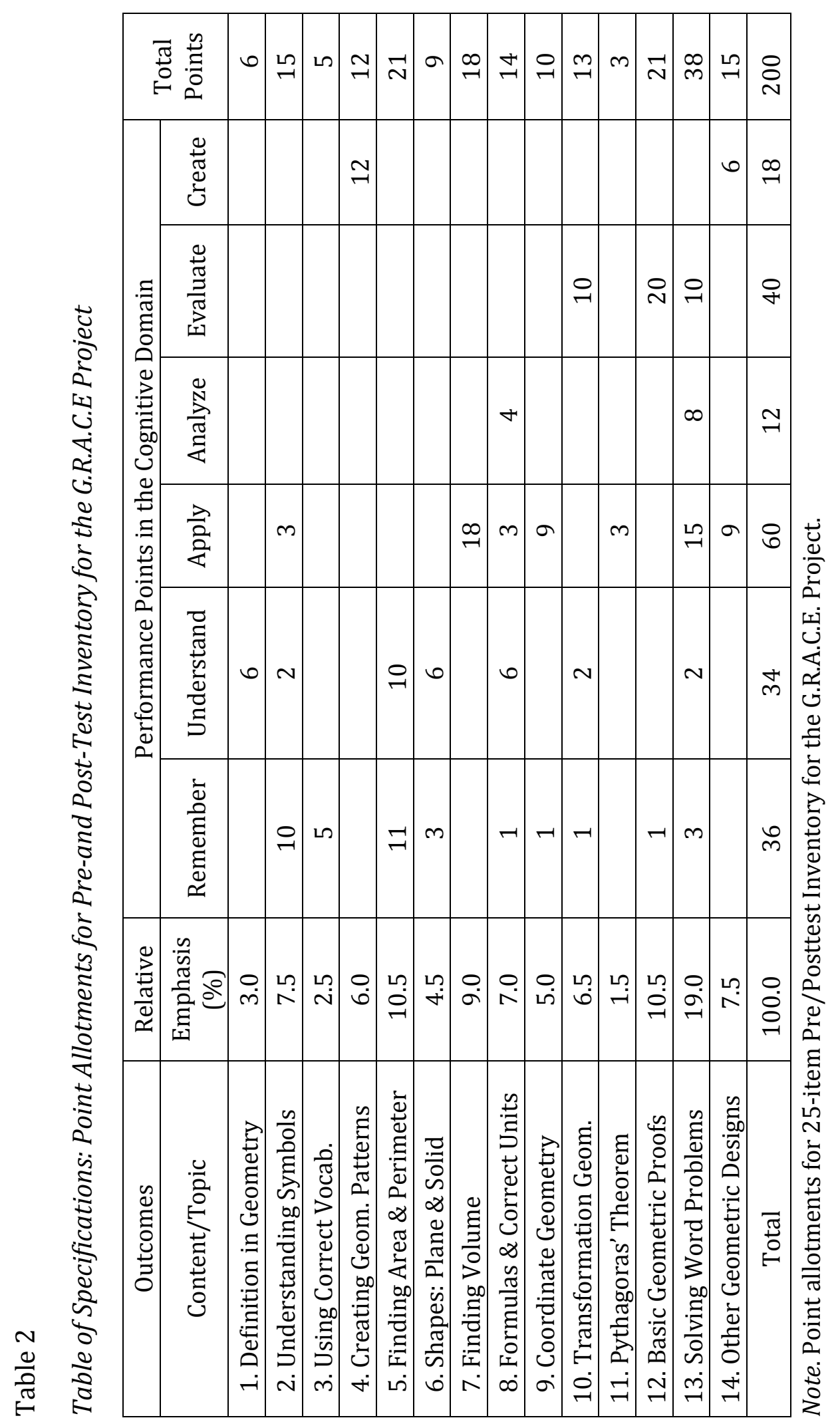




\section{The Affective Instrument}

In keeping with the criteria listed above, a 20 -item affective instrument requiring Likert-type responses, along with two open-ended type questions, was prepared (see Appendix D). Items were randomly presented with the following classifications: Items $1,3,5,7,9,16,17,18,19$, and 20 are concerned with learners' perception of geometry. Items $6,8,12$, and 15 seek to determine the extent of learners' awareness of the importance of geometry. Criteria for the structure and organization of the items were derived from the literature (Gregor, 1996; Oppenheim, 1966).

To assess learners' commitment to the learning of geometry, items 4, 11, and 14 were included, and items 2, 10, and 13 for learners' level of confidence in geometry. Selmanovic (1996) classified items on the affective instrument. Both preand post-test scores were convert into percentages and compared. In addition, a measure of effect size was calculated for assessment of impact.

The two open-ended items, 20 and 21, were included specifically to elicit comments that were factored into the revision of the instructional process to create a more favorable environment for learners to engage geometry confidently and successfully.

Again, five credentialed, experienced math educators and different groups of doctoral students reviewed the affective instrument for internal consistency. The same instrument with different open-ended items was used for post-test inventory. Open-ended questions for post-test sought to elicit from learners (a) the extent to which they have achieved their goals, and (b) attitudes and behaviors that were 
particularly motivating. In essence, these questions were concerned with characteristics of the G.R.A.C.E. Program that enhance learners' appreciation for and determination toward mastery of geometry concepts.

Step 4: Initial Product Development, Group of 2

The initial preparation of the items needed to begin the G.R.A.C.E. Project was completed, following extensive peer and expert reviews. During several scheduled meetings, doctoral candidates from Andrews University School of Education offered helpful suggestions and assisted with editing of the document. Selected professors from different departments (Dr Elvin Gabriel. Dr. Larry Burton, Dr. Lee Davidson. Dr. Tevni Grajales, and Dr. Lionel Matthews) also made suggestions for improvement of the product. The insights gained from these sessions were documented and compared with those contained in the literature. The instructional product consisted of (a) 25 behavioral objectives, (b) the affective pre-/post-test (Appendix D), (c) the cognitive pre-/post-test with criteria (Appendix B), (d) the developer's manual (Appendix F), and (e) the participants' manual (Appendix E). The manuals provided a detailed outline of core content to be covered along with examples and clear instructions.

At this stage of the developmental process, the step-by-step sequencing of content was attempted as an experiment with two subjects from the target population. First, the affective and cognitive pre-tests were administered and secured for grading; then, the subjects were exposed to the entire instructional content. Both subjects participated in planned activities including: measuring, 
calculating, completing exercises in geometry, and engaging in teacher-led and peergroup discussions. Results obtained from the cognitive pre-test are shown in Table 3. Subjects responded to items indicated by objectives 3, 5, and 19 only. This indicated that 22 items, or $88 \%$ of the items, were probably new to the subjects.

Full-scale curriculum delivery was the next step. The task at first seemed daunting, but as time progressed changes began to take place. After some adjustments in my teaching method it was observed that one student was more confident and was always willing to assist her peer. The other student was often timid and made careless mistakes on a regular basis. I started to use more concrete objects and demonstrations which proved to be very helpful. For example, one subject remarked, "This thing is confusing," and the other seemed to concur. But from the same lips I heard: "Geometry is interesting; I understand the concepts very clearly." At the conclusion of instruction both students appeared empowered. This was evidenced by their verbal commitment to continue pursuing the study of geometry, expressions of appreciation for the way the lesson was taught, and expression of confidence in their personal ability to achieve mastery on the posttest.

The cognitive post-test scores were in marked contrast to pre-test scores. Both participants scored $100 \%$ on 15 or $60 \%$ of the stated objectives. They also scored $80 \%$ or greater on 22 out of 25 , or $88 \%$, of the stated objectives. One of two participants scored $80 \%$ or greater on all 25 stated objectives. This level of achievement met the standard set in chapter 3 , if the group is to achieve mastery. 
Performance on objectives $3,6,13,14,20$, and 25 fell short of $100 \%$ but met the expected standard. However, the minimum score required for mastery was not obtained for objectives 10,15, and 22. The last four lines in Table 3 indicate: (a) the percentage of subjects scoring $80 \%$ or greater on each objective, (b) the mean percentage score for pre-test on each objective, (c) the mean percentage score for the post-test on each objective, and (d) the difference between pre- and post-test mean scores.

In their written responses both subjects indicated that they thought that they accomplished their goals. The more confident subject achieved $80 \%$ or better on all 25 objectives, whereas the other subject achieved similar scores on only 22 out of 25 objectives.

In preparation for the next tryout, components of the curriculum were modified. On the basis of subjects' observations or requests, some narratives in both the students' and the developer's handbook were revised for greater clarity. Revisions were also made to test items 1, 6, and 10. Question \#1 was changed to require multiple rather than a single response. Question \#6 was modified by replacing a pentagon with a small hexagon. A hexagon and a smaller pentagon were presented as similar figures. The error was pointed out by one subject who remarked that it was confusing since the number of corresponding sides of the figures was different. The original single response intended for question \#10 was also changed to a multiple response type question to elicit a more thorough response. 


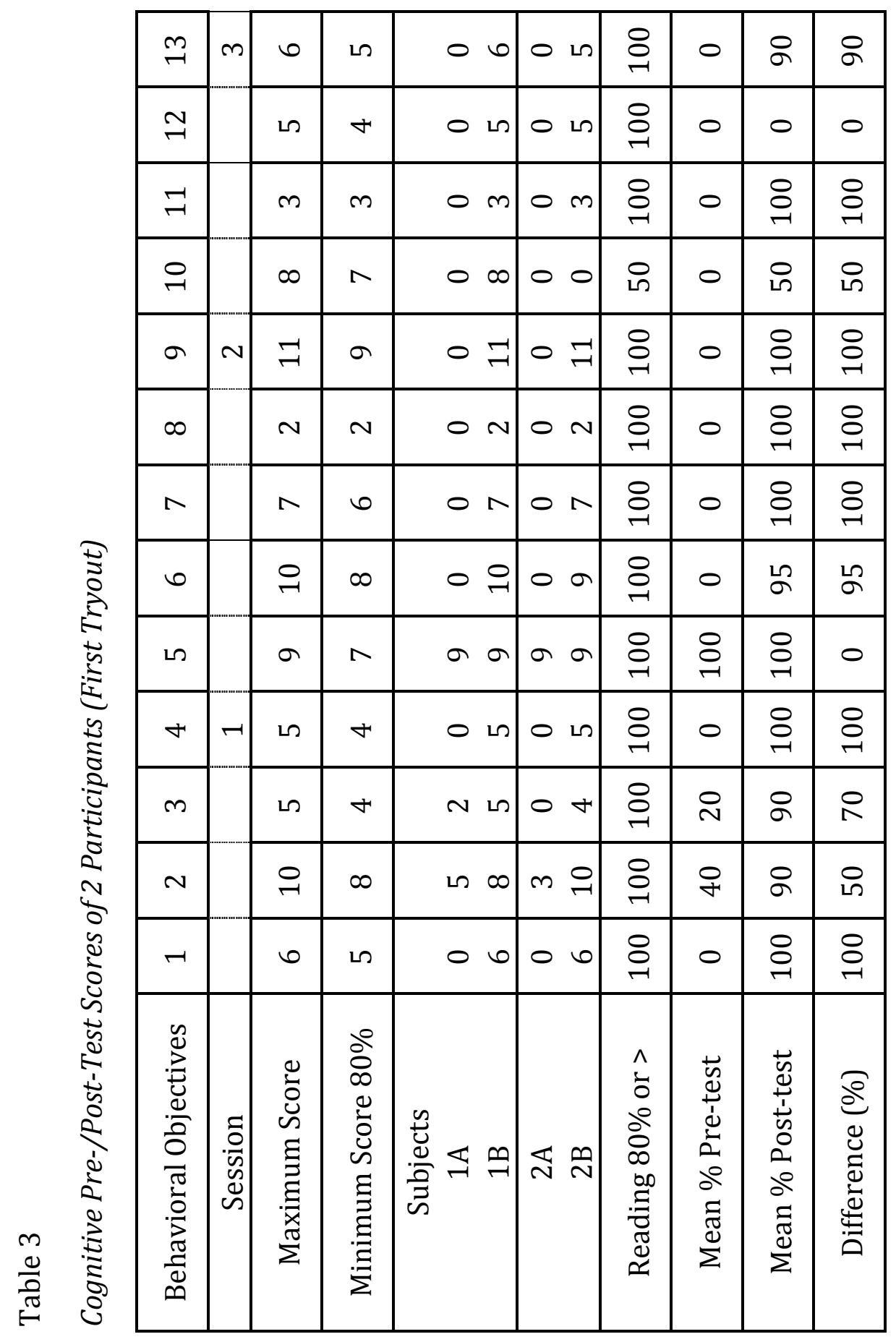




\begin{tabular}{|c|c|c|c|c|c|c|c|c|c|}
\hline$\stackrel{\llcorner}{N}$ & & $\stackrel{0}{-}$ & $\infty$ & $0 \stackrel{-1}{1}$ & $0 a$ & $\stackrel{8}{\circ}$ & 0 & 으 & นั \\
\hline$\stackrel{⿱ 亠}{N}$ & & $\stackrel{0}{-1}$ & $\infty$ & $0 a$ & $0 a$ & $\stackrel{\circ}{\circ}$ & 0 & ᄋ & ๙ \\
\hline$\stackrel{n}{N}$ & L & $\stackrel{+}{\leftrightarrows}$ & $\underset{-}{-}$ & $\circ \underset{\sim}{\rightleftarrows}$ & $0 \stackrel{+}{\leftrightarrows}$ & $\stackrel{\circ}{\circ}$ & 0 & 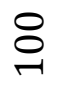 & $\stackrel{\circ}{\circ}$ \\
\hline 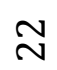 & & $\underset{+}{\leftrightarrows}$ & 가 & $0 \underset{-}{+}$ & 00 & 온 & 0 & 온 & 온 \\
\hline$\stackrel{\sim}{\sim}$ & & 6 & ᄂ & 06 & 06 & $\stackrel{\circ}{\circ}$ & 0 & $\stackrel{8}{\circ}$ & $\stackrel{\circ}{\circ}$ \\
\hline ㄱ & & $\stackrel{\circ}{ }$ & $\infty$ & $0 \infty$ & $0 a$ & $\stackrel{\circ}{\circ}$ & 0 & ㅇ & ㅇ \\
\hline$\stackrel{\sigma}{\sim}$ & + & $\stackrel{\circ}{\rightarrow}$ & $\infty$ & ᄂ & $\sim \stackrel{\circ}{\sim}$ & 옥 & $\stackrel{\text { 을 }}{m}$ & 음 & 느 \\
\hline$\stackrel{\infty}{\sim}$ & & 6 & L & 06 & 06 & 응 & 0 & $\stackrel{8}{\circ}$ & $\stackrel{\circ}{\circ}$ \\
\hline 근 & & 6 & ᄂ & 06 & 06 & 옹 & 0 & 응 & 응 \\
\hline$\stackrel{0}{-1}$ & & $\stackrel{0}{-1}$ & $\infty$ & $0 \stackrel{0}{0}$ & $0 \stackrel{0}{0}$ & 응 & 0 & 응 & $\stackrel{\circ}{\circ}$ \\
\hline 늑 & $m$ & $m$ & $m$ & $0 \mathrm{~m}$ & 00 & 운 & 0 & 운 & 용 \\
\hline む & & $\underset{+}{\leftrightarrows}$ & ન & ○ & $0 m$ & 음 & 0 & ๙ & ๙ \\
\hline 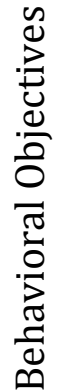 & .ే & 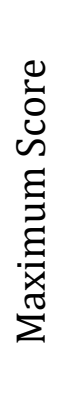 & 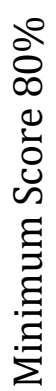 & 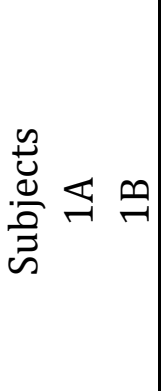 & 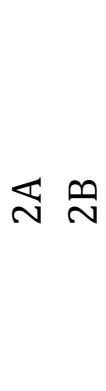 & 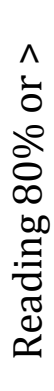 & 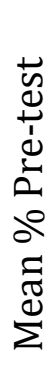 & 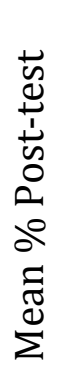 & 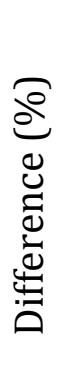 \\
\hline
\end{tabular}




\section{Modification of Affect, Group of 2}

Comparison of the means of the affective pre- and post-tests scores for two subjects revealed a $16 \%$ difference and an effect size of 0.708 . The values indicated that the difference of $16 \%$ between the post- and pre-test scores was important with a medium effect. Table 4 shows subjects' pre- and post-test percentage scores on the affective instrument. The percentage difference between post- and pre-test scores is also given.

Pre-test scores of 56 and 70 were averaged. Post-test scores of 61 and 93 were also averaged, and the difference between means, 79 and 63, or the mean of the differences of 5 and 23, represents the change in participants' perceptions and/or attitude toward understanding of geometry concepts. This change appears to be congruent with participants' indication of their intentions expressed in response to open-ended items included in the affective instrument.

Table 4

Affective Test Scores of 2 Participants

\begin{tabular}{cccc}
\hline Subjects & Pre-Test & Post-Test & $\begin{array}{c}\text { Post-test } \\
\text { Pre-test } \\
\text { Difference }\end{array}$ \\
\hline 1 & 56 & 61 & 5 \\
2 & 70 & 93 & 23 \\
Mean & 63 & 79 & 16 \\
\hline
\end{tabular}




\section{Step 5: Product Tryout, Group of 4}

The second group of subjects consisted of two girls and two boys from the South Bend Seekers Pathfinder Club. The cognitive pre-test result of this group was similar to that of the first group. This provided further confirmation of participants' unfamiliarity with geometry content even at the very basic level. Of the 10 items that were attempted, one child demonstrated mastery on 4 out of the 25 objectives; one child on 2 out of the 25 objectives, one child on a single objective, and one child on none of the objectives. Scores ranged from $0 \%$ to $100 \%$ on selected items attempted on the cognitive pre-test.

Much attention was given to individuals who appeared timid. Confidencebuilding strategies were regularly implemented. For example, subjects were liberally commended for their effort and more practice was given for reinforcement of selected geometry concepts. Group participation was found to be very helpful, as all participants were determined to succeed together. Subjects indicated that they were now ready for the post-test.

On the cognitive post-test, three children scored $80 \%$ or better on all 25 objectives whereas one child achieved mastery on 21 of the 25 objectives. Scores ranged from 20 to $100 \%$ on the cognitive post-test items. The percentage mastery as prescribed for the G.R.A.C.E. Program increased from 50 to $75 \%$ on the second tryout. Table 5 presents results of the cognitive pre- and post-test.

Since this modest increase from the first tryout still fell short of the minimum requirement for mastery, this indicated the need for further modification of different components of the curriculum. Specifically, I focused on rewording or 
restructuring of format as subjects provided feedback. For example, question \#1 was further modified to better reflect its stated objective. Question \# 14 was changed to include detailed application of the density formula. Question \#20 was simplified by rewording to omit reference to the origin, use of the standard $\mathrm{x}$ and $\mathrm{y}$ axes, (instead if L1 and L2), and three classifications were required instead of the original six. The wording of question \# 21 was revised for clarity, since at first it suggested that the learner should construct a cylinder instead if the net of a cylinder. This was quite misleading. However, the change sought to communicate the intent of the developer to both learner and program coordinator more effectively. Again, these changes were reflected in manuals, pre-and post-tests and criteria for the test. Thus, the modified product was ready to be used with the next group of subjects.

\section{Modification of Affect, Group of 4}

Comparison of the means of the affective pre- and post-tests scores for four subjects revealed a $24 \%$ difference, and an effect size of 0.968 . The values indicated that the difference of $24 \%$ between the post- and pre-test scores was important with a large effect. Table 6 shows subjects' pre- and post-test percentage scores on the affective instrument. The percentage difference between post- and pre-test scores is also given. 


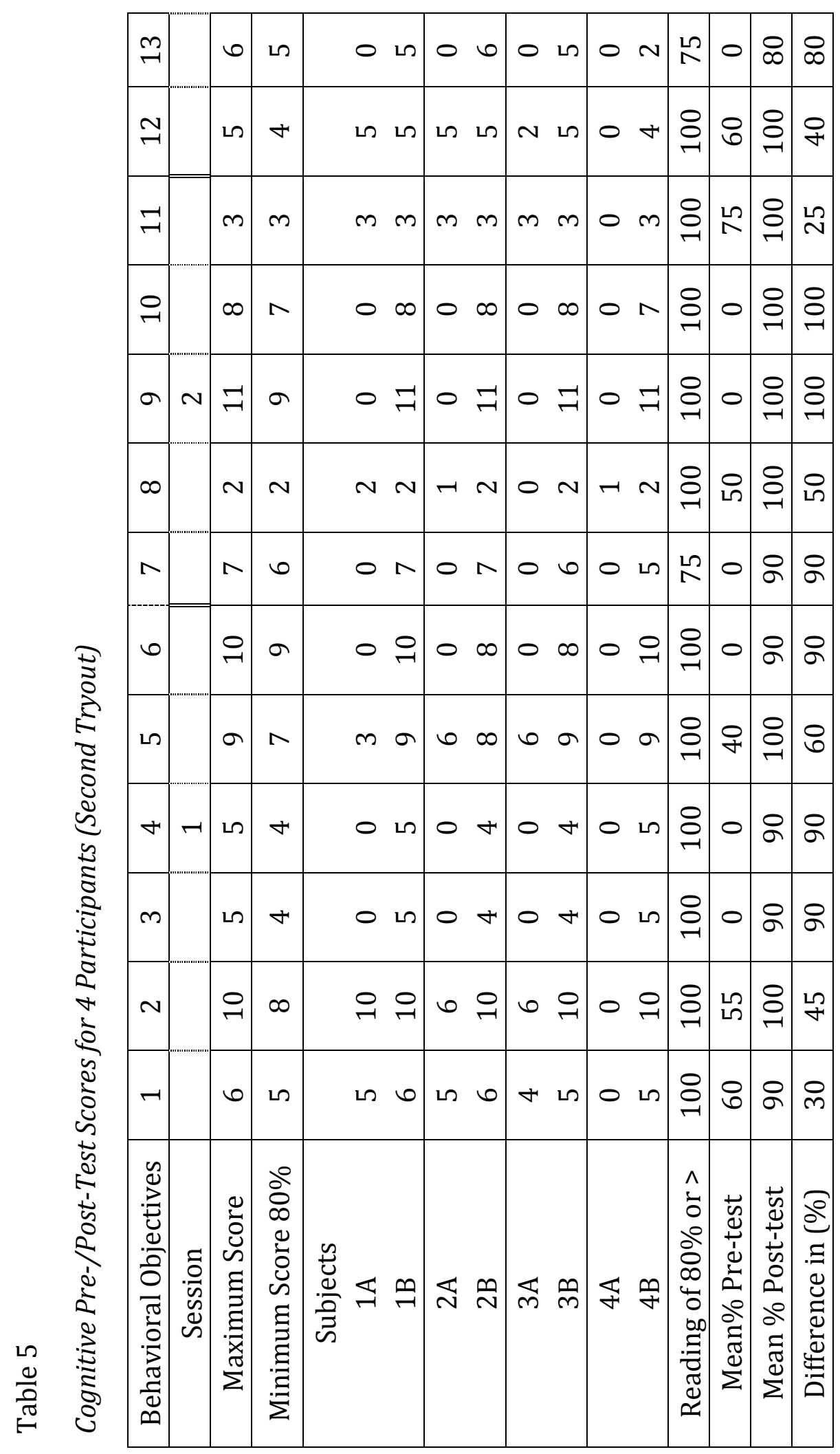




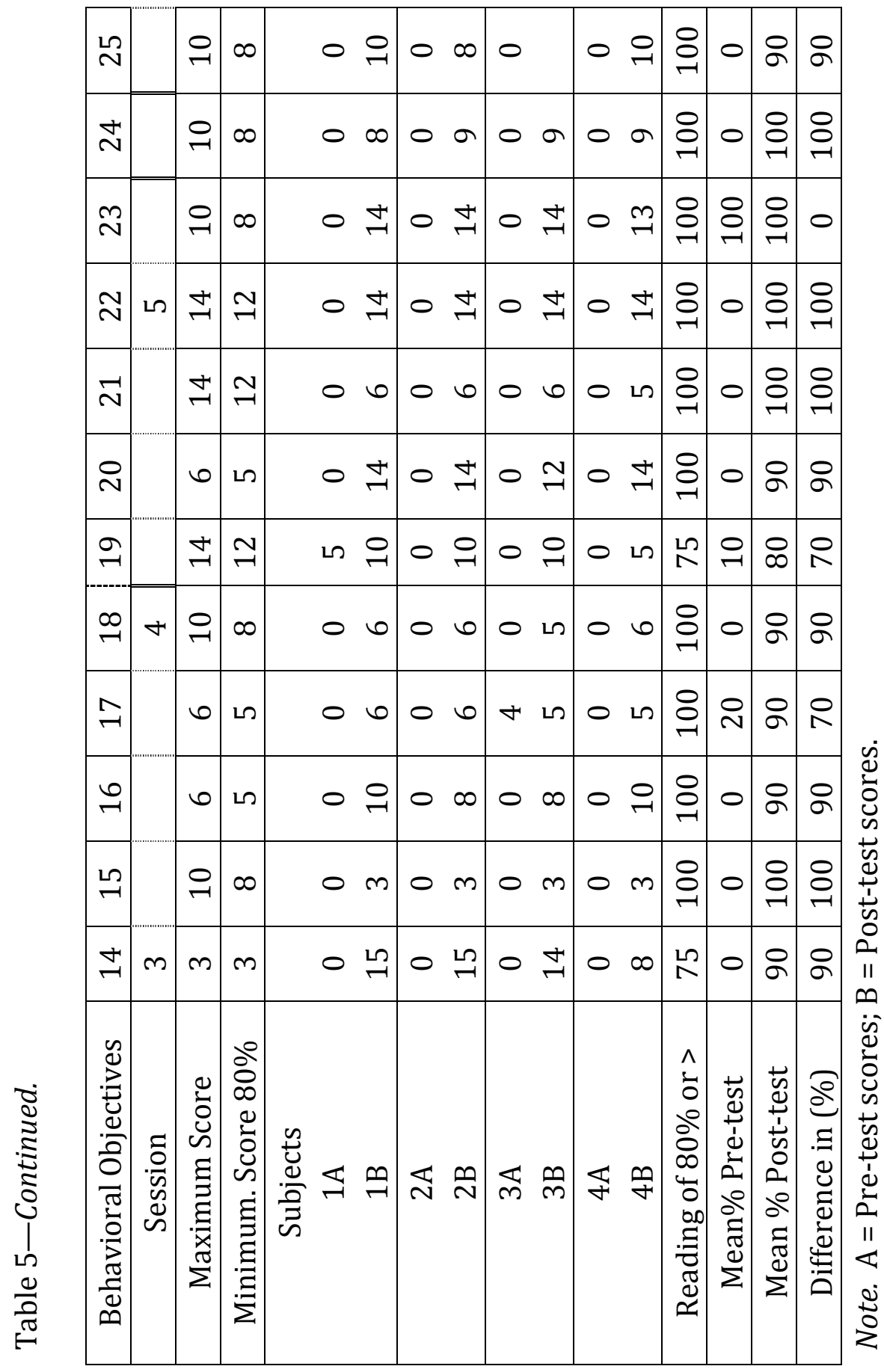


Table 6

Affective Test Scores of 4 Participants

\begin{tabular}{cccc}
\hline Subjects & Pre-Test & Post- Test & $\begin{array}{c}\text { Post-test } \\
\text { Pre-test } \\
\text { Difference }\end{array}$ \\
\hline & & & \\
2 & 56 & 80 & 24 \\
3 & 71 & 88 & 17 \\
4 & 58 & 82 & 24 \\
Mean & 63 & 86 & 29 \\
\hline
\end{tabular}

Step 6: Product Revision, Group of 8

The modified version of the G.R.A.C.E. Project in its complete form was presented to a third group of 8 subjects, following administration of the pre-tests. Scores on 23 behavioral objectives on the cognitive pre-test fell below the $80 \%$ minimum required for mastery. Four subjects scored $0 \%$ on all 25 behavioral objectives. Three subjects scored $80 \%$ on one behavioral objective, and one subject scored a minimum of $80 \%$ on two behavioral objectives (see Table 7). The pre-test results confirmed earlier findings that seventh- and eighth-level-subjects in the target population for this study were never before exposed to a formal program in geometry. However, the progress made by the previous groups in the post-test was very encouraging, so I proceeded cautiously but confidently with the instructional delivery. I found that the modifications were quite helpful. Complaints about lack of clarity of test items diminished. All 8 subjects seemed to have been grasping the 


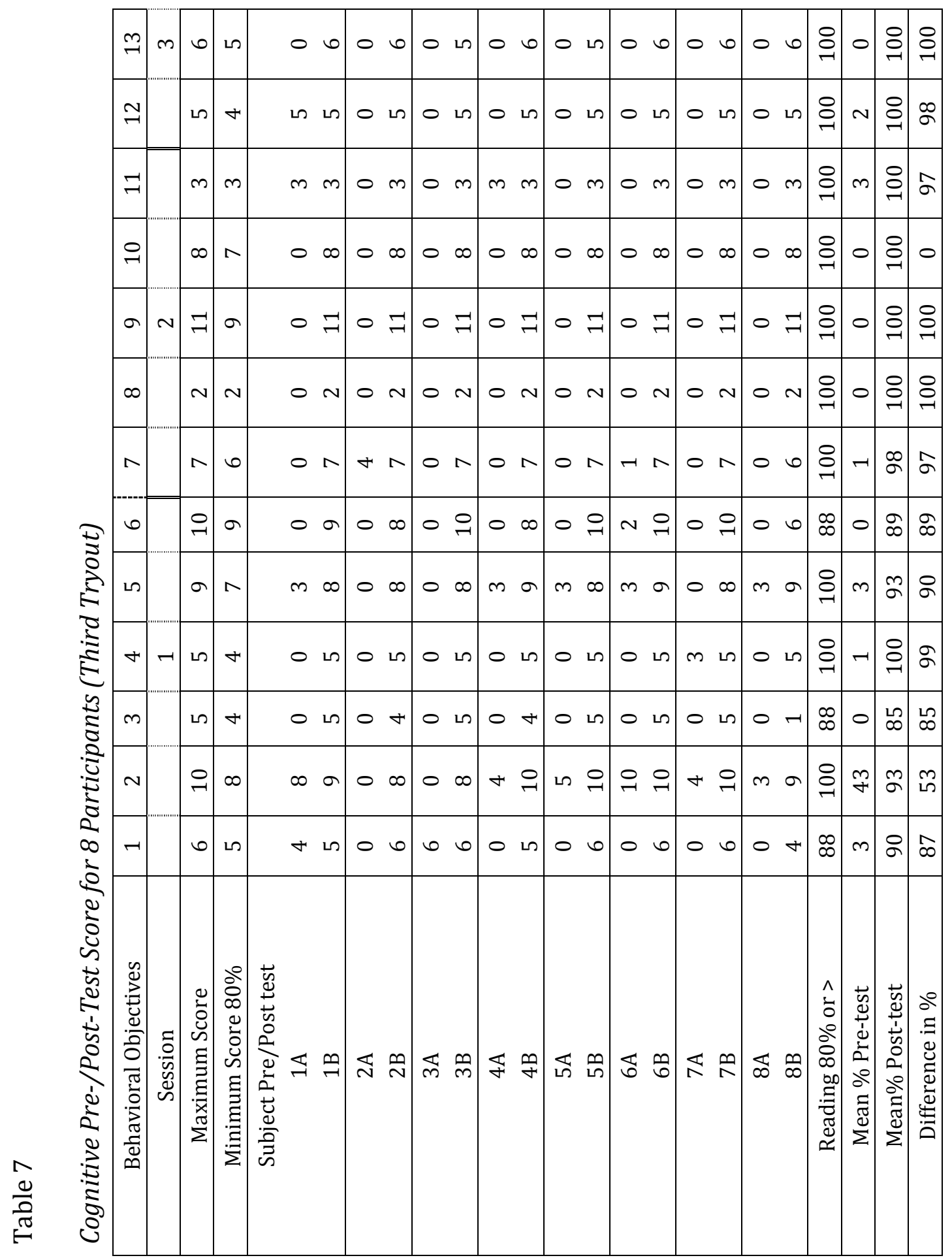




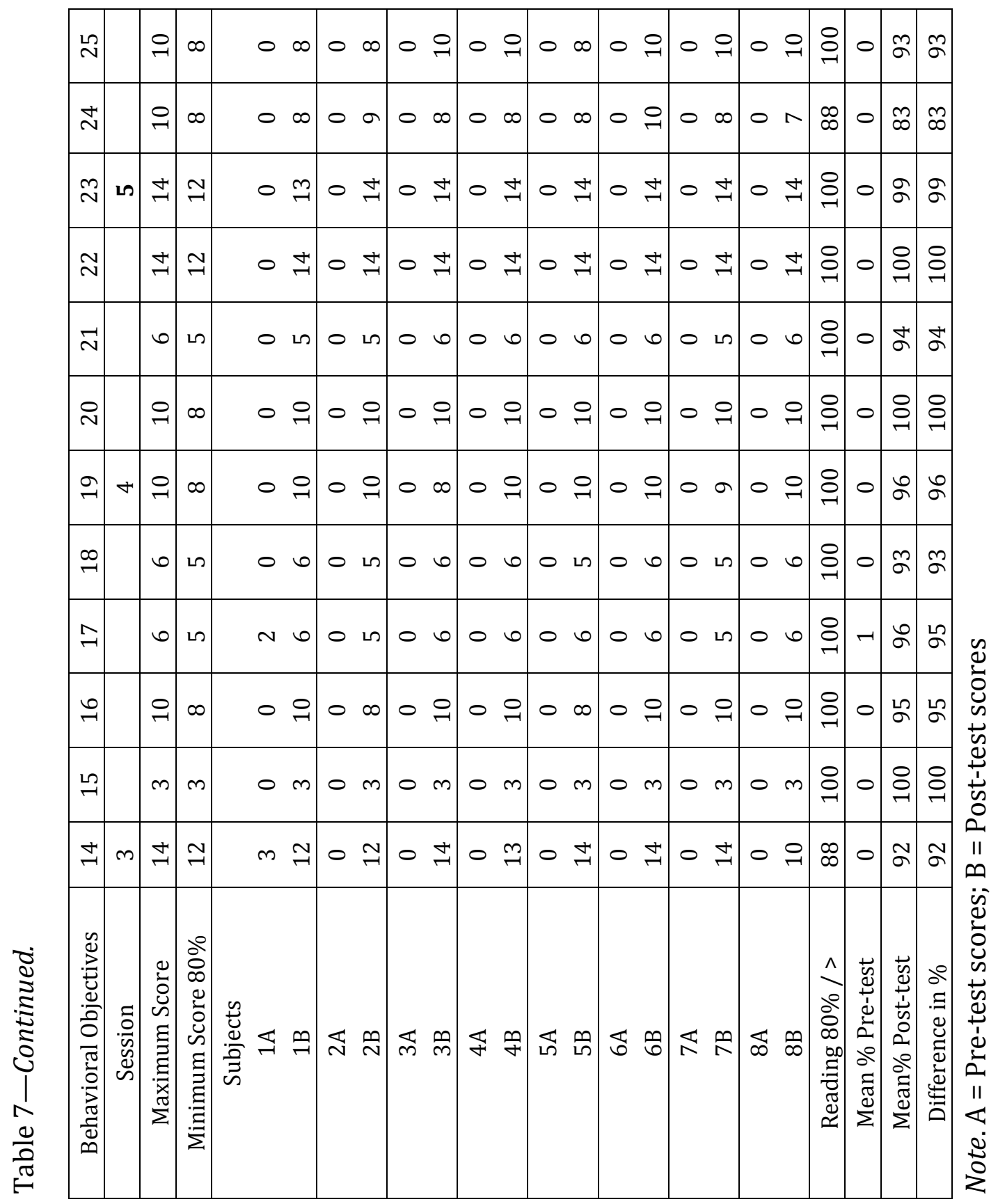


concepts quite readily. However, I continued to emphasize the practices that seemed most helpful for this age group. Briefly put, I was learning from my experiences.

Again, evidences of readiness among group members were demonstrated. All participants were getting answers to selected questions at a faster rate than the previous groups.

Scores on the cognitive post-test inventory were very encouraging. All 8 subjects achieved mastery on 23 behavioral objectives. Seven subjects (87.5\%) scored $80 \%$ or better on all 25 objectives. Mastery was attained based on the criterion specified for the G.R.A.C.E. Project. Only one subject failed to achieve the required minimum score of $80 \%$ on behavioral objectives 1 and 3 .

This performance disparity among learners provided me with a reason to take another look at selected questions and/or instructional strategies for further modifications. Final review and modifications were made to the entire project. Question 22 was reworded for greater clarity, since conflicting requirements were identified. The use of calculator was specified as well as estimation. The exact calculation component was omitted. Other adjustments were made to the cognitive instrument, participants' manual, and developer's manual for better alignment and consistency.

Special attention was given to detail, since this was to be the final revision made in preparation for full implementation with the largest group of subjects. Consequently, wording of many questions were slightly adjusted (in the manuals and pre-and post-test documents) for greater clarity. In addition to these 
minor/general changes, I focused on the preliminaries for sections A to E of the developer's manual. Scriptural ideas related to the study of geometry were presented in a more learner- friendly mode. These changes were primarily intended to encourage greater interaction between instructor and participants, as the instructor seeks to engage in the faith integration process.

The preceding tryouts were used to refine the curriculum in preparation for full-scale implementation with the large group. Consequently, each component of the curriculum was again revised. The cumulative experience gained during previous tryouts enabled the preparation of a more relevant curriculum and a better equipped instructor. As a result, I was both optimistic and confident that the subjects' performance on the cognitive post-test would meet or exceed the criterion set for mastery. Would I be able to declare the curriculum empirically developed?

\section{Modification of Affect, Group of 8}

Comparison of the means of the affective pre- and post-tests scores for eight subjects revealed a $21.5 \%$ difference, and an effect size of 0.903 . These values indicated that the difference of $21.5 \%$ between the post- and pre-test scores was important with a large effect. Table 8 shows subjects' pre- and post-test percentage scores on the affective instrument. The percentage difference between post- and pre-test scores is also given.

\section{Step 7: Final Tryout and Analysis, Group of 25}

The final tryout was administered to 25 subjects in three separate groups. The first group of 13 was comprised of Pathfinders who were in attendance at the Peterson 
Warren Academy in Detroit, Michigan. Two of the three sessions were held in settings that are different from the regular Pathfinder instructional setting. The second group consisted of 7 subjects from the Eau Claire SDA Pathfinder Club and the third group of subjects consisted of a combined group of 5 members from Shiloh, Illinois, and Gary Night, Indiana, Pathfinder clubs.

In order to maintain consistency, the materials and instructional delivery were standardized for all three groups. Efforts were made also to deliver instruction under similar conditions for all groups. For example, adequate lighting, clean, organized, and quiet work area, and adequate space for participants to move about characterized the instructional setting for each of these groups.

Table 8

Affective Test Scores of 8 Participants

\begin{tabular}{cccc}
\hline Subjects & Pre-Test & Post-Test & $\begin{array}{c}\text { Post-test } \\
\text { Pre-test } \\
\text { Difference }\end{array}$ \\
\hline & & & \\
\hline & 62 & 82 & 20 \\
3 & 61 & 70 & 09 \\
4 & 50 & 81 & 31 \\
5 & 56 & 91 & 25 \\
6 & 73 & 74 & 18 \\
7 & 57 & 90 & 17 \\
8 & 61 & 80 & 29 \\
Mean & 56 & 81 & 24 \\
& 59.5 & & 21.5 \\
\hline
\end{tabular}


The cognitive pre-test scores for the final group of 25 subjects was $0 \%$ for all of the behavioral objectives except $2,3,5,7,8$, and 10 . These results suggested that subjects were largely unfamiliar with the material and therefore avoided attempting these questions. Results are presented in Table 9.

Twenty-four out of 25 subjects (96\%) achieved scores of $80 \%$ or better on all of the stated objectives on the cognitive post-test. One subject, or $4 \%$, failed to achieve the level of mastery prescribed for the G.R.A.C.E. Project. The mean scores on the cognitive pre-test ranged from $0 \%$ to $14 \%$, and $86 \%$ to $100 \%$ on the cognitive post-test.

\section{Cognitive Behavior}

The cognitive pre-test was given to participants prior to instruction in order to determine entry-level performance. Results indicated that the subjects were unfamiliar with the core content of this curriculum. Performance fell short of the $80 \%$ mark on all objectives except objectives 2,5 , and 10 . In fact, the overall pre-test scores for all subjects fall within the $0-25 \%$ range (see Table 9). This level of performance provided insights regarding participants' geometry needs as well as the effort required for successful completion of the G.R.A.C.E. Project.

The cognitive post-test scores for the final group of 25 subjects indicated that 24 out of 25 , or $96 \%$, of subjects did achieve mastery of $80 \%$ or higher of the criteria on each of the 25 behavioral objectives. The mean scores for the post-test fall within the $75-100 \%$ range. 
Results for each behavioral objective (as shown in Table 9) are as follows:

The mean pre-test score on behavioral objective 1 was $0 \%$. The mean posttest score was 94 , an increase of $94 \%$, and $100 \%$ of the learners achieved at least $80 \%$ on the post-test.

The mean pre-test score on behavioral objective 2 was $14 \%$. The mean post-test score was 95 , an increase of $81 \%$, and $100 \%$ of the learners achieved at least $80 \%$ on the post-test.

The mean pre-test score on behavioral objective 3 was $8 \%$. The mean posttest score was 91 , an increase of $83 \%$, and $100 \%$ of the learners achieved at least $80 \%$ on the post-test.

The mean pre-test score on behavioral objective 4 was $0 \%$. The mean posttest score was 93, an increase of 93\%, and $100 \%$ of the learners achieved at least $80 \%$ on the post-test.

The mean pre-test score on behavioral objective 5 was 3 percent. The mean post-test score was 98 , an increase of $95 \%$, and $100 \%$ of the learners achieved at least $80 \%$ on the post-test.

The mean pre-test score on behavioral objective 6 was $0 \%$. The mean posttest score was 96 , an increase of $96 \%$, and $100 \%$ of the learners achieved at least $80 \%$ on the post-test.

The mean pre-test score on behavioral objective 7 was $1 \%$. The mean posttest score was 96 , an increase of $95 \%$, and $100 \%$ of the learners achieved at least 80 percent on the post-test. 


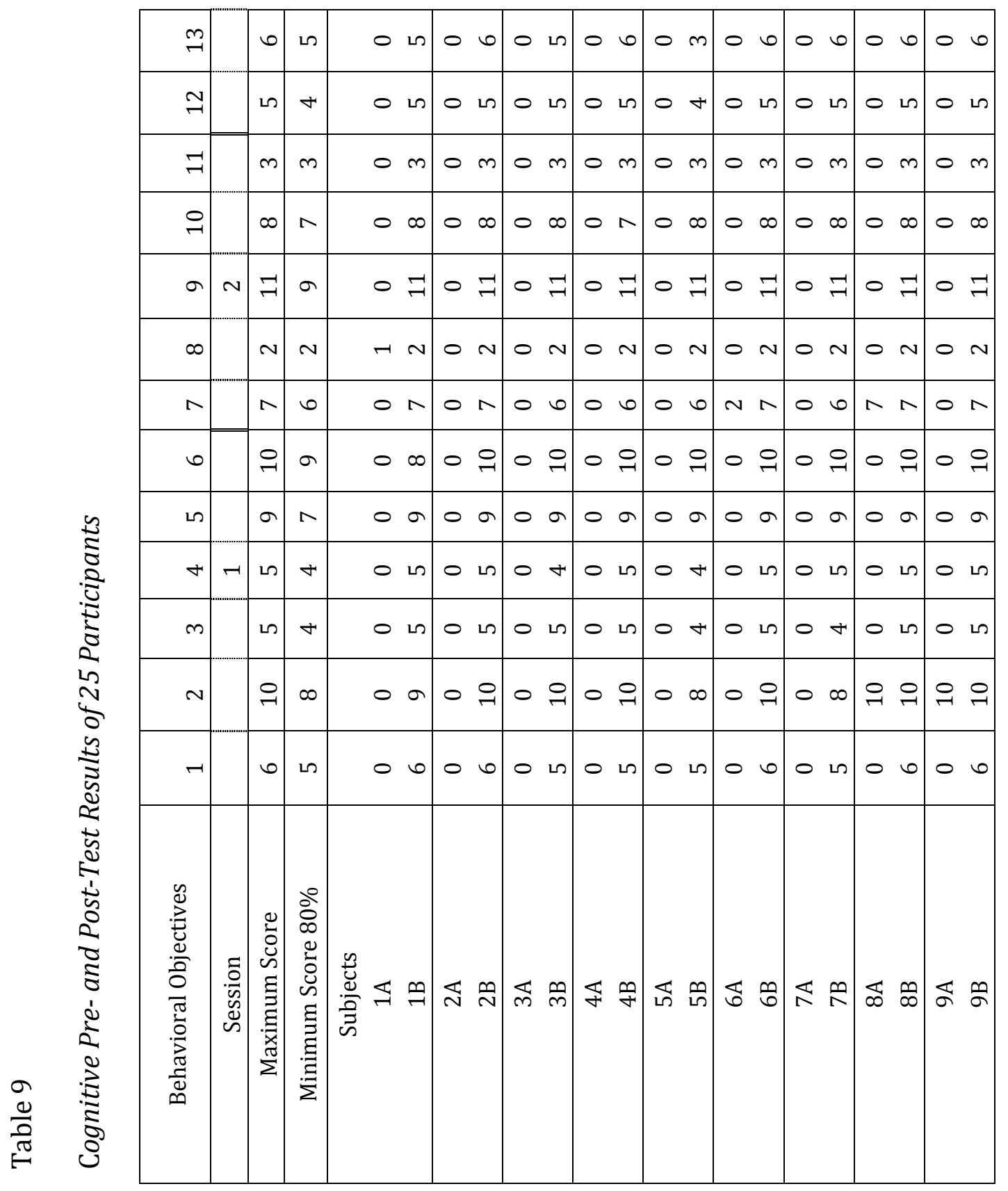




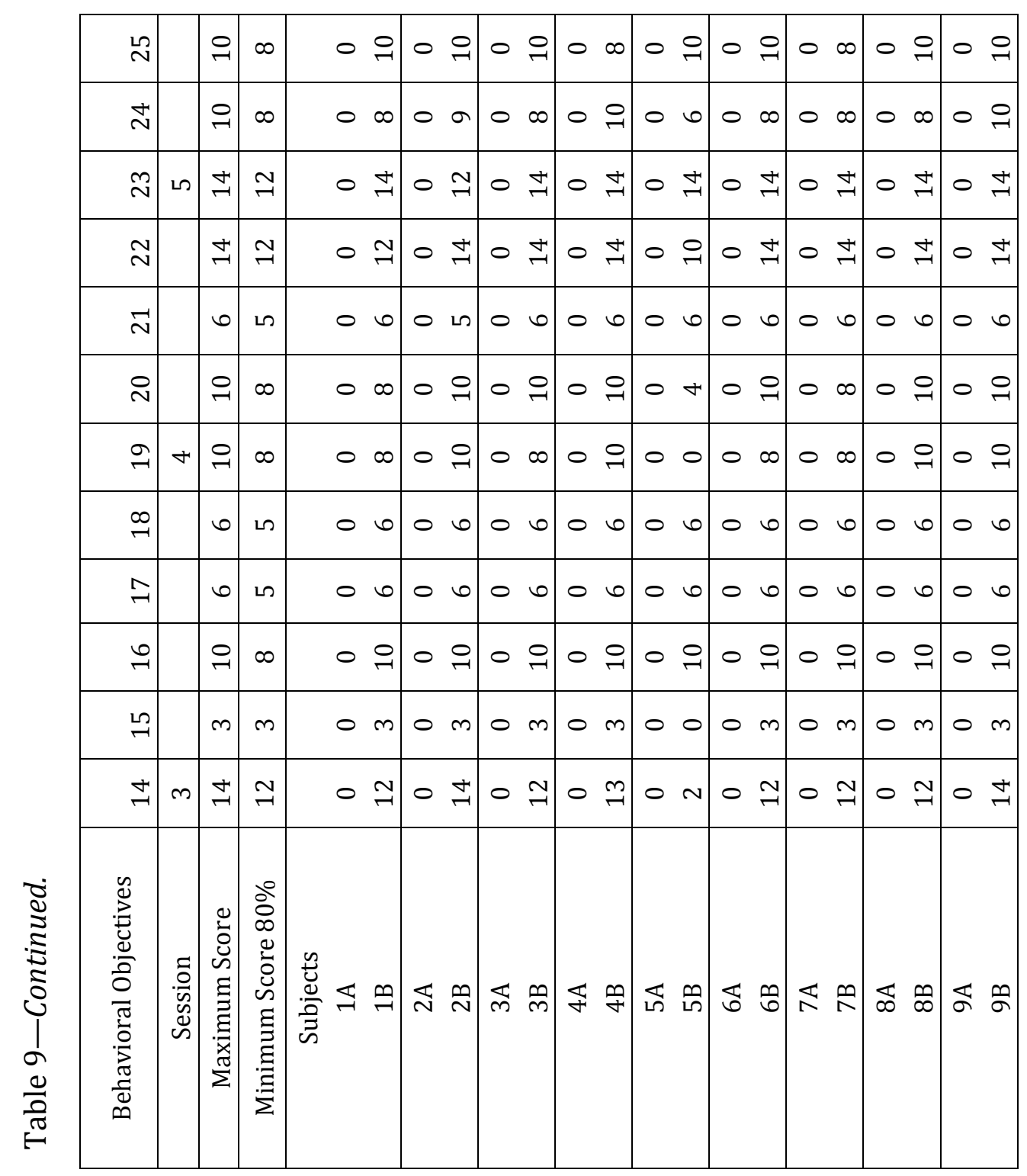




\begin{tabular}{|c|c|c|c|c|c|c|c|c|c|}
\hline$\stackrel{m}{-1}$ & 0 م & 0 ᄂ & 0 L & 06 & 0 L & 0 L & 0 L & 00 & $0 \mathrm{~L}$ \\
\hline$\underset{\sim}{\sim}$ & $0 \mathrm{Ln}$ & $0 \%$ & 0 เก & 0 L & 0 ᄂ & $0 \%$ & $0 \%$ & 0 L & 0 L \\
\hline$\exists$ & $0 m$ & $0 \mathrm{~m}$ & $0 \mathrm{~m}$ & $0 \mathrm{~m}$ & $0 \mathrm{~m}$ & $0 \mathrm{~m}$ & $0 \mathrm{~m}$ & $0 \mathrm{~m}$ & $0 \mathrm{~m}$ \\
\hline 윽 & $0 \infty$ & $0 \infty$ & $0 \infty$ & $0 \infty$ & $0 \infty$ & $0 \infty$ & $0 \infty$ & $0 \infty$ & $0 \infty$ \\
\hline$a$ & 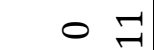 & 0 & $0 \exists$ & $0 \exists$ & $0=$ & $0 ت$ & $0 ت$ & $0 \exists$ & $0 ت$ \\
\hline$\infty$ & $0 N$ & $0 N$ & $0 N$ & $0 N$ & $0 N$ & $0 N$ & $0 N$ & $0 N$ & $0 N$ \\
\hline$\Lambda$ & $0 N$ & $\begin{array}{ll}0 & 0\end{array}$ & 00 & $0 N$ & $0 N$ & $0 \Omega$ & $0 N$ & $0 N$ & 00 \\
\hline 0 & $0 \stackrel{\circ}{\circ}$ & 00 & $0 \stackrel{-}{\circ}$ & $0 \sigma$ & 0 욱 & 0 욱 & $0 \infty$ & 0 어 & $\circ \stackrel{\circ}{\circ}$ \\
\hline L & $0 a$ & 0 & $0 \infty$ & $0 a$ & $0 a$ & $0 a$ & $0 a$ & $0 \sigma$ & $0 \sigma$ \\
\hline$\psi$ & $0 \%$ & $0 \%$ & 0 L & 0 เ & $0 \%$ & $0 \%$ & $0 \%$ & 0 L & 0 L \\
\hline$m$ & 0 Ln & $0 \%$ & $0 \%$ & 0 L & $0 \%$ & 0 L & $0 \%$ & 0 L & $0 \%$ \\
\hline$N$ & $0 \stackrel{-}{\circ}$ & 0 & $0 \stackrel{-1}{1}$ & 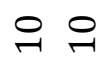 & $0 \infty$ & $0 \infty$ & $0 \infty$ & 0 엉 & 0 욱 \\
\hline-1 & 00 & 0 ᄂ & 00 & 00 & $0 \mathrm{Ln}$ & 06 & 00 & 00 & 00 \\
\hline 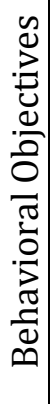 & 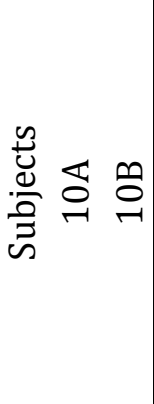 & 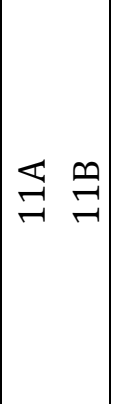 & 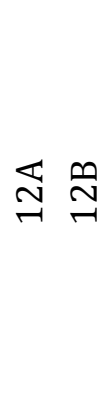 & $\underset{m}{\stackrel{m}{n}}$ & $\underset{\ddagger}{\rightleftarrows}$ & ํํㄱ เึ็ & $\underset{\sim}{\mathbb{\sigma}} \underset{\sim}{\bullet}$ & 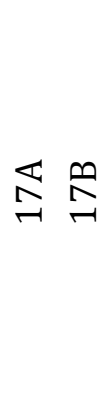 & $\underset{\sim}{\mathbb{\sim}} \underset{\sim}{\infty}$ \\
\hline
\end{tabular}




\begin{tabular}{|c|c|c|c|c|c|c|c|c|c|}
\hline$\stackrel{\sim}{N}$ & $\circ \stackrel{\circ}{\circ}$ & $0 \stackrel{\circ}{1}$ & $\circ$ 음 & 0 우 & $0 \stackrel{\circ}{\circ}$ & $\circ$ 욱 & 0 욱 & $0 \infty$ & $\circ$ 욱 \\
\hline$\stackrel{+}{\sim}$ & 0 우 & $0 \infty$ & 0 윽 & 0 윽 & $0 \infty$ & 0 욱 & $0 \infty$ & 0 욱 & $0 \stackrel{-1}{1}$ \\
\hline N & ○ & $0 \underset{+}{+}$ & ○ & $0 \underset{ت}{\sharp}$ & ○ & $\circ \underset{ন}{\sharp}$ & $0 \cong$ & ○ & ○ \\
\hline 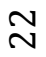 & $0 \underset{ت}{\leftrightarrows}$ & $0 \stackrel{-}{\sim}$ & $0 \underset{二}{\leftrightarrows}$ & $0 \underset{二}{\sharp}$ & $0 \underset{-}{-}$ & $0 \underset{G}{\leftrightarrows}$ & $0 \stackrel{-}{-}$ & $0 \underset{ت}{む}$ & ○ \\
\hline$\vec{v}$ & 00 & 00 & 06 & 00 & 00 & 06 & 00 & 00 & 06 \\
\hline 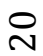 & 0 우 & $\circ$ 윽 & 0 욱 & 0 어 & $0 \infty$ & $0 \infty$ & $0 \infty$ & 0 욱 & $0 \infty$ \\
\hline$\stackrel{\sigma}{-1}$ & $0 \stackrel{-1}{1}$ & $0 \infty$ & 0 욱 & 0 욱 & $0 \infty$ & $0 \infty$ & $0 \infty$ & $0 \stackrel{-1}{1}$ & $0 \infty$ \\
\hline$\stackrel{\infty}{-}$ & 00 & 00 & 06 & 06 & 00 & 06 & 06 & 00 & 00 \\
\hline 강 & 00 & 06 & 06 & 06 & 00 & 00 & 06 & 06 & 06 \\
\hline$\stackrel{0}{-1}$ & $0 \stackrel{-1}{1}$ & 0 욱 & $\circ \stackrel{ }{-1}$ & 0 억 & $0 \stackrel{\circ}{\circ}$ & $0 \stackrel{-}{\circ}$ & $0 \infty$ & $0 \stackrel{-1}{1}$ & $\circ \stackrel{\circ}{-1}$ \\
\hline$\stackrel{\text { L }}{\sim}$ & $0 \mathrm{~m}$ & $0 \mathrm{~m}$ & $0 \mathrm{~m}$ & $0 \mathrm{~m}$ & $0 \mathrm{~m}$ & $0 \mathrm{~m}$ & $0 \mathrm{~m}$ & $0 \mathrm{~m}$ & $0 \mathrm{~m}$ \\
\hline$\underset{\Xi}{\Xi}$ & $0 \underset{7}{\mathbb{1}}$ & $0 \underset{-1}{ }$ & $0 \underset{I}{ }$ & $0 \stackrel{+}{二}$ & $0 \underset{I}{ }$ & $0 \underset{-1}{N}$ & $0 \underset{I}{ }$ & $0 \underset{-}{+}$ & $0 \underset{H}{\sharp}$ \\
\hline 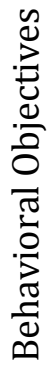 & 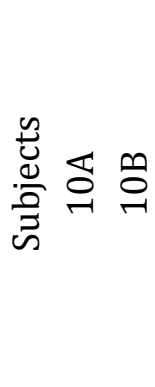 & $\underset{\exists}{\leftrightarrows}$ & $\underset{\sim}{\underset{\sim}{\sim}} \underset{\sim}{\sim}$ & $\underset{m}{\vec{m}} \stackrel{m}{\sim}$ & $\underset{\neg}{\stackrel{q}{\ddagger}}$ & เి เి เి & 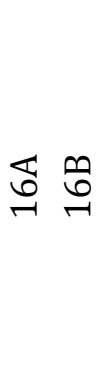 & $\underset{\sim}{\mathbb{N}}$ & 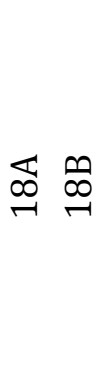 \\
\hline
\end{tabular}




\begin{tabular}{|c|c|c|c|c|c|c|c|c|c|c|c|}
\hline$m$ & 00 & 00 & 00 & 06 & 00 & 0 L & 00 & ন & 0 & નુ & б̆ \\
\hline$\stackrel{\simeq}{-}$ & 0 L & 0 L & 0 L & 0 L & 0 L & 0 ᄂ & 0 L & ○ & 0 & ลે & ลิ \\
\hline$\exists$ & $0 \mathrm{~m}$ & $0 \mathrm{~m}$ & $0 \mathrm{~m}$ & $0 \mathrm{~m}$ & $0 \mathrm{~m}$ & $0 \mathrm{~m}$ & $0 \mathrm{~m}$ & ○ & 0 & 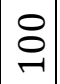 & ○ \\
\hline$\stackrel{0}{-}$ & $0 N$ & $\infty \infty$ & $0 \infty$ & $0 r$ & $0 \infty$ & $0 N$ & $0 \infty$ & ○ & -1 & å & $\infty$ \\
\hline$a$ & $0 ت$ & 07 & $0=$ & 07 & $0 \exists$ & $0 \stackrel{\circ}{\circ}$ & $0 ت$ & ○ & 0 & g & a \\
\hline$\infty$ & $\sim N$ & $0 N$ & $\circ \sim$ & $0 \mathrm{~N}$ & $0 N$ & $0 N$ & $0 N$ & 음 & $\sim$ & 음 & $\propto$ \\
\hline$\Lambda$ & 00 & $0 N$ & $0 N$ & 06 & 00 & 00 & 06 & 8 & -1 & 이 & ตั \\
\hline 0 & $0 \infty$ & $0 \stackrel{\circ}{\circ}$ & $0 \infty$ & $0 \stackrel{-1}{\circ}$ & 0 욱 & $0 a$ & 0 이 & ᄋ & 0 & ட̊ & a \\
\hline L & $0 \infty$ & $m a$ & $0 \sigma$ & $0 \infty$ & $m a$ & $0 \infty$ & $0 \sigma$ & 8 & $m$ & $\infty$ & 으 \\
\hline 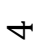 & 0 L & $\neg$ ת & 0 L & $0 \%$ & 0 L & 0 L & $0 \%$ & 응 & 0 & na & n \\
\hline$m$ & $0 \%$ & S & 0 L & $0 \%$ & 0 L & $0 \%$ & $0 \%$ & ○ & $\infty$ & न & $\stackrel{m}{\infty}$ \\
\hline$N$ & $m \stackrel{ }{\circ}$ & L & 0 욱 & $0 \stackrel{-1}{\circ}$ & $\infty$ 욱 & $0 \stackrel{-1}{1}$ & 0 욱 & 음 & $\stackrel{+}{+}$ & 능 & $\not$ \\
\hline-1 & 00 & 0 L & 00 & 0 L & $\sim 0$ & 0 L & 06 & 8 & 0 & పे & హ゙ \\
\hline 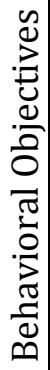 & 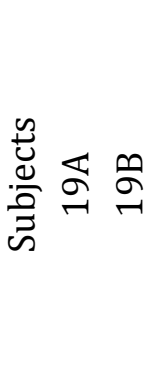 & 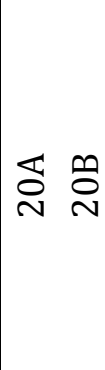 & $\underset{\sim}{\stackrel{\varpi}{\sim}}$ & $\underset{N}{\mathbb{N}} \stackrel{\sim}{N}$ & $\underset{\sim}{\mathbb{N}} \stackrel{m}{\sim}$ & $\underset{\sim}{\stackrel{্}{\sim}} \underset{\sim}{\sim}$ & ฝึ & 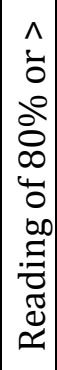 & 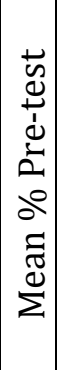 & 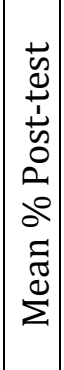 & 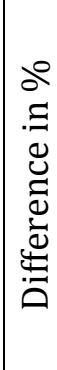 \\
\hline
\end{tabular}




\begin{tabular}{|c|c|c|c|c|c|c|c|c|c|c|c|}
\hline$\stackrel{\mathrm{L}}{\sim}$ & $0 \sigma$ & $0 \stackrel{0}{-1}$ & $0 \infty$ & $0 \stackrel{-1}{\circ}$ & $0 \stackrel{-1}{1}$ & $0 a$ & $0 \infty$ & $\stackrel{\circ}{\circ}$ & 0 & ถั & ตั \\
\hline$\stackrel{\sim}{\sim}$ & $0 \infty$ & $0 \infty$ & $0 a$ & $0 \infty$ & $0 \infty$ & $0 a$ & $0 \infty$ & హ゙ & 0 & $\widehat{\infty}$ & $\infty$ \\
\hline$\underset{\sim}{\sim}$ & $0 \underset{\leftarrow}{\leftrightarrows}$ & $0 \underset{\sqsupset}{\sharp}$ & $0 \underset{+}{む}$ & $0 \underset{1}{二}$ & $0 \underset{二}{\ddagger}$ & $0 \stackrel{m}{\rightarrow}$ & $0 \underset{\leftarrow}{\leftrightarrows}$ & $\stackrel{8}{\circ}$ & 0 & 天े & a \\
\hline$\underset{N}{N}$ & $0 \underset{t}{\leftrightarrows}$ & $\circ \underset{ت}{\sharp}$ & 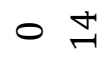 & $0 \underset{+}{\ddagger}$ & $0 \underset{\leftarrow}{\stackrel{H}{二}}$ & $0 \stackrel{m}{\rightarrow}$ & $0 \stackrel{m}{\sim}$ & ন & 0 & ถ้ & ตั \\
\hline$\vec{\sim}$ & 00 & 00 & 06 & 00 & 00 & 00 & 0 L & $\stackrel{\circ}{\circ}$ & 0 & ริ & g \\
\hline$\stackrel{ }{\sim}$ & $0 \stackrel{\circ}{\circ}$ & $\circ \stackrel{0}{-1}$ & $0 \stackrel{0}{-1}$ & $0 \infty$ & $0 \stackrel{0}{\circ}$ & $0 \stackrel{-}{\circ}$ & $0 \stackrel{0}{\circ}$ & ন & 0 & ন & ๙ু \\
\hline$\stackrel{\sigma}{-}$ & $0 \infty$ & $\circ \stackrel{0}{-1}$ & $0 \stackrel{\circ}{\circ}$ & $0 \infty$ & $0 \stackrel{0}{\circ}$ & $0 a$ & $0 \infty$ & ন & 0 & $\begin{array}{l}\bullet \\
\infty\end{array}$ & $\infty$ \\
\hline$\stackrel{\infty}{-}$ & 00 & 00 & 06 & 06 & 00 & 00 & 00 & $\stackrel{8}{\circ}$ & 0 & $\stackrel{\circ}{\circ}$ & $\underset{-1}{\stackrel{1}{-1}}$ \\
\hline$\approx$ & 00 & 00 & 06 & 06 & 06 & 00 & 00 & $\stackrel{8}{\circ}$ & 0 & $\stackrel{\circ}{\circ}$ & $\stackrel{\circ}{\circ}$ \\
\hline$\underset{-1}{0}$ & $0 \infty$ & 0 욱 & $0 a$ & $0 \infty$ & $0 \stackrel{0}{\circ}$ & 0 윽 & $0 \infty$ & $\stackrel{8}{\circ}$ & 0 & ต้ & o \\
\hline$\stackrel{20}{\sim}$ & $0 \mathrm{~m}$ & $0 \mathrm{~m}$ & $0 m$ & $0 m$ & $0 \mathrm{~m}$ & $0 \mathrm{~m}$ & $0 m$ & ন & 0 & $\stackrel{\circ}{\circ}$ & $\stackrel{8}{\circ}$ \\
\hline$\Xi$ & $0 \stackrel{m}{-}$ & $0 \cong$ & $0 \stackrel{m}{=}$ & $0 \stackrel{m}{=}$ & $0 \stackrel{m}{=}$ & $0 \stackrel{m}{\rightarrow}$ & $0 \stackrel{\sim}{\sim}$ & ন & 0 & 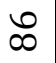 & $\infty$ \\
\hline 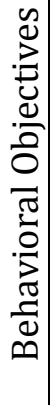 & 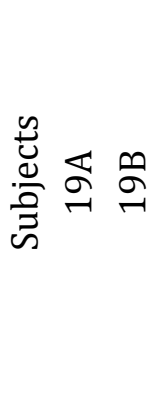 & 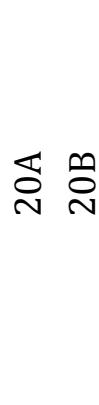 & 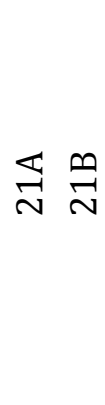 & $\underset{\mathbb{N}}{\mathbb{N}} \stackrel{\mathbb{N}}{\mathbb{N}}$ & $\underset{m}{\stackrel{m}{v}}$ & 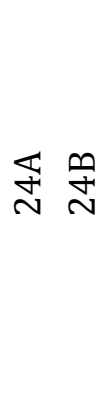 & ฝึ & 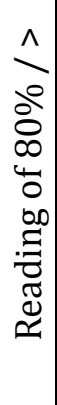 & 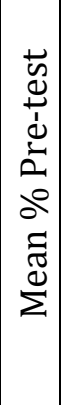 & 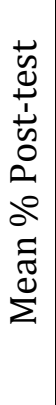 & 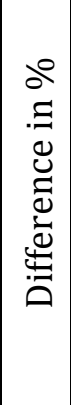 \\
\hline
\end{tabular}


The mean pre-test score on behavioral objective 8 was $2 \%$. The mean posttest score was 100, an increase of $98 \%$, and $100 \%$ of the learners achieved at least $80 \%$ on the post-test.

The mean pre-test score on behavioral objective 9 was $0 \%$. The mean posttest score was 99, an increase of 99\%, and $100 \%$ of the learners achieved at least $80 \%$ on the post-test.

The mean pre-test score on behavioral objective 10 was $1 \%$. The mean posttest score was 99, an increase of 98\%, and $100 \%$ of the learners achieved at least 80 percent on the post-test.

The mean pre-test score on behavioral objective 11 was $0 \%$. The mean posttest score was 97 , an increase of $97 \%$, and $100 \%$ of the learners achieved at least $80 \%$ on the post-test.

The mean pre-test score on behavioral objective 12 was $0 \%$. The mean posttest score was 100, an increase of $100 \%$, and $100 \%$ of the learners achieved at least $80 \%$ on the post-test.

The mean pre-test score on behavioral objective 13 was $0 \%$. The mean posttest score was 91 , an increase of $91 \%$, and $94 \%$ of the learners achieved at least $80 \%$ on the post-test.

The mean pre-test score on behavioral objective 14 was $0 \%$. The mean posttest score was 86 , an increase of $86 \%$, and $94 \%$ of the learners achieved at least $80 \%$ on the post-test. 
The mean pre-test score on behavioral objective 15 was $0 \%$. The mean posttest score was 100, an increase of $100 \%$, and $100 \%$ of the learners achieved at least $80 \%$ on the post-test.

The mean pre-test score on behavioral objective 16 was $0 \%$. The mean posttest score was 96 , an increase of $96 \%$, and $100 \%$ of the learners achieved at least $80 \%$ on the post-test.

The mean pre-test score on behavioral objective 17 was $0 \%$. The mean posttest score was 100, an increase of $100 \%$, and $100 \%$ of the learners achieved at least $80 \%$ on the post-test.

The mean pre-test score on behavioral objective 18 was $0 \%$. The mean posttest score was 100 , an increase of $100 \%$, and $100 \%$ of the learners achieved at least $80 \%$ on the post-test. The mean pre-test score on behavioral objective 19 was $0 \%$. The mean post-test score was 86 , an increase of $86 \%$, and $94 \%$ of the learners achieved at least $80 \%$ on the post-test.

The mean pre-test score on behavioral objective 20 was $0 \%$. The mean posttest score was 92, an increase of $92 \%$, and $94 \%$ of the learners achieved at least $80 \%$ on the post-test.

The mean pre-test score on behavioral objective 21 was $0 \%$. The mean posttest score was 99, an increase of $99 \%$, and $100 \%$ of the learners achieved at least $80 \%$ on the post-test.

The mean pre-test score on behavioral objective 22 was $0 \%$. The mean posttest score was 96 , an increase of $96 \%$, and $94 \%$ of the learners achieved at least $80 \%$ on the post-test. 
The mean pre-test score on behavioral objective 23 was $0 \%$. The mean posttest score was 99, an increase of 99\%, and 100\% of the learners achieved at least $80 \%$ on the post-test.

The mean pre-test score on behavioral objective 24 was $0 \%$. The mean posttest score was 87 , an increase of $87 \%$, and $94 \%$ of the learners achieved at least $80 \%$ on the post-test.

The mean pre-test score on behavioral objective 25 was $0 \%$. The mean posttest score was 96 , an increase of $96 \%$, and $100 \%$ of the learners achieved at least $80 \%$ on the post-test. The comparatively high percentage score on the post-test indicated that even though the curriculum core content was new it was mastered by almost all of the subjects. The refining of the instructional product continued even after the final tryout.

Expert recommendations after my dissertation defense led to further major revisions. All of the objectives were reworded to be more specific. Question 6 was upgraded to specify that congruent shapes were also similar. Questions number 10, 12,15 and 20 were adjusted for alignment with stated objectives and to minimize confusion. Question \# 20 was further modified to remove ambiguity. At first it suggested that learners should plot points without including the Cartesian plane. The final version specifies classification of coordinate pairs mentally in six categories rather than the original three categories.

The diagram in questions 16 was improved to show missing grid lines and a second design was included in question 17 for comparison. Both objective and content of questions 13 were adjusted for proper sequencing of geometric 
statements. Consistency in statement of objectives in table, pre/post-test, criteria for test, and in both manuals was also attempted. Also, typographical errors were identified and corrected throughout the document during the refining process.

The changes described in the above paragraph were necessary to ensure accuracy and consistency among different components of the instructional product. For example, stated outcomes were used to determine the type of questions formulated as well as the scope and sequence of instructional materials.

\section{Modification of Affect, Group of 25, Affective Behavior}

Since learning involves both affective and cognitive components, the Baker and Schutz (1971) model framework for instruction links affective behaviors to cognitive performance outcomes. Positive affect is desirable, as it helps to produce more positive responses to the stimuli of learning.

Several appropriate strategies were implemented for affect. For example, the effort made to establish good rapport with learners builds mutual confidence, facilitates effective communication, and creates an environment that is conducive to effective learning (Leonard, Bourke, \& Schofield, 2004). Therefore an underlying assumption of this study is that outcome of the post-test was influenced by affective strategies implemented during the instructional product development process.

Comparison of the means of the affective pre- and post-test scores for twenty-five subjects revealed a $22 \%$ difference along with an effect size of 0.894 . These values indicated that the difference of $22 \%$ between the post- and pre-test scores was important with a large effect. Table 10 shows subjects' pre- and post-test 
Table 10

Affective Test Scores of 25 Participants

\begin{tabular}{|c|c|c|c|}
\hline Subjects & Pre-Test & Post-Test & $\begin{array}{l}\text { Post-test } \\
\text { Pre-test } \\
\text { Difference }\end{array}$ \\
\hline 1 & 40 & 70 & 30 \\
\hline 2 & 60 & 72 & 12 \\
\hline 3 & 50 & 70 & 20 \\
\hline 4 & 50 & 76 & 26 \\
\hline 5 & 66 & 82 & 16 \\
\hline 6 & 44 & 83 & 39 \\
\hline 7 & 58 & 71 & 13 \\
\hline 8 & 47 & 74 & 27 \\
\hline 9 & 47 & 81 & 34 \\
\hline 10 & 60 & 73 & 13 \\
\hline 11 & 50 & 80 & 30 \\
\hline 12 & 47 & 67 & 20 \\
\hline 13 & 42 & 73 & 31 \\
\hline 14 & 56 & 80 & 24 \\
\hline 15 & 62 & 77 & 15 \\
\hline 16 & 74 & 82 & 08 \\
\hline 17 & 42 & 51 & 13 \\
\hline 18 & 40 & 75 & 35 \\
\hline 19 & 52 & 81 & 29 \\
\hline 20 & 70 & 86 & 16 \\
\hline 21 & 58 & 83 & 25 \\
\hline 22 & 54 & 87 & 33 \\
\hline 23 & 50 & 76 & 26 \\
\hline 24 & 60 & 80 & 20 \\
\hline 25 & 56 & 80 & 24 \\
\hline Mean & 54 & 76 & 22 \\
\hline
\end{tabular}


percentage scores on the affective instrument. The percentage difference between post- and pre-test scores is also given.

During the curriculum development delivery process with the large group of 25 subjects, deliberate efforts were made to enhance positive affect, in keeping with the Baker and Schutz (1971) Instructional Product Development Model.

My actions included but were not limited to those mentioned below:

1. Highlighting the long-term benefits of a proper foundation in geometry during the junior-high-school years

2. Maintaining a high level of enthusiasm while providing instruction

3. Engaging participants in prayer before each sessions begins

4. Encouraging peer support toward greater understanding of selected concepts in geometry

5. Inviting questions and comments from participants throughout the process

6. Establishing basic criteria for learning environment including:

(a) clean and well ventilated, (b) adequate illumination,

(c) uncluttered and spacious, (d) well organized and quiet

7. Displaying a high level of competence and professionalism

8. Commending participants liberally for their effort

9. Emphasizing the high level of success among previous participants who completed the G.RA.C.E. Project 
10. Becoming excited about the aesthetic beauty of a world filled with geometric designs and patterns.

These affective strategies have also been delineated in the administrator's manual.

It was assumed that the group of 25 subjects was motivated toward the learning of concepts in geometry. The learners demonstrated much enthusiasm; they willingly assisted each other, and expressed appreciation for the meaningful activities. The classroom climate was affirming and all subjects seemed to enjoy their new experience with geometry. I observed that they became very articulate when pointing out inconsistencies or identifying areas that were a bit confusing at first.

Engaging a first course in geometry could have been overwhelming for any group of middle-graders; however, the learners were attentive, interested, and cooperative. As a result, ideas and concepts that would be otherwise difficult to grasp were readily absorbed. This may be attributed partly to the adjusted sequencing of topics and a consistently clear, simple pattern of instruction.

This study assumes that the modification of affect played an important role in participants' cognitive mastery of selected concepts in geometry, as indicated by the cognitive post-test results. Perhaps it also contributed to participants' renewed desire for the continuing study of concepts in geometry. 


\section{Summary}

The empirical development of a geometry curriculum for junior-high-level Pathfinders required systematic planning, testing, and revisions, utilizing the input of three groups of subjects. Comparison of pre- and post-test scores, written feedback, and verbal suggestions were used as a basis for repeated revision and modification of all components of the curriculum during its developmental stages. Mastery of the 25 performance objectives was achieved at the $80 / 80$ level prescribed for the G.R.A.C.E. Project. Simultaneously, positive modification of affect was also in progress. 


\section{CHAPTER 5}

\section{SUMMARY, CONCLUSIONS, AND RECOMMENDATIONS}

The chronic lack of achievement in mathematics nationwide has raised concerns throughout the United States (Darling-Hammond, Holtzman, Gatlin, \& Heilig, 2005). This heightened awareness of the importance of mathematics to $21^{\text {st. }}$ century survival resulted in renewed effort among stakeholders to implement corrective measures. Response at the national level resulted in the No Child Left Behind (NCLB) Act and its related innovations. Following the No Child Left Behind Act of 2001, national attention was turned to after-school programs' potential to supplement academic learning (Huang, 2006). Response at the state level resulted in the modification of the mathematics curriculum in terms of prescribed standards and benchmarks (Marzano, 2003). Response at the local/district level focused mainly on: teacher preparation, effective teaching strategies, standardized testing, and student achievement. Despite all of this effort, consensus has been reached among many school districts that the K-12 system could not alone address all the needs; hence, there is necessity for a supplement that is specifically designed to support K-12 efforts (Lauer et al., 2006).

The current emphasis on performance standards and testing has led schools to look to the after-school hours as time that can be spent developing children's academic skills (Harvey \& Shortt, 2001). Research shows that out-of-school time 
(OST) programs can increase educational equity by (a) providing socioeconomically disadvantaged youth with comparable experiences to their more affluent peers, (b) fostering high expectations from adults other than school teachers, and (c) enabling participants to develop "new basic skills" such as literacy, numeracy, teamwork, and problem solving (AYPF, 2004). Durlak and Weissberg (2005) underscored findings of several other researchers that after-school programs not only impact achievement in reading and mathematics, but also promote important personal skills. Further, they proposed the following list of additional benefits: (a) improving youths' feeling of self-confidence and self-esteem, (b) school bonding (positive feelings and attitude toward school), (c) positive social behaviors, (d) improving school grades, and (e) increasing achievement test scores. Pathfinder clubs are well established out-of-school time (OST) programs. They provide children with opportunities to develop skills and interests in activities such as arts and crafts, science, reading, and a range of outdoor-type learning experiences. Programs' focus on participants' holistic development included a spiritual dimension. Interviews with many active members of the Pathfinder clubs revealed that they were performing poorly in math and would benefit from additional instruction in mathematics. The purpose of this study was to develop an instructional product in the form of a geometry curriculum for seventh- to eighthgrade-level Pathfinders of the Lake Union Conference of Seventh-day Adventists.

This product, the Geometry in Real-life Application Curriculum Experiences (G.R.A.C.E.) Project provides a needed resource that if rightly implemented could 
increase enrollment in the Pathfinder program, build participants' self-esteem, and improve math achievement for all club members.

The G.R.A.C.E. Project specifies instructional content, material, and teaching activities. It also specifies assessment criteria and instruments. This project was undertaken in response to the existing need for an instructional product that is specifically tailored to address the mathematical cognitive development needs of seventh- and eighth-grade-level Pathfinders of the Lake Union Conference of Seventh-day Adventists.

The process of developing this curriculum utilized participants' input from different groups of an increasing larger number of subjects. This teamwork engaged in between participants and instructor created a source of first-hand information that was needed to establish relevance of the curriculum.

\section{Literature Review Summary}

Information pertinent to the focus of this research project was selected from a variety of sources, organized, and presented in chapter 2 . Below is a concise account of the main issues addressed.

The promise of equal and quality education for every child, as specified by the U.S. K-12 education system, was never delivered for 130 years. Fullan (1993) and Ralston (2005) remind us of the enormous challenges faced by the public school system, despite the efforts made to improve at all levels. Confirmation of the existing crisis, especially in mathematics and science, has been upheld by results from 
several international comparison studies. Particular attention was given to mathematics and science achievement at the junior-high-school level.

As a result of this crisis, there is an increasing trend among school districts toward the recognition of supplemental education programs. Unique circumstances have given rise to the proliferation of out-of-school time curricula all across the United States (AYPF, 2006).

These programs have proven to be highly effective, in terms of improved participants' educational achievement. Some features of OST programs include: emphasis on hands-on learning, interactivity, constructivism, and a variety of grouplearning initiatives. Some programs address remediation needs of young people in specific subject areas whereas others focus on development of individuals' selfesteem, positive behaviors, or strategies for improving test scores. Durlak and Weissberg's (2005) analyses of 73 after-school programs support the overall claims, among researchers, of higher academic achievement and improved self-esteem and confidence among youth. The SDA Pathfinder clubs, like Boy Scouts and the YMCA, are a traditional OST program that provides a wide range of practical and academictype activities for club participants. This geometry curriculum will add to these resources.

Understanding the theoretical foundations of curriculum is indispensable, if the developing curriculum is to find its unique spot in the field of knowledge. For example, Bobbitt (1918) and Tyler (1949/1986) are well-known foundation curriculum theorists whose works influenced later theorists such as Glasser (1998), Taber (1962) and Baker and Schutz's (1971), whose model is being utilized in this 
study. Still, later theorists including Naden (1992), Gregor (1996), and Bailey (1997) have interpreted, adjusted, and used Baker and Schutz's (1971) instructional product development model in the development of specialized curriculum in their field.

Five variations of subject-area-focused curricula found, in the literature, emphasize the what of curriculum, whereas four instructional approaches along with their philosophical peculiarities focus on the how of curriculum. The studentcentered approach, on the other hand, seems to be more concerned with the who associated with curriculum. Pertinent literature related to this study identifies two methods of organizing curriculum-subject- and student-centered approaches. Elements of the humanistic worldview of famous curriculum theorists such as John Dewey, Carl Rogers, and Abraham Maslow are supported by Burton (1970) who thinks that curriculum ought to be related to students' personal growth, feelings, and happiness. However, he is cognizant of what Anderson (2004) refers to as the component that is omitted--the Theistic view--a view that presents God as the Creator of humankind. White (1952) advocates a more perfect curriculum, based on the authority of the Holy Scriptures. She pioneered the Seventh-day Adventist Christian Education Model, which focuses on learners' symmetric development.

\section{Math Standards and Focal Points}

In response to the equity crisis, the No Child Left Behind (NCLB) Act was signed into law, and the U.S. K-12 education system became largely standard-driven. The NCTM revised the traditional mathematics curriculum, and prescribed content 
and guidelines for instruction and assessment. This initiative brought into existence the Mathematics Education Reform Movement which was based on the proposition that a mathematics curriculum should reflect what is important for the future and include advances in technology (Reys, 2002). As a result, students were allowed to use calculators, graphing calculators, and other available technical tools to assist them in solving math problems quickly and efficiently (p. 2). Further concerns regarding the relatively poor performance of U.S. students (when compared to students of other industrialized countries) led to the development of curriculum focal points by the NCTM. The intent was to facilitate students' mastery of contents by objectives while covering fewer topics in greater depth (Reys, Lindquist, Lambdin, \& Smith, 2007).

Theorists: Their Influence on Math Education Since mathematics competency development is a cognitive process, the planning, structure, and delivery of this curriculum conforms to a framework from a variety of theoretical perspectives. Jean Piaget's famous theory of cognitive development classifies cognition into the following four stages of increasingly more sophisticated modes: Pre-operational, Sensory-motor, Concrete-Operational, and Formal-Operational.

Similarly, Jerome Bruner demonstrated a unique understanding of the thought processes which he divided into enactive, iconic, and symbolic skills. He believed that knowledge is most effectively gained by personal discovery and was 
able to apply scientific rigors to unobserved mental process as was done by behaviorists on observable, measurable responses.

Vygotsy's constructivism appears to be consistent with Jerome Bruner's works as well as Dewey's (1916/1997) problem-based instruction. It is a view of learning in which learners create understanding from their own experiences. Children are allowed to learn by actively interacting with their environment. This theory has implications for middle- and junior-high-school learners who, of necessity, need to shore up their foundation in lower-level skills in preparation for more advanced math applications.

Ellen White introduced a new perspective into the conversation. Her holistic, Christ-centered approach to curriculum delivery diverted significantly from the more behaviorist, scientific models. Foundation theorists such as Bobbitt (1918), Tyler (1949/1986) and Taba (1962) agree with White's (1903) idea that the primary function of curriculum should develop the learner's power to think rather than be mere reflectors of the thoughts of others. In essence, White believed that when faith is combined with reason it creates a more balanced approach. Her claim transcended any pedagogical basis, but Schwarz (1979) noted that she impacted educational thought for more than a century and provided evidences of scriptural and inspirational authority.

\section{Mathematics Achievement}

The increasing awareness of the positive impact of math achievement on personal and societal development, in a borderless world, is evidenced by the 
number of mathematics and science-related studies that were recently done. In addition, several international organizations (including IAEEA, SIMSS, and TIMSS) have conducted comparison studies since the early 1960s. Results consistently indicated comparatively poor performance or marginal progress in selected areas. However, a recent topical analysis by Ginsburg et al. (2005) confirmed several previous reports that progress has not been made in the areas of geometry and measurement.

Several math and science curricula, at the middle- and high-school levels, have been recommended by Clewell et al. (2005) based on their potential for increased student achievement. Details regarding the functioning of these curricula may be understood in terms of selected best practices that have been aggressively implemented by visionary educators. Examples of these curricula include: Direct Instruction (DI), which focuses on mastery based on the division of complex constructs into their component parts. The Integrated Mathematics, Science, and Technology program (IMaST) promotes hands-on learning by implementing the constructivist approach that involves active student participation. Also, the National Council of Teachers of Mathematics (NCTM) Standards places considerable emphasis on conceptual understanding, problem solving, and the constructivist pedagogy. Students are encouraged to experiment, investigate, ask questions, reflect, and communicate their ideas and conclusions. The standards also seek to bridge the performance and achievement gaps between the U.S. K-12 students and the rest of the world. 
John A. Van de Walle (2004) emphasized the need for systematic geometry instruction for middle-school students. The hierarchy of geometry understandings proposed by this theorist detailed the following five levels of learning: basic single shape recognition, recognition of classes of shapes, recognition of properties and relationships among these properties, producing and examining conjectures, and understanding deductive axiomatic systems for geometry. This framework is intended to provide context but does not prescribe what to teach.

Seventh- to Eighth-Grade-Level Geometry Achievement

The importance of bridging the achievement gap in mathematics cannot be overstated. This study seeks to provide an adequate foundation in geometry as the basis for future success in mathematics. Studies support engagement of middleschool students in gateway courses as a prerequisite for higher achievement later. NCTM Standards emphasize the importance of adequate geometry in Grades 5-8. Geometry allows for a variety of practical applications in the real-world setting. Burton (2003) believes that conceptual understanding gained through the use of manipulatives may be the key to bridging the gap between meaningless practices and effective learning. A study by the U. S. Department of Education (1997) found a $71 \%$ to $29 \%$ college enrollment rate among low-income students who took geometry and algebra and those who did not. The Van Heile (1986) model recommends a linking of geometric concepts and understandings on a continuum from simple concrete to more abstract levels by the eighth grade. 
Curriculum Design: Relevance for the $21^{\text {st }}$ Century

The Baker and Schutz (1971) model establishes its roots in prior established models. Its design allows for flexibility without compromising key elements of designs that are enduring. Several later researchers found this model very useful in developing curricula in their chosen fields of interest. I agree with Bailey (1997) that since the Baker and Schutz (1971) model facilitated the works of many curriculum developers, it was unquestionably relevant in the late 1990s. A recent study by Fauser et al. (2006) identified specific content and objectives, instructional design, and instructional product as being important. Their System-Oriented Model which appears to be an adjusted version of the Baker and Schutz (1971) model, which is also relevant today in terms of Akker et al. (2007) who describe a relevant curriculum as one that is carefully examined and tailored for the context and culture in which it is to be implemented.

\section{Method}

Results from both national and international comparison testing, which began during the early 1960s, brought about an awareness of the magnitude of the crisis in math and science in American schools. In response, curriculum developers became more systematic in their emphasis on accountability both in the development and delivery of curriculum (Tanner \& Tanner, 1987). The Baker and Schutz (1971) Instructional Product Development Model was organized as part of the trend in curriculum development that started in the 1960s. During the decades of the 80s and 90s this approach became very popular, and this was evidenced by 
the number of published articles and papers relative to this methodology. Even though the popularity of this method declined (Pratt, 1994), the Baker and Schutz (1971) method maintained its advantages of strict designer and instructor accountability and the conceptualization of the curriculum as developed as a team initiative involving learners and instructor.

This study utilized elements from at least four variations of the Baker and Schutz (1971) model which consists of the following seven steps: (a) Product Formulation, (b) Instructional Specification, (c) Item Try-out, (d) Product Development, (e) Product Tryout, (f) Product Revision, and (g) Operations Analysis. Naden (1992) proposed a 10-step version of the Baker and Schutz (1971) model which he reorganized into the following steps: (a) The Learner, (b) The Topic, (c) Behavioral Objectives, (d) Pre- and Post-test Questions, (e) Criteria for Evaluation, (f) Lecture Outlines, (g) Item Try-out, (8) Revision, (h) Product Retesting, and (i) Final Tryout and Analysis. While Selmanovac (1996) and Gregor (1996) developed instructional products using the Naden (1992) 10-step version, Bailey (1997) maintained the original 7-step format. It is to be noted that the Baker and Schutz (1971) model allows for some flexibility as long as the modifications maintain the key components of the model.

In keeping with the primary purpose of this research project, the seven-step model proposed by Baker and Schutz (1971), and adopted by Bailey (1997), was chosen. The first step was identifying the learners. Then, the topic was selected, followed by the formulation of 25 behavioral objectives. The preparation of items for the pre- and post-test inventory, along with evaluation criteria, was also 
completed. Acceptable performance for the G.R.A.C.E. Project was set at the 80/80 level; meaning that mastery is achieved only when $80 \%$ of the learners score at least $80 \%$ of the criteria for each of the 25 objectives on the cognitive post-test. Specific strategies were implemented to promote positive effects toward mastery of these objectives, which are listed in chapter 3 in the "Methodology" section. I proceeded to outline the contents of both developer's and participant's manuals. Appropriate materials needed for hands-on activities and on-the-spot research was also selected.

The product was exposed to groups consisting of 2, 4, and 8 subjects (from the target population). Participants were allowed to share their opinions or give suggestions regarding any aspect of the program. The input from each group was used to modify the product. The revision process continued for all tryout sessions. Finally, the curriculum in its polished stage was administered to a sufficiently large group of 25 subjects to allow for statistical analysis of the results.

Scores for both affective pre-and post-test for all four groups of participants were documented and converted to percentages. Pre-and post-test means were also calculated for comparison. Also, effect size for each of the four participating groups was calculated using the formula " $n^{2}=t^{2} /\left(t^{2+} d f\right)$.

\section{Findings}

The primary purpose of this study was to empirically develop an instructional product designed to provide Pathfinder participants in the Great Lakes area with an adequate foundation in geometry. I engaged 39 Pathfinder members from the target audience in the G.R.A.C.E. Project. Of these learners, 14 were 
involved in three tryouts and 25 in a full-scale implementation with a polished version of the curriculum. The process generated understandings that were evidenced by the outcome--a product in the form of an empirically developed curriculum and groups of young people who not only increased their understanding of geometry concepts but have also produced the evidence.

First, the product was justifiable only in terms of the established need for it. Prior to the planning stage of this project, the need for an instructional product in mathematics was established by means of interviews. Pathfinder leaders, conference officials, and club members believed that there was an urgent need for a mathematics component to upgrade the Pathfinder program. Review of available literature and web inquiries confirmed this need as well. Second, the course must first be charted before embarking on the journey. Therefore, the formulation of behavioral objectives was very crucial. The third understanding was the pivotal role of subjects' input in the perfecting of a subject-friendly product. The repeated revision of the product was done in terms of feedback from all participants. Fieldtesting of the product gave legitimacy to the project. Practical work done with the youth in their natural learning environment generated a context-rich understanding of learning behaviors.

On the cognitive pre-test, all participants in all three tryout sessions failed to achieve mastery on most of the 25 objectives. Such performance was expected, since the subjects were being exposed for the first time to a formal geometry program, and their understanding of concepts in geometry was limited. On the same post-test, one of two subjects achieved $80 \%$ or greater on all 25 objectives in the first tryout. 
The difference between post-and pretest means on the affective exam was $16 \%$. Three out of four of the subjects (from the second group) scored $80 \%$ or greater on the cognitive post-test. This performance indicated an increase over the previous group, and there was a mean difference of $24 \%$ between the affective post-and pretest. For the third group of 8 subjects, seven (87.5\%) of subjects achieved mastery on the cognitive post-test. A $21.5 \%$ difference between the affective post-and pretest was also documented. A moderate effect size was found for the first group and a large effect size for the second and third groups.

The preliminary revisions of all aspects of the curriculum followed the seven systematic steps of the empirical development process. And the stage was now set for a more effective curriculum delivery with the final group of 25 subjects. Mastery was achieved by 24 of the 25 (96\%) of the combined group of Pathfinder participants from the Ypsilanti, Eau Claire, Gary Night, and Shiloh clubs. Results of the cognitive post-test indicated that $80 \%$ or more of subjects, who completed the G.R.A.C.E. Project, scored $80 \%$ or greater on each of the 25 objectives. This gave indication that the empirical development process was now completed.

I observed that each successive group of subjects made greater progress as the instructional product developed. Participants' input as reflected in successive curricular revisions was found to have a cumulative positive impact. As a result, the impact of intervention on subjects' attitude/interest in geometry was indicated by increasingly larger measures of effect size. Finally, the full-scale implementation of the project with the largest group yielded a result that exceeded the standard set for mastery. 


\section{Discussion}

Curriculum lies at the heart of an educator's desire to make a difference in human lives. "To ask meaningful questions about what should be taught and learned invokes basic assumptions about what it means to enable the growth of human beings and society" (Marshall et al., 2000, p. 2). This study brought me into contact with some of the most critical issues related to teaching and learning. It was the combination of instructor-participant actions and interactions that guided the process which ended in the desired outcomes-evidences of effective participants' learning and an empirically developed instructional product. Moreover, selected understandings were generated as I engaged in the planning, structuring, delivery, assessment, and evaluation processes. Major findings presented below are discussed in terms of the theoretical framework for this study and evidences found in the literature.

The lack of a needed resource (namely a geometry curriculum) to assist Pathfinder club members in developing competence in mathematics indicated that there was room for improvement. This need was also the basis of my justification for the development of a new product. The model used for this project stipulated the confirmation of a specific need for the product as the number one criterion for instructional product development. During the introductory phase of each tryout, subjects' responses on the pre-test provided evidences that these young people were lacking basic skills and understanding in mathematics, which was consistent with previously released national and international studies (Crosswhite, Ginsburg et 
al. 2005; Jenner \& Jenner, 2007;[PISA], 2003/2006; 1985; Silver, 1998; TIMSS, 1995).

I also discovered that participants' input was critical to the fine-tuning of the curriculum. It provided another perspective- that of the learner - which is most important. Participants' input helps to promote a common language that is more easily understood by instructor and learner alike. It also helps to establish partnership and ensure curriculum relevance. These features are consistent with current research-based practices which promote a high standard of performance that is evidenced by high mathematics achievement (Kilpatrick, Swafford, \& Findell, 2001).

Many transformations in students were observed during the curriculum development process. For example, I detected contrasts during the before-and-after phases of the project. Participants discussed their uncertainties to begin and their confidence later. Contrast was also evident in the pre- and post-test scores. The overall frail attempt on the pre-test accelerated to mastery of concepts at the end. The high level of success achieved by these learners may be attributed to participants' roles in the curriculum development process. In other words, participants responded favorably to the stimuli of learning, which they themselves helped to create (Loke, Wong, \& Kan, 1999).

This experience also increased my understanding of the critical importance of field-testing in the development of what may be regarded as the relevant curriculum. First, the pre-instructional inventory allowed me to determine the competence level of each participant in the subject area. Then, participants' learning 
was observed and monitored in their natural ecology. I discovered that similarities and differences among groups are determinants of the scope and design of the instruction; meaning, that there is no effective one-cut-fits-all teaching strategy. Hence, teaching strategies implemented for this project were designed to help each participant perform to the best of his/her ability. For example, whereas one student understood the concept of volume by simply listening to the explanation and joining in the discussion, her peer seemed confused. So, I engaged the perplexed student in measuring the dimensions of the cube and multiplying the three values to get a product. A third child was asked to join me in stocking and counting cubes in order to arrive at the correct understanding of the concept of volume (Burton, 2003; Silver, 2002; Usiskin, 1995; Vandewalle \& Folk, 2008; Sherman, Richardson, \& Yard, 2005.

It was the pre-instructional inventory that gave the first credible signal regarding the quantity and quality of work and the energy output needed to help subjects achieve mastery on the post-test. The curriculum became relevant only when each participant (regardless of learning style) benefited in the context of their natural learning environment (Bransford, Brown, \& Cocking, 2000; Gardner, 1993; Silver, Strong, \& Perini, 2000).

The framework used in the development of the instructional product for this study included the necessity to pinpoint individuals' needs. Sometimes young people prefer to fake success and get lost in the group rather than to admit that they do not understand something. This understanding was helpful as I focused on the type of practices that were most helpful in assisting the young people in the learning 
process. Research-based practices include paying special attention to the individual. This may be due to the assumption that individuals possess different strengths and weaknesses. Individuals also respond favorably to affective behaviors that are intended to support, encourage, compliment, and affirm. In fact evidence exists in the literature in favor of the correlation between participants' positive cognitive outcomes and instructors' affective behaviors (Sakiz, 2007; Turner \& Patrick, 2006; Wilkins \& Ma, 2003).

A noteworthy observation was the performance trend of the groups of subjects. The progress made was in direct proportion to the development of the instructional product. In other words, as the product improved so did the performance of participants on the post-test. It was the various modifications at each stage of the development process that helped to shape the product into a more relevant curriculum. Thus, the major finding of this study was that it is possible to create curricula that help students master geometric concepts (Kember, Ho, \& Hong, 2008; Soslau \& Yost, 2007).

The impact of educational intervention on group test scores should be given some consideration. Howell recommends that reports should "go beyond simple significance testing to some measure of effect size" (Howell, 2002, p. 110). The modest effect size for the first group of subjects was important, even though the measure was not statistically significant. The effect size indicated a measure of change or impact, which suggested that the subjects made some improvement in their attitude/interest toward the learning of geometry concepts as a result of the instruction. The large effect size for the second and third groups suggested that 
significant modification was made in subjects' attitude/interest as well. This level of achievement was consistent with improved scores on the cognitive post-test.

For the largest group of 25 subjects, the modification of affect was large. This significant improvement in attitude and interest toward understanding of geometry concepts may be attributed to selected affective traits which were demonstrated by the teacher as subjects were actively engaged in the learning process (Marsh, 2000; Raymond, Goodwin \& Niles, 2005).

\section{Recommendations}

1. Based on my confirmation of the existing need for a workable knowledge of geometry among Pathfinders and the absence of available resource to address this need, it is suggested that this empirically developed curriculum, "The G.R.A.C.E. Project: Making Meaning and Applications," be made available for review and adoption by the executive body of the Seventh-day Adventist Pathfinder Organization of the Lake Union Conference.

2. Since one of the primary intents of current educational research is to improve products and practices, it is being recommended that this instructional product be further modified to include more extensive practice exercises to meet the needs of participants and instructors who may choose to engage this curriculum on an adjusted schedule that is more convenient.

3. This product was prepared primarily for its target audience, in keeping with educational research protocol; therefore, it is recommended that modifications of contents and format of the G.R.A.C.E. Project be done prior to the delivery of this 
curriculum to participants who do not fall within the 12-14 year-old age group or meet the criteria specified.

4. It is recommended that the items prepared for this curriculum be utilized in the training of potential instructors in the Pathfinder program who will coordinate the program of instruction for seventh- and eighth-grade level Pathfinder participants.

The test items developed for this project were specifically designed to measure subjects' mastery of geometry concepts within a specified time frame. Thus, the modification of this instructional product for regular instructional settings would require the development of a modified test that may be different from those for this study.

I believe that if the above recommendations were to be implemented, this would lead to significantly:

1. Better understanding among Pathfinder executives of the cognitive development needs of club members, as they observe its positive impact on their level of achievement, self esteem, and attitude toward geometry.

2. Improved overall achievement and confidence in geometry among junior high-school-level Pathfinder participants.

3. Enhanced geometry readiness skills among Pathfinder participants at all three levels (5-6, 7-8, and 9-10).

4. Enhanced instructional skills and geometry awareness of program coordinators of seventh- and eighth-grade-level Pathfinder programs. 


\section{Suggestions for Further Study}

This study was highly specialized focusing on the empirical development of an instructional product to facilitate the intellectual development of seventh- and eighth-grade-level Pathfinder participants. However, the development process has revealed several other needs that were either beyond the scope of this study or were not addressed in the study. Therefore, some areas that need further study are suggested below.

1. Research clearly indicates the dynamic nature of curriculum work. Therefore, a study to critically examine each component of the G.R.A.C.E. Project and suggest improvement may serve to enhance its effectiveness, in an evolving educational climate.

2. Now that an appropriate instructional product has been developed for Pathfinders, a study that utilizes random sampling techniques with large sample sizes may yield important data regarding general usability of the product.

3. Even though the short-term (less than 2 months) impact of the G.R.A.C.E. Project on participants' understanding of interest in geometry was high, there was no opportunity to assess participants' long-term retention, which is even more desirable. A study to compare participants' level of retention of geometry understanding after 1 year could further confirm the program's effectiveness.

4. Follow-up studies to compare participants' level of geometry understanding in the medium- and long term (that is after 3 and 6 years) could also serve to provide empirical data which are indispensable to future curriculum development initiatives. 
6. A follow-up study to determine participants' perception of the impact of seventh- and eighth-grade-level geometry on upper level geometry/mathematics achievement could serve to verify research findings which attribute future achievement in mathematics to the mathematics foundation laid earlier. 
APPENDICES 
APPENDIX A

DIARY OF THE PROCESS 


\section{DIARY OF THE PROCESS}

The interplay of many subjective factors impacts the development of an instructional product. For example, personal perceptions related to the empirical development process are important. This diary gives an account of my personal experiences during the process. It is intended to give readers of this dissertation an overview of what transpired "behind the scene" during the period of December, 2007 to April of 2008.

Some factors that influenced the development of this curriculum include:

1. My personal satisfaction with the benefits gained over the years, as a student as well as an instructor in mathematics.

2. The continuing appeal, among researchers and educators alike, for the preparation of a more numerate work force, by $21^{\text {st }}$ century standards.

3. My passion to underscore the theoretical perspective of many educators who maintained that alignment of the curriculum as planned with the curriculum as taught and the curriculum as tested constitutes the formula for satisfactory overall learner achievement.

4. The potential of a geometry curriculum for broader integration of faith and learning.

5. The satisfaction that comes with knowing that through this medium, many learners, today and for years to come may be guided in the right direction.

I became aware of personal deficiencies in matters related to development of a formal curriculum, and was determined to learn the art of developing one. Of the various curriculum development models reviewed, the Baker and Schutz (1971) 
model appeared more developer-friendly and realistic. This method prescribes the details, allows for some flexibility, and utilizes the cooperative effort of participants and instructor in the empirical development process. Also, to maintain balance, the method combines both process- and product-oriented approaches.

Clearly stated performances, in the form of behavioral objectives, gave direction regarding choice of instructional materials, teaching methodology, and relevance of test items. The tendency to create an overload for the learners became a real challenge. However, I have learned to organize, limit, and deliver curriculum, in terms of the assessed needs of learners rather than my own perceptions. This understanding prepared me for the ups and downs that were later encountered.

With much encouragement and suggestions from my colleagues, dissertation committee members, and my advisor, Dr. Larry Burton, I developed the initial instrument for the modification of affect. It turned out that the final draft was vastly different than the original, but the changes helped me reflect on the importance of the affective domain. Thus, personal factors such as confidence, sense of worthwhile accomplishment, healthy perception of the value of a task, and the making of meaning for all learners, are critical factors related to higher academic achievement. And when educators give attention to these variables, they are likely to be more effective in the discharge of their duties.

\section{First Tryout - December 7, 2007 to January 9, 2008}

The first two subjects were females from the All Nations Pathfinder club. Both girls attended local public schools and indicated that they were interested in 
learning more skills in geometry. I discovered that the mother of one of the subjects was a student whom I taught mathematics in high school during the late 1980s in Jamaica. Planned sessions were initially arranged for Sundays between the hours of 10:00 am and 12:00 noon, but I soon learned there was a conflict with the regular Pathfinder program. Frankly, I became immediately frustrated with what I perceived as disregard for attention to matters of greater importance. Nevertheless, I gained the confidence to renegotiate for Tuesdays from 7:00 pm to 8:00 pm. We began the first session with prayer, followed by the administration of the pre-tests.

Then the fear of the unknown became real. Both subjects seemed overwhelmed by the volume of work to be completed. As a result, I documented the first comment: "This thing is confusing." This statement alluded to what my real task was going to be, if in fact I was to achieve my noble ambition of motivating learners toward the successful completion of the G.R.A.C.E. Project. I made the necessary corrections immediately, gave a positive comment, and thanked the subject for beginning to assist with the development process. On other occasions the subjects pointed out mistakes which I had overlooked, much to my dismay. For example, during the third session it was pointed out to me that I presented a pentagon and a hexagon as similar shapes. Again adjustments had to be made. However, I was determined to maintain high enthusiasm, and a positive attitude throughout the process. In addition, post-dismissal feedback was very helpful.

The final session included comprehensive review of content to be tested. Next, the cognitive post-test was administered followed by the cognitive affective 
post-test. Both subjects expresses confidence in the level of competence developed and demonstrated. And post dismissal comments in general were very helpful.

\section{Second Tryout - January 10 to February 13, 2008}

The second tryout with the modified product was met with even greater challenges. Most subjects were not available during the time scheduled for the project. However, I managed to negotiate a more condensed schedule that would allow subjects to complete the program in 4-5 sessions instead of the previously intended 7 sessions. So I began with a group consisting of two boys and two girls from the South Bend Seekers Pathfinder club. These learners seemed particularly intrigued by the promise of much learning and follow-up instructor support. Parents were very cooperative to have all participants delivered on time for each session.

One strength of this tryout was the standardization of instruction. Every learner participated based on guidelines presented in the administrator's manual. However, I did not allow this to stifle creativity. The subjects continued to make new discoveries of my curriculum development inexperience. Some test items, for instance, were a bit ambiguous while others were "overloaded." I soon discovered that it was the repeated "embarrassment" that created the conditions for improvement. My authority was not only challenged by these junior high level participants, it was shared. Then I began to understand how vulnerable I became, and that it was alright to wear the hats of a humble learner and an effective instructor simultaneously. 
There were times when I felt a bit frustrated but I made every effort to find the source of my frustration. It could possibly have been the learner's or instructor's attitude, the schedule, the questions, or the mode of instruction. Whatever the case, adjustments were regularly made to different components of the curriculum to make it more learner-friendly. Also, I experienced a sense of satisfaction when subjects made repeated positive comments. They expressed appreciation for the ease with which they were able to grasp geometry concepts which could otherwise be a source of frustration. These comments, in many ways, indicated the possibility of the completion of another successful tryout.

\section{Third Tryout - February 15 to March 12, 2008}

The third group of eight participants was engaged in another tryout with the entire modified product. I became conscious of the fact that this was our last effort to "perfect" the curriculum before its final testing on a large group. So, I was careful to stick to the practices which proved to be most helpful. For example, I often asked learners if they needed a break when they seemed most excited about what they were doing. I became pleasantly surprised when they unanimously chose to continue on task.

One observation that seemed to occur throughout these sessions was subject's failure to respond to cognitive pre-test items. There seemed to have been a "universal" geometry phobia at the beginning of each tryout. A small number of subjects attempted to respond to as many cognitive post-test questions as possible. Still, the results at best were marginal. However, the intervention elicited more 
positive comments and suggestions for modification of test items number 1,3 , and 22.

The subjects were not only learning; they were making their contribution to the refining of the curriculum for its final implementation in the empirical development process. Their spirit of cooperation was encouraging. At the conclusion of the post-tests I expressed confidence in their ability to succeed and my appreciation for their spirit of generosity.

\section{Fourth Tryout - March 15 to April 20, 2008}

First Part

Implementation of the curriculum in its polished form was anticipated to be my most exciting presentation, but the challenge to bring together twenty-five 7-8 level Pathfinder club members in one place was unbeatable. Since this was only a remote possibility, given that some clubs have very few 7-8 level members, I was forced to arrange to meet with separate groups in Eau Claire, Detroit and Chicago. The sessions in Eau Claire consisted of seven subjects- all of whom are students at the SDA elementary school. The Baker and Schutz (1971) Instructional Product Development model controls for gender bias by focusing on group size rather than gender ratio comprising the group.

I was satisfied with the status of the curriculum after repeated revisions. The first seven of 25 subjects engaged the curriculum in similar manner as the previous tryout sessions. Cognitive and affective pre-tests were administered, collected, and secured. Content delivery during the planned sessions proceeded as expected. The 
lack of confusion was a function of the repeated revisions over several months. I realized that guidelines for the implementation should be carefully followed. The standardization of instruction for all three groups comprising the group of 25 subjects would be necessary for consistency and relevance.

I learned that certain characteristics are common to different groups that fall within the 12-14 age range. For example, if they get their questions answered and find a task meaningful, their level of motivation soars and high achievement becomes an attractive option. On the contrary, confusion and perceptions of meaninglessness associated with academic tasks inevitably leads to discouragement and failure.

Second Part

The curriculum was also implemented with 13 subjects from the Yipsilante SDA church Pathfinder club. Standard procedures guided the process. First, I detailed the plan with special emphasis on the benefits associated with the GRACE Project. Again, all activities were carefully coordinated, but I learned that without some level of creativity and the instructor's emphasis on affective variables, mastery of curriculum cannot be guaranteed. I also learned that effective communication and thorough preparation pay large dividends. Participants engaged the GRACE Project with a high level of enthusiasm. Again the impact of the revision process was evidenced by what appeared to be a more learner-friendly product. As a result, I was pleasantly surprised with the level of cooperation among subjects during the 
intervention. The effort made by most participants toward helping their peers master curriculum contents was admirable.

Third Part

Two boys and three girls from the Greater Chicago area engaged the G.R.A.C.E. Project. They were joined by two other learners who were not members of the target population. Therefore, data from these individuals were not used for this study. This last session conformed to the routine established over the course of many months. The materials, instructions, and teaching were identical to those used with the other two groups. One challenge encountered was a noisy area to be in. However, within 30 minutes, I made the adjustment. Subjects were reassigned to a private room without distractions. This adjustment was in keeping with planned strategies for emphasizing the affective component of the GRACE Project. As a result of the wealth of experiences gained throughout the development process, harmony was maintained throughout the process. I discovered that the more practice engaged in the less challenging it was to achieve our desired target- mastery of geometry concepts.

I also learned that the effort put forth by the instructor to achieve satisfactory results was probably the most important variable in instructional planning and delivery. If I had to do this again, I would extend the time for all participants over the time spent developing this curriculum. For example, the $71 / 2$ hours seemed inadequate, since it did not provide enough time for a better quality learner-instructor interaction. As a result, I think that instead of 90-minute 
sessions, I would have liked to have 2-hour sessions. Finally, I realized that if the formative process is carefully engaged in, then summative evaluation may not become a fear factor for learners. 
APPENDIX B

ALIGNMENT OF OBJECTIVES, STANDARDS AND CONTENT 


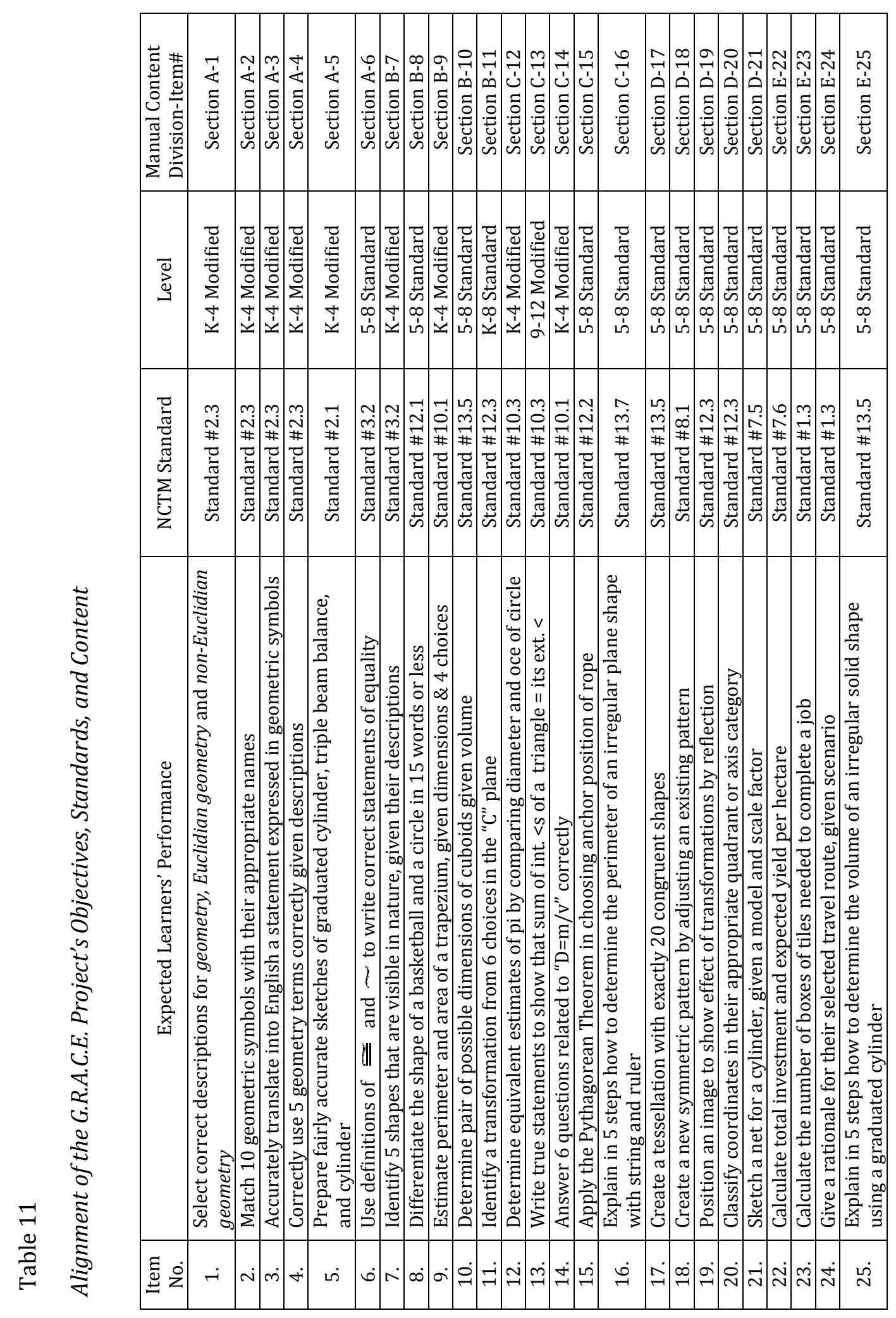


APPENDIX C

COGNITIVE INSTRUMENT 


\section{COGNITIVE EDUCATIONAL INSTRUMENT}

Pre -and Post- Instructional Inventory

COGNITIVE INSTRUMENT

Code

Question 1 (6 points): Match each term, (1) geometry, (2) Euclidian geometry, and (3) non-Euclidian geometry with the best description below. Use "0" to indicate no match.
A. Includes the study of plane geometry which focuses on 2-dimensional features
B. Literally means "earth measurement"
C. Focuses on measuring of all planets
D. Focuses on the study of earth features such as latitudes and great circles
E. All of the above 
Question 2 (10 points): Match the geometric symbol with its correct name by placing the letter to the right in the column marked "A."

\begin{tabular}{|c|c|c|c|}
\hline \# & Symbol & A & Meaning of Symbol \\
\hline 1 & $\mathrm{~b}$ & & Similarity between shapes/ figures .......M \\
\hline 2 & $\overleftrightarrow{\mathrm{AB}}$ & & 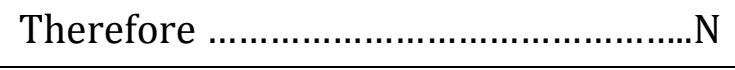 \\
\hline 3 & $\Delta$ & & Right angle \\
\hline 4 & $\cong$ & & Line AB …...................................... \\
\hline 5 & $\perp$ & & Triangle \\
\hline 6 & $\angle$ & & Line segment $\mathrm{AB}$ \\
\hline 7 & $\therefore$ & & 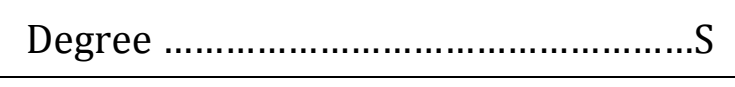 \\
\hline 8 & $\sim$ & & Congruency of shapes/ figures ........... T \\
\hline 9 & $\overline{\mathrm{AB}}$ & & Perpendicular ....................................... \\
\hline 10 & 0 & & Angle \\
\hline
\end{tabular}

Question 3 (5 points): On the lines provided below, translate the following geometric statement completely in English: "Oce of a $0=\mathbf{2} \boldsymbol{\pi r}=\boldsymbol{\pi d}$ but $\boldsymbol{A}=\boldsymbol{\pi} \boldsymbol{r}^{2}$ " 
Question 4 (5 points): For a-e supply the correct vocabulary word that best describes the process, description or definition presented:

A. These two angles, 40 degrees and 140 degrees, are because they add up to 180 degrees.

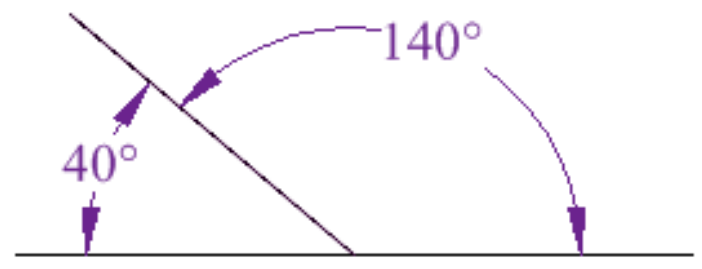

B. A one-word geometric term for "element of design that shows balance and congruency on both sides of a mirror line."

C. Name for an assumption that is accepted without proof in geometry. For example: "If two lines intersect, then they intersect in exactly one point."

D. The corresponding angles of all triangles below are congruent. This means the triangles are
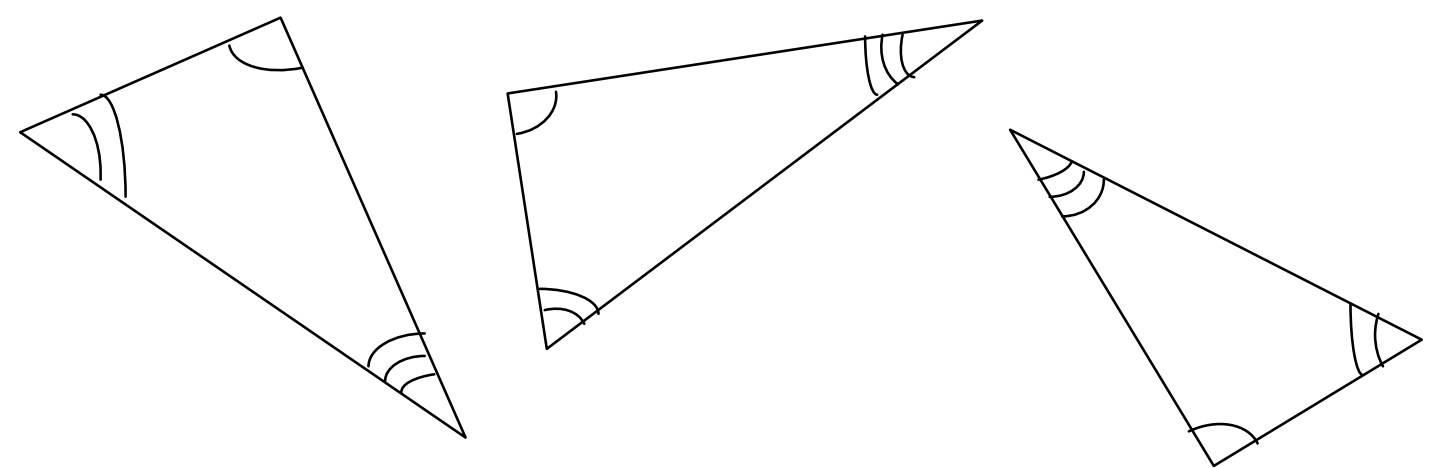

E. If $\mathrm{C}$ is the center of the circle, then the shaded region in the figure below is a of the circle.

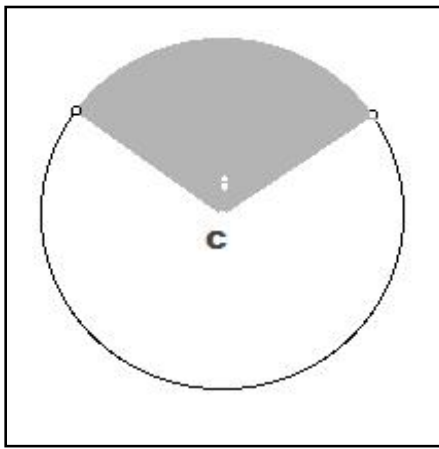


Question 5 (9 points): Prepare fairly accurate sketches of items indicated below to reflect unique properties of each.

\begin{tabular}{|l|l|l|}
\hline Graduated Cylinder & Triple Beam Balance & Cylinder \\
\hline & & \\
& & \\
& & \\
& & \\
\hline
\end{tabular}

Question 6 (11points): Use definitions of congruency and similarity to write correct statements of equality.

A

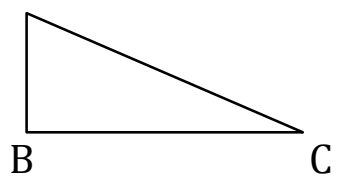

$\mathrm{D}$

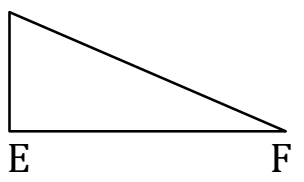

A. If $\Delta \mathrm{ABC}$ and $\Delta \mathrm{DEF}$ are congruent, then what true statements can you make? 

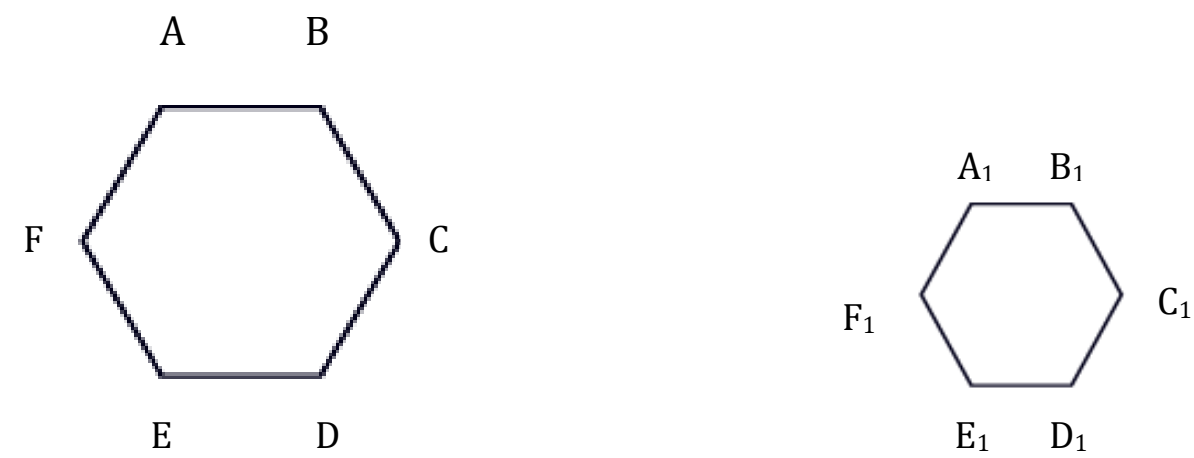

B. If the two hexagons are similar then what true statements can you make?

Question 7 (7 points): The Master Designer has included a variety of geometric shapes in nature. For a-e name the shape described:

A. The general plan of the pine trees

B. The general elevation of the pine tree

C. Shape of each cell of the honeycomb

D. General shape of the trunk of a tree

E. Shape of a grapefruit/orange

Question 8 (2points): In 15 words or less state the essential difference between the shape of a basketball and the shape of a circle, on the lines provided below. 
Question 9 (11 points): Verify the best estimates of the perimeter and area respectively of the trapeze-shaped diagram below. Given that line segment $A B$ is vertical. Show your work clearly.

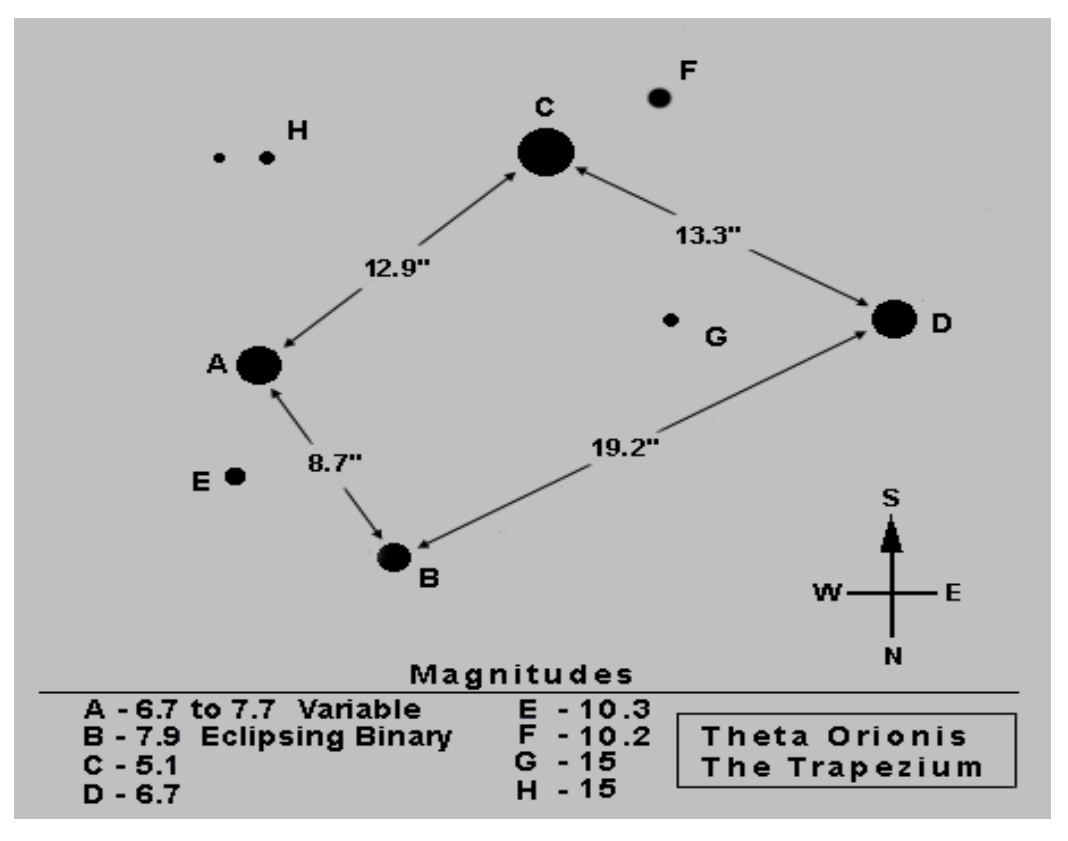
A. Perimeter: 1) 155
2) 169
3) 234
4) 55
B. Area:
1) 44
2) 54
3) 144
4) 23712

Question 10 (6 points): For the diagram provided below (not necessarily drawn to scale) give two different sets of dimensions that would result in a volume of 120 cubic centimeters.

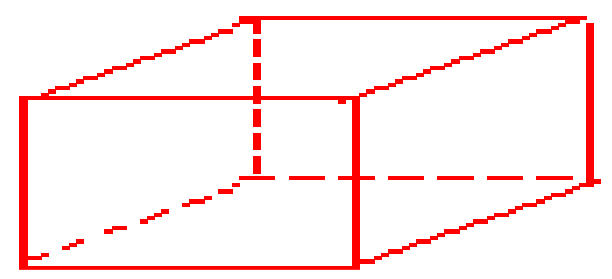

Set 1: L__ W_

Set 2: $\mathrm{L}_{-} \mathrm{W}_{-} \mathrm{H}_{-} \mathrm{H}_{-}$ 
Question 11 (3 points): Circle the letter below that best describes the transformation.

\begin{tabular}{|l|l|l|l|l|l|l|l|l|l|}
\hline & & & & & & & & & \\
\hline
\end{tabular}
A. vertical translation
C. double translation
E. enlargement
B. rotation
D. horizontal translation 
Question 12 (5 points): In terms of comparative lengths, determine the approximate relationship between the ray and the circle; then, choose the pair of values below that best indicates this relationship.

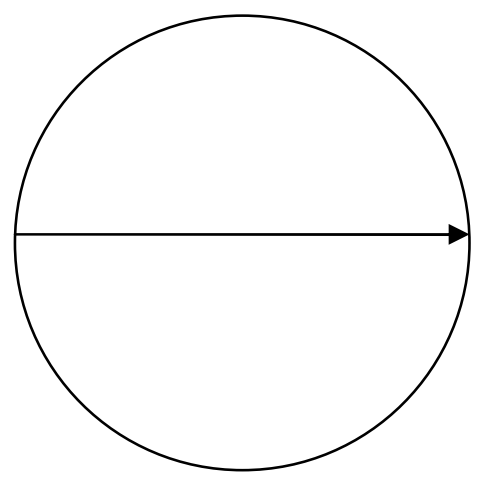
A. $10 / 3$
B. $31 / 3$
C. $31 / 7$
D. $71 / 3$
E. $22 / 7$

Question 13 (5 points): Justify with a series of true statements that the measure of the exterior angle $x$ (in the figure) equals the sum of the measures of angles $Q$ and $R$.

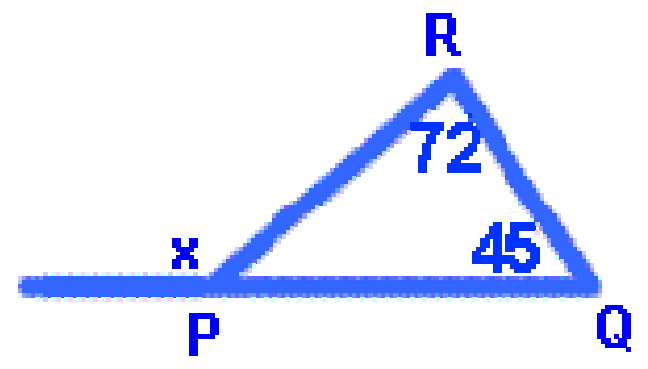


Question 14 (15 points): A rectangular block measures 240 units on a triple beam balance, if its base area and height are 12 and $5 \mathrm{~cm}$, calculate its density then answer the questions below.

A. What is the appropriate unit for area of the base?

B. What is the correct formula for density?

C. What formula was most likely used to calculate the base area?

D. Which value represents the density?

E. The ratio unit used to express density is?

F. Explain "E" completely. 
Question 15 (3points): A Pathfinders team is about to erect a flagpole. Choose the anchor position of the rope "R" when stretched, at 10 feet, in order to have a 90degree angle where the flagpole meets the ground. Given that the horizontal axis uses the same scale as the vertical axis $(1,2,3, \ldots)$.
A. Position \#6
B. Position \#7
C. Position \#8
D. Position midway between \#8 and \#9
E. Position beyond \#9

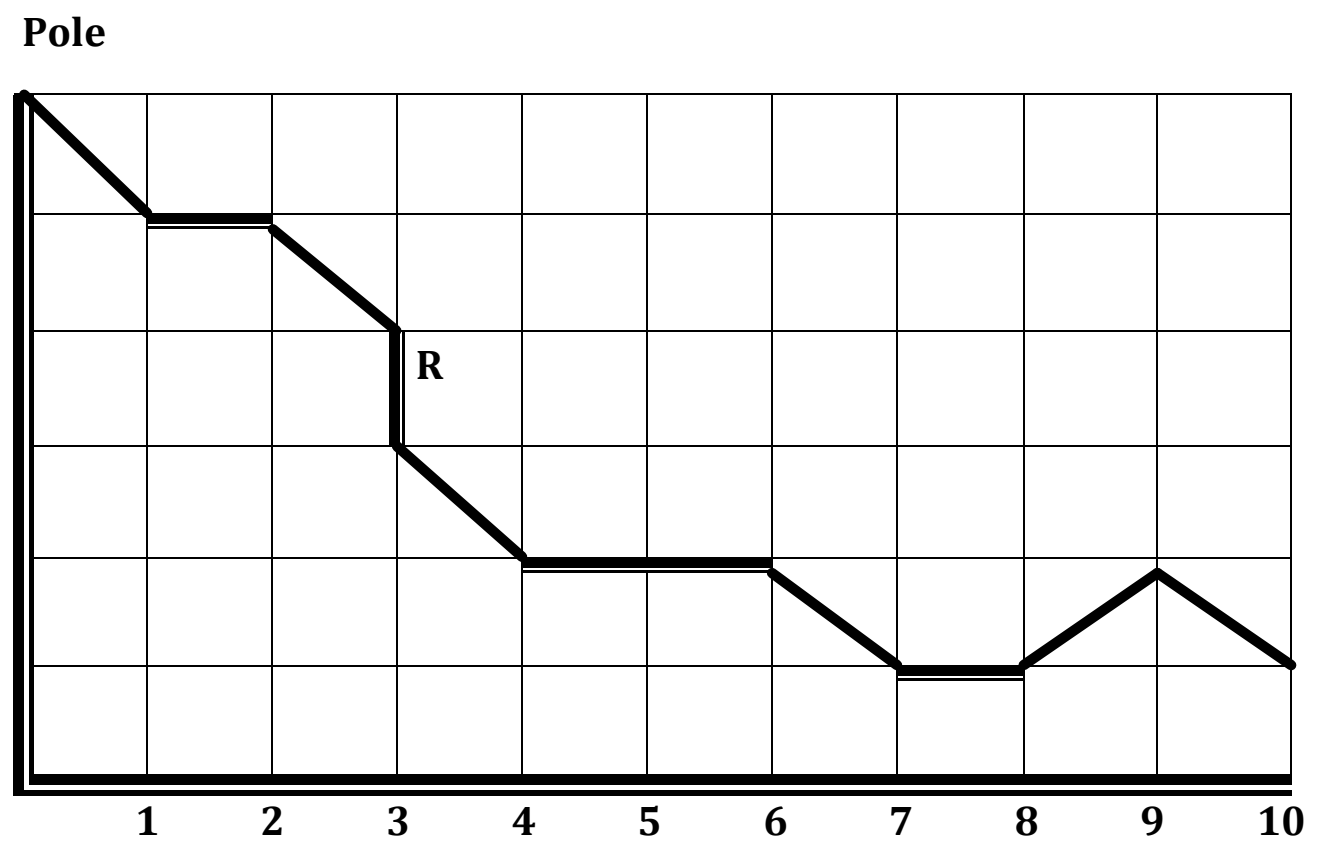


Question 16 (10 points): Explain in five steps exactly how you would determine the perimeter of the irregular plane shape below.

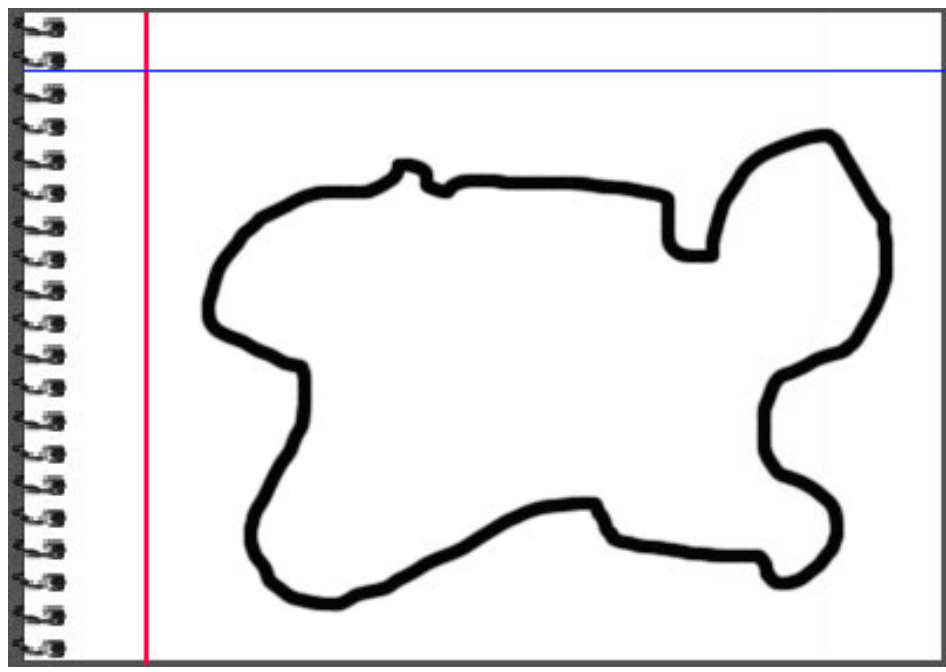

Question 17 (6 points): In the rectangular space below, create a tessellation with exactly 20 congruent shapes. 
Question 18 (6 points): Rearrange the segments of the square below to create a new symmetric pattern of your choice.

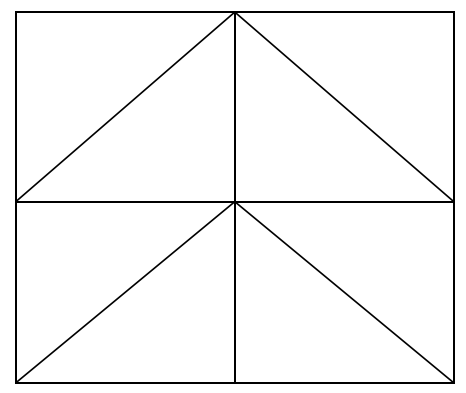

Question 19 (10 points): Suppose the window 'M" shown below experiences double transformation in the form of reflection through L2 and L1 respectively. Draw the resulting shapes.

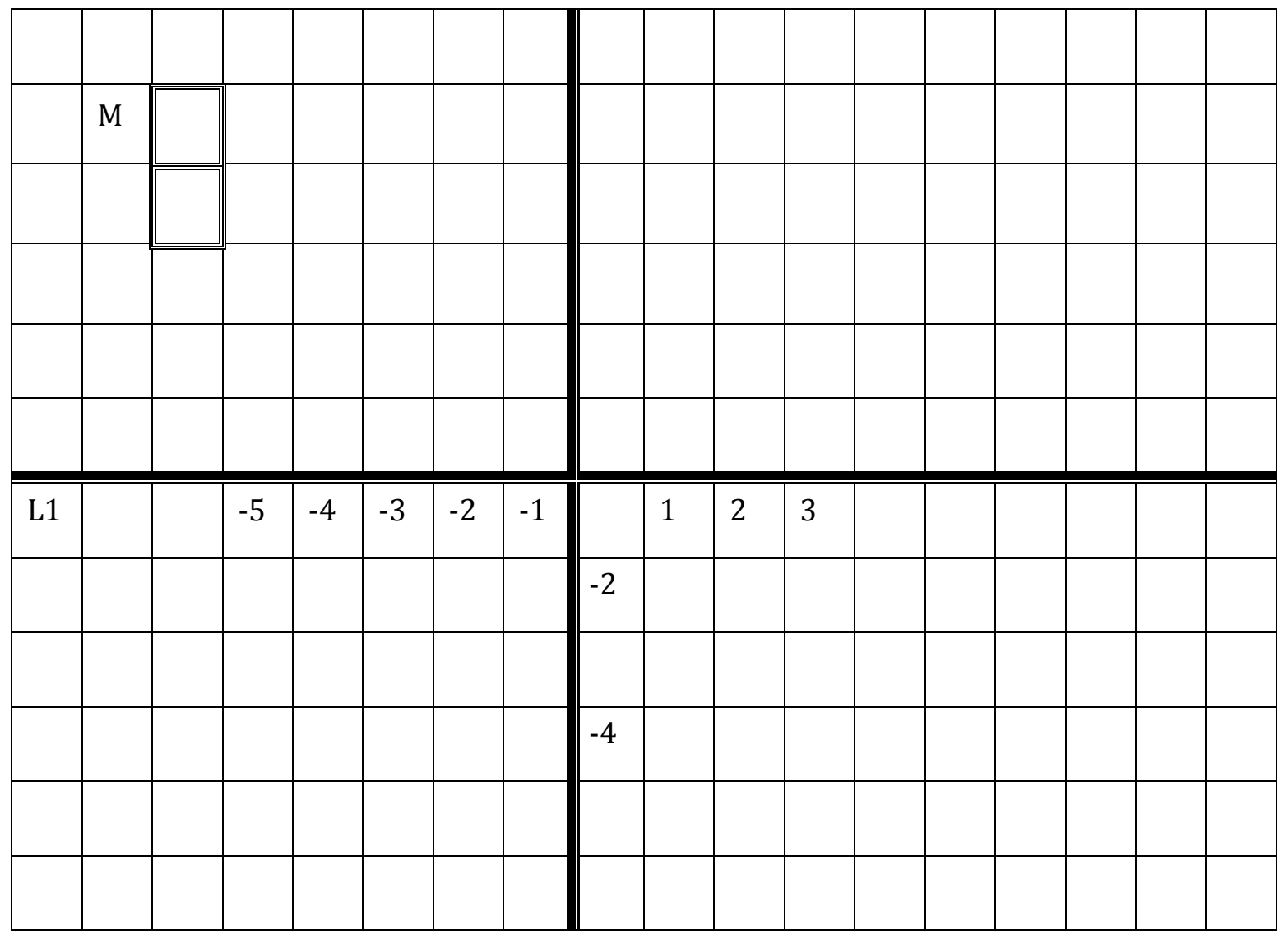

L2 
Question 20 (14 points): Coordinates in the Cartesian plane may be organized by the following categories: I, II,III, IV, X-axis \& Y-axis. Determine mentally where each pair belongs then classify the coordinates below in each category.

$(-1,5),(0,8),(4,5),(-6,-6),(23,0),(0,0),(9,7),(6,0),(4,-8),(-7,5),(-3,-9),(2,2)$

$(13,-4),(0,7),(11,0),(1,-7),(6,23),(33,-5),(0,-2),(20,2),(-3,-3),(4,-6),(-16,4)$

I.

II.

III.

IV.

X-axis.

Y-axis.

Question 21 (6points): Based on the scale factor 2, construct a net for a similar cylinder from the net given below.

\begin{tabular}{|l|l|}
\hline & \\
\hline & \\
\hline & \\
\hline
\end{tabular}


Question 22 (15 points): A 20 meter by 10 meter rectangular garden yields $80 \mathrm{lb}$ of soy beans with application of five - $\$ 2.89$ bags of fertilizer. At the same rate, estimate the dollar amount of investment and yield respectively that could be expected from a 1 - hectare plot.

Question 23 (5 points): Given that a flat area of ground to be tiled is shaped like a //gram, how many boxes containing 24 square-foot tiles would you purchase for the job if its dimensions are as follows: base $=35$ feet, height $=15$ feet, and slant side $=$ 20 feet? Assume that tiles may be cut cleanly into pieces with no waste.
A. 21
B. 22
C. 24
D. 30
E. 437

Question 24 (5 points): It is known that path AC (shown on figure 3 below) is mountainous; but path $\mathrm{AB}$ and $\mathrm{BC}$ are coastal areas. Imagine that you are a Master Guide. Describe a scenario and rationale for choosing route $\mathrm{ABC}$. Then describe a scenario and rationale for choosing route AC. Each answer should be 30 words or less.

Fig. 3

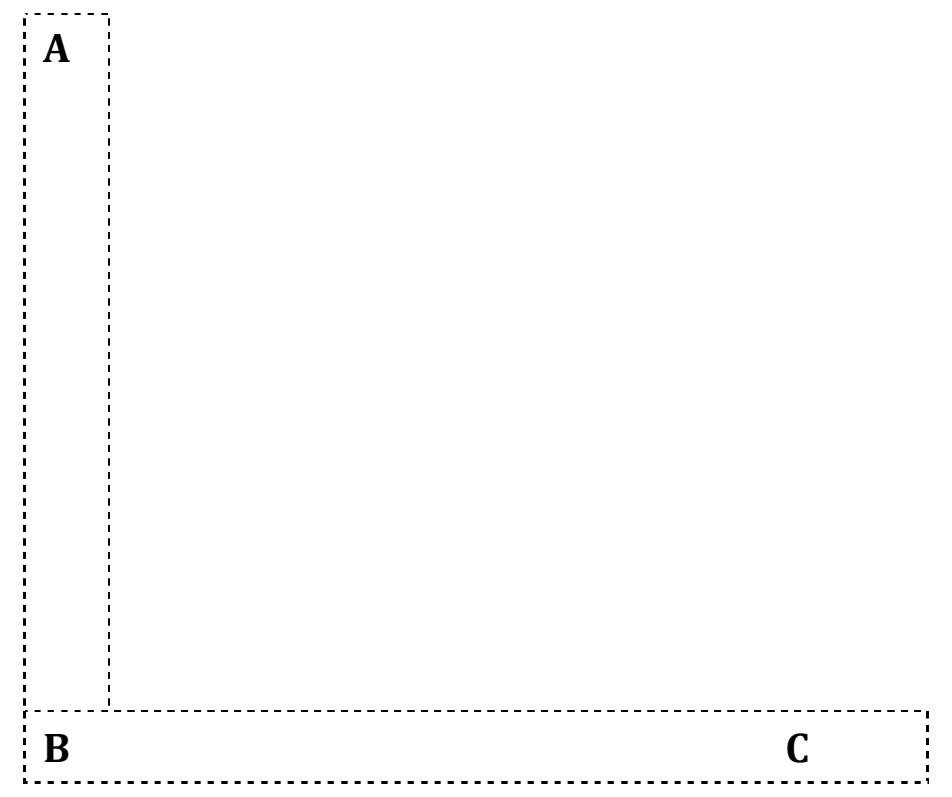


Question 25 (10 points): On the lines provided below, explain in 5 steps how you would determine the volume of a broken piece of rock that is approximately 3.5 centimeters in diameter, using a graduated cylinder. 
APPENDIX D

CRITERIA FOR COGNITIVE INSTRUMENT 


\title{
COGNITIVE EDUCATIONAL INSTRUMENT
}

\author{
Pre -and Post- Instructional Inventory
}

\section{CRITERIA FOR COGNITIVE INSTUMENT}

Question 1 (6 points): Match each term, geometry (1), Euclidian geometry (2), and non-Euclidian geometry (3) with the best description below. Use " 0 " to indicate no match.
A. Includes the study of plane geometry which focuses on 2-dimensional features (2)
B. Literally means "earth measurement" (1)
C. Focuses on measuring of all planets__ 0
D. Focuses on the study of earth features such as latitudes and great circles (3)
E. All of the above ___

\section{( 2 points for each correct description)}


Question 2 (10 points): Match the geometric symbol with its correct name by placing the letter to the right in the column marked "A."

\begin{tabular}{|c|c|c|c|}
\hline \# & Symbol & A & Meaning of Symbol \\
\hline 1 & $\mathrm{~b}$ & $\mathbf{0}$ & Similarity between shapes/ figures........M \\
\hline 2 & $\overleftrightarrow{\mathrm{AB}}$ & $\mathbf{P}$ & 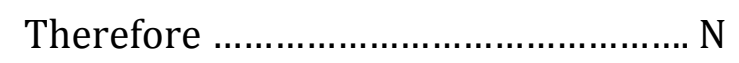 \\
\hline 3 & $\Delta$ & $\mathbf{Q}$ & Right angle \\
\hline 4 & $\cong$ & $\mathbf{T}$ & Line AB \\
\hline 5 & $\perp$ & $\mathbf{U}$ & 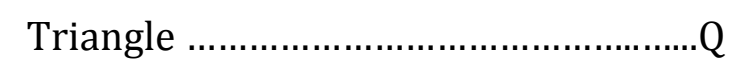 \\
\hline 6 & $\angle$ & $\mathbf{V}$ & Line segment $\mathrm{AB}$ \\
\hline 7 & $\therefore$ & $\mathbf{N}$ & Degree \\
\hline 8 & $\longrightarrow$ & $\mathbf{M}$ & Congruency of shapes/ figures ............T \\
\hline 9 & $\overline{\mathrm{AB}}$ & $\mathbf{R}$ & 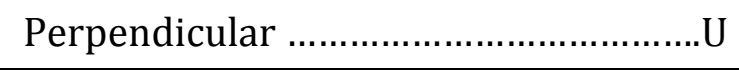 \\
\hline 10 & 0 & $\mathbf{S}$ & Angle \\
\hline
\end{tabular}

(1 point for each correct response)

Question 3 (5 points): On the lines provided below, translate the following geometric statement completely in English: "Oce of a $0=\mathbf{2} \pi \boldsymbol{r}=\boldsymbol{\pi d} \boldsymbol{b u t} \boldsymbol{A}=\boldsymbol{\pi} \boldsymbol{r}^{\mathbf{2}}$

THE CIRCUMFERENCE OF A CIRCLE EQUALS TWO TIMES PI TIMES ITS RADIUS OR PI TIMES ITS DIAMETER, BUT ITS AREA EQUALS PI TIMES ITS RADIUS SQUARED. 
Question 4 (5 points): For a-e supply the correct vocabulary word that best describes the process, description or definition presented:

A. These two angles, 40 degrees and 140 degrees, are supplementary because they add up to 180 degrees.

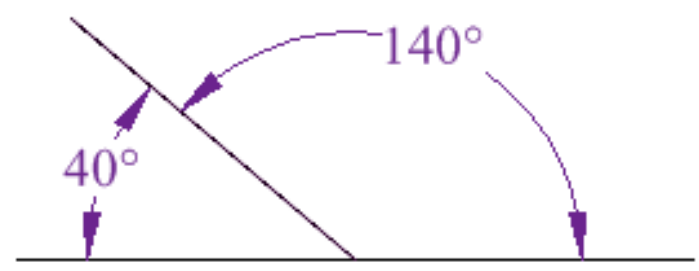

B. A one-word geometric term for "element of design that shows balance and congruency on both sides of a mirror line." Symmetry

C. Name for an assumption that is accepted without proof in geometry. For example: "If two lines intersect, then they intersect in exactly one point." Postulate or axiom

D. The corresponding angles of all triangles below are congruent; this means the triangles are similar.
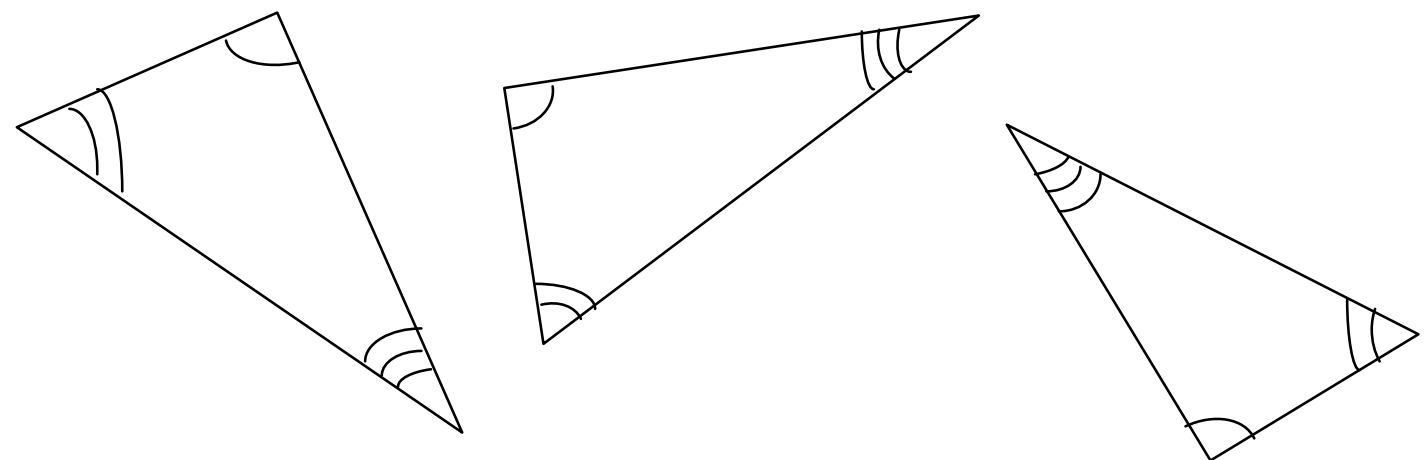

E. If $\mathrm{C}$ is the center of the circle, then the shaded region in the figure below, is a

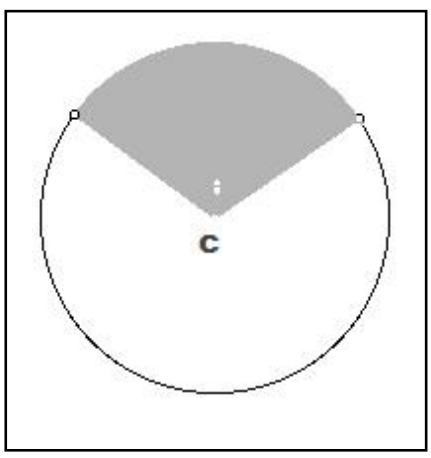
sector of the circle. 
Question 5 (9 points): Prepare fairly accurate sketches for the items indicated below to reflect unique properties of the each item.

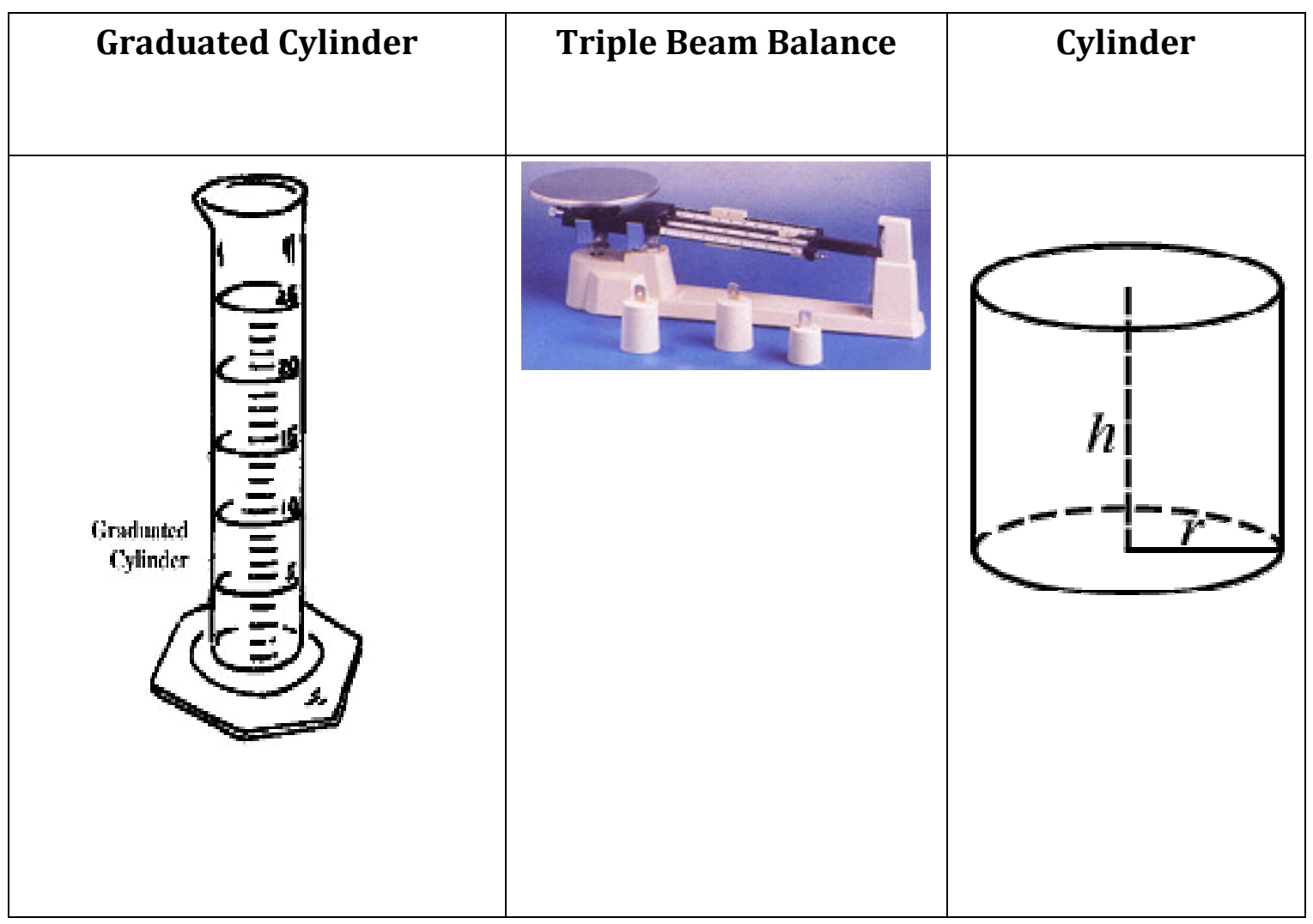

(For graduated cylinder, 1 point each for base, curved surface and scale) (For Triple Beam Balance, I point each for body, scaled beams, and landing) (For regular cylinder, I point each for curved surface, circular base, labeled radius \& height) 
Question 6 (11points): Use definitions of congruency and similarity to write correct statements of equality.
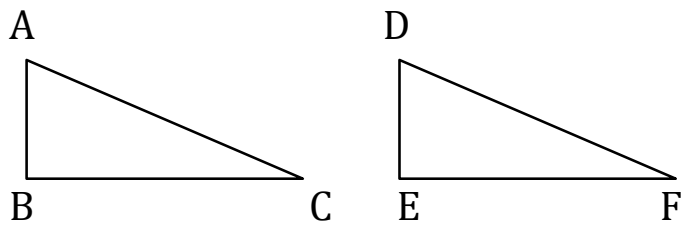

A. If $\Delta \mathrm{ABC}$ and $\triangle \mathrm{DEF}$ are congruent, then what true statements can you make?

1. $\mathrm{AB}=\mathrm{DE}$----- corresponding sides of congruent triangles

2. $\mathrm{BC}=\mathrm{EF}-----$ corresponding sides of congruent triangles

3. $\mathrm{AC}=\mathrm{DF}$----- corresponding sides of congruent triangles

(Note, since all 3 pairs of corresponding angles are $=\Delta \mathrm{ABC}$ is also similar to $\Delta$ DEF.)

P $\quad$ Q

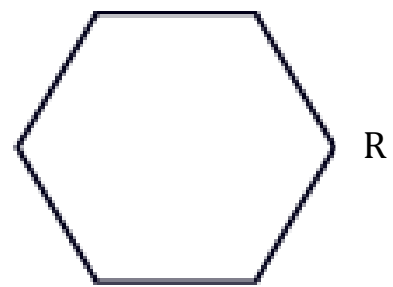

$\mathrm{T}$

S

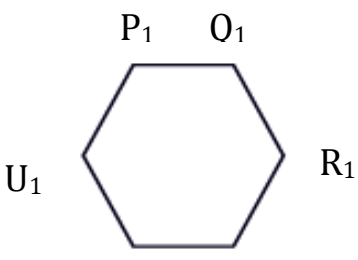

$\mathrm{T}_{1} \quad \mathrm{~S}_{1}$

B. If the two hexagons are similar then what true statements can you make?

1. Angle $\mathrm{P} \cong=$ Angle $\mathrm{P}_{1}$ (or $\mathrm{m} \angle \mathrm{P}=\mathrm{m} \angle \mathrm{P}_{1}$ )

2. Angle $Q \cong=$ Angle $Q_{1}$

3. Angle $\mathrm{R} \cong=$ Angle $\mathrm{R}_{1}$

4. Angle $S \cong=$ Angle $S_{1}$

5. Angle $\mathrm{T} \cong=$ Angle $\mathrm{T}_{1}$

6. Angle $U \cong=$ Angle $U_{1}$

( 2 points each for definition; 1 point for describing congruent shape as being similar; 1 point for each of 6 statements of equality) 
Question 7 (7 points): The Master Designer has included a variety of geometric shapes in nature. For a-e name the shape described:
A. The general plan of the pine trees circle
B. The general elevation of the pine tree triangle
C. Shape of each cell of the honeycomb hexagon
D. General shape of the trunk of a tree cylinder
E. Shape of a grapefruit/orange sphere

( 2 points for definition -A; 2 points for definition-B; 1 point each correct shape -C, D, \&E)

Question 8 (2points): In 15 words or less state the essential difference between the shape of a basketball and the shape of a circle, on the lines provided below.
A basketball is a 3-dimensional solid but a circle is a 2-dimensional plane shape. 
Question 9 (11 points): Verify the best estimates of the perimeter and area respectively of the trapeze-shaped diagram below. Given that line segment $A B$ is vertical. Show your work clearly.

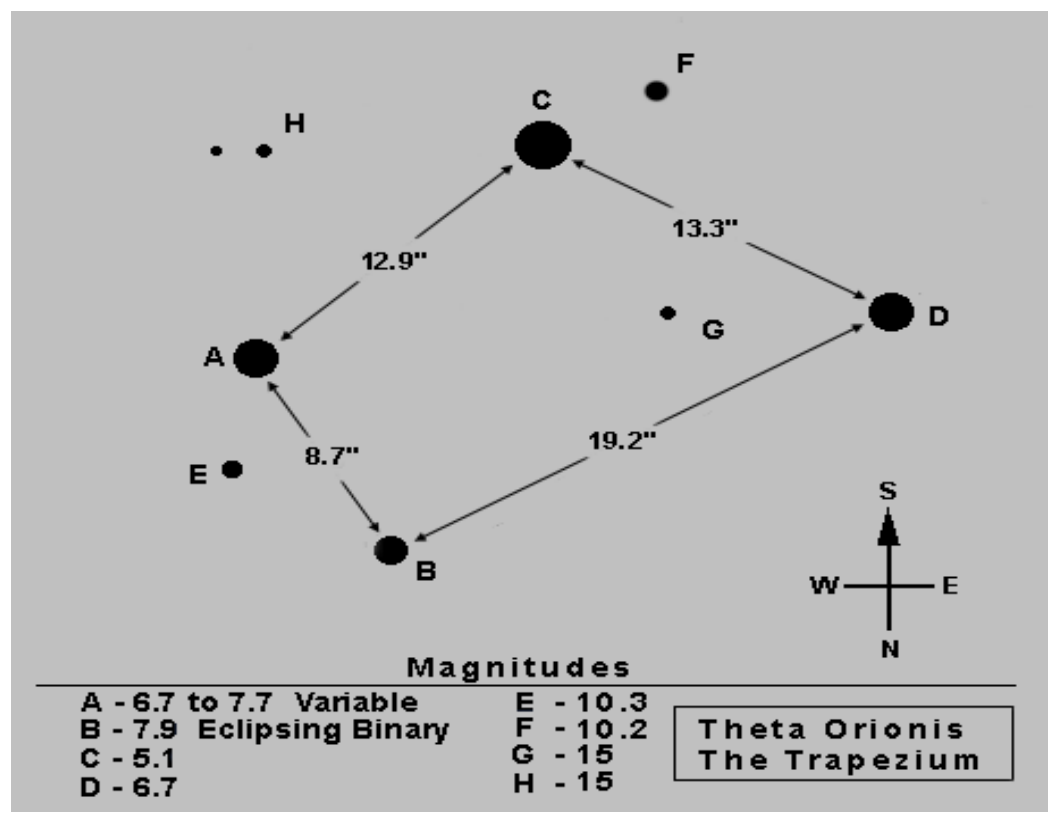
A. Perimeter:
1) 155
2) 169
3) 234
4) 55
B. Area:
1) 44
2) 54
3) 144
4) 23712

( 7 points for correct choice and application of formulas; 2 points for each correct answer)

Question 10 (6 points): For the diagram provided below (not necessarily drawn to scale) give two different sets of dimensions that would result in a volume of 120 cubic centimeters.

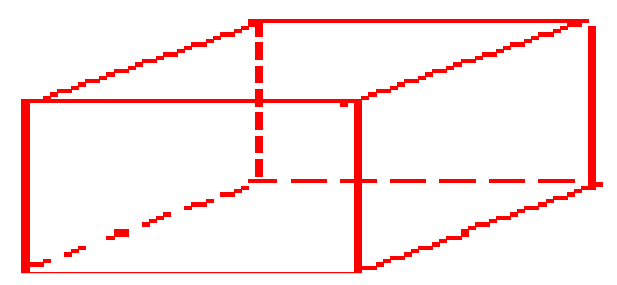

Set 1: $\quad L=10 \quad W=4 \quad H=3$

Set 2: $\quad \mathrm{L}=6 \quad \mathrm{~W}=5 \quad \mathrm{H}=4$

Other combinations of three positive numbers whose product is 120 are acceptable $(2,1 / 2$, and 120 for example) 
Question 11 (3 points): Circle the letter below that best describes the transformation.

\begin{tabular}{|l|l|l|l|l|l|l|l|l|l|}
\hline & & & & & & & & & \\
\hline
\end{tabular}
A. vertical translation
C. double translation
E. enlargement
B. rotation
D. horizontal translation

Question 12 (5 points): In terms of comparative lengths, determine the relationship between the ray and the circle; then, choose the pair of values below that indicates this relationship.

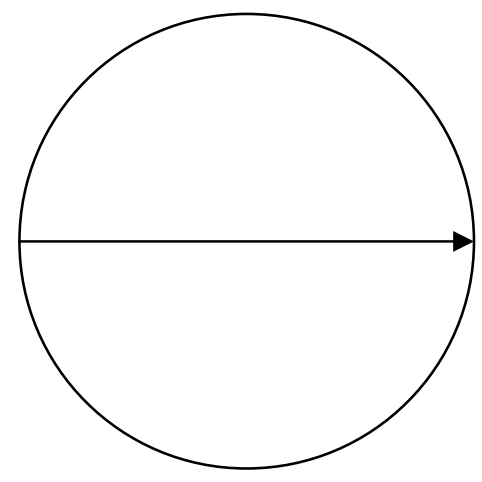

Both C \& E are correct estimates/approximations of pi.
A. $10 / 3$
B. $31 / 3$
C. $31 / 7$
D. $71 / 3$
E. $22 / 7$

( 3 points for accuracy in comparing; 2 points for identifying correct value of estimate for pi) 
Question 13 (10points) Justify with a series of true statements that the measure of the exterior angle $x$ (in figure 1) equals the sum of the measures of angles $Q$ and $R$.

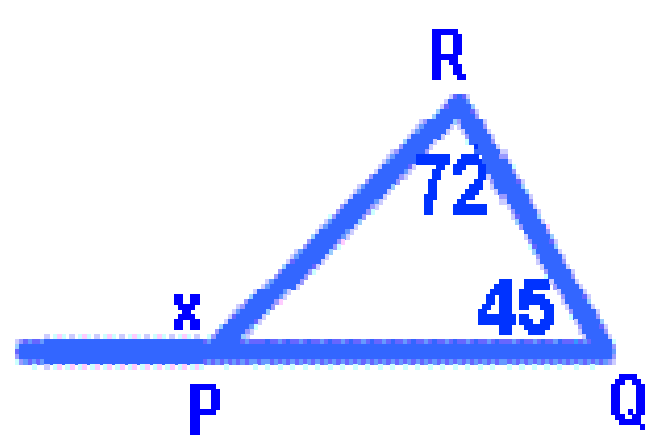

\section{For any $\triangle P R Q$}

- $m \angle \mathrm{P}+m \angle R+m \angle Q=180$

- $m \angle R+m \angle Q=180-m \angle \mathrm{P}$

- $m \angle P+m \angle X=180$

- $m \angle X=180-m \angle P$

- So, $m \angle X=m \angle R+m \angle Q$

- $\quad$ Thus, , $m \angle X=72+45=117$

Note: The ordering of these statements is not unique. Any logical ordering is acceptable. The specific measurements of angle $R$ and $Q$ could be substituted in earlier than the last step.

\section{(2 points for each correct statement)}

Question 14 (15 points): A rectangular block measures 240 units on a triple beam balance, if its base area and height are 12 and $5 \mathrm{~cm}$, calculate its density then answer the questions below.

A. What is the appropriate unit for area of the base? square centimeter $\left(\mathbf{c m}^{2}\right)$

B. What is the correct formula for density? $\mathbf{D}=\mathbf{m} / \mathbf{v}$

C. What formula was most likely used to calculate the base area? $\mathbf{A}=\mathbf{l} \mathbf{x} \mathbf{w}$

D. Which value represents the density? $240 / 60=4$

E. The ratio unit used to express density is? $\mathbf{g} / \mathbf{c m}^{\mathbf{3}}$

F. Explain "E" completely. Mass is measured in grams (g) and volume in $\mathrm{cm}^{3}$. Since density is a combined unit, it is expressed using the ratio of both units $\left(\mathrm{g} / \mathrm{cm}^{3}\right)$.

(3 points for correct application of " $D=m / v$ "; 2 points for each correct response for 1-5; 2 points for explaining “ $E$ " completely). 
Question 15 (3points): A Pathfinders team is about to erect a flagpole; choose the anchor position of the rope "R," when stretched at 10 unit lengths, in order to have a 90-degree angle where the flagpole meets the ground. Given that the horizontal axis uses the same scale as the vertical axis $(1,2,3, \ldots)$.
A. Position \#6
B. Position \#7
C. Position \#8 (Reason: Use Pythagorean Theorem).
D. Position midway between \#8 and \#9
E. Position beyond \#9

\section{Pole}

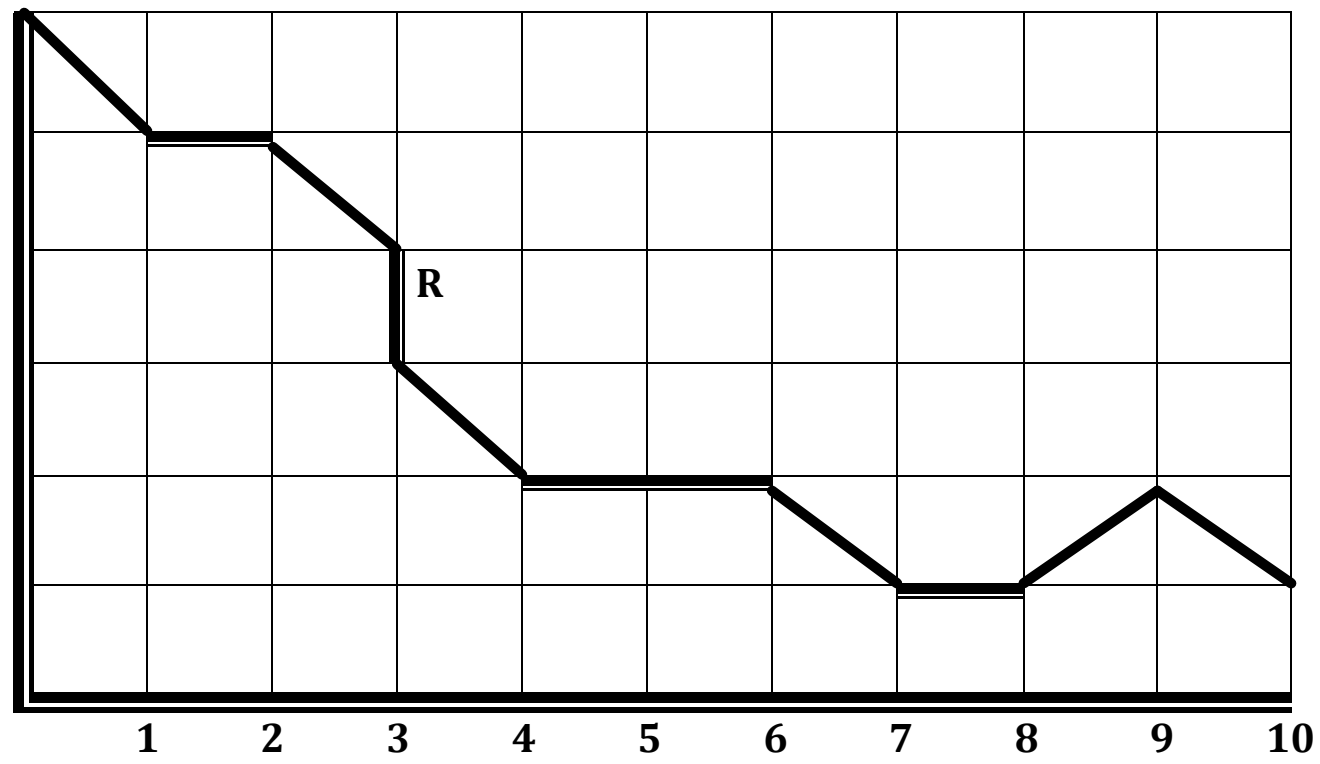


Question 16 (10 points): Explain in five steps exactly how you would determine the perimeter of the irregular plane shape below.

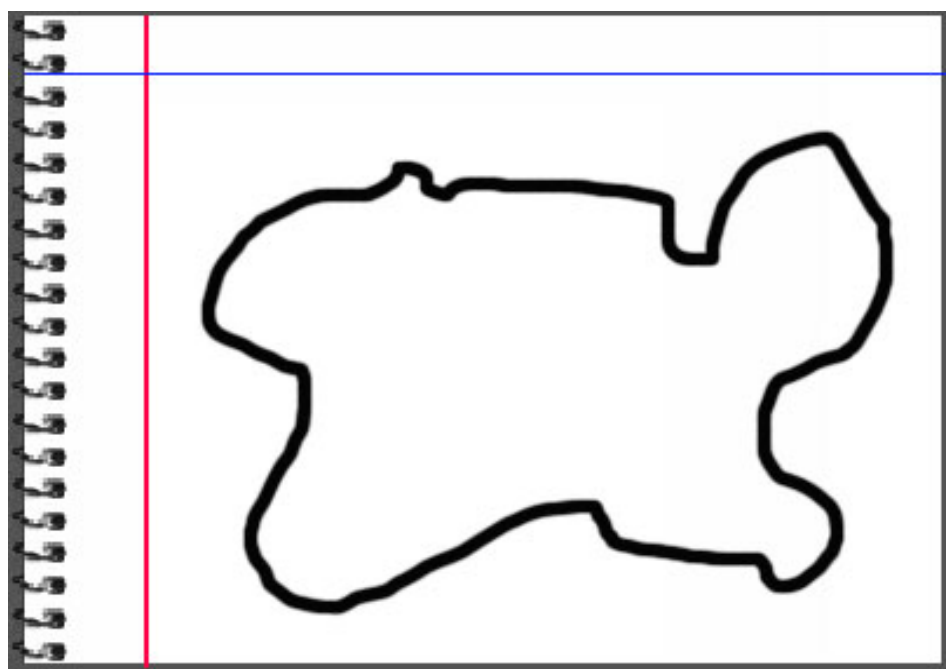

A. Have string/cord, scissors and ruler ready.

B. Trace irregular shape with cord (without overlapping or stretching).

C. Clearly mark or cut the string/cord where it meets the initial end, then remove string from around the edge of the shape.

D. Use ruler to measure string from the initial end to the mark or cut, taking care not to stretch the string past its natural length.

E. Record measurement of perimeter of irregular shape.

(2 points for each step) 
Question 17 (6 points): In the rectangular space below, create a tessellation with exactly 20 congruent shapes.

The congruent rectangles below form a tessellation

\begin{tabular}{|l|l|l|l|l|l|l|l|l|l|}
\hline & & & & & & & & & \\
\hline & & & & & & & & & \\
\hline
\end{tabular}

One alternative answer:

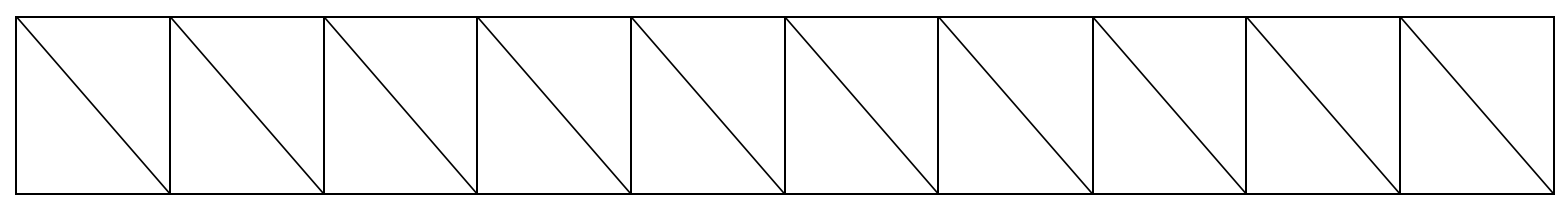

\section{Another alternative answer:}

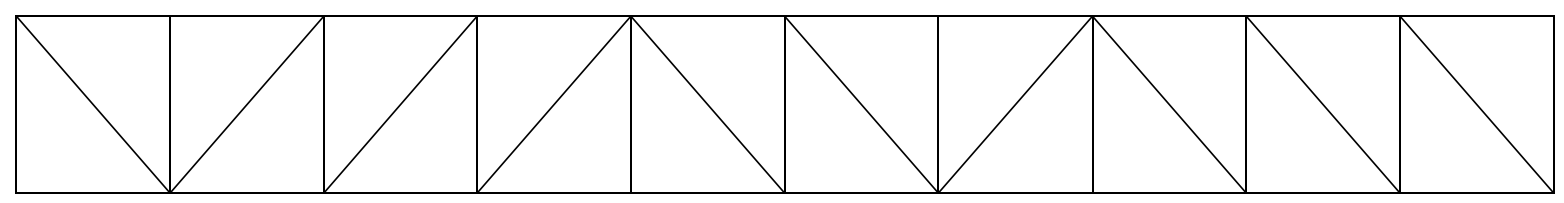

\section{Another alternative answer:}

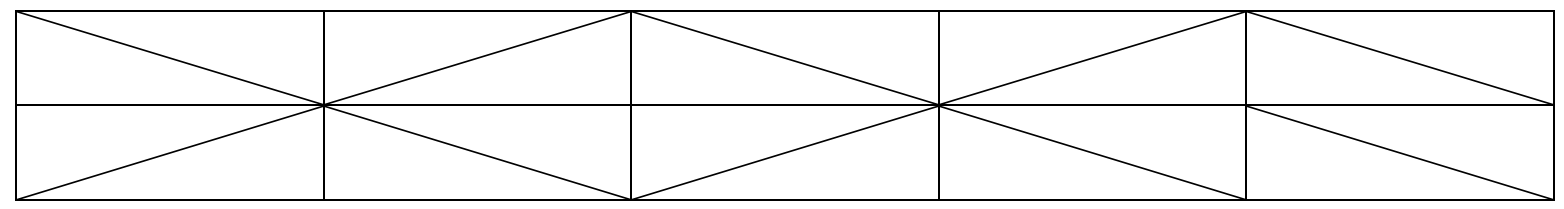

Question 18 (6 points): Rearrange the segments of the square below to create a new symmetric pattern of your choice.

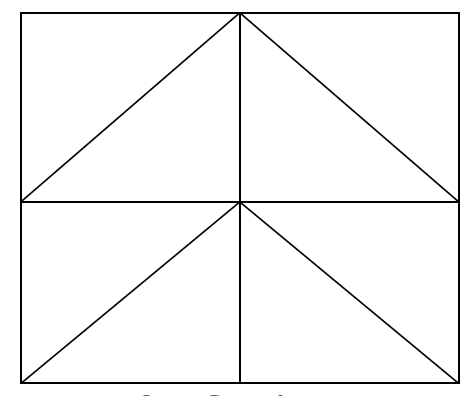

ORIGINAL 


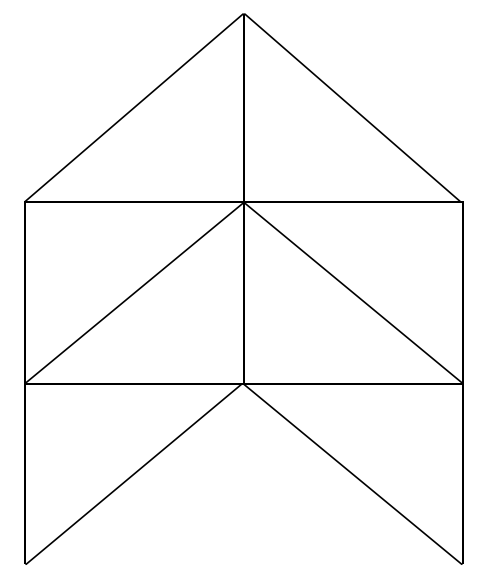

SAMPLE PATTERN \#1

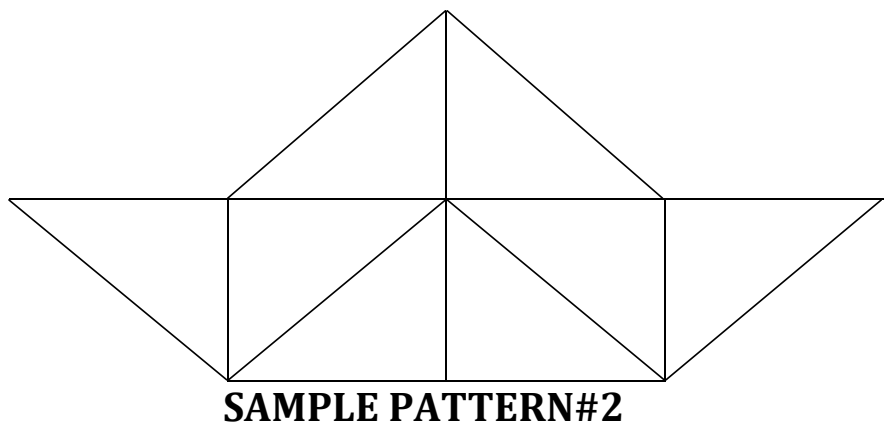


Question 19 (10 points): Suppose the window "M" shown below experiences double transformation in the form of reflection through L2 and L1 respectively. Draw the resulting shape.

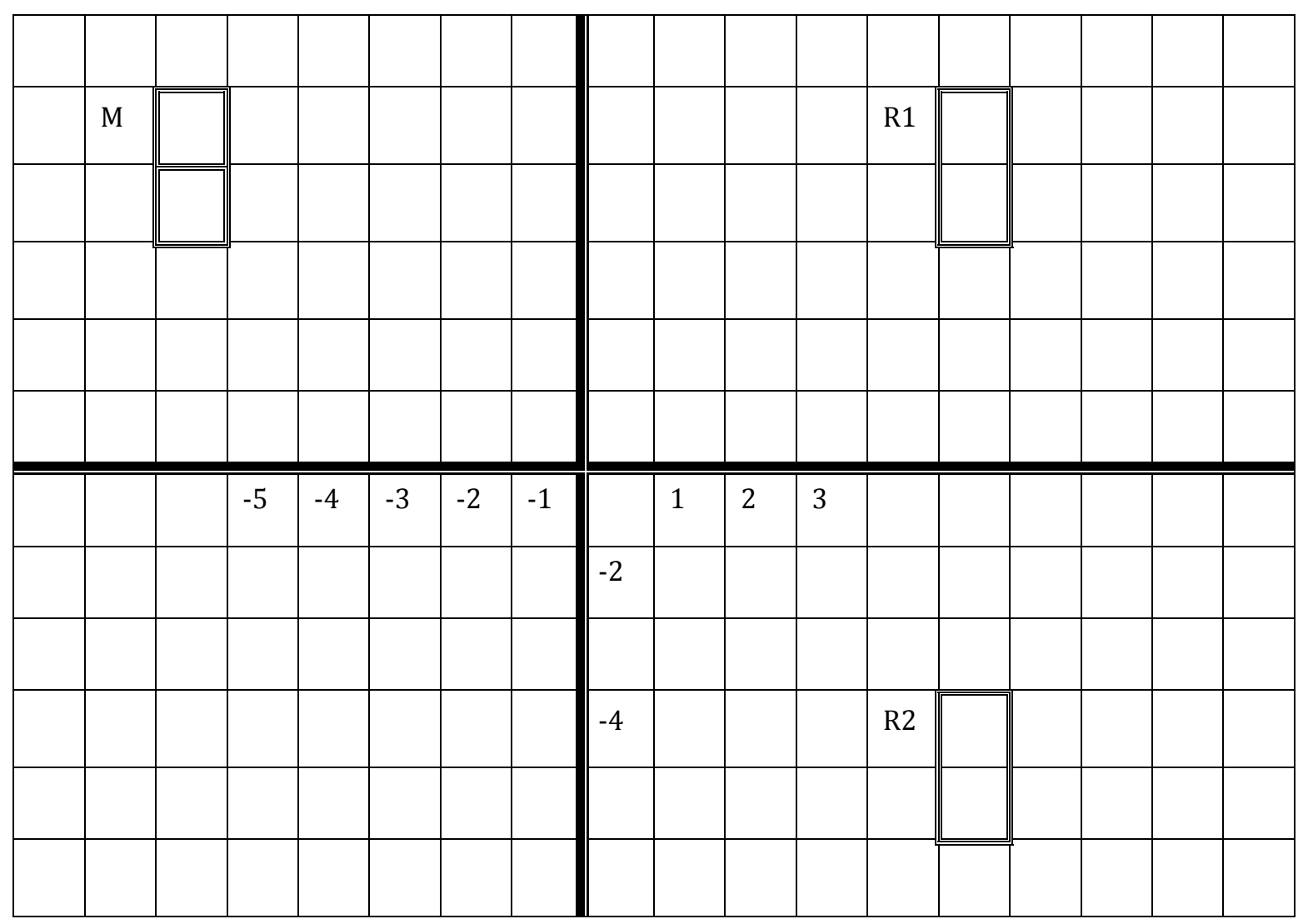

L2

(5 points for correct positioning of R1; 5 points for correct positioning of R2)

Question 20 (14 points): Coordinates in the Cartesian plane may be organized by the following categories: I, II,III, IV, X-axis \& Y-axis. Determine mentally where each pair belongs then classify the coordinates below in each category.

$(-1,5),(0,8),(4,5),(-6,-6),(23,0),(0,0),(9,7),(6,0),(4,-8),(-7,5),(-3,-9),(2,2)$

$(13,-4),(0,7),(11,0),(1,-7),(6,23),(33,-5),(0,-2),(20,2),(-3,-3),(4,-6),(-16,4)$
I. $\quad(4,5)(9,7)(2,2)(6,23)(20,2)$
II. $\quad(-1,5)(-7,5)(-16,4)$
III. $(-6,-6)(-3,-9)(-3,-3)$
IV. $(4,-8)(13,-4)(1,-7)(33,-5)(4,-6)$
X-axis. $(23,0)(6,0)(11,0)(0,0)$
Y-axis. $(0,8)(0,7)(0,-2)(0,0)$

(12 points for the 6categories; 2 points for mentally classifying coordinates) 
Question 21 (6points): Based on the scale factor 2 construct a net for a similar solid from the net given below.

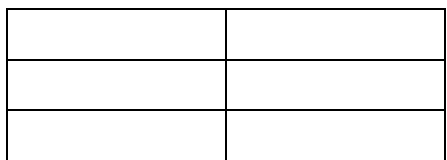

The net below has $2 \times 2$ long units in length and $3 \times 2$ short units in height

\begin{tabular}{|l|l|l|l|}
\hline & & & \\
\hline & & & \\
\hline & & & \\
\hline & & & \\
\hline & & & \\
\hline
\end{tabular}

Question 22 (10 points): A 20 meter by 10 meter rectangular garden yields 80lb of soy beans with application of five - $\$ 2.89$ bags of fertilizer. At the same rate, estimate the dollar amount of investment and yield respectively, that could be expected from a 1 - hectare plot.

\begin{tabular}{|c|c|c|}
\hline 200 sq. meters & 80 lbs & $5 \times 3=\$ 15.00$ \\
\hline $50 \times 200=10000$ & $50 \times 80=4000$ & $50 \times 15=\$ 750.00$ \\
\hline
\end{tabular}

ANSWER: \$750.00 AND 4000 LBS (other close estimates are acceptable). Participants are expected to know that 1 hectare $=10000$ sq. meters in order to earn maximum points for this question.

REASON: $200 \& 10000$ SUGGEST A SCALE FACTOR OF 50. THEREFORE, BOTH INVESTMENT AND EXPECTED YIELD ARE 50 TIMES AS MUCH.

(7 points for reading and analyzing; 4points for understanding of hectare and scale factor; 4 points for correct calculations).

Question 23 (5 points): Given that a flat area of ground to be tiled is shaped like a //gram, how many boxes containing 24 square-foot tiles would you purchase for the job if its dimensions are as follows: base $=35$ feet, height $=15$ feet, and slant side $=$ 20 feet? Assume that tiles may be cut cleanly into pieces with no waste.

\section{$35 \times 15=525 ; 525 / 24=21 \& 11 / 14$. B 22 the best answer}
A. 21
B. 22
C. 24
D. 30
E. 437

(5 points for step-by-step calculation of correct answer)

Question 24 (10 points): It is known that path AC (shown on figure 3 below) is mountainous; but path $\mathrm{AB}$ and $\mathrm{BC}$ are coastal areas. Imagine that you are a Master Guide. Describe a scenario and rationale for choosing route $A B C$. Then describe a 
scenario and rationale for choosing route AC. Each answer should be 30 words or less.

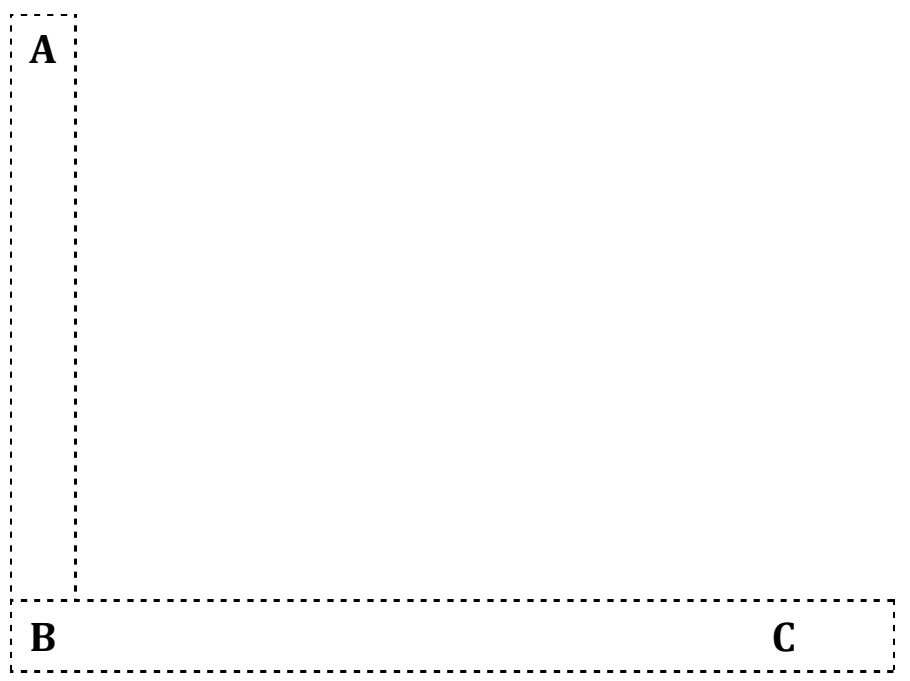

A variety of appropriate responses may be considered. Two possible answers are:

1. I would choose Path AC because it is a shorter distance than A--B-C and Pathfinders are often familiar with such challenges.

2. I would choose the coastal route, which is usually flat, in order to conserve on energy, even though the distance is greater.

Question 25 (10 points): On the lines provided below, explain in 5 steps how you would determine the volume of a broken piece of rock that is approximately 3.5 centimeters in diameter.

A. Have a graduated cylinder with water volume \#1 marked

B. Submerge the rock into the water

C. Record water volume \#2

D. Subtract water volume\#1 from volume\#2

E. Verify and record correct volume of the stone

( 2 points for each step) 
APPENDIX E

INSTRUMENT FOR MODIFICATION OF AFFECT 


\section{AFFECTIVE PRE- AND POST-TEST INVENTORY \\ Instrument for Measuring Modification of Affect}

Code:

Read each statement carefully; then circle "SA" if you strongly agree, "A" if you agree, "U" if you are undecided, "D" if you disagree, and "SD" if you strongly disagree with the statement.

1. I really like geometry.

$$
\begin{array}{lllll}
1 & 2 & 3 & 4 & 5 \\
\text { SA } & \text { A } & \text { U } & \text { D } & \text { SD }
\end{array}
$$

2. I am satisfied with my present level of achievement in geometry.

$\begin{array}{lllll}1 & 2 & 3 & 4 & 5 \\ \text { SA } & \text { A } & \text { U } & \text { D } & \text { SD }\end{array}$

3. Geometry is useless

$\begin{array}{lllll}1 & 2 & 3 & 4 & 5 \\ \text { SA } & \text { A } & \text { U } & \text { D } & \text { SD }\end{array}$

4. I want to spend more time learning geometry.

$\begin{array}{lllll}1 & 2 & 3 & 4 & 5 \\ \text { SA } & \text { A } & \text { U } & \text { D } & \text { SD }\end{array}$

5. I enjoy learning geometry.

$\begin{array}{lllll}1 & 2 & 3 & 4 & 5 \\ \text { SA } & \text { A } & \text { U } & \text { D } & \text { SD }\end{array}$

6. I am aware of geometry applications in architecture.

$\begin{array}{ccccc}1 & 2 & 3 & 4 & 5 \\ \text { SA } & \text { A } & \text { U } & \text { D } & \text { SD }\end{array}$


7. Geometry is boring.

$\begin{array}{lllll}1 & 2 & 3 & 4 & 5 \\ \text { SA } & \text { A } & \text { U } & \text { D } & \text { SD }\end{array}$

8. I am aware that I use geometry in many daily activities.

$\begin{array}{ccccc}1 & 2 & 3 & 4 & 5 \\ \text { SA } & \text { A } & \text { U } & \text { D } & \text { SD }\end{array}$

9. A good foundation in geometry will be helpful in my life.

$\begin{array}{lllll}1 & 2 & 3 & 4 & 5 \\ \text { SA } & \text { A } & \text { U } & \text { D } & \text { SD }\end{array}$

10. I know enough geometry to help my peers.

$\begin{array}{ccccc}1 & 2 & 3 & 4 & 5 \\ \text { SA } & \text { A } & \text { U } & \text { D } & \text { SD }\end{array}$

11. I often open my geometry books at home.

$\begin{array}{lllll}1 & 2 & 3 & 4 & 5 \\ \text { SA } & \text { A } & \text { U } & \text { D } & \text { SD }\end{array}$

12. I am familiar with the geometry standards for my grade level.

$\begin{array}{ccccc}1 & 2 & 3 & 4 & 5 \\ \text { SA } & \text { A } & \text { U } & \text { D } & \text { SD }\end{array}$

13. I would like to help my peers learn more geometry.

$\begin{array}{lllll}1 & 2 & 3 & 4 & 5 \\ \text { SA } & \text { A } & \text { U } & \text { D } & \text { SD }\end{array}$


14. I am interested in keeping track of my progress in geometry.

$\begin{array}{lllll}1 & 2 & 3 & 4 & 5 \\ \text { SA } & \text { A } & \text { U } & \text { D } & \text { SD }\end{array}$

15. I am aware of geometry applications in nature.

$\begin{array}{ccccc}1 & 2 & 3 & 4 & 5 \\ \text { SA } & \text { A } & \text { U } & \text { D } & \text { SD }\end{array}$

16. Geometry is important.

$\begin{array}{lllll}1 & 2 & 3 & 4 & 5 \\ \text { SA } & \text { A } & \text { U } & \text { D } & \text { SD }\end{array}$

17 Geometry is interesting.

$\begin{array}{lllll}1 & 2 & 3 & 4 & 5 \\ \text { SA } & \text { A } & \text { U } & \text { D } & \text { SD }\end{array}$

18. Geometry is important in my life.

$\begin{array}{ccccc}1 & 2 & 3 & 4 & 5 \\ \text { SA } & \text { A } & \text { U } & \text { D } & \text { SD }\end{array}$

\section{Pre-test only Items}

19. Briefly state what you expect to accomplish from this class.

20. Briefly state what you are willing to contribute toward achieving your goals.

\section{Post-test Only Items}

19. State the progress you made during the 5 sessions.

20. State the main features of the program that was helpful. 
APPENDIX F

The G.R.A.C.E. PROJECT - MAKING MEANING AND APPLICATION

(PARTICIPANT'S MANUAL) 
The G.R.A.C.E Project

Making Meaning in Geometry

PARTICIPANT'S MANUAL

by

Donaldson Washington Williams

2008 


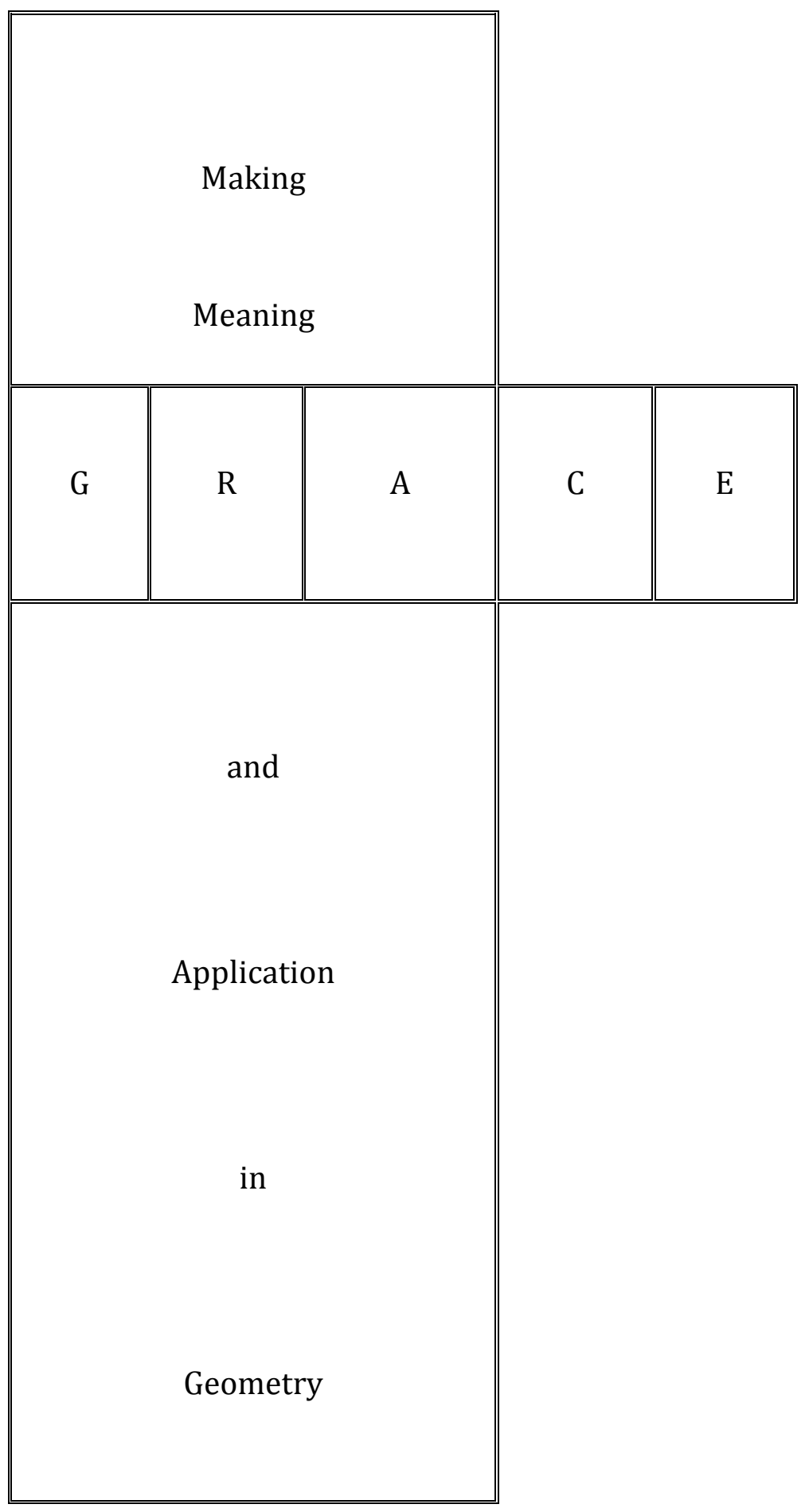




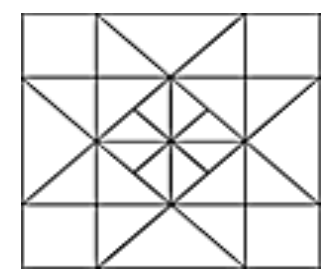

\section{SESSION A：FOUNDATIONS OF GEOMETRY}

\section{Six Behavioral Objectives}

1. The learner will select correct descriptions for: geometry, Euclidian geometry, and non-Euclidian geometry, given 5 selections/choices.

2. The learner will match ten geometric symbols with their appropriate names.

3. The learner will accurately translate into English a statement expressed in geometric symbols.

4. The learner will correctly use five geometry terms, given descriptions.

5. The learner will prepare fairly accurate sketches of graduated cylinder, triple beam balance, and cylinder.

6. The learner will use definitions of congruency and similarity to write correct statements of equality.

Thought for First Session: God brought everything into existence (including mankind and principles, patterns and designs in geometry). Genesis1:1 
OBJECTIVE 1: Select correct descriptions for geometry, Euclidian geometry, and nonEuclidian geometry.

Materials: Globe, dictionary excerpt, portrait of Euclid

Method: Discussion

Activity: Participate in discussion, read and answer questions

A. GEOMETRY: This word is made up of 2 root words, "geo" which means earth, and "meter" which means measurement. When combined into one word, they literally mean MEASUREMENT OF THE EARTH or simply EARTH MEASUREMENT.

B. EUCLIDIAN GEOMETRY: Euclid was a famous mathematician who formally developed plane geometry. A plane is a flat, 2-dimensional surface. He developed several rules that are accepted without question (postulates) and used by students and professionals in solving geometric problems.

C. NON-EUCLIDIAN GEOMETRY: Some famous mathematicians, (for example Gauss) considered geometry that deals with measurement on a non-flat surface. For example, on a sphere parallels do intersect, so one postulate has been changed.

\section{Discussion Questions}

1. What are some terrestrial features that are measured?

2. What name is given to the practice of measuring earth's features such as rivers, farmlands, and mountains?

3. What term above includes "plane geometry"?

4. Have you gained any new knowledge from this process?

5. What three questions can you answer accurately from this process?

Summary Notes 
OBJECTIVE 2: Match ten geometric symbols with their appropriate names.

Materials: Chart, hand-outs

Methods: Peer interview, drills \& practice

Activity: Classify symbols into two groups (known and unknown), verify the known with your peers, then draw and label each unknown symbol three times. Finally, match all symbols accurately as directed.

From the chart of symbols provided draw the symbol that corresponds with each name.

\begin{tabular}{|l|l|}
\hline \multicolumn{1}{|c|}{ Name of Geometric Symbol } & Design of Geometric Symbol \\
\hline 1. right angle & \\
\hline 2. congruent & \\
\hline 3. similarity & \\
\hline 4. therefore & \\
\hline 5. greater than or equal to & \\
\hline 6. perpendicular & \\
\hline 7. angle & \\
\hline 8. line $\mathrm{AB}$ & \\
\hline 9. line segment $\mathrm{AB}$ & \\
\hline 10. degree/s & \\
\hline 11. arc & \\
\hline 12. plane & \\
\hline 13. circumference & \\
\hline 14. pi & \\
\hline
\end{tabular}

\section{Discussion Questions}

1. Why are symbols used in geometry?

2. How may we communicate effectively using the language of geometry?

3. From your perspective, how beneficial is this activity?

OBJECTIVE 3: Accurately translate into English a statement expressed in geometric symbols.

Materials: Chart with geometric symbols, handbook, checklist.

Methods: Peer coaching, practice drills, demonstration 
Activity: Review circle vocabulary example: $A, C, O c e, r, r^{2}, d,\left(A=\pi x r^{2}\right),(C=$ $\pi \times d)$, etc; then practice at least three simple translations such as ( $C=\pi \times d)$ meaning: "Circumference of a circle is approximately equal to $\pi$ times its diameter."
A. $r^{2}=r \times r \operatorname{not} 2 \times r$
B. $d=r+r=2 \times r$
C. Oce $=\pi \times \mathrm{d}$
D. $A=\pi \times r^{2}$

\section{Discussion Questions}

1. What are some motions that form circles?

2. How important is circular motion to travel and industry?

3. Why may junior high students use $\mathrm{pi} \approx 3$ or $\mathrm{pi} \approx 3.14$ ?

4. Can you find in the Bible where 3 is used for an estimate for pi?

OBJECTIVE 4: Correctly use five geometry terms given descriptions.

Materials: Manual, chart containing geometric processes

Methods: Discussion, peer review

Activity: Fill in the blank spaces in A then proceed with B, C, D, \& E.

A. SUPPLEMENTARY ANGLES add up to 180 degrees. Half of a circle is a turn of 180 degrees. Therefore the following pairs of angles are supplementary -

50 and 130

80 and 100

30 and (complete) and 70 (complete)

60 and (complete). 
B. Some letters of the alphabet are symmetric while others are not. Look for balance and equality in size on either side of the line of symmetry. Some patterns are symmetric while others are not.

The letter $A$ is symmetric with a vertical line of symmetry.

The letter B is symmetric with a horizontal line of symmetry.

The letter $\mathrm{C}$ is also symmetric with a horizontal line of symmetry.

The letter D is symmetric with a horizontal line of symmetry.

The human body is symmetric with a vertical line of symmetry.

Identify 2 other symmetric patterns, 2 non-symmetric patterns, 5 other symmetric letters, and 5 asymmetric letters. Verify correctness with at least one peer.

C. POSTULATES are geometric propositions that are accepted (without questions/proof) and used as the basis for developing a logical argument. For example: If $B$ is between $A$ and $C$, then $A B+B C=A C$.

D. Similar shapes have equal corresponding angle measures but may have different side lengths; for example, the shape of your textbook and that of the chalkboard. Both have 4 right angles.

E. Congruent shapes have both equal corresponding angle measures and equal corresponding side lengths. Note that for triangles, if all three corresponding side lengths are equal, then the corresponding angle measures must also be equal; so the triangles are congruent. This is the Side-Side-Side (SSS) Theorem

F. What is the difference between a sector and a segment of a circle? Answer: A sector is shaped like a slice of pie with the two sides of the pie formed by two radii (the point of the pie is the center of the circle). A segment is a piece/section of the circle cut off by a chord (any line between two points on the circle).

\section{Discussion Questions}

1. If an area of study has its own unique vocabulary, then we may conclude that discipline has (complete). Hint- It allows for communication.

2. Symmetry is a design feature that was originated by whom? 
OBJECTIVE 5: Prepare fairly accurate sketches of graduated cylinder, triple beam balance, and cylinder.

Materials: chart containing sketch diagrams, manual

Methods: observation, imitation, demonstration

Activity: From the trace diagrams completed during introduction, sketch the following items in the space provided below:

\begin{tabular}{|c|c|c|}
\hline Graduated Cylinder & Triple Beam Balance & Cylinder \\
\hline & & \\
\hline
\end{tabular}

\section{Discussion Questions:}

1. What is the essential difference between a cylinder and a graduated cylinder?

2. What are the main features of a triple beam balance?

3. Which of the above equipment is concerned with mass?

4. Which of the above equipment is concerned with volume?

5. What are some units of volume? Mass? 
OBJECTIVE 6: Use definitions of congruency and similarity to write correct statements of equality.

Materials: charts containing proof samples and manual.

Methods: Demonstrations, peer coaching.

Activity: Identify corresponding sides of congruent triangles. Then fill in the blank spaces below.

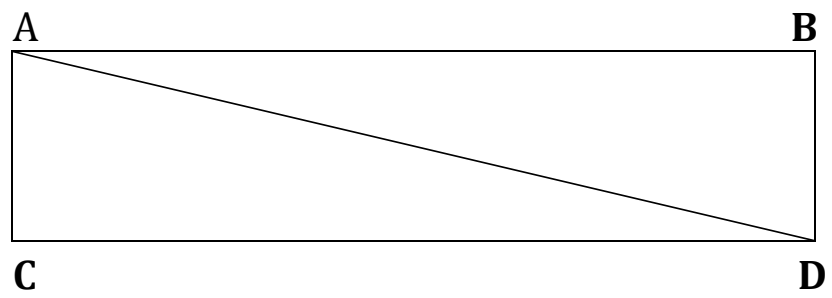

STATEMENTS OF EQUALITY: CONGRUENCY

$\Delta \mathrm{ABD} \& \Delta \mathrm{ACD}$ are $\cong$ if corresponding ____ are exactly the same.

1. $\mathrm{AB}=$

2. $\mathrm{AC}=$

3. $\mathrm{AD}=$

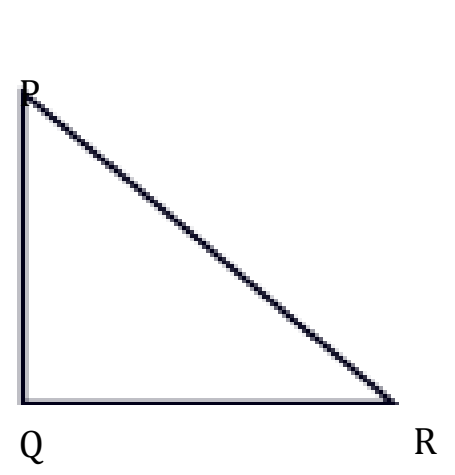

$\mathrm{P}$

$\mathbf{P}_{1}$

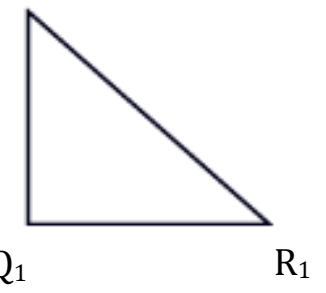

STATEMENTS OF EQUALITY: SIMILARITY

$\mathrm{PQR} \& \mathrm{P}_{1} \mathrm{Q}_{1} \mathrm{R}_{1}$ are if their corresponding are congruent.

1. Angle P

2. Angle $\mathrm{Q}_{1}$

3. Angle R 
Comparison: Congruent shapes must have the same SHAPE (angles) and SIZE.

Similar shapes must have the same SHAPE but may be different sizes

\section{Discussion Questions:}

1. Is the model of a house congruent to the house?

2. Is the model of a house similar to the house?

3. Identical houses built from the model are congruent. True/False?

4. What does the reflexive property mean? Hint: Examine congruent triangles above. 

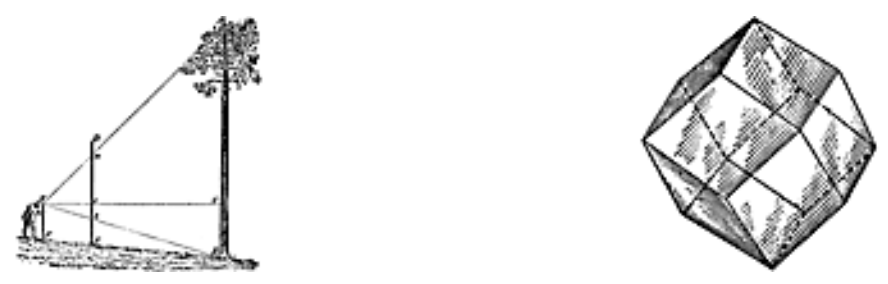

SESSION B: GEOMETRY ALL AROUND US

\section{Duration: 90 minutes/ or five 18-min Sessions}

Format: Interactive Group

Five Behavioral Objectives

7. The learner will identify five geometric shapes that are visible in nature, given clear descriptions of each.

8. The learner will differentiate between basketball and circle (in terms of their unique properties) in 15 words or less.

9. The learner will choose the best estimates of area and perimeter of a trapezium, given four choices.

10. The learner will determine a pair of possible dimensions of a cuboid whose volume is given.

11. The learner will identify a transformation out of six choices, given a diagram of the transformation of a shape in the Cartesian plane.

Thought for second session: Visible things in the heavens (example constellation) and on this earth declare God's wisdom and the work of his hands. Psalms 19:6. 
OBJECTIVE 7: Identify five geometric shapes that are visible in nature, given clear descriptions.

Materials: Chart containing descriptions, manual

Methods: discussion, peer sharing

Activity: For each description on chart, write the name of the shape. Then, compare answers with two of your peers.

A. The general plan(top view) of the pine trees

B. The general elevation(side view) of the pine tree

C. Shape of each cell of the honeycomb

D. General shape of the trunk of a tree

E. Shape of a grapefruit/orange

\section{Discussion Questions}

1. How many items did you get correct?

2. Who is the originator of geometric patterns and designs?

OBJECTIVE 8: Differentiate between basketball and circle in 15 words or less.

Materials: chart containing sphere and circle peculiarities

Methods: observation, discussion, cooperative learning

Activity: Prepare t-chart with list of similarities and differences between both shapes, then state in 15 words or less the difference between the shapes.

Comparing and Contrasting the Sphere and the Circle

\begin{tabular}{l|l}
\multicolumn{1}{c|}{ SIMILARITIES } & DIFFERENCES \\
\hline 1. Both are round & \\
2. Both are geometric shapes & \\
3. & \\
4. & \\
5. &
\end{tabular}




\section{Discussion Questions}

1. How are cylinders, cones, and cubes alike?

2. How are triangles, rectangles, and trapezoids alike?

3. Containers have ( complete)

4. But, plane figures have only 2

5. What are examples of (approximate) spheres?

6. What are examples of (approximate) circles? 
OBJECTIVE 9: Choose the best estimates of area and perimeter of a trapezium, given four choices.

Materials: manual, chart containing formulas of plane shapes.

Methods: Peer sharing, drills \& practice

Activity: Find area and perimeter of the trapezoid below, given that $\mathrm{b} 1=$ $8 \mathrm{~cm}, \mathrm{~b} 2=10 \mathrm{~cm}$, and $\mathrm{h}=6 \mathrm{~cm}, \mathrm{SI}=9 \mathrm{~cm} \& \mathrm{~S} 2=7 \mathrm{~cm}$. Work with a group member then compare answers before showing it to the facilitator.

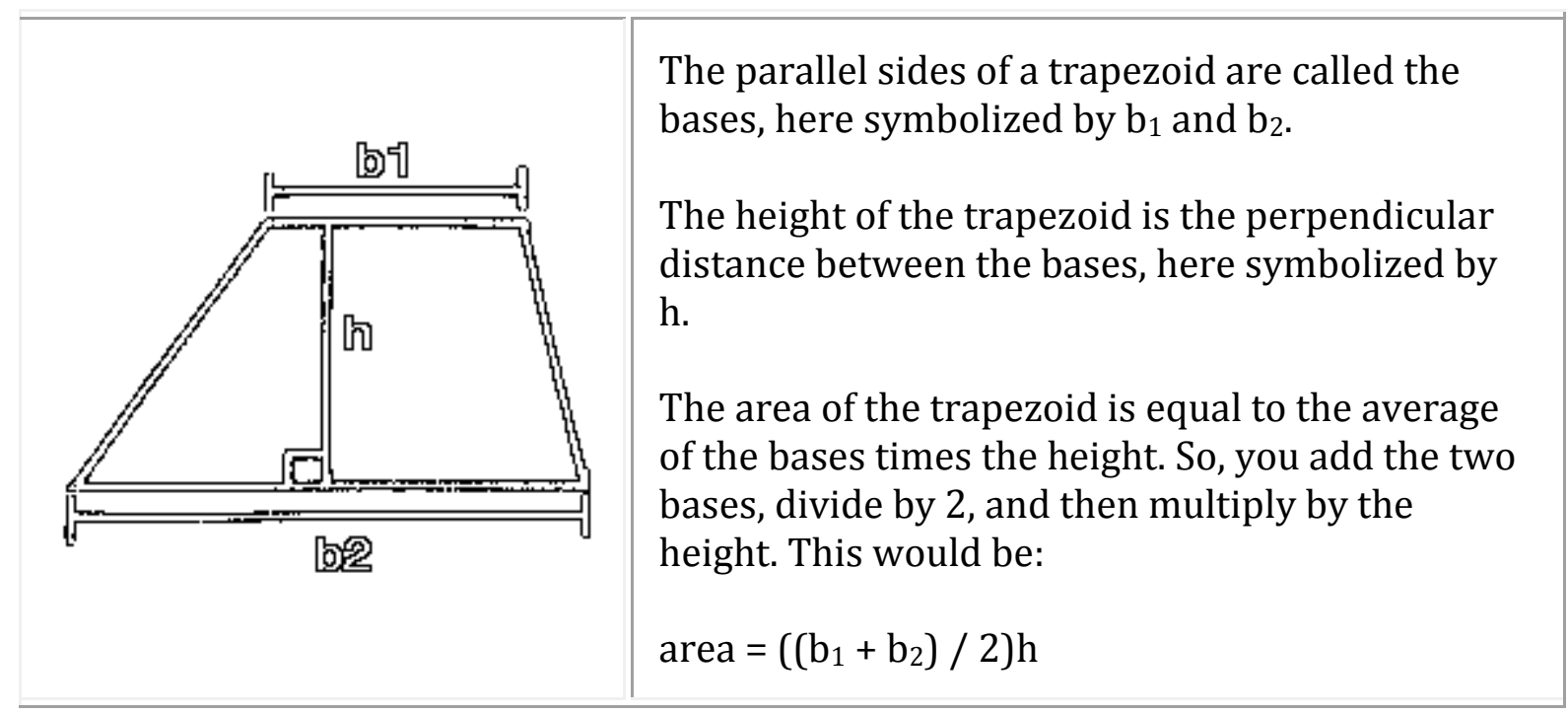

\section{Discussion Questions:}

1. Instead of the number 6 , the value could be 5.97 or 6.02 . How would this change things? Why?

2. What pair values could have been assigned for 8 and 10 ?

3. Which formulas were used in this activity?

4. Can you explain why those two formulas work? 
OBJECTIVE 10: Determine a pair of possible dimensions of a cuboid whose volume is given.

Materials: manual, model of cuboid, ruler

Methods: observation, demonstration, hands-on

Activity: Measure and record length, width \& height of cuboid in $\mathrm{cm} /$ inch.

Multiply all 3 lengths to get volume in cubic centimeters or cubic inches. Then complete the following statements below with at least one group member.

A cuboid is a box-shaped object. It has six flat sides and all angles are right angles.

All of its faces are rectangles.

It is also a prism because it has the same crosssection along a length. In fact it is a rectangular prism.

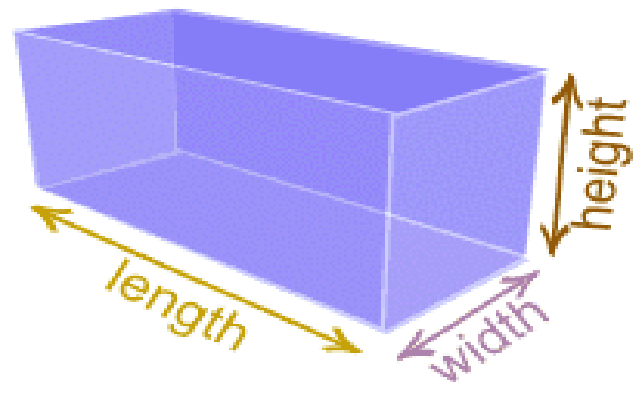

The volume of a cuboid is 200 cubic centimeters. Which of the dimension sets below are possible?
A. $\mathrm{L}=10 \mathrm{~cm}$
$\mathrm{W}=5 \mathrm{~cm}$
$\mathrm{H}=4 \mathrm{~cm}$
B. $\mathrm{L}=4$
$\mathrm{W}=10$
$\mathrm{H}=5$
C. $\mathrm{L}=80$
$\mathrm{W}=50$
$\mathrm{H}=70$
D. $\mathrm{L}=20$
$\mathrm{W}=5$
$\mathrm{H}=2$

\section{Discussion Questions}

1. Is a cuboid regular or irregular? Why?

2. A synonym for "number of cubes that fits within a given space" is?

3. What are two other metric units of volume? and 
OBJECTIVE 11: Identify a transformation out of six choices, given a diagram of the transformation of a shape in the Cartesian plane.

Materials: manual, grid sheets, chalkboard,

Methods: Discussion, demonstration, hands-on

Activity: Show that a double translation has occurred.

\begin{tabular}{|l|l|l|l|l|l|l|l|l|l|l|}
\hline & & & & & & & & & & \\
\hline & & & & & & & & & & \\
\hline & & & & & & & & & & \\
\hline
\end{tabular}

\section{Discussion Questions}

1. What do you notice about KI and K2?

2. What two routes are likely for this transformation?

3. In what other ways are images transformed? 

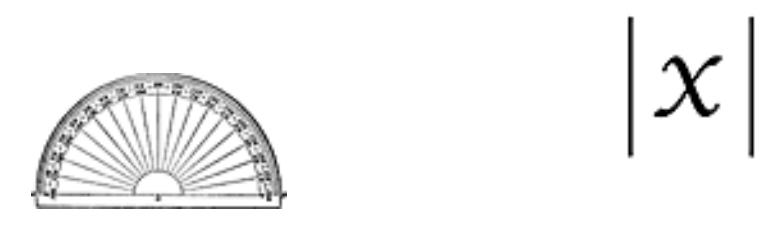

\section{SESSION C: UNDERSTANDING KEY PRINCIPLES IN G E O M E T R Y}

\section{Duration: 90 minutes or five 18-minute sessions}

Five Behavioral Objectives

12. The learner will determine equivalent estimates of pi by comparing diameter and circumference of a circle.

13. The learner will write true statements leading to the conclusion that for any triangle $\mathrm{RPQ}$, the sum of the interior angles equals the exterior angle.

14. The learner will answer six questions related to the formula " $\mathrm{D}=\mathrm{m} / \mathrm{v}$ " correctly.

15. The learner will apply the Pythagorean Theorem by selecting the appropriate anchor position of the rope, when a pole is erected at 90 degrees with the ground, given a diagram showing the various positions and the rope.

16. The learner will explain in five steps how to determine perimeter of an irregular plane shape with a string and ruler.

Thought for third session: God is able to provide instructions and wisdom to human beings if they are willing to use their knowledge of geometry to build (whether character or a temple) as He directs. 1 Kings 6. 
OBJCTIVE 12: Determine equivalent estimates of pi by comparing diameter and circumference of a circle.

Materials: manual, chart containing pi, cord, scissors, ruler

Methods: Hands-on demonstration, discussion, peer sharing

Activity: Use the cord to form a circle with its diameter. Extend the circumference and compare it with diameter to see the relationship. Record the estimated number of times longer than its diameter is the length of the circumference.

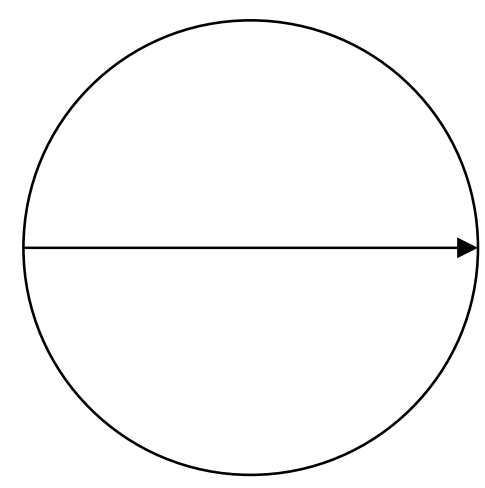

Label the circle with: radius, chord, circumference, and diameter then respond to the questions below.

\section{Discussion Questions}

1. Is pi a ratio, fraction or both?

2. What is a mixed fractional estimate of pi?

3. What is a decimal approximation of pi?

4. What is an improper fraction estimate of pi?

5. Why is it ok for younger learners to use 3 as an estimate for pi?

6. Is the definition of pi abundantly clear to you now?

OBJCTIVE 13: Write true statements leading to the conclusion that for any triangle $\mathrm{RPQ}$, the sum of the interior angles equals the exterior angle.

Materials: manual, chart containing samples of proof

Methods: discussion, exposition, peer sharing, hand-outs 
Activity: Identify what is given that helps you develop your argument. Find the $3^{\text {rd }}$ angle of the triangle, then draw conclusion regarding equality.

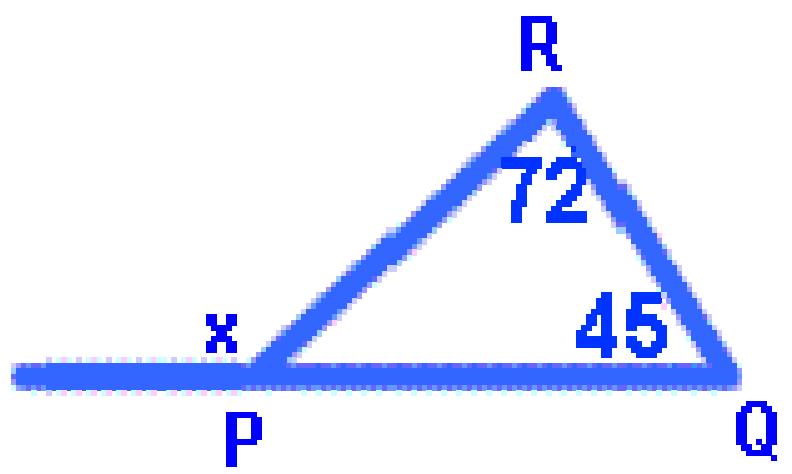

How may we determine the value of the unmarked angle inside of the triangle? What is the relationship between the unmarked angle inside of the triangle and the angle X? Would this process always work? Try to write out the general steps of this process.

\section{Discussion Questions}

1. What is the difference between inductive and deductive reasoning?

2. Where was each kind of reasoning used above?

3. Can a statement be proved by inductive reasoning?

4. How would you rate this introduction to proof in geometry? (easy, difficult, challenging, manageable)

OBJECTIVE 14: Answer six questions related to " $D=m / v$ " correctly.

Materials: a rectangular block of wood, manual, ruler, calculator

Methods: Cooperative learning, hands-on, discussion

Activity: Discuss procedure for finding density. Assign part of the task to different group members; then finalize the answers. 
A rectangular block measures 360 units on a triple beam balance, if its base area and height are 9 and $8 \mathrm{~cm}$, calculate its density then answer the questions below.

A. What is the appropriate unit for base area?

B. What is the correct formula for density?

C. What formula was most likely used to calculate the base area?

E. Which value represents the density?

F. The ratio unit used to express density is?

G. Explain “E” completely.

\section{Discussion Questions}

1. Which material has the lower density, sponge or wood?

2. Is density related to weight?

OBJECTIVE 15: Apply the Pythagorean Theorem by selecting the appropriate anchor position of the rope when a pole is erected at 90 degrees with the ground.

Materials: chart containing Pythagoras' theorem, manual, grid containing diagram, string or cord, measuring tape, table of values based on Pythagorean Theorem.

Methods: Outdoor demonstration, hands-on, observation, discussion

Activity: Based on the 3-4-5 relationship established by Pythagoras, adjust the slant line (when stretched at 5 unit lengths) so that it is positioned correctly.

Given that the horizontal axis uses the same scale as the vertical axis, what is the correct anchor position on the vertical axis?

A. Position \#2 
B. Position \#4

C. Position \#6

D. Between positions \#4 \& \#6

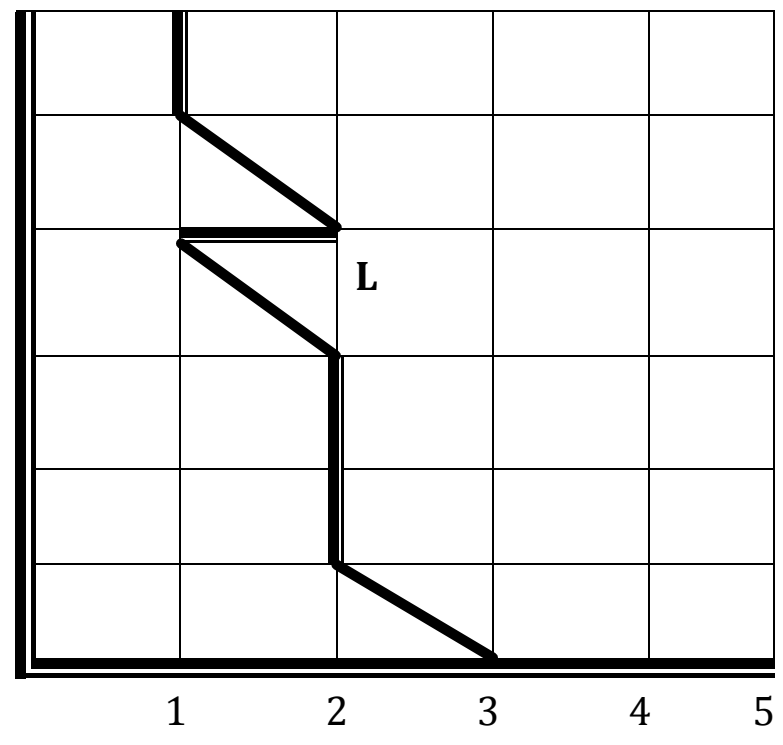

\section{Discussion Questions}

1. What are the 3 related equations that make up the Pythagoras' theorem?

2. The square root of 30 falls between which two whole numbers?

3. Do you find the application of this theorem easy, ok, difficult or impossible?

4. Why do you think this theorem is so important in architecture?

5. Why do you consider it important to be learned in middle school?

6. Is the concept easy, difficult, ok, or too difficult?

OBJECTIVE 16: Explain in five steps exactly how to determine the perimeter of an irregular plane shape with a string and ruler.

Materials: manual, cord, trace diagram of the shape, marker, ruler

Methods: Hands-on, demonstration, discussion, observation 
Activity: Place cord exactly over the irregular diagram. Mark where the cord meets the initial end. Remove and measure the cord; then, record the measurement as perimeter of the shape in centimeters or inches.

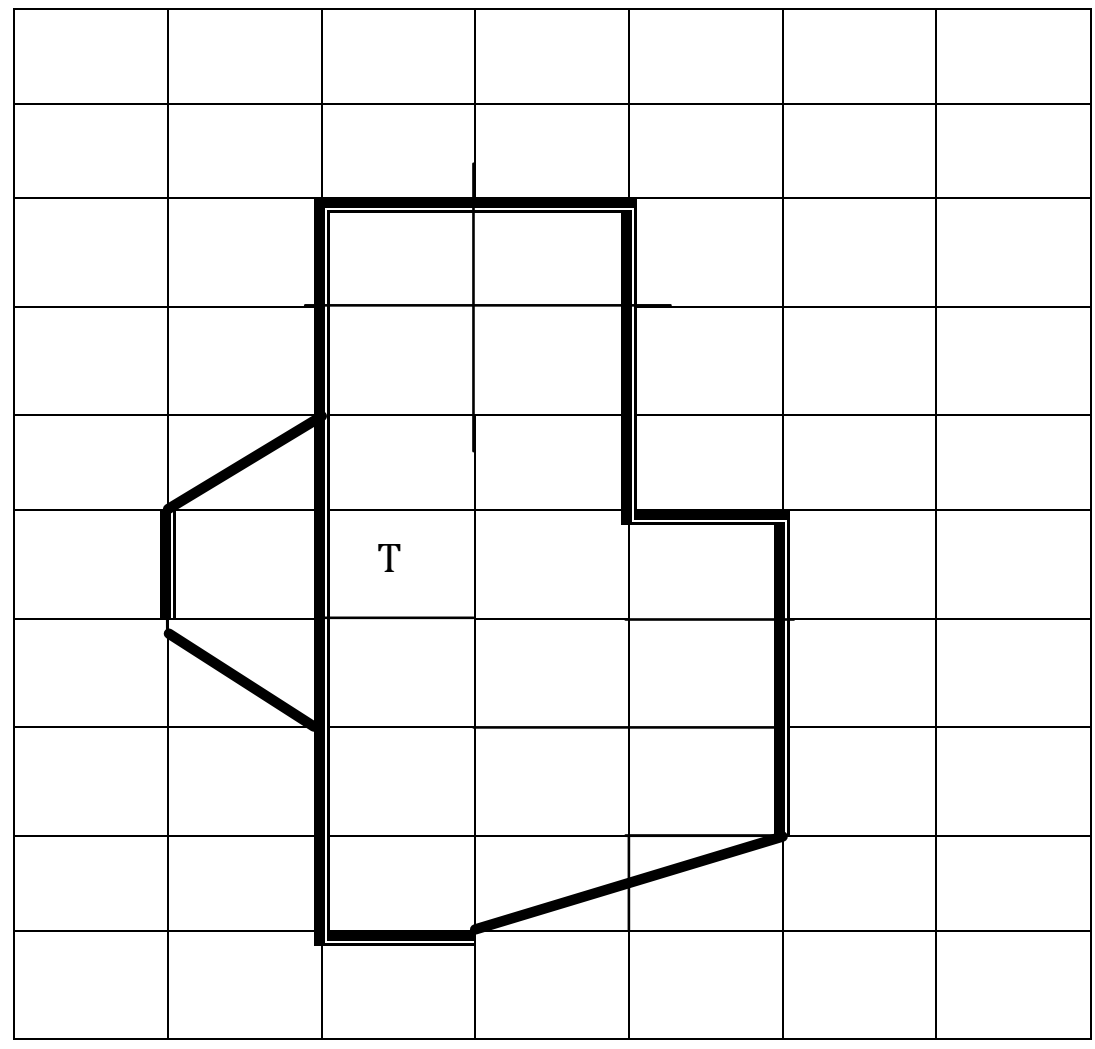

\section{Discussion Questions}

1. What are 2 examples of regular shapes?

2. Can you repeat at least 4 steps in finding perimeter of irregular shapes?

3. Should you stretch the string tightly against the ruler when measuring it? Did you stretch it that tightly when following the shape?

4. For the shape "T" above, which line segment is not included in perimeter?

5. Why was it not included?

6. Why is a ruler needed for perimeter of irregular shapes? 

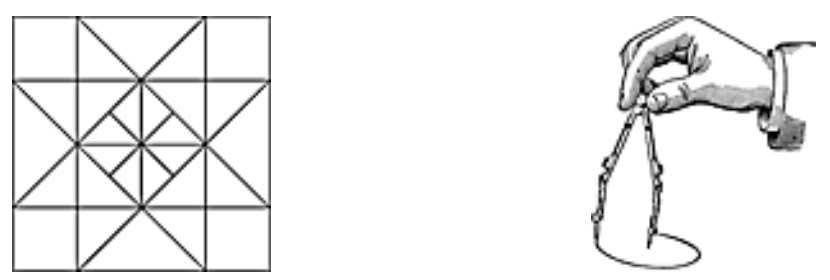

SESSION D: CONSTRUCTING MEANING IN GEOMETRY

\section{Duration: 90 Minutes or Five 18-minute Sessions}

Five Behavioral Objectives

17. The learner will create a tessellation with exactly 20 congruent patterns.

18. The learner will rearrange segments of a design to create a new symmetric pattern.

19. The learner will position an image to show the effect of transformations by reflection through $x$ and $y$ axes.

20. The learner will classify coordinates in their appropriate quadrants or axis category.

21. The learner will sketch a net for a cylinder, given a model and scale factor.

Thought for fourth session: If God works with us our work will not be in vain, but if He doesn't our work can only be a failure. Psalms 127:1. 
OBJECTIVES 17 \&18: Create at least two types of patterns.

Materials: Charts showing various designs - standard and adjusted.

Methods: observation, demonstration, discussion, personalized activity

Activity: Examine samples then create a design of your choice and at least two adjusted patterns. The adjusted patterns must be symmetric (See chart with patterns).

Personalized Tessellation:

Adjusted Symmetric Pattern 1:

Adjusted Symmetric Pattern 2:

\section{Discussion Questions}

1. Where may we find tessellations?

2. Where may we find symmetric patterns?

3. What do patterns do for us?

4. How do you feel after creating a really "cool" pattern?

5. What name is given to a pattern created by an arrangement of stars in the heavens? 
OBJECTIVE 19: Position an image to show the effect of transformations by reflection through the $x$ and $y$ axes.

Materials: grid, manual, pencil/pen

Methods: demonstration

Activity: Show the position 1 and position 2 of the shape that has been transformed by reflection through the $\mathrm{x}$-axis and $\mathrm{y}$-axis respectively.

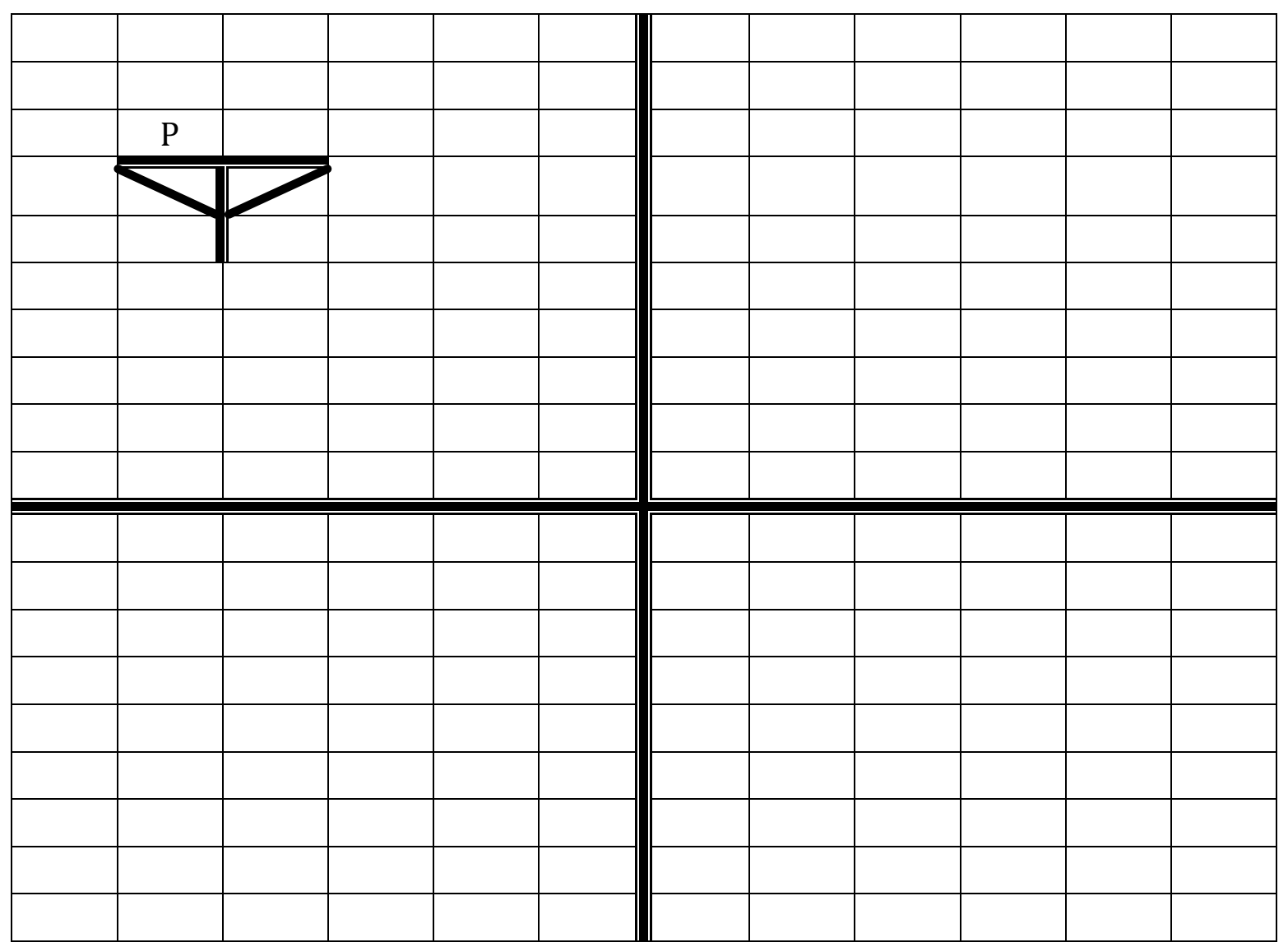

\section{Discussion Questions}

1. Is reflection a form of transformation?

2. Are reflected images similar?

3. Are reflected images congruent?

4. If a pre-image is 4 steps from the reflection axis, how many steps should the image be from the axis?

5. Is this activity difficult, easy, ok, almost impossible? 
OBJECTIVE 20: Classify coordinates in their correct quadrant or axis category.

Materials: manual, chart containing quadrants and axes clearly labeled

Methods: observation, discussion, group and individual responses.

Activity: First, number the axes then describe characteristics of coordinates based on where they belong. For example: $(0,0)$ belongs in the origin and $(4$, 5) belongs to Q1.

For each group of coordinates below, indicate whether it is: Pos X, Pos. Y, Neg. X, Neg. Y, QI, QII, QIII, or QIV.

$(0, Y)$

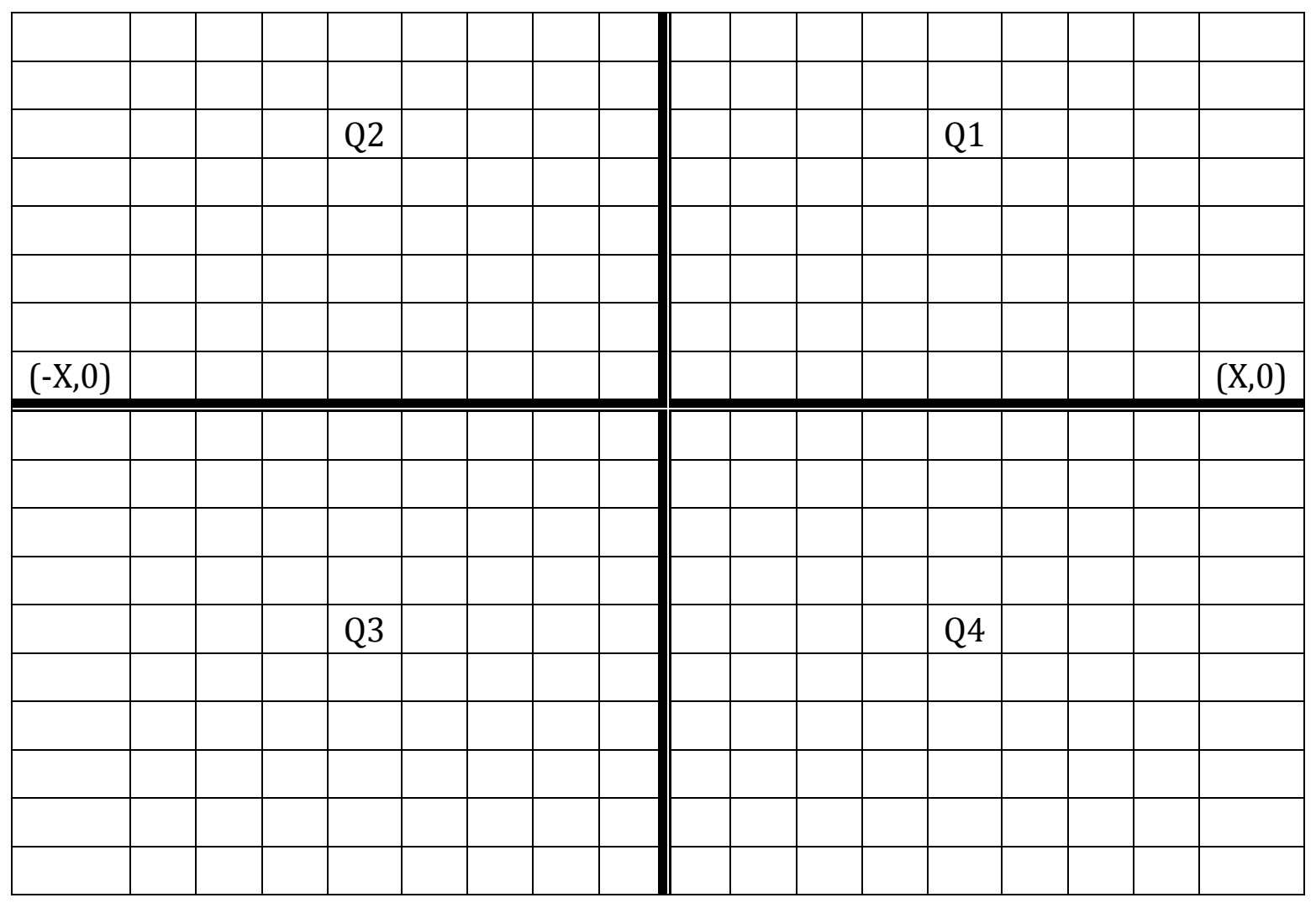

$$
(0,-Y)
$$

1. $(-2,-4),(-4,-5),(-6,-1) \quad$ 2. $(3,3),(5,8),(2,9) \quad 3 .(-3,0),(-6,0),(-9,0)$

4. $(5,0),(25,0),(9,0) \quad$ 5. $(0,3),(0,8),(0,4) \quad 6 .(0,-2),(0,-8),(0,-5)$

7. $(-2,2),(-8,7),(-3,7) \quad$ 8. $(8,-2),(6,-5),(3,-6)$ 


\section{Discussion Questions}

1. What name is given to a system of intersecting lines and a pair of numbered axes?

2. Can you identify the positive only region? The negative only region?

3. Where does the $(0,0)$ position fall?

4. Which position do you find it difficult to identify?

5. Is this area of the study: too difficult, ok, easy, or too easy?

6. What does each intersection represent?

7. Without looking at the Cartesian plane, can you tell the quadrant or axis category for each coordinate pair below?

$$
(-2,-4),(2,4),(2,-4),(-2,4), \&(0,4) \&(2,0)
$$

OBJECTIVE 21: Sketch a net for a similar cylinder, given scale factor and model

Materials: Paper, scissors, ruler, manual

Methods: Hands-on, demonstration, discussion, PBL

Activity: Measure circumference and height of the model then use a scale factor of 3 to construct a similar solid.

3 columns \& 5 rows

\begin{tabular}{|l|l|l|}
\hline & & \\
\hline & & \\
\hline & & \\
\hline & & \\
\hline & & \\
\hline
\end{tabular}




\section{Discussion Questions}

1. Is the curved surface area of a cylinder a rectangle?

2. How many times larger than the model is the cylinder?

3. How were you able to tell?

4. Does the plan create an open or closed cylinder?

5. Was this activity difficult, ok, easy, or too easy? 

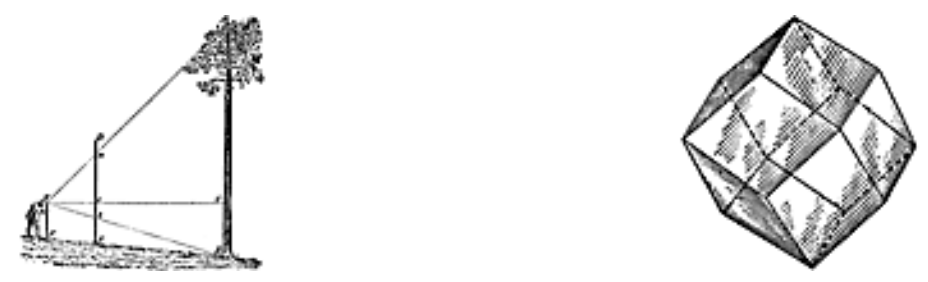

\section{SESSION E: USING GEOMETRY TOSOLVE PROBLEMS}

\section{Duration: 90 minutes or four 23-minute sessions}

Five Behavioral Objectives

22. The learner will apply the proportion principle in calculating total investment and expected yield per hectare.

23. The learner will calculate the number of boxes of tiles needed to tile a parallelogram, given job description.

24. The learner will give a rationale for their selected travel route, given a written scenario.

25. The learner will explain in five steps how to determine the volume of an irregular solid, using a graduated cylinder.

Thought for the fifth session: Noah's understanding of geometry helped him accomplish God's will. His effort resulted in the saving of the lives of many animals and his family. Genesis 6:9. 
OBJECTIVE 22: Apply the proportion principles in calculating total investment and expected yield per hectare

Materials: manual, calculator

Methods: PBL, peer review, discussion

Activity: Complete a table based on information given. Use appropriate estimates rather than exact values (use a calculator to verify the relative accuracy of your answer).

Fact Needed: 1 hectare $=10000$ square meters

A 10 meter by 10 meter rectangular garden yields $50 \mathrm{lb}$ of soy beans with application of five - $\$ 3.97$ bags of fertilizer. At the same rate, estimate the dollar amount of investment and expected yield respectively that could be expected from a 1 - hectare plot?
A. $\$ 700.00 / 4000 \mathrm{lb}$
B. $\$ 2000.00 / 5000 \mathrm{lb}$
C. $\$ 400.00 / 5000 \mathrm{lb}$
D. $\$ 700.00 / 6000 \mathrm{lb}$
E. $\$ 500.00 / 7000 \mathrm{lb}$

\begin{tabular}{|l|l|l|}
\hline & Original & $\mathrm{X}$ \\
\hline Area & & \\
\hline Yield & & \\
\hline Fertilizer Cost & & \\
\hline
\end{tabular}

\section{Discussion Questions}

1. One hectare is equal to how many square meters?

2. The original garden was how many square meters?

3. How many 100 s can you get from 10000 ?

4. A proper estimate of $\$ 2.97$ is $\$ 2.00$. True/false?

5. What is an estimate of the cost of fertilizer for the $10 \times 10$ meter garden?

6. How many $50 \mathrm{sq} \mathrm{m}$ are there in 1 hectare?

7. What is the scale factor linking 5 and 20? 8 and 24? 50 and 10000 ?

8. Is this problem difficult, easy, ok, or impossible? 
OBJECTIVE 23: Calculate the number of boxes of tiles needed to tile a parallelogram, given a job description.

Materials: calculator, manual, pencil/pen, eraser

Methods: PBL, discussion, peer review

Activity: Read scenario carefully. Determine formula, shape and or procedure involved.

Given that a flat area of ground to be tiled is shaped like a //gram, how many boxes containing 12 one-foot-square tiles would you purchase for the job if its dimensions are as follows: base $=18$ feet, height $=9$ feet, and slant side $=$ 10 feet?

\section{Discussion Questions}

1. What does a //gram look like?

2. Is a rectangle a // gram?

3. Is a square a //gram?

4. Is a triangle a //gram?

5. What formula is used to find the area of a //gram?

6. Can you explain why this formula works?

7. Is the length of the slant side needed to find area?

8. How could you use the Pythagorean theorem and a bit of work to find the area?

9. Do you like the formula better?

10. Will you have to cut any tiles?

11. Will you have left over tiles after the job is completed? 
OBJECTIVE 24: Give a rationale for a selected route for travel.

Materials: manual, chart with diagram and scenario

Methods: Cooperative learning, discussion, perspectives

Activity: Select Route AC or A--B--C then list 2 reasons why you would make that choice

Scenario: Hikers are encouraged to conserve on energy and time. It is known that path $\mathrm{AC}$ is mountainous; but path $\mathrm{AB}$ and $\mathrm{BC}$ are coastal areas. Imagine that you are a Master Guide; which route would you recommend? Provide your rationale in 30 words or less.

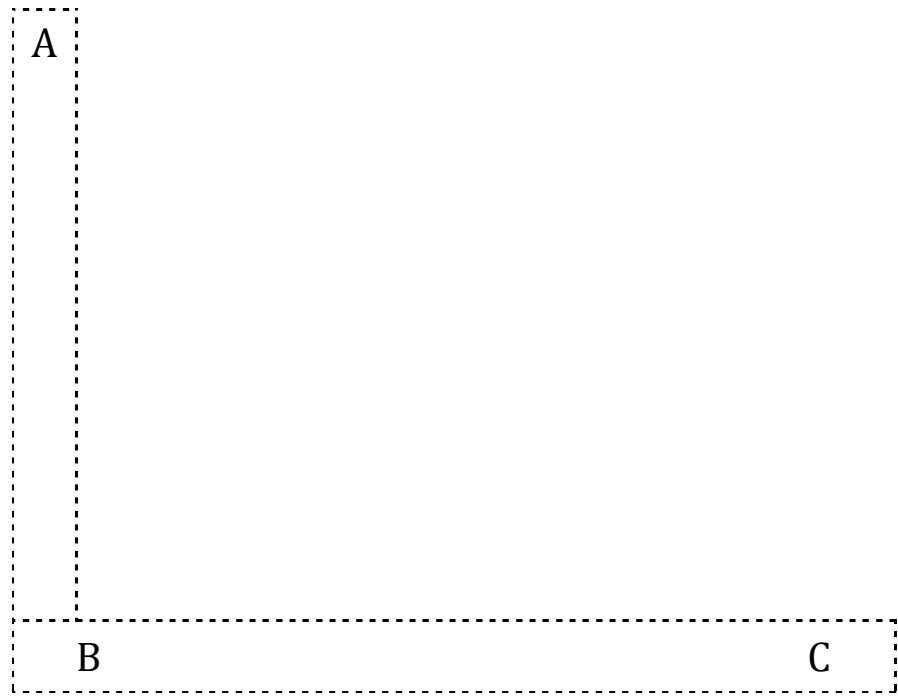

\section{Discussion Questions}

1. What could be the consequence of a bad judgment?

2. Does geometry always involve calculations?

3. What calculation or information could be helpful in making this decision?

4. Is this question vague or clear enough? 
OBJECTIVE 25: Explain in five steps how to determine the volume of an irregular solid using a graduated cylinder.

Materials: water, graduated cylinder, irregular object (small stone)

Methods: Hands-on, demonstration

\section{Activity:}

Step1: Pour liquid in graduated cylinder and record first liquid volume.

Step2: Submerge irregular object into liquid in graduated cylinder.

Step 3: Record second liquid volume.

Step 4: Subtract first liquid volume reading from second liquid volume reading to get volume of irregular solid.

Step 5: Verify and record correct volume of the irregular object

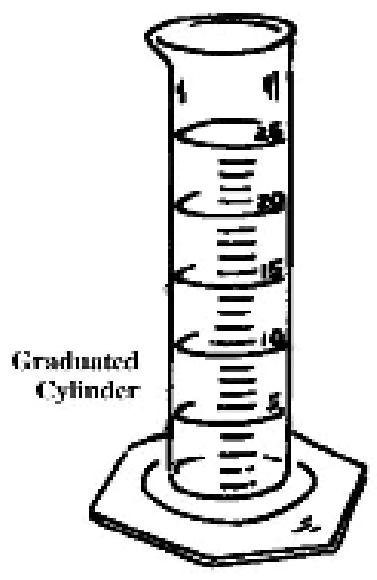

\section{Discussion Questions}

1. What are 2 examples of regular solids?

2. What are 2 examples of irregular solids?

3. What is the difference between a regular and a graduated cylinder?

4. Can you repeat the 5 steps demonstrated above?

5. Is $1 \mathrm{ml}$ equal to 1 cubic $\mathrm{cm}$ ? Yes/no 
APPENDIX G

THE G.R.A.C.E.PROJECT - MAKING MEANING AND APPLICATION IN GEOMETRY

(DEVELOPER'S MANUAL) 


\section{Out-of-School Time (OST) Program}

The G.R.A.C.E Project: Making Meaning and Application in Geometry

\section{DEVELOPER'S MANUAL}

by

Donaldson Washington Williams

August 2008 


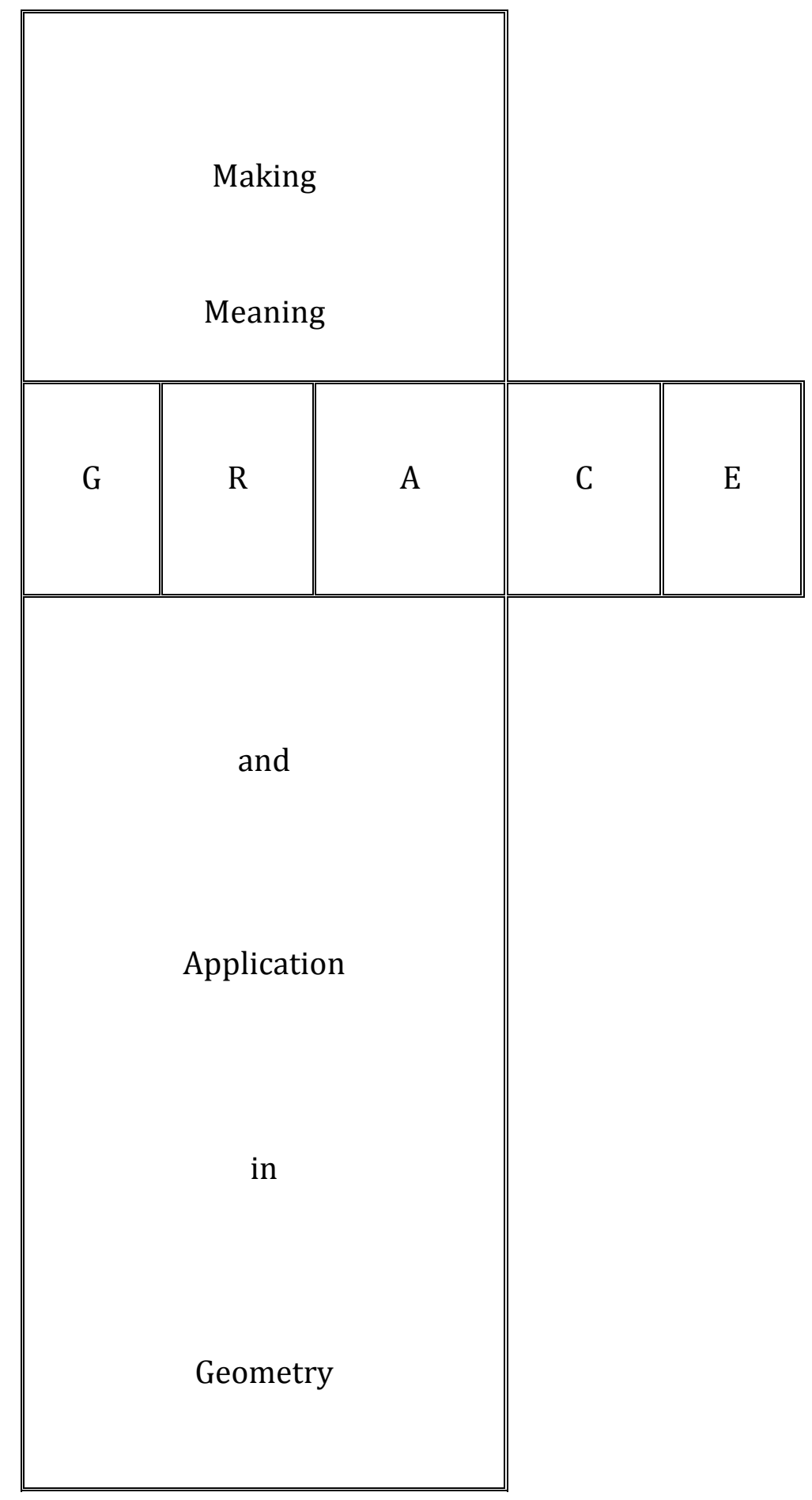




\title{
Introduction
}

Current educational research designs often show variations. However, one constant that is recognized by researchers, is that each design is intended to improve achievement. The GRACE Project is no exception and may best be understood by the acronym explained below:

G - Geometry (in) -- Focuses on foundational vocabulary, principles and designs

R - Real-life -------- Relates to every-day human activities

A - Application ----- Profitable use of principles and skills learned

C - Curriculum ----- 25 clearly-stated outcomes to be mastered by subjects

E - Experience ------ The quality of the encounter as subject engages in geometry

The G.R.A.C.E. Project is designed to make meaning and useful application in geometry.

The developer's manual is not designed to give answers; it is a plan to assist participants in seeking a solution for each problem. It is a resource that a parent or responsible adult may use to guide the learning process. It is totally unacceptable for anyone to write answers without first seeking an understanding of the principle involved in working the problem.

For further clarification of any question, kindly contact the developer at 708843 3243 or 2694714000 . The benefits that middle grade students are likely to gain from this curriculum will be worth the sacrifice in the long-term.

\begin{abstract}
Aim
Two target accomplishments have been specified for this project. The cognitive component focuses on participants' mastery of selected concepts in geometry, while renewed confidence, awareness and a positive attitude toward geometry constitute the primary affective outcomes.
\end{abstract}

\section{Rationale}

The indisputable lack of adequate foundation in geometry among U.S students is well emphasized in the literature. SDA Pathfinders at the 7-8 (transitional) level are often engaged in activities and functions which require an adequate knowledge of geometry. This project addresses the question of whether a proper foundation in geometry may enhance participants' confidence and competence in the way they carry out assigned duties. It also seeks to address the need to infuse faith issues into the study of geometry in such a way that the discovery of new principles in 
geometry may illuminate their vision of Ultimate Intelligence in the creation of a world filled with design.

\section{Purpose}

The purpose of the G.R.A.C.E. Project was to develop and test an instructional product through active engagement of participants.

\section{Objectives}

Twenty-five clearly stated performances have been organized into five groups. Each group of objectives falls under a main heading which presents core contents to be mastered in one session. Mastery for the GRACE Project is set at $80 \%$ on each of the 25 objectives. Items have been selected based on recommended state (Michigan, Illinois, and Indiana) and national standards for $7^{\text {th }}$ and $8^{\text {th }}$ grade geometry. Recent Focal Points emphases on fewer topics and greater depth have also been considered.

The GRACE Project also presents an integrated learning plan in which instruction is delivered in an atmosphere where learners are encouraged to seek a greater understanding of the Creator of principles and patterns in geometry.

\section{Audience and Pre-requisites}

Individuals are considered eligible to participate in the GRACE Project if they: (1) are members of a local Pathfinder club, (2) are students at the seventh- or eighthgrade-level, who needed help in geometry and (3) currently hold membership in any church of the Lake Union Conference. Success of each participant may be greatly enhanced if he/she has acquired the basic skills taught in geometry between $3^{\text {rd }}$ and $6^{\text {th }}$ grade. Nevertheless, following the pre-test, the instructor will determine the instructional needs of each participant. Willingness to participate actively and cooperatively and complete follow-up assignments appropriately, are some attributes of the participant who is likely to achieve mastery of contents with relative ease.

\section{Description of Subject-matter}

The GRACE Project addresses basic principles, vocabulary and contents which the researcher believes will provide a reasonably good foundation in geometry. These are presented under the following 5 headings: Foundations of Geometry, Geometry All Around Us, Understanding Key Principles in Geometry, Constructing Meaning in Geometry, and Using Geometry to Solve Problems. By implementing a variety of methods and engaging learners in an interactive learning adventure, mastery of content is expected to occur within the $7 \frac{1}{2}$ hours allotted for the instruction. 


\section{Instructional Plan}

The framework for instruction includes the following five components:

1. Negotiate Classroom Climate - The initial instructor-learner interaction is expected to conclude with clear understanding of expectations and resolutions for a productive encounter for the duration specified for the GRACE Project.

2. Pre-instructional Inventory - Participants will be assigned a code for identification. Names are not allowed for the purpose of maintaining anonymity. Responses on the pre-test will provide helpful information regarding their level of competence in geometry as well as their needs and expectations. Seating arrangement will be specified by the test administrator. Participants are required to direct questions only to test coordinator. Test materials will be collected and immediately locked away in a secure file. Findings will be utilized in the delivery of more effective instruction.

3. Selection of Relevant Methods and Materials - A mixed method with emphasis on Problem-Based Learning (PBL) and the constructivist approach will be used throughout the process. Discussion, illustration, demonstration, and cooperative learning will also be implemented as needed. Materials will be selected and made available on the basis of relevance. For example, calculators will be provided for activities requiring calculations. Other basic materials such as scissors, cord, geometry set items, charts and models will be made available to all participants. Additional resources such as overhead projector, computer, and audio visual aids may also be used where necessary.

4. Focus on Mastery of Core Content - First, objectives to be addressed during the session will be clearly articulated by the instructor. Materials needed to facilitate the process will be made available, and the chosen method/s of instruction will be determined. Participants will then be engaged in guided individual or group projects. The instructor will provide support by answering questions, giving illustrations, and doing demonstrations. To conclude the session, each group will engage in answering key questions related to the content learned. Participants will also be required to do verifications, make corrections and collect assignments to be completed for the following session.

A minimum score of $80 \%$ on each of the 25 behavioral objectives is the goal set for each learner. In order to achieve this standard, the cooperative effort of the facilitator; learner, and parents will be sought. For example, review of contents and completion of assigned home activities in preparation for the next session will need the attention of a responsible adult. 
5. Post-instructional Inventory- Established protocol for the administration of post-test will be followed as indicated above for the pre-test. These include seating arrangement, method of distributing, collecting and securing test documents. Special care will be taken in recording test score data in order to comply with the wishes of subjects and their parents.

\section{Other Resources Necessary for Successful Teaching of the Curriculum}

The G.R.A.C.E. Project is intended to provide adequate materials to facilitate participants' mastery of selected geometric concepts. Contents of developer's and participant's manuals are supplemented by relevant charts. Although the GRACE Project is not a technology-based program, participants may find the computer useful for reinforcement activities. As a result, the list of websites below has been recommended:

1. http://mathforum.org/library/drmath/drmath.middle.html

2. http://www.ies.co.jp/math/java/geo/pythasvn/pythasvn.html

3. http://www.ies.co.jp/math/java/geo/congruent.html

4. http://standards.nctm.org/document/chapter6/geom.htm

5. http://www.k111.k12.il.us/King/math.htm\#Geometry/

Continuous assessment will be implemented to familiarize participants with the contents covered during each session. Regular quizzes will be given (both oral and written) followed by discussions for the purpose of providing clarity. All activities including projects are designed to teach worthwhile concepts related to the study of geometry. Discussions will be teacher-led and all projects will be supervised by the instructor or his trained designee. 

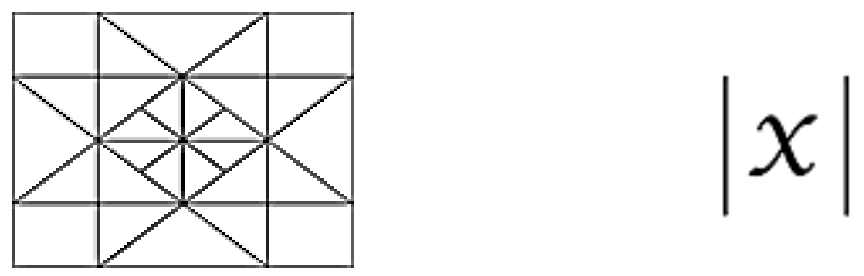

SE S I O N A: FOUNDAT IONS OF GEOMETRY

It all begins with a point. A point marks a position in space but does not indicate a dimension. However a series of points form a line segment which

has a single dimension. Where two line segments meet

an angle is formed. Three line segments can form

the simplest closed shape-a triangle. Plane

shapes are 2-dimensional. Plane shapes

can be used to form beautiful patterns.

However, it takes a third dimension

to form a solid shape. For example,

a rectangle has two dimensions

(length $\mathrm{L}$ and width $\mathrm{W}$ ) but a

rectangular prism has three

dimensions (length $\mathrm{L}$

width $\mathrm{W}$ and height $\mathrm{H}$ ). 
The circle is a unique plane shape. It has circumference, diameter and radius. And the relationship between the length of the diameter and its circumference forms a standard estimated value known as pi.

\section{Multiple Roles of the Instructor/Facilitator}

Duration: 90 minutes

Format: Interactive Group

The instructor arrives 15 minutes before participants to examine the room to ensure that:

- furniture is polished and sanitized with no sharp edges

- lighting is adequate and temperature modest

- the room is uncluttered with adequate space for the size of the group

- materials are relevant, adequate, organized, and accessible to all participants

- charts containing formulas, sample questions and solutions, instructions, and diagrams are conspicuously displayed.

The instructor welcomes participants by acknowledging each on a first-name basis. Participants are already aware of nature of the project as well as the expectations. Nevertheless, the instructor articulates a brief reminder in a positive, affirming tone. The instructors also makes mention of his/her commitment and availability to assist participants in achieving the goals set for this session. 


\section{Administering the Combined Pre-test}

You are expected to remain in your assigned seat during this pre-test. However, you may seek permission if you need to use the restroom, or stretch for a minute or two. Read all instructions carefully before attempting each question. Direct all questions to your facilitator. Do not waste time on questions you know you are unable to answer; instead, put an "N" to indicate you are not able to do it. There is absolutely no penalty for not being able to answer a question. This test is to help us determine how much help you will need to complete the program successfully. Use your assigned code (not your name) to identify your work. If you finish before the time, hand in your test then proceed to work on the puzzle provided. Your test materials will be collected and placed in a secure file at the conclusion of this session. You will begin at and conclude at

\section{Foundations of Geometry: Making Spiritual Connection}

Genesis 1:1 tells us that a Creator brought into existence principles, patterns, shapes and designs. In the same chapter He creates us like Himself. Hence we are intelligent, and (Participants may be asked to assist in completing the above statement). The instructor will conclude that the shapes patterns and principles to be explored should remind us of His wisdom and love for us. The instructor prays to open the sessions. 


\section{Session A: Foundations of Geometry}

This session consists of 6 lessons. Performance is specified as follows:

1. The learner will select correct descriptions for: geometry, Euclidian geometry, and non-Euclidian geometry, given 5 selections/choices.

2. The learner will match ten geometric symbols with their appropriate names.

3. The learner will accurately translate into English a statement expressed in geometric symbols.

4. The learner will correctly use five geometry terms, given descriptions.

5. The learner will prepare fairly accurate sketches of graduated cylinder, triple beam balance, and cylinder.

6. The learner will use definitions of congruency and similarity to write correct statements of equality.

\section{Lesson Outline for First Session}

1. Define geometry, Euclidian geometry, and non-Euclidian geometry.

2. What is the name of the each of ten basic geometric symbols?

3. What is the English equivalent of a statement written in geometric symbols?

4. What are the correct vocabulary words for five basic processes in geometry?

5. What are some essential features of: (a) graduated cylinder (b) cylinder and (c) triple beam balance?

6. Why is $\mathrm{A}+\mathrm{B}=\mathrm{C}$ if $\mathrm{A} \& \mathrm{~B}$ are interior angles of a triangle and $\mathrm{C}$ is its exterior angle? 
OBJECTIVE 1 (6 points): Select correct descriptions for geometry, Euclidean geometry, and non-Euclidean geometry.

Materials: Globe, dictionary excerpt, portrait of Euclid

Method: Discussion

Activity: Participate in discussion, read and answer questions.

Duration: 15/90 minutes

A. GEOMETRY: This word is made up of 2 root words, "geo" which means earth, and "meter" which means measurement. When combined into one word, they literally mean MEASUREMENT OF THE EARTH or simply EARTH MEASUREMENT.

B. EUCLIDIAN GEOMETRY: Euclid was a famous mathematician who focused on plane geometry. A plane is a flat, 2-dimensional surface. He developed several rules that are accepted without question (postulates) and used by students and professionals in solving geometric problems.

C. NON-EUCLIDIAN GEOMETRY: Some famous mathematicians, (example Gauss) focused on geometry that deals with measurements on a non-flat surface. For example, on a sphere parallels do intersect. So one postulate has been changed.

\section{Discussion Questions}

1. What are some terrestrial features that are measured?

2. What name is given to the practice of measuring earth's features, such as rivers, farmlands, and heights of mountains?

3. What term above includes "plane geometry"?

4. Have you gained any new knowledge from this process?

5. What three questions can you answer accurately from this process? 
OBJECTIVE 2: Match ten geometric symbols with their appropriate names.

Materials: Chart, hand-outs

Methods: Peer interview, drills \& practice

Activity: Classify symbols into two groups (known and unknown), verify the known with your peers, then draw and label each unknown symbol three times. Finally, match all symbols accurately as directed.

Duration: 15/90 minutes

For the chart of symbols provided, draw the symbol that corresponds with each name.

\begin{tabular}{|l|l|}
\hline \multicolumn{1}{|c|}{ Name of Geometric Symbol } & Design of Geometric Symbol \\
\hline 1. right angle & \\
\hline 2. congruent & \\
\hline 3. similarity & \\
\hline 4. therefore & \\
\hline 5. greater than or equal to & \\
\hline 6. perpendicular & \\
\hline 7. angle & \\
\hline 8. line AB & \\
\hline 9. line segment AB & \\
\hline 10. degree/s & \\
\hline 11. arc & \\
\hline 12. plane & \\
\hline 13. circumference & \\
\hline 14. pi & \\
\hline
\end{tabular}

\section{Discussion Questions}

1. Why are symbols used in geometry?

2. How may we communicate effectively using the language of geometry?

3. From your perspective, how beneficial is this activity? 
Summary Notes 
OBJECTIVE 3: Accurately translate into English a statement expressed in geometric symbols.

Materials: Chart with geometric symbols, handbook, check list

Methods: Peer coaching, practice drills, demonstration

Activity: Review circle vocabulary example: A, Oce, $r, r^{2}, d,\left(A=\pi \times r^{2}\right),(C=\pi$ $\mathbf{x ~ d})$, etc; then practice at least three simple translations such as $(C=\pi \mathbf{x} d)$ meaning: "Circumference of a circle is approximately equal to $\pi$ times its diameter."

Key: A (area), C or Oce (circumference), $\mathrm{r}$ (radius), $\boldsymbol{r}^{2}$ (radius $\mathrm{x}$ radius), $\mathrm{d}$ (diameter)

$\pi$ (pi -a value that tells how many diameters equals the length of the Oce of the circle)

A. $r^{2}=\mathrm{r} \times \mathrm{r} \operatorname{not} 2 \times \mathrm{r}$

B. $d=r+r=2 \times r$

C. Oce $=\pi \times d$

D. $A=\pi \times r^{2}$

\section{Discussion Questions}

1. What are some motions that form circles?

2. How important is circular motion to travel and industry?

3. Why may junior high students use $\mathrm{pi} \approx 3$ or $\mathrm{pi} \approx 3.14$ ?

4. Can you find in the Bible where 3 is used for an estimate for pi? 
OBJECTIVE 4: Correctly use five geometry terms, given descriptions.

Materials: Manual, chart containing geometric processes

Methods: Discussion, peer review

Activity: Fill in the blank spaces in A then proceed with B, C, D, \& E.

A. Supplementary angles add up to 180 degrees. Half of a circle is a turn of 180 degrees. Therefore the following pairs of angles are supplementary -

$\underline{50 \text { and } 130} \quad \underline{80 \text { and } 100}$

30 and $\underline{\mathbf{1 5 0}}$ (complete) 60 and $\underline{\mathbf{1 2 0}}$ (complete) $\underline{\mathbf{1 1 0}}$ and 70 (complete)

B. Some letters of the alphabet are symmetric while others are not. Look for balance and equality in size on either side of the line of symmetry. Some patterns are symmetric while others are not.

The letter A is symmetric with a vertical line of symmetry.

The letter B is symmetric with a horizontal line of symmetry.

The letter $\mathrm{C}$ is also symmetric with a horizontal line of symmetry.

The letter D is symmetric with a horizontal line of symmetry.

The human body is symmetric with a vertical line of symmetry.

Identify 2 other symmetric patterns, 2 non-symmetric patterns, 5 other symmetric letters, and 5 asymmetric letters. Verify correctness with at least one peer.

C. POSTUlATES are geometric propositions that are accepted (without questions/proof) and used as the basis for developing a logical argument. For example: If $\mathrm{B}$ is between $\mathrm{A}$ and $\mathrm{C}$, then $\mathrm{AB}+\mathrm{BC}=\mathrm{AC}$.

D. Similar shapes have equal corresponding angle measures, but may have different side lengths; for example, the shape of your textbook and that of the chalkboard. Both have 4 right angles.

E. Congruent shapes have both equal corresponding angle measures and equal corresponding side lengths. Note that for triangles if all three corresponding side lengths are equal then the corresponding angle measures must also be equal so the triangles are congruent. This is the Side-Side-Side (SSS) Theorem. 
F. What is the difference between a sector and a segment of a circle? Answer: A sector is shaped like a slice of pie with the two sides of the pie formed by two radii (the point of the pie is the center of the circle). A segment is a piece/section of the circle cut off by a chord (any line between two points on the circle).

\section{(1 point for each correct response)}

\section{Discussion Questions}

1. If an area of study has its own unique vocabulary, then we may conclude that discipline has a LANGUAGE OF ITS OWN (complete). Hint- It allows for communication.

2. Symmetry is a design feature that was originated by whom? GOD 
OBJECTIVE 5: Prepare fairly accurate sketches of graduated cylinder, triple beam balance, and cylinder.

Materials: chart containing sketch diagrams, manual

Methods: observation, imitation, demonstration

Activity: From the trace diagrams completed during introduction, sketch the following items in the space provided below:

Graduated Cylinder Triple Beam Balance

\section{Discussion Questions:}

1. What is the essential difference between a cylinder and a graduated cylinder?

2. What are the main features of a triple beam balance?

3. Which of the above equipment is concerned with mass?

1. Which of the above equipment is concerned with volume?

2. What are some units of volume? Mass? 
OBJECTIVE 6: Use definitions of congruency and similarity to write correct statements of equality.

Materials: charts containing proof samples and manual

Methods: Demonstrations, peer coaching

Activity: Identify corresponding sides of congruent triangles. Then fill in the blank spaces below.

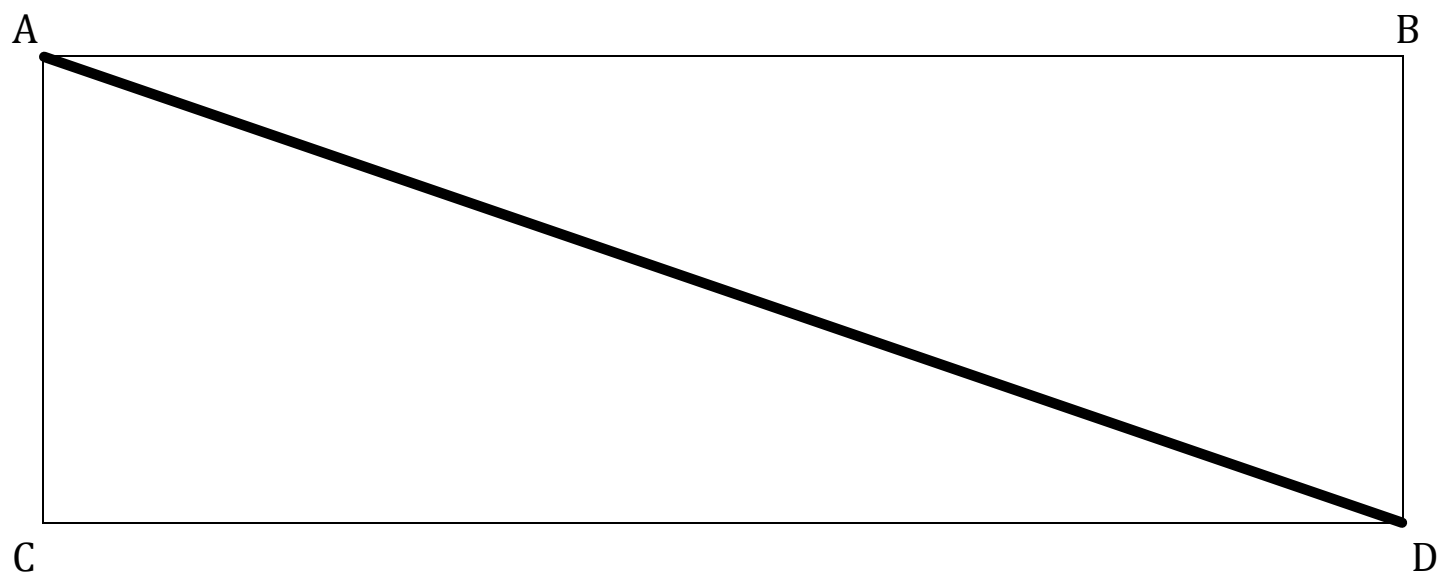

\section{STATEMENTS OF EQUALITY: CONGRUENCY}

$\Delta$ ABD \& $\Delta$ ACD are $\cong$ figures if corresponding sides are exactly the same.

1. $\mathrm{AB}=\mathrm{CD}$

2. $\mathrm{AC}=\mathrm{BD}$

3. $\mathrm{AD}=\mathrm{AD}$

Since all 3 corresponding angles are also congruent, $\Delta$ ABD is similar to $\Delta$ ACD. STATEMENTS OF EQUALITY: SIMILARITY

$\Delta \mathrm{PQR} \& \Delta \mathrm{P}_{1} \mathrm{Q}_{1} \mathrm{R}_{1}$ are similar if their corresponding angles are congruent

1. Angle $\mathrm{P} \cong=$ Angle $\mathrm{P}_{1}$

2. Angle $Q \cong=$.Angle $Q_{1}$

3. Angle $\mathrm{R} \cong=$.Angle $\mathrm{R}_{1}$ 

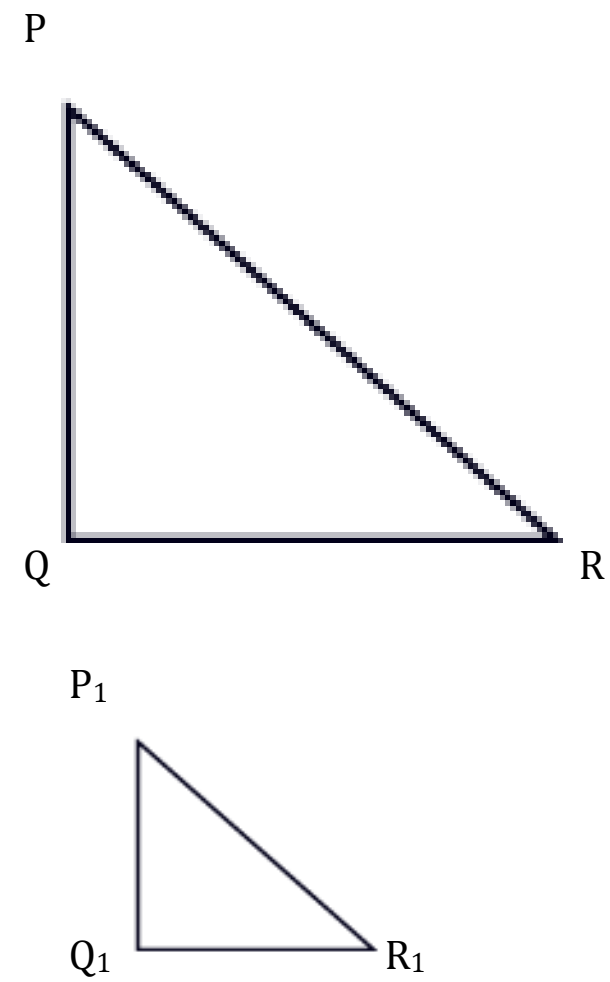

Comparison: Congruent shapes must have the same SHAPE (angles) and SIZE. Similar shapes must have the same SHAPE but may be different sizes.

\section{Discussion Questions:}

1. Is the model of a house congruent to the house?

2. Is the model of the house similar to the house?

3. Identical houses built from the model are congruent. True/False?

4. What does the reflexive property mean? Hint: Examine congruent triangles above.

\section{Note to Participants}

Each concept taught must be given your fullest attention if you plan to score $80 \%$ or better on the post-test. You are also being encouraged to continue participating in all reinforcement activities which are designed to clarify what you have already learned. Practice exercises completed at home will also be helpful. 

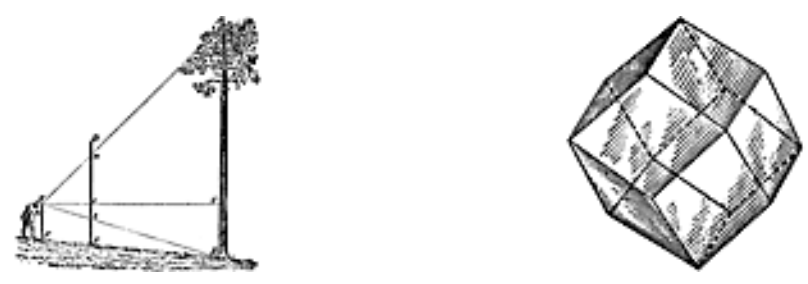

SESSION B: GEOMETRY ALLAROUND US

Reoccurring patterns in nature capture our attention from time to time. For example, the triangle elevation of the pine tree, the bell-shaped design of hills and mountains and the spherical motif of the grapefruit and passion fruit. Points, angles, shapes and designs can be identified not only in nature but also in the architecture. We can learn geometry from general observations but keen attention is needed if we must master important concepts needed to improve our lives. 


\section{Multiple Roles of the Instructor/Facilitator}

Duration: 90 minutes

Format: Interactive Group

The instructor arrives 15 minutes before participants to examine the room to ensure that:

- furniture is polished and sanitized with no sharp edges

- lighting is adequate and temperature modest

- the room is uncluttered with adequate space for the size of the group

- materials are relevant, adequate, organized, and accessible to all participants

- charts containing formulas, sample questions and solutions, instructions, and diagrams are conspicuously displayed

The instructor welcomes participants by acknowledging each on a first-name basis. Participants are already aware of nature of the project as well as the expectations. Nevertheless, the instructor articulates a brief reminder in a positive, affirming tone. The instructor directs a commendation toward each participant then renews his/her commitment and availability to assist participants in achieving the goals set for this session.

\section{Geometry All Around Us: Making a Spiritual Connection}

Psalms 19:6 tells us that evidences of a Creator are revealed by patterns, shapes and designs in the heavens as well as all around us. He created us like Himself. Hence when we study in the heavens and on the earth we are learning more about our

(Participants may be asked to assist in completing the above statement). The instructor will conclude that the shapes patterns and principles to be explored should remind us of His wisdom and love for us. Then prayer is offered.

Welcome to Session B of the G.R.A.C.E. Project where geometry is made simple. 


\section{Session B: Geometry All Around Us}

This session consists of 5 lessons. Performance is specified as follows:

7. The learner will identify five geometric shapes that are visible in nature, given clear descriptions of each.

8. The learner will differentiate basketball and circle (in terms of their unique properties) in 15 words or less.

9. The learner will choose the best estimates of area and perimeter of a trapezium, given four choices.

10. The learner will determine a pair of possible dimensions of a cuboid whose volume is given.

12. The learner will identify a transformation out of six choices, given a diagram of the transformation of a shape in the Cartesian plane.

\section{Lesson Outline for Second Session}

1. What is the name of the shape being described?

2. What is the essential difference between a globe and a circle?

3. Appropriate estimates of area and perimeter of trapezoid.

4. Dimensions of cubes having equal volumes.

5. Describing transformation as observed. 
OBJECTIVE 7: Identify five geometric shapes that are visible in nature, given clear descriptions.

Materials: Chart containing descriptions, manual

Methods: Discussion, peer sharing

The Master Designer has included a variety of geometric shapes in nature. For a-e name the shape described:

A. The general plan of the pine trees circle

B. The general elevation of the pine tree triangle

C. Shape of each cell of the honeycomb hexagon

D. General shape of the trunk of a tree cylinder

E. Shape of a grapefruit/orange sphere

\section{Discussion Questions}

1. How many items did you get correct?

2. Who is the originator of geometric patterns and designs?

OBJECTIVE 8: Differentiate between basketball and circle (in terms of their unique properties) in 15 words or less.

Materials: chart containing sphere and circle peculiarities

Methods: observation, discussion, cooperative learning

Activity: Prepare t-chart with list of similarities and differences between both shapes, then state in 15 words or less the difference between the shapes.

Hint: Focus on classification and properties of each. 


\section{Comparing and Contrasting the Sphere and the Circle}

\begin{tabular}{l|l}
\multicolumn{1}{c|}{ SIMILARITIES } & DIFFERENCES \\
\hline 1. Both are round & \\
2. Both are geometric shapes & \\
3. & \\
4. & \\
5. &
\end{tabular}

\section{Discussion Questions}

1. How are cylinders, cones and cubes similar?

2. How are triangles, rectangles and trapezoids similar?

3. Containers have capacity/volume.

4. But, plane figures have only 2 dimensions

5. What are examples of approximate spheres?

6. What are examples of approximate circles?

OBJECTIVE 9: Choose best estimates of area and perimeter of a trapezium, given four choices.

Materials: manual, chart containing formulas of plane shapes

Methods: Peer sharing, drills \& practice

Activity: Find area and perimeter of the trapezoid below, given that $\mathrm{b} 1=$ $8 \mathrm{~cm}, \mathrm{~b} 2=10 \mathrm{~cm}$, and $\mathrm{h}=6 \mathrm{~cm}, \mathrm{SI}=9 \mathrm{~cm} \& \mathrm{~S} 2=7 \mathrm{~cm}$. Work with a group member then compare answers before showing it to the facilitator. 


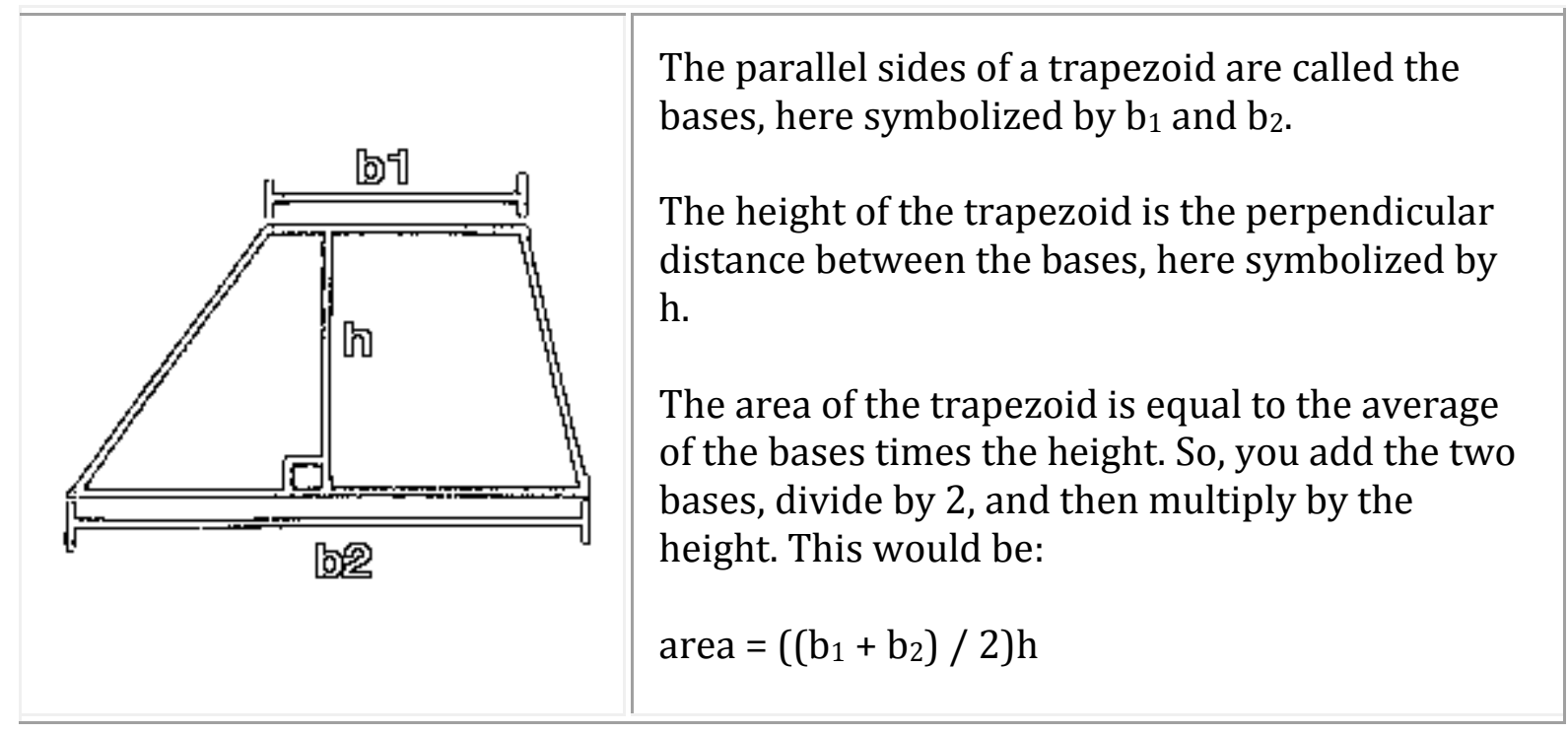

\section{Discussion Questions:}

1. Instead of the number 6 , the value could be 5.97 or 6.02 . How would this change things? Why?

2. What pair of values could have been assigned for 8 and 10 ?

3. Which formulas were used in this activity?

4. Can you explain why those two formulas work?

OBJECTIVE 10: Determine a pair of possible dimensions of a cuboid whose volume is given.

Materials: manual, model of cuboid, ruler

Methods: observation, demonstration, hands-on

Activity: Measure and record length, width \& height of cuboid in $\mathrm{cm} /$ inch. Multiply all 3 lengths to get volume in cubic centimeters or cubic inches. Then complete the following statements below with at least one group member.

A cuboid is a box-shaped object. It has six flat

sides and all angles are right angles. 
And all of its faces are rectangles.

It is also a prism because it has the same cross-section along a length. In fact it is a rectangular prism.

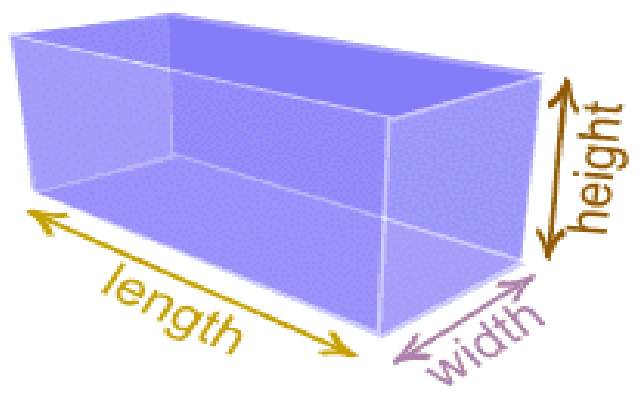

1. The volume of a cuboid is 200 cubic centimeters. Which of the dimension sets below are possible?
A. $\mathrm{L}=\mathbf{1 0} \mathrm{cm}$
$\mathrm{W}=5 \mathrm{~cm} \quad \mathrm{H}=\mathbf{4} \mathrm{cm}$
B. $L=4 \mathbf{c m}$
$W=10 \mathrm{~cm} \quad H=5 \mathrm{~cm}$
C. $\mathrm{L}=80 \mathrm{~cm}$
$W=50 \mathrm{~cm} \quad \mathrm{H}=70 \mathrm{~cm}$
D. $\mathrm{L}=20 \mathrm{~cm}$
$\mathrm{W}=5 \mathrm{~cm} \quad \mathrm{H}=\mathbf{2} \mathrm{cm}$

\section{Discussion Questions}

1. Is a cuboid regular or irregular? Why?

2. A synonym for "number of cubes that fits within a given space" is?

3. What are two other metric units of volume? and 
OBJECTIVE 11: Identify transformation out of six choices, given a diagram of the transformation of a shape in the Cartesian plane.

Materials: manual, grid sheets, chalkboard

Methods: Discussion, demonstration, hands-on

Activity: Show that a double translation has occurred.

\begin{tabular}{|l|l|l|l|l|l|l|l|l|l|l|}
\hline & & & & & & & & & & \\
\hline & & & & & & & & & & \\
\hline & & & & & & & & & & \\
\hline
\end{tabular}

\section{Discussion Questions}

1. What do you notice about KI and K2?

2. What two routes are likely for this transformation?

3. In what other ways are images transformed? 

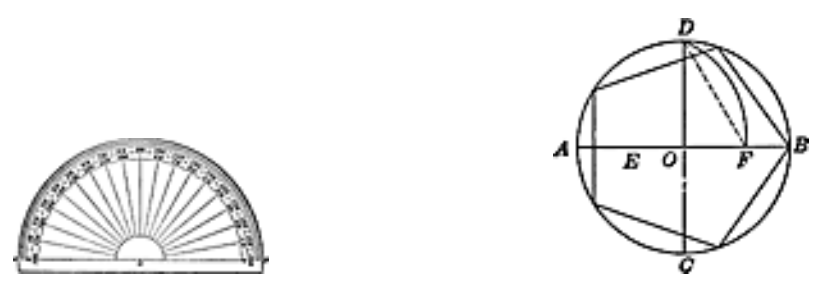

\title{
SES S I N C: UNDERST AND ING KEY PR INCIPLES IN
} G E O M E T R Y

\author{
Many geometric principles are based on observations. For example a \\ reflection of a pre-image is identical to the pre-image. $0 r$, \\ half of a revolution equals 180 degrees, since \\ a complete turn covers a distance \\ of 360 degrees.
}




\section{Multiple Roles of the Instructor/Facilitator}

Duration: 90 minutes

Format: Interactive group

The instructor arrives 15 minutes before participants to examine the room to ensure that:

1. Furniture is polished and sanitized with no sharp edges.

2. Lighting is adequate and temperature modest.

3. The room is uncluttered with adequate space for the size of the group.

4. Materials are relevant, adequate, organized, and accessible to all participants.

5. Charts containing formulas, sample questions and solutions, instructions, and

6. Diagrams are conspicuously displayed.

The instructor welcomes participants by acknowledging each on a first-name basis. Participants are already aware of nature of the project as well as the expectations. Nevertheless, the instructor articulates a brief reminder in a positive, affirming tone. The instructor directs a commendation toward each participant with specific reference to his/her progress during the previous session then renews his/her commitment and availability to assist participants in achieving the goals set for this session. Instructor exudes much enthusiasm.

\section{Understanding Key Principles in Geometry: Making a Spiritual Connection}

1 Kings Chapter 6 tells us that our Creator is able to enhance our knowledge of principles patterns, shapes and designs in geometry. He created us like Himself. Hence, when we study how He gave clear and imparted for the building

of His , we know for sure that we can depend on Him to help us build characters for eternity. Ask learner to assist in completing the above statement/s. The instructor concludes that the shapes patterns and principles to be explored should remind us of His wisdom. and love for us. The instructor/participant prays to open sessions. 


\section{Session C: Understanding Key Principles in Geometry}

This session consists of 5 lessons. Performance is specified as follows:

12. The learner will determine equivalent estimates of pi by comparing diameter and circumference of a circle.

13. The learner will write true statements leading to the conclusion that for any triangle $\mathrm{RPQ}$, the sum of the interior angles equals the exterior angle.

14. The learner will answer six questions related to the formula " $\mathrm{D}=\mathrm{m} / \mathrm{v}$ " correctly.

15. The learner will apply the Pythagorean Theorem by selecting the appropriate anchor position of the rope, when a pole is erected at 90 degrees with the ground, given a diagram showing the various positions and the rope.

16. The learner will explain in five steps how to determine perimeter of an irregular plane shape with a string and ruler. 


\section{Lesson Outline for Third Session}

1. What are the equivalent mixed and improper fractional estimates of pi?

2. Why is the sum of interior angles of a triangle equal to its exterior angle?

3. What are the components of density?

4. How does Pythagoras' theorem function?

5. How is the perimeter of an irregular shape determined?

OBJECTIVE 12: Determine equivalent estimates of pi by comparing diameter and circumference of a circle.

Materials: manual, chart containing pi, cord, scissors, ruler

Methods: Hands-on demonstration, discussion, peer sharing

Activity: Use the cord to form a circle with its diameter. Extend the circumference and compare it with diameter to see the relationship. Record the estimated number of times longer than its diameter is the length of the circumference.

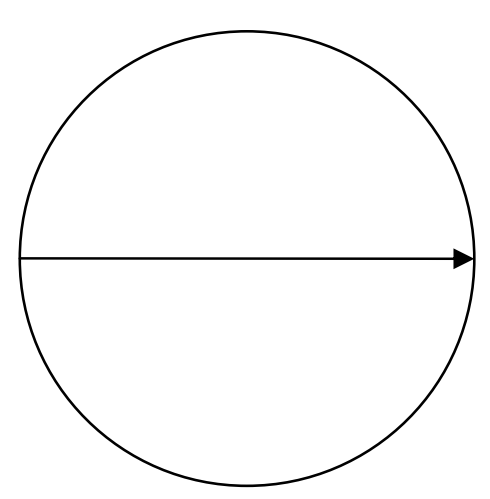

Label the circle with: radius, chord, circumference, and diameter, then respond to the questions below.

\section{Discussion Questions}

1. Is pi a ratio, fraction or both?

2. What is a mixed fractional estimate of pi?

3. What is a decimal approximation of pi?

4. What is an improper fraction estimate of pi? 
5. Why is it ok for younger learners to use 3 as an estimate for pi?

6. Is the definition of pi abundantly clear to you now?

OBJECTIVE 13: Write true statements leading to the conclusion that for any triangle $\mathrm{RPQ}$, the sum of the interior angles equals the exterior angle.

Materials: manual, chart containing samples of proof

Methods: discussion, exposition, peer sharing, hand-outs

Activity: Identify what is given that helps you develop your argument. Find the $3^{\text {rd }}$ angle of the triangle, then draw conclusion regarding equality.

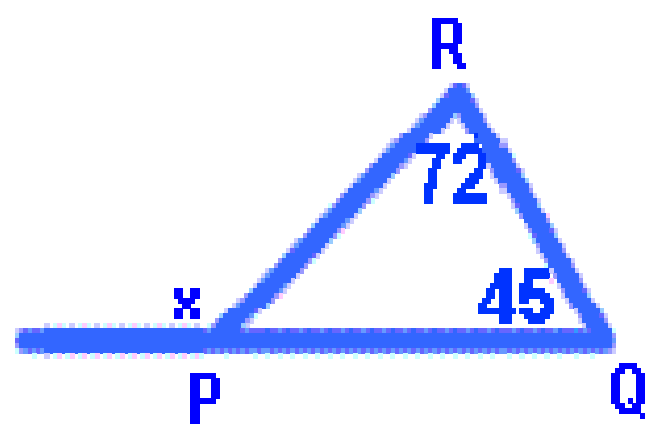

\section{For any $\triangle P R Q$}

- $m \angle \mathrm{P}+m \angle R+m \angle Q=180$

- $m \angle R+m \angle Q=180-m \angle \mathrm{P}$

- $m \angle P+m \angle X=180$

- $m \angle X=180-m \angle P$

- So, $m<X=m<R+m<Q$

- Thus,,$m \angle X=72+45=117$

How may we determine the value of the unmarked angle inside of the triangle? What is the relationship between the unmarked angle inside of the triangle and angle X? Would this process always work? Try to write out the general steps of this process.

\section{Discussion Questions}

1. Why is the difference between inductive and deductive reasoning?

2. Where was each type of reasoning used above?

3. Can statements be proved by inductive reasoning? 
4. How would you rate this introduction to proof in geometry? (easy, difficult, challenging, manageable)

OBJECTIVE 14: Answer six questions related to " $\mathrm{D}=\mathrm{M} / \mathrm{V}$ " correctly.

Materials: a rectangular block of wood, manual, ruler, calculator

Methods: Cooperative learning, hands-on, discussion

Activity: Discuss procedure for finding density. Assign part of the task to different group members; then finalize the answers.

A cylindrical block measures 360 units on a triple beam balance, if its base area and height are 9 and $8 \mathrm{~cm}$, calculate its density then answer the questions below.

1. What is the appropriate unit for base area?

2. What is the correct formula for density?

3. What formula was most likely used to calculate the base area?

4. Which value represents the density?

5. The ratio unit used to express density is?

6. Explain "E" completely.

\section{Discussion Questions}

1. Which material has the lower density, sponge or wood?

2. Is density related to weight? Mass? Or both? 
OBJECTIVE 15: Apply the Pythagorean Theorem by selecting the appropriate anchor position of the rope when a pole is erected at 90 degrees with the ground, given a diagram showing the various positions and the rope.

Materials: chart containing Pythagoras' theorem, manual, grid containing diagram, string or cord, measuring tape, table of values based on PT

Methods: Outdoor demonstration, hands-on, observation, discussion

Activity: Based on the 3-4-5 relationship established by Pythagoras, adjust the slant line (when stretched at 5 unit lengths) so that it is positioned correctly, given that the horizontal axis uses the same scale as the vertical axis.

A. Position \#2

B. Position \#4

C. Position \#6

D. Between positions \#4 \& \#6

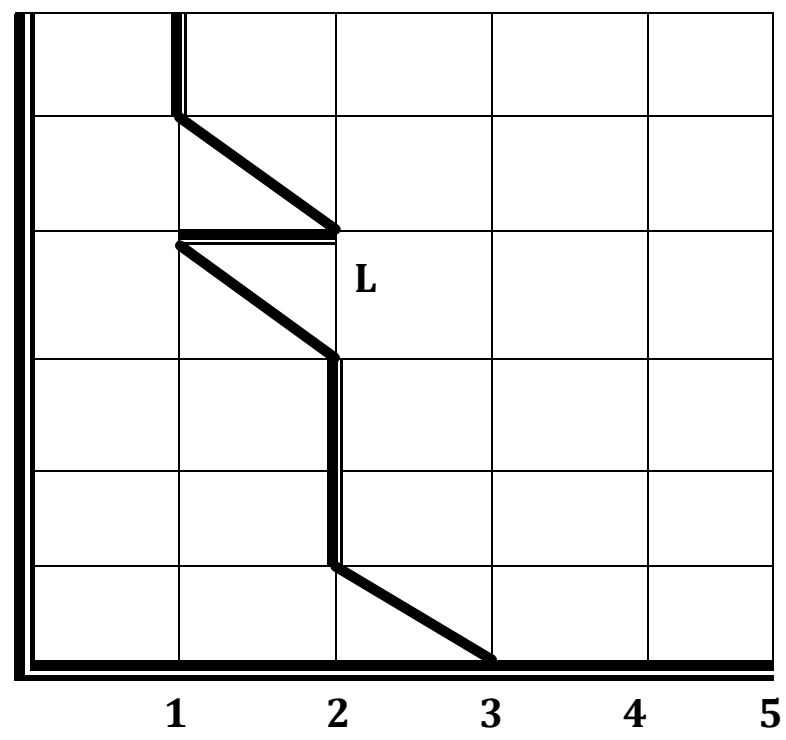

\section{Discussion Question}

1. What are the 3 related equations that make up the Pythagoras' theorem?

2. The square root of 30 falls between which two whole numbers?

3. Do you find the application of this theorem easy, ok, difficult or impossible?

4. Why do you think this theorem is so important in architecture?

5. Why do you consider it important to be learned in middle school? 
6. Is the concept easy, difficult, ok, or too difficult?

OBJECTIVE 16: Explain in five steps how to determine the perimeter of an irregular plane shape with a string and ruler.

Materials: manual, cord, trace diagram of the shape, marker, ruler

Methods: Hands-on, demonstration, discussion, observation

Activity: Place cord exactly over the irregular diagram. Mark where the cord meets the initial end. Remove and measure the cord; then, record the measurement as perimeter of the shape in centimeters or inches.

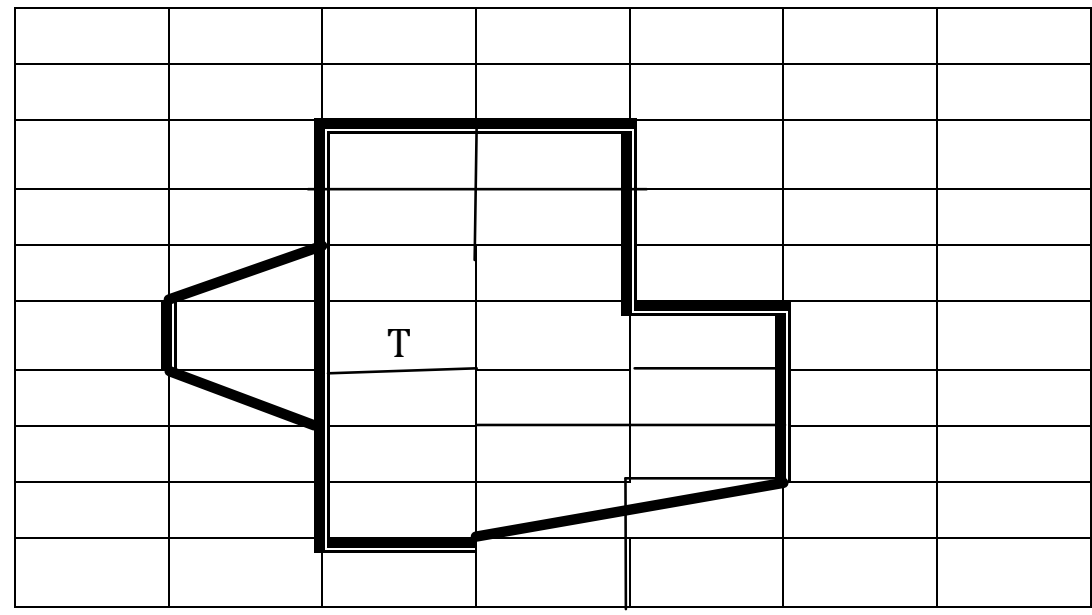

\section{Discussion Questions}

1. What are 2 examples of regular shapes?

2. Can you repeat at least 4 steps in finding perimeter of irregular shapes?

3. Should you stretch the string tightly against the ruler when measuring it? Did you stretch it that tightly when following the shape?

4. For the shape "T" above, which line segment is not included in perimeter?

5. Why was it not included?

6. Why is a ruler needed for perimeter of irregular shapes? 

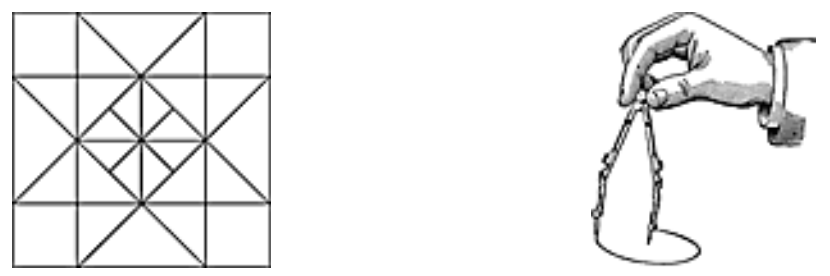

SESSION D: CONSTRUCTING MEANING IN GEOMETRY

We may design our own patterns and structures in geometry. This is known as creativity. Or, we may imitate the creative works of others.

Whenever we engage in meaningful activities

that enrich our experiences and improve

the quality of our lives we are

experiencing the benefits

of geometry. 


\section{Multiple Roles of the Instructor/Facilitator}

Duration: 90 minutes

Format: Interactive Group

The instructor arrives 15 minutes before participants to examine the room to ensure that:

- furniture is polished and sanitized with no sharp edges

- lighting is adequate and temperature modest

- the room is uncluttered with adequate space for the size of the group

- materials are relevant, adequate, organized, and accessible to all participants

- charts containing formulas, sample questions and solutions, instructions,

- and diagrams are conspicuously displayed.

The instructor welcomes participants by acknowledging each on a first-name basis. Participants are already aware of nature of the project as well as the expectations. Nevertheless, the instructor articulates a brief reminder in a positive, affirming tone. The instructors also makes mention of his/her commitment and availability to assist participant $\mathrm{s}$ in achieving the goals set for this session.

\section{Constructing Meaning in Geometry: Making a Spiritual Connection}

Psalms 127:1 tells us that our Creator wants us to build with Him so that our work may not be in vain. True meaning of our work comes only as becomes (Participants may be asked to assist in completing the above statement). The instructor will conclude that when we include God in our projects we become partners with Him and He delights to use our talents for the up-building of His cause. The instructor/participant volunteer prays to open the sessions. 


\section{Session D: Constructing Meaning in Geometry}

This session consists of 5 lessons. Performance is clearly specified as follows:

17. The learner will create a tessellation with exactly 20 congruent patterns.

18. The learner will rearrange segments of a design to create a new symmetric pattern.

19. The learner will position an image to show the effect of transformations by reflection through $x$ and $y$ axes.

20. The learner will classify coordinates in their appropriate quadrants or axis category.

21. The learner will sketch a net for a cylinder, given a model and scale factor.

\section{Lesson Outline for Third Session}

1. What are tessellations?

2. What are congruent, symmetric patterns?

3. What constitutes transformation by reflection?

4. How many coordinate positions exist?

5. How to use a model in construction 
OBJECTIVES 17 \&18: Create a tessellation. Create a symmetric pattern.

Materials: Charts showing various designs - standard and adjusted

Methods: observation, demonstration, discussion, personalized activity

Activity: Examine samples then create a design of your choice and at least two adjusted patterns. The adjusted patterns must be symmetric (See charts with patterns.)

Personalized Tessellation:

Adjusted Symmetric Pattern 1:

Adjusted Symmetric Pattern 2:

\section{Discussion Questions}

1. Where may we find tessellations?

2. Where may we find symmetric patterns?

3. What do patterns do for us?

4. How do you feel after creating a really "cool" pattern?

5. What name is given to a pattern created an arrangement of stars in the heavens? 
OBJECTIVE 19: Position an image to show the effect of transformations by reflection through the $x$ and $y$ axes.

Materials: grid, manual, pencil/pen

Methods: demonstration

Activity: Show the position 1 and position 2 of the shape that has been transformed by reflection through the $x$-axis and $y$-axis respectively.

\begin{tabular}{|l|l|l|l|l|l||l|l|l|l|l|l|}
\hline & & & & & & & & & & & \\
\hline
\end{tabular}

\section{Discussion Question}

1. Is reflection a form of transformation?

2. Are reflected images similar?

3. Are reflected images congruent?

4. If a pre-image is 4 steps from the reflection axis, how many steps should the image be from the axis?

5. Was this activity difficult, easy, ok, too easy, or almost impossible? 
OBJECTIVE 20: Classify coordinates in their correct quadrant or axis category.

Materials: manual, chart containing quadrants and axes clearly labeled

Methods: observation, discussion, group and individual responses

Activity: First, number the axes then describe characteristics of coordinates based on where they belong. For example: $(0,0)$ belongs in the origin and $(4$, 5 ) belongs to Q1. For each group of coordinates below, indicate whether it is:

Pos X, Pos Y, Neg X, Neg Y, QI, QII, QIII, or QIV.
1. $(-2,-4),(-4,-5),(-6,-1)$
2. $(3,3),(5,8),(2,9)$
3. $(-3,0),(-6,0),(-9,0)$
4. $(5,0),(25,0),(9,0)$
5. $(0,3),(0,8),(0,4)$
6. $(0,-2),(0,-8),(0,-5)$
7. $(-2,2),(-8,7),(-3,7)$
8. $(8,-2),(6,-5),(3,-6)$

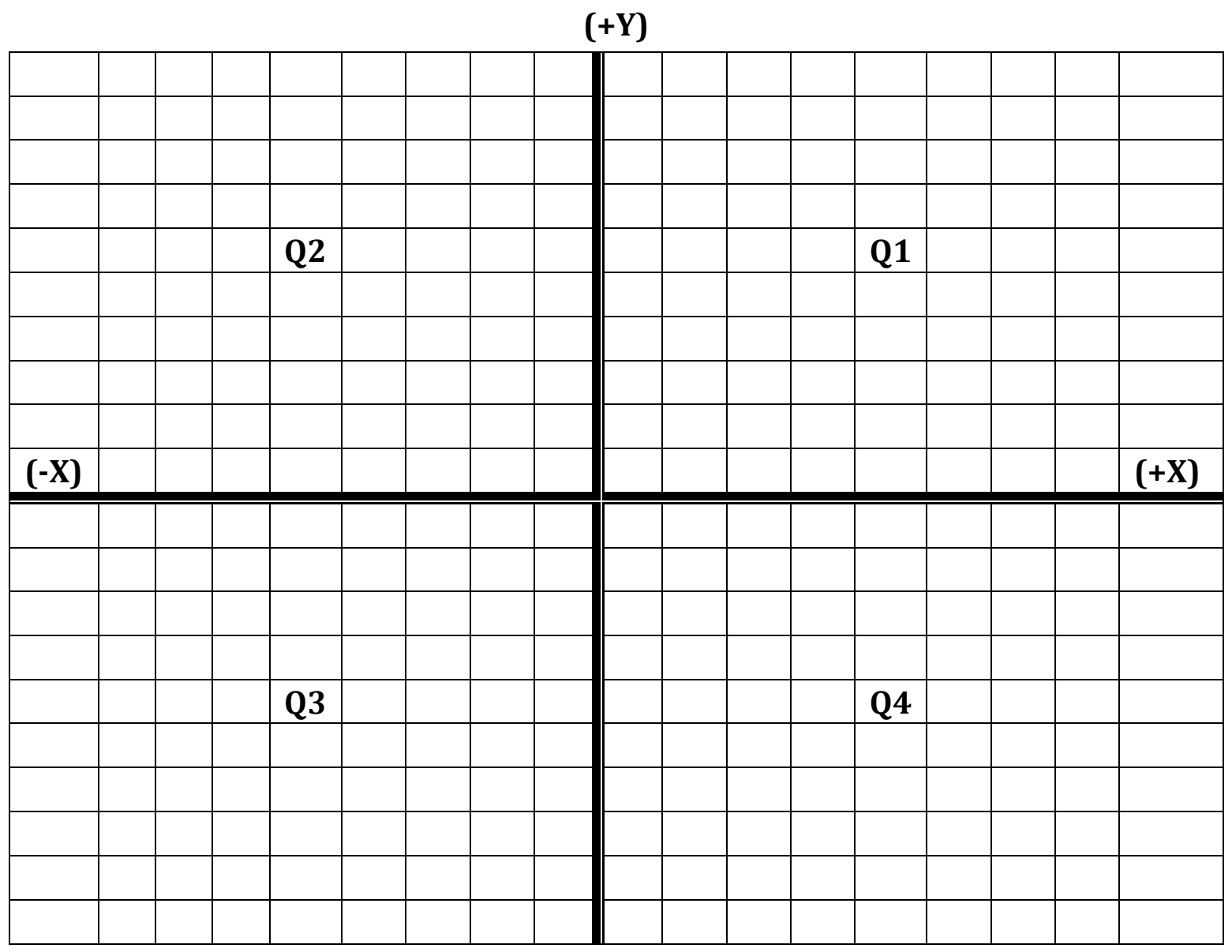




\section{Discussion Questions}

1. What name is given to a system of intersecting lines and a pair of numbered axes?

2. Can you identify the positive only region? The negative only region?

3. Where does the $(0,0)$ position fall?

4. Which position do you find difficult to identify?

5. What does each intersection represent?

6. Without looking at the Cartesian plane, can you tell the quadrant or axis category for each coordinate pair below?

$(-2,-4),(2,4),(2,-4),(-2,4), \&(0,4) \&(2,0)$ 
OBJECTIVE 21: Sketch a net for a similar cylinder, given scale factor and model

Materials: Paper, scissors, ruler, manual

Methods: Hands-on, demonstration, discussion, PBL

Activity: Measure circumference and height of the model then use a scale factor of 3 to construct a similar solid.

$\mathbf{3}$ columns $\& \mathbf{5}$ rows

\begin{tabular}{|l|l|l|}
\hline & & \\
\hline & & \\
\hline & & \\
\hline & & \\
\hline & & \\
\hline
\end{tabular}

$\mathbf{3} \mathbf{3}=9$ columns $\& \mathbf{5} \times \mathbf{3}=15$ rows

\begin{tabular}{|l|l|l|l|l|l|l|l|l|}
\hline & & & & & & & & \\
\hline & & & & & & & & \\
\hline & & & & & & & & \\
\hline & & & & & & & & \\
\hline & & & & & & & & \\
\hline & & & & & & & & \\
\hline & & & & & & & & \\
\hline & & & & & & & & \\
\hline & & & & & & & & \\
\hline & & & & & & & & \\
\hline & & & & & & & & \\
\hline
\end{tabular}

( 3 points for correct interpretation of scale factor; 3 points for sketch having correct proportions)

\section{Discussion Questions}

1. Is the curved surface area of a cylinder a rectangle?

2. How many times larger than the model is the cylinder?

3. How were you able to tell?

4. Does the plan create an open or closed cylinder?

5. Is this activity difficult, easy, ok, too easy, or almost impossible? 

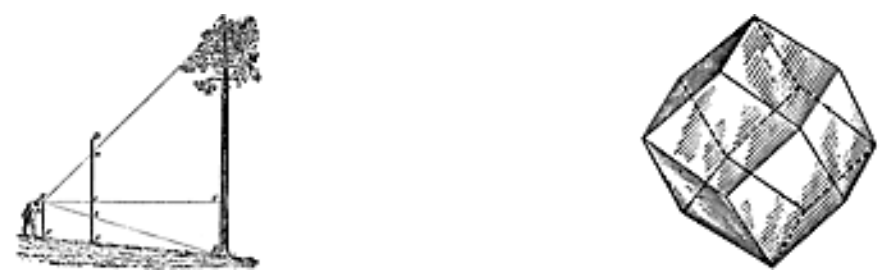

SESSION E: USING GE M T TRY TO SOLVE PROBLEMS

If Pathfinders need to purchase tiles to cover a $100 \mathrm{ft} x \mathbf{7 5 f t}$ surface they first of all need to determine the cost in the form of a reasonable estimate.

If the center pole of the tent is not vertical, they need

to find a way to correct the problem. And if

they need to construct a storage with a

capacity of 120000 cubic feet, they

really have some groundwork to

do. The above are practical

problems that an

understanding

of geometric

concepts

may help

resolve. 


\section{Multiple Roles of the Instructor/Facilitator}

Duration: 90 minutes

Format: Interactive Group

The instructor arrives 15 minutes before participants to examine the room to ensure that:

- furniture is polished and sanitized with no sharp edges

- lighting is adequate and temperature modest

- the room is uncluttered with adequate space for the size of the group

- materials are relevant, adequate, organized, and accessible to all participants

- charts containing formulas, sample questions and solutions, instructions, and diagrams are conspicuously displayed.

The instructor welcomes participants by acknowledging each on a first-name basis. Participants are already aware of nature of the project as well as the expectations. Nevertheless, the instructor articulates a brief reminder in a positive, affirming tone. The instructors also makes mention of his/her commitment and availability to assist participant $s$ in achieving the goals set for this session.

\section{Using Geometry to Solve Problems: Making Spiritual Connection}

Genesis 6:9 God specifies dimensions for the building of an Ark. He also imparts wisdom and courage to His servant Noah who used his knowledge of geometry to please God. We may also seek to God who is ready and willing

to knowledge to us. (Participants may be asked to assist in completing the above statement). The instructor will conclude that God is able to help us learn principles and skills that we may use in His service. Instructor or volunteer prays to open the sessions. 


\section{Section E: Using Geometry to Solve Problems}

This session consists of 5 lessons. Performance is specified as follows-

\section{The learner will:}

22. The learner will apply the proportion principle in calculating total investment and expected yield per hectare.

23. The learner will calculate the number of boxes of tiles needed to tile a parallelogram, given job description.

24. The learner will give a rationale for their selected travel route, given a written scenario.

25. The learner will explain in five steps how to determine the volume of an irregular solid, using a graduated cylinder.

\section{Course Outline}

1. Making table of values based on stated criterion

2. Using calculator for accurate calculations.

3. Using creative judgment in decision making

4. Finding volume of irregular solid 
OBJECTIVE 22: Apply the proportion principle in calculating total investment and expected yield per hectare.

Materials: manual, calculator

Methods: PBL, peer review, discussion

Activity: Complete a table based on information given. Use appropriate estimates rather than exact values (use calculator to verify the relative accuracy of your answer).

Fact Needed: 1 hectare $=10000$ square meters

A 10 meter by 10 meter rectangular garden yields $50 \mathrm{lb}$ of soy beans with application of five - $\$ 3.97$ bags of fertilizer. At the same rate, estimate the dollar amount of investment and expected yield respectively that could be expected from a 1 - hectare plot?
A. $\$ 700.00 / 4000 \mathrm{lb}$
B. $\$ 2000.00 / 5000 \mathrm{lb}$
C. $\$ 400.00 / 5000 \mathrm{lb}$
D. $\$ 700.00 / 6000 \mathrm{lb}$
F. $\$ 500.00 / 7000 \mathrm{lb}$

\begin{tabular}{|l|l|l|}
\hline & Original & X 100 \\
\hline Area & $\underline{\mathbf{1 0 0} \text { sq meter }}$ & $\underline{\mathbf{1 0 0 0 0} \text { sq meter }}$ \\
\hline Yield & $\underline{\mathbf{8 0 ~ \mathbf { ~ l b }}}$ & $\underline{\mathbf{8 0 0 0 l b}}$ \\
\hline Fertilizer Cost & $\underline{\mathbf{\$ 1 5 . 0 0}}$ & $\underline{\mathbf{1 5 0 0 . 0 0}}$ \\
\hline
\end{tabular}

\section{Discussion Questions}

1. One hectare is equal to how many square meters?

2. The original garden was how many square meters?

3. How many 100 s can you get from 10000 ?

4. A proper estimate of $\$ 2.97$ is $\$ 2.00$. True/false?

5. What is an estimate of the cost of fertilizer for the $10 \times 10$ meter garden?

6. How many 50 sq. meters are there in 1 hectare?

7. What is the scale factor linking 5 and 20 ? 8 and 24 ? 50 and 10000 ?

8. Is this problem difficult, easy, ok, or impossible? 
OBJECTIVE 23: Calculate number of boxes of tiles needed to tile a parallelogram, given a job description.

Materials: calculator, manual, pencil/pen, eraser

Methods: PBL, discussion, peer review.

Activity: Read scenario carefully. Determine formula, shape and or procedure involved. Given that a flat area of ground to be tiled is shaped like a //gram, how many boxes containing 12 one-foot-square tiles would you purchase for the job if its dimensions are as follows: base $=18$ feet, height $=9$ feet, and slant side $=10$ feet?

Solution Steps: 1. Sketch the shape indicated and put in all dimensions.

2. Calculate total \# of tiles needed for the complete job.

3. Divide by the number of tiles in each box.

4. Give a justifiable estimate.

\section{Discussion Questions}

1. What does a //gram look like?

2. Is a rectangle a // gram?

3. Is a square a //gram?

4. Is a triangle a //gram?

5. What formula is used to find the area of a //gram?

6. Can you explain why this formula works?

7. Is the length of the slant side needed to find area?

8. How could you use the Pythagorean theorem and a bit of work to find the area?

9. Do you like the formula better?

10. Will you have to cut any tiles?

11. Will you have left over tiles after the job is completed? 
OBJECTIVE 24: Give a rationale for their selected travel route, given a written scenario.

Materials: manual, chart with diagram and scenario

Methods: Cooperative learning, discussion, perspectives

Activity: Select Route AC or A--B--C then list 2 reasons why you would make that choice

Scenario: Hikers are encouraged to conserve on energy and time. It is known that path $\mathrm{AC}$ is mountainous; but path $\mathrm{AB}$ and $\mathrm{BC}$ are coastal areas. Imagine that you are a Master Guide; which route would you recommend? Provide your rationale in 30 words or less.

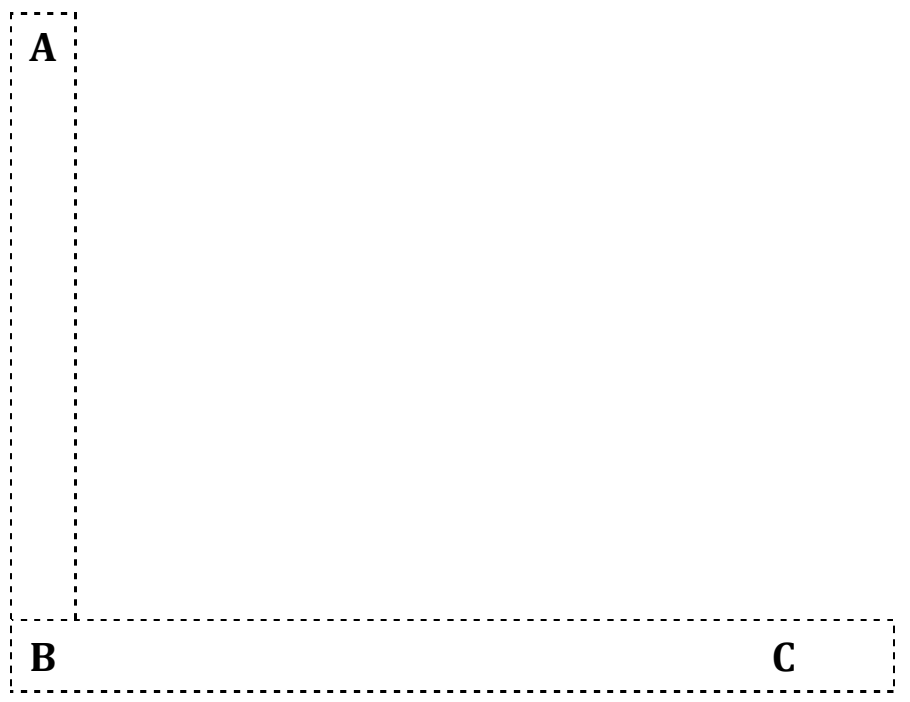

Possible Response \#1:

I would choose A ----- B ----- C because coastal areas are usually flat and requires less energy for travel. It is a longer route but allows for faster travel which conserves on time.

Possible Response \#2:

OR: I would choose route A-C because it is a shorter route, and Pathfinders are trained to overcome obstacles rather to avoid them.

\section{Discussion Questions}

1. What could be the consequence of a bad judgment?

2. Does geometry always involve calculations?

3. What calculation or information could be helpful in making this decision?

4. Is the question vague or clear enough? 
OBJECTIVE 25: Explain in five steps how to determine the volume of an irregular solid using a graduated cylinder.

Materials: water, graduated cylinder, string, or cord, irregular object (small stone)

Methods: Hands-on, demonstration

\section{Activity:}

Step1: Pour liquid in graduated cylinder and record first liquid volume.

Step2: Submerge irregular object into liquid in graduated cylinder.

Step 3: Record second liquid volume.

Step 4: Subtract first liquid volume reading from second liquid volume reading to get volume of irregular solid.

Step 5: Verify and record correct volume of the irregular object

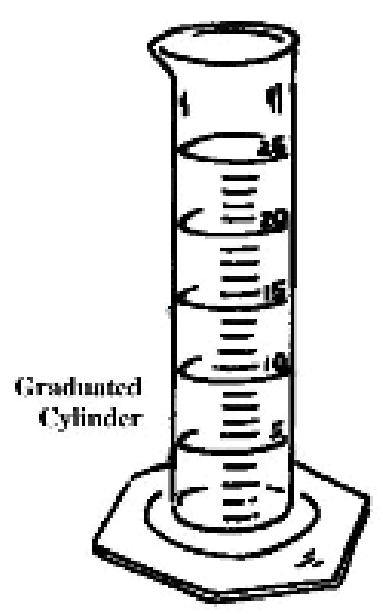

\section{Discussion Questions}

1. What are 2 examples of regular solids?

2. What are 2 examples of irregular solids?

3. What is the difference between a regular and a graduated cylinder?

4. Can you repeat the 5 steps demonstrated above?

5. Why did we use the cord or string?

6. Is $1 \mathrm{ml}$ equal to $1 \mathrm{cubic} \mathrm{cm}$ ? Yes/no 
REFERENCE LIST 


\section{REFERENCE LIST}

Akker, J. V. D., Gravemeijer, K., McKenny, S., \& Nieveen, N. (2007). Educational design research. New York: Routledge.

Akker, J. J. H. van den. (2003). Curriculum perspectives: An introduction. In J. van den Akker, W. Kuiper, \& U. Hameyer (Eds.), Curriculum landscape and trends (pp. 1-10). Dordrecht: Kluwer Academic Publishers.

American Association for the Advancement of Science. (1993). The benchmark online nature of mathematics. Retrieved July 4, 2006, from http://www.project2061.org/publications-RESOURC

American Youth Policy Forum. (2004, April 20). Outcomes for children and youth in the out-of-school time: What the evidence says. Retrieved November 23, 2005, from http://www.aypf.org/forumbriefs/2004/fbo43004.htm

American Youth Policy Forum. (2006). Helping youth succeed through out-of-school time programs. Retrieved June 10, 2006, from http://www.aypf.org/publications/HelpingYouthOST2006.pdf

Anderson, J. (2004). Curriculum design and assessment (Syllabus: EDCI552). Berrien Springs, MI: Andrews University, School of Education.

Anderson, L. W., Krathwohl, D. R., Airasian, P. W., Cruikshank, K. A., Mayer, R. E., \& Pintrich, P. R. (Eds.). (2001). A taxonomy for learning, teaching, and assessing: A revision of Bloom's taxonomy of educational objectives. New York: Longman.

Anderson-Butcher, D., Newsome, W. S., \& Ferrari, T. M. (2003). Participation in Boy's and Girl's Clubs and relationships to youth outcomes. Journal of Community Psychology, 31(1), 39-55.

Apple, M. W., \& King, N. R. (1977). What do schools teaching. In A. Molnar \& J. A. Zahorik, (Eds.), Curriculum theory (pp. 108-126). Washington, DC: Association for Supervision \& Curriculum Development.

Association for the Advancement of Health Education. (1994). Cultural awareness and sensitivity: Guidelines for health educators. Reston, VA: Author.

Bailey, R. A. (1997). The empirical development of an instructional product designed to enhance the cognitive awareness of and the modification of effect toward the disability condition. Unpublished doctoral dissertation, Andrews University, Berrien Springs, MI.

Baker, R. L., \& Schutz, R. E. (1971). Instructional product development. New York: Van Nostrand Reinhold. 
Baldi, S., Jin, Y., Skemer, M., Green, P. J., Herget, D., \& Xi, H. (2007). Highlights from PISA 2006: Performance of U.S. 15-year-old students in science and mathematics literacy in an international context. Washington, DC: U.S. Department of Education, National Center for Educational Statistics (NCES).

Barth, F. (1969). Ethnic groups and boundaries: The social organization of culture difference. Boston: Little, Brown \& Co.

Bates, A. W. (1995). Technology, open learning and distance education. New York: Routledge.

Beilin, H., \& Pufall, P. B. (Eds.). (1992). Piaget's theory: Prospects and possibilities. Hillsdale, NJ: Lawrence Erlbaum Associates.

Bell, A., \& Heath, B. (1993). Dances of identity: Finding an ethnic self in the arts. In S. B. Heath \& M. N. McLaughlin (Eds.), Identity and inner city youth (pp. 69-93). New York: Teacher's College Press.

Benjamin, H. (1939). The saber-toothed curriculum. New York: McGraw-Hill.

Bestor, A. (1956). The restoration of learning. New York: Alfred Knopf.

Bloom, B. S., Max, E. D., Furst, E. J., Hill, W. H., \& Krathwohl, D. R. (1956). Taxonomy of educational objectives: Handbook 1: Cognitive domain. New York: Longman.

Bobbitt, F. (1918). The curriculum. Boston: Houghton Mifflin Co.

Borton, T. (1970). Reach, touch, and teach. New York: McGraw-Hill.

Boudreau, J. E. (1999). A treatment on middle school students to increase student achievement on geometry skills. Unpublished master's thesis, California State University, Dominguez Hills.

Braddock, J. H., Royster, D. A., Winfield, L. F., \& Hawkins, R. (1991). Bouncing back: Sport and academic resilience among African American students. Education \& Urban Society, 24(10), 113-131.

Bransford, J. D., Brown, A. L., \& Cocking, R. R. (Eds.). (2000). How people learn: Brain, mind, experience, and school. Washington, DC: National Academy Press. (Available online at http://books.nap.edu/catalog/6160.html)

Braswell, J., Daane, M., \& Grigg, W. (2003). The nation's report card: Mathematics highlights 2003. Washington, DC: U.S. Department of Education, National Center for Education Statistics. 
Braxton, S., Bronico, K., \& Looms, T. (1995). Instructional design methodologies and techniques. Retrieved January 30, 2006, from University of Michigan, Educational Software Design and Authoring Web site: http://www.umich.edu/ ed626/Gerlach_Ely/ge_main.htm

Brook, J., Nomura, C., \& Cohen, P. (1989). A network of influences on adolescent drug involvement: Neighborhood, school, peer, and family. Genetic, Social, \& General Psychology Monographs, 115(1), 303-321.

Bruner, J. S. (1960). The process of education. Cambridge, MA: Harvard University Press.

Bruner, J. S., Goodnow, J. J., \& Austin, G. A. (1956). A study of thinking. Quarterly Review of Biology, 32(3), 314-315.

Burton, L. D. (2003, April). The 'formal," the "planned," and the "learned" curriculum in an elementary education methods course for mathematics: Three perspectives on course content. Paper presented at the meeting of the Association for the Advancement of Curriculum Studies, Chicago, IL.

Bush, G. W. (2005). No child left behind: Expanding the promise: Guide to President Bush's FY 2006 education agenda. Washington, DC: U. S. Department of Education.

Campbell, P. (2006). School Accountability Letter \#2. Retrieved July 22, 2007, from http://www.stls.frb.org/publications/re/letter/apr_04.htm

Carter, L. S. (1969). The system approach to education: Mystique and reality. Educational Technology, 24, 29-37.

Clewell, B. C., Consentino de Cohen, C., Campbell, P. B., \& Perlman, L. (2005). Review of evaluation studies of mathematics and science curriculum and professional development models. Retrieved September 25, 2008, from http://www.urban.org/publications/411149.html

Chickering, A. W., \& Gamson, Z. (1987). Seven principles for good practice in undergraduate education. AAHE Bulletin, 40(7), 3-7.

Collings, E. (1923). An experiment with a project curriculum. New York: Macmillan Company.

Commission on Reorganization of Secondary Education. (1918). Cardinal principles of secondary education. Bulletin \#35. Washington, DC: U. S. Bureau of Education. 
Cordero, G., \& Garcia Garduno, J. M. (2004). The Tylerian curriculum model and the reconceptualists. Interview with Ralph W. Tyler (1902-1994). Revista Electronica de Investigacion Educativa, 6(2). Retrieved July 2, 2008, from http://redie.uabc.mx/vol6no2/contenido-cordero.html

Crosswhite, F. J. (1985). Second International Mathematics Study summary report for the United States. Champaign, IL: Stipes Publishing Company.

Darling-Hammond, L., Holtzman, D., Gatlin, S. J., \& Heilig, J. V. (2005). Does teacher preparation matter? Evidence about teacher certification, teach for America, and teacher effectiveness. Retrieved September 25, 2008, from http://www.ncate.org/documents/EdNews/StanfordTeacherCertificationRe port.pdf

Dewey, J. (1915). Schools of tomorrow. New York: E.P. Dutton \& Company.

Dewey, J. (1997). Democracy and education: An introduction to the philosophy of education. New York: Free Press. (Original work published 1916)

Driscoll, D. P., Woodruff, V., Christensen, D., \& Houlihan, T. G. (2005). Using NCLB funds to support extended learning time: Opportunity for afterschool program. The Council of Chief State Officers (CCSO). Retrieved July 30, 2008, from http://www.financeproject.org/publications/usingnclbfunds.pdf

Durlak, J. A., \& Weissberg, R. P. (2005). Outcomes from afterschool programs. Paper presented at the meeting of the W.T. Grant Foundation on After-School Grantees, Washington, DC.

Earls, J. M. (2007). Science and mathematics: A formula for $21^{\text {st }}$ century success. Retrieved July 24, 2008, from http://regents.ohio.gov/samepac/reports/ SAMEPAC_REPORT_FINAL_1-22.pdf

Edmonds, R. (1986). Characteristics of effective schools. In U. Neisser (Ed.), The school achievement of minority children: New perspectives (pp. 93-104). Hillsdale, NJ: L. Erlbaum Associates.

Eggen, P., \& Kauchak, D. (2001). Educational psychology: Windows on classrooms (5 $5^{\text {th }}$ ed.). Upper Saddle River, NJ: Prentice Hall.

Eglash, R. (2006). Culturally situated design tools: Ethnocomputing from field site to classroom. American Anthropologist, 108(2) 347-362.

Enderle, J. D., Liebler, C. M., Haapala, S. A., Hart, J. L., Thonakkaraparayil, N. T., Romonosky, L. L. et al. (2004). The University of Connecticut biomedical engineering mentoring program for high school students. Biomedical Sciences Instrumentation, 40, 484-490. 
Engelhard, G. (1990). Gender differences in performance on mathematics items: Evidence from the United States and Thailand. Contemporary Educational Psychology, 15, 13-26.

Fabiano, R. (2004). After school in Lincoln Square at Martin Luther King Jr. High School (Fact Sheet Report). Washington, DC: Policy Studies Associates.

Farbman, D.A. (2003) The forgotten eighty percent: The case for making the most of children's out-of-school time. Retrieved June 9, 2003, from Massachusetts 2020 website http://www.mass2020.org/whitepaperFINAL.pdf

Fauser, M., Henry, K., \& Norman, D. K. (2006). Comparison of alternative instructional design model. Online Notebook. Retrieved July 22, 2008, from http://deekayen.net/ comparison-alternative-instructional-design-model

Fennell, S. (2007). President's messages: Focal points: Where we are and what's next. NCTM News Bulletin (March 7, 2007). Retrieved August 25, 2008, from http://www.nctm.org/about/president.aspx

Ferguson, G. A., \& Takane, Y. (1989). Statistical analysis in psychology and education. New York: McGraw-Hill.

Flinders, D., \& Thornton, S. (2004). The curriculum studies reader ( $2^{\text {nd }}$ ed.). New York: Routledge Falmer.

Fullan, M. (1993). Change focus. London: Falmer Press.

Galbo, K. (1989, April). Peer coaching: Preliminary findings regarding the reality of follow through. Paper presented at the annual meeting of the American Educational Research Association, San Francisco.

Garcia Garduno, J. M. (1995). The consolidation of curriculum theory in the United States (1912-1949). Revista Latinoamericana de Estudios Educativos, 15(2), 57-81.

Gagne, R. M., \& Briggs, L. J. (1974). Principles of instructional design. New York: Holt, Rhinehart, \& Winston.

Gardner, H. (1993). Multiple intelligences: The theory in practice. New York: Basic Books.

Gentry, C. G. (1994). Introduction to instructional development: Process and technique. Belmont, CA: Wadsworth Publishing Company. 
Ginsburg, A., Leinwand, S., Anstrom, T., \& Pollock, E. (2005). What the United States can learn from Singapore's world-class mathematics system (and what Singapore can learn from the United States). Washington, DC: American Institute for Research.

Ginsburgh, H. P., \& Opper, S. (1988). Piaget's theory of intellectual development (3 ${ }^{\text {rd }}$ ed.). Englewood Cliffs, NJ: Prentice Hall.

Glasser, W. (1998). The quality school: Managing students without coercion (Rev. ed.). New York: HarperPerennial.

Glatthorn, A. A., \& Joyner, R. L. (2005).Writing the winning thesis or dissertation: A step-by-step guide ( $2^{\text {nd }}$ ed.). Thousand Oaks, CA: Corwin Press.

Gordon, C. W. (1957). The social system of the high school: A study in the sociology of adolescence. Glencoe, IL: Free Press.

Grant, M. M. (2002). Getting a grip on project-based learning: Theory, cases, and recommendations. Meridian: A Middle School Computer Technologies Journal, 5(1), 1-3. Retrieved September 25, 2008, from http://www.ncsu.edu/ meridian/win2002/514/index.html

Gregor, R. (1996). The empirical development of a curriculum on the issues concerning the history of ancient Israel. Unpublished doctoral dissertation, Andrews University, Berrien Springs, MI.

Gronlund, N. E. (2000). How to write and use instructional objectives (6 $6^{\text {th }}$ ed.). Upper Saddle, NJ: Merrill.

Gronlund, N. E. (2006). Assessment of student achievement (8 ${ }^{\text {th }}$ ed.). New York: Pearson Education.

Grootenboer, P., \& Hemmings, B. (2007) Mathematics performance and role played by affective and background factors. Mathematics Education Research Journal, 19(3), 3-20.

Gustafson, K. L., \& Branch, R. M. (2002). Survey of instructional development models ( $4^{\text {th }}$ ed.). Syracuse, NY: ERIC Clearing house on Information \& Technology. (ED477517)

Habenicht, J., \& Burton, L. (2004). Teaching the faith: An essential guide for building faith-shaped kids. Hagerstown, MD: Review \& Herald.

Harvey, B., \& Shortt, J. (2001). Working together for children and families: A community's guide to making the most of out-of-school time. Wellesley, MA: National Institute on Out-of-School Time. 
Heller, C., \& Hawkins, J. (1994). Teaching tolerance: Notes from the front line. Teachers College Record, 95(3), 227-268.

Herrera, T., \& Owens, D. (2001). Realizing reform in school mathematics. Theory \& Practice, 40(2), 84 -92.

Hillman, M. (2007). Side streets: A research-based mathematics intervention program. The Princeton Review. Retrieved June 25, 2008, from http://www.tprk12.com/SS_M_WhitePaper_2007_FINAL.pdf

Hollyman, D. (2007). Bruner's work on cognition and constructivism: A web overview. Retrieved August 14, 2007, from http://augeocities.com/vanunoo/Humanature/ bruner.html

Horn, L., \& Nunez, A. (2000). Mapping the road to college: First-generation students' math track, planning, strategies, the context of support. Washington DC: U.S Department of Education. (NCES 2000-153)

Horowitz, J. E. (2005). Inside highschool reform: Making the changes that matter. San Francisco: WestEd.

Howard, J. (1990). Getting smart: The social construction of intelligence. Lexington, MA: The Efficiency Institute.

Howe, R. (1998) The AMS and mathematics education: The revision of the "NCTM Standards." Retrieved June 25, 2008, from http://www.ams.org/notices/ 199802/ howe.pdf

Howell, D. C. (2002). Statistical methods for psychology (5th ed.). Pacific Grove, CA: Duxbury.

Huang, R. (2002). Mathematics teaching in Hong Kong and Shanghai: A classroom analysis from the perspective of variation. Unpublished doctoral dissertation, The University of Hong Kong.

Husen, T. (Ed.). (1967). International study of achievement in mathematics (Vols. 1-2. New York: John Wiley \& Sons.

Hutchins, R. M. (1936). The higher learning in America. New Haven, CT: Yale University Press.

Ianni, F. A. J., \& Josephs, L. S. (1964). The curriculum research and development program of the U. S. Office of Education. Journal of Educational Research, 58, 348-351. 
Imel, S. (1988). Workplace literacy programs (Report No. 70). Columbus, OH: ERIC Clearinghouse on Adult, Career, and Vocational Education. (ERIC Document Reproduction Service No. ED 292974)

International Association for the Evaluation of Educational Achievement. (1967). The first international mathematics study (FIMS). Amsterdam: Author.

Jarrett, J. L. (1977). I'm for the basics: But let me define them. Phi Delta Kappan, 59(4), 235-239.

Jenner, E., \& Jenner, L. W. (2007). Results from a first-year evaluation of academic impacts of an after-school program for at-risk students. Journal of Education for Students Placed at Risk, 12(2), 213-237.

Johnson, L. B. (1964). A time for action. New York: Washington Square Press.

Jones, E. E. (1984). Social stigma: The psychology of marked relationships. New York: Freeman.

Jones, R. (2001). Involving parents is a whole new game: be sure to win! Education Digest, 67(3), 36-43.

Jordan, W. J., \& Nettles, S. M. (1999). How students invest their time out of school: Effects on school engagement, perceptions of life chances, and achievement (Rep. No. 29). Baltimore, MD: Center of Research on the Education of Students Placed At Risk (CRESPAR).

Marsh, H. W. (2002). Causal ordering of academic self-concept and achievement. Paper presented at the Self-concept Enhancement and Learning Facilitation Research Centre International Conference, Sydney, Australia.

Kame'enui, E. J., Carnine, D. W., Dixon, R. C., Simmons, D. C., \& Coyne, M. D. (2002). Effective teaching strategies that accommodate diverse learners ( $\left.2^{\text {nd }} \mathrm{ed}.\right)$. Upper Saddle River, NJ: Merrill Prentice Hall.

Kanter, P. F. (1992). Helping your child learn. Retrieved July 4, 2006, from http://www.kidsource.com/kidsource/content/learnmath_index.html

Kember, D., Ho, A., \& Hong, C. (2008). The importance of establishing relevance in motivating student learning. Active Learning in Higher Education, 9(3), 249263.

Kilpatrick, J., Swafford, J., \& Findell, B. (Eds.) (2001). Conclusions and recommendations. In J. Kilpatrick \& B. Findell (Eds.), Adding it up: Helping children learn mathematics (pp. 408-432). Washington, DC: National Academy Press. 
Kim, T. H. (2006). Impact of inquiry-based teaching on student mathematics achievement and attitude. Unpublished dissertation, University of Cincinnati.

Kirkpatrick, W. H. (1995). The project method. In F. M. Schultz (Ed.), Sources: Notable selections in education (1 ${ }^{\text {st }}$ ed., pp. 26-33). Guilford, CT: Dushkin Publishing Group. (Original work published 1918)

Krajcik, J., Czerniak, C., \& Berger, C. (1999). Teaching children science: A projectbased approach. Boston: McGraw-Hill.

Lagemann, E. C. (1997). Contested terrain: A history of education research in the United States, 1890-1990. Educational Researcher, 26(9), 5-17.

Lappan, G. (2000). A vision of learning to teach for the 21st century. School Science and Mathematics, 100(6), 319-326.

Lappan, G. (1998). Texts and teachers: Keys to improved mathematics learning. Retrieved September 25, 2008, from http://www.nctm.org/about/ content.aspx?id=1024

Larson, R.W. (2002). How U.S. Students Spend their Time: What it Tells Us About their Development. Psychological Science Journal, 10(5), 60-164.

Lauer, P. A., Akiba, M., Wilkerson, S. B., Apthrup, H.S., Snow, D., \& Martin-Glenn, M. (2006). Helping youth succeed through out-of-school time programs. Review of Educational Research, 76(2), 275-313.

Laver, P. A., Akiba, M., Wilkerson, S. B., Apthorp, H. S., Snow, D., \& Glen, M. L. (2006). Out-of-school-time program: A meta-analysis of effects for at-risk students. Review of Educational Research, 76(2), 275-313. Retrieved July 13, 2007, from http://www.apps.isiknowledge.com/CCC/CW.cgi?CustomersID= CCC\&CustomersIP=143.207

Leath, A. T. (2003). Report advocate changing in the culture of science and math education. The AIP Bulletin of Science: Policy News. Retrieved July 6, 2006, from http://www.acp.org/fyi/2003/063.html.

Leath, A. T. (2005, November 4). Recommendations from new national academics report. FYI: The AIP Bulletin of Science Policy News, 157. Retrieved July 6, 2006, from http://www.aip.org/fyi/2005/157.html

Lemke, M., Sen, A., Pahlke, E., Partelow, L., Miller, D., Williams, Tr., Kastberg, D., \& Joceltyn, L. (2005). International outcomes of learning in mathematics literacy and problem solving: PISA 2003 results from the U. S. perspective. Washington, DC: U. S. Department of Education, National Center for Education Statistics. 
Leonard, C., Bourke, S. \& Schofield, N. (2004). Affecting the affective: Affective outcomes in the context of school effectiveness, school improvement, and quality schools. Issues in Educational Research, 14(1), 1-28.

Levin, D. U., \& Lezotte, L. W. (1990). Unusually effective schools: A review and analysis of research and practice. Madison, WI: National Center for Effective Schools Research and Development.

Loke, A. Y., Wong, F., \& Kan, E. (1997). An action learning study of teacher-student partnership: Integration of theory and practice in health education. In D. Kember, B. Lam, L. Yan, J. C. K. Yum, \& S. B. Liu (Eds.), Case studies of improving teaching and learning from the action learning project (pp. 79-87). Hong Kong: Action Learning Project.

Lucas, D. M. (2004). The perceptions of the importance of math and math education in Appalachia. Retrieved July 22, 2008, from http://www.acclaimmath.org/docs/monographs/Monograph_01_Lucas.pdf.

Lucas, D. M. (2005). A rural community's perception of the importance of math and math education in Appalachia. Athens, OH: ACCLAIM.

Ma, X., \& Xu, J. (2004). Determining the causal ordering between attitude toward mathematics and achievement in mathematics. American Journal of Education, 110(3), 256-280.

Malhoit, G. (2005). Providing rural students with a high quality education: The rural perspective on the concept of educational adequacy. Arlington, VA: The School and Community Trust.

Marshall, J. D., Sears, J. T., Schubert, W. H., Stollenwerk, D. A., et al. (2000). Turning points in curriculum: A contemporary American memoir. Upper Saddle River, NJ: Merrill.

Marzano, R. J. (2003) Notes and reflections for professional development from professional developers. Naperville, IL: North Central Regional Educational Laboratory. Retrieved July 3, 2008, from Error! Hyperlink reference not valid.

Mathematical Sciences Education Board. (2002). Studying classroom teaching as a medium for professional development: Proceedings of a U.S. - Japan workshop. Washington, DC: Author.

McCarthy, C. (1994). Multicultural discourses and curriculum reform: A critical perspective. Educational Theory, 44(1), 81-118.

McLaughlin, B. (2007, Summer). Building a field. Out-of-School Time Newsletter, p. 1. 
McMillan, J. H., \& Schumacher, S. (2001). Research in education (5 ${ }^{\text {th }}$ ed.). New York: Addison Wesley Longman.

Naden, R. C. (1992). Empirical development of curriculum materials. Unpublished manuscript.

National Center for Educational Statistics. (1999). Third international mathematics and science study. Retrieved November 10, 2003, from http://nces.ed.gov/timss/

National Center for Education Statistics. (2007). Academic pathways, preparation, and performance: A descriptive overview of the transcripts from the high school graduating class of 2003-04. NCES 2007-316. Washington, DC: Author.

National Committee of the National Education Project on Instruction. (1963). Planning and organizing for teaching. Washington, DC: National Education Association.

National Council of Teachers of Mathematics. (1989). Curriculum and evaluation standards for school mathematics. Reston, VA: Author.

National Council of Teachers of Mathematics. (1992). Curriculum and evaluation standards for school mathematics. Reston, VA: Author.

National Council of Teachers of Mathematics. (1997). NCTM helps launch discussion on $\mathrm{K}-14$ algebra $\left(34^{\text {th }} \mathrm{ed}.\right)$. Reston, VA: Author.

National Science Foundation. (2000). Poor test scores constitutes national emergency. Retrieved July 30, 2008, from http://www.accessmylibrary.com/coms2/ summary_02866-28593881_ITM

National Science Foundation. (2006). Science and engineer indicators. Arlington, VA: Division of Resource Statistics. (NSB06-01) Retrieved July 30, 2008, from http://www.nsf.gov.statistics/seind06/front/contrib.htm\#top

Newman, S. A., Fox, J. A., \& Flynn, E. A. (2000). American afterschool choice: The prime time for juvenile crime or youth enrichment and achievement. Retrieved July 13, 2006, from the Fight Crime: Invest in Kids website: http://www.fightcrime.org

Novak, J. D. (1986). The importance of emerging constructivist epistemology for mathematics education. Journal of Mathematical Behavior, 5(2), 181-184.

Oppenheim, A. N. (1966). Questionnaire design and attitudinal measurement. New York: Basic Books. 
Pascopella, A. (2007). Focal Points for Pre-K-8 Math. District Administrator: The Magazine for K-12 Education Leaders. Retrieved July 13, 2008, from http://www.districtadministraion.com/viewarticle.aspx?articleid=1164

Perrone, V. (1994). How to engage students in learning. Educational Leadership, 51(5), 11-13.

Peter, N. (2002). Outcomes and research in out-of-school time program and design. Philadelphia, PA: Best Practices Institute.

Phenix, P. H. (1962). The disciplines as curriculum content. In A. H. Passow (Ed.), Curriculum crossroads. New York: Teacher's College Press.

Piaget, J. (1950). The psychology of intelligence. San Diego, CA: Harcourt Brace Jovanovich.

Piaget, J. (1970). Piaget theory. In P. Mussen (Ed.), Carmichael's manual of child psychology: Vol. 1. New York: Wiley.

Piha, S. (2004). Promising practice report: The afterschool program in Lincoln Square at MLKJr. High School campus. New York: Wellesley College.

Plank, S. B., \& Jordan, W. J. (1997). Reducing talent loss: The impact of information, guidance, and actions on post-secondary enrollment (Report No. 9). Baltimore: Johns Hopkins University, Center for Research on the Education of Students Placed At Risk.

Popham, W. J., \& Baker, E. I. (1970). Systematic instruction, Inglewood, Cliffs, NJ: Prentice Hall.

Postlethwaite, N. T. (1967). School organization and student achievement. A study based on achievement in mathematics in twelve countries. New York: John Wiley \& Sons.

Pratt, D. (1980). Curriculum design and development. New York: Harcourt Brace Jovanovich.

Pratt, D. (1994). Curriculum planning: A handbook for professionals. Orlando, FL: Harcourt Brace.

Quesinberry, E. (2002). Result from nation's report card shows improvement in math: narrowing of achievement gap. Retrieved July 22, 2008, from http://www.ed.gov?news/pressreleases.

Raymond, C. L., Goodvin, S., \& Niles, R (2005). Identifying the attitudes and traits of teachers with an at-risk student population in a multi-cultural urban high school International. Journal of Educational Management, 19(5), 437-449. 
Ralston, A. (2005). The real scandal in American school mathematics. Education Week, 24(33), 35.

Ravitch, D. (2006). National standards: ' 50 standards for 50 states' is a formula for incoherence and obfuscation. Education Week, 25(17), 54-8.

Rebello, N.S., Cui, L., Bennett, A.G., Zollman, D.A. \& Ozmek, D.J. (2007). Transfer of Learning in Problem-Solving in the context of Mathematics and Physics. Retrieved September 26, 2007 from http://web.phys.ksu.edu/paper/ 2006/TransferInPro

Reys, R. (2002, November 15). Reform mathematics education. Christian Science Monitor. Retrieved July 8, 2008, from http://www.cmonitor.com/2002/ 1115/p09s01-coop.html

Reys, R. (2003). Assessing the impact of standards-based middle grades mathematics curriculum materials on student achievement. Journal for Research in Mathematics Education, 34(1), 74-95.

Reys, R. E., Lindquist, M. M., Lambdin, D. V., \& Smith, N. L. (2007). Helping children learn mathematics ( $8^{\text {th }}$ ed.). Hoboken, NJ: John Wiley and Son.

Richards, M. N. (2002). Variables related to the successful completion of the first year in business calculus at three Jamaican universities. Unpublished doctoral dissertation, Andrews University, Berrien Springs, MI.

Ridings, J. (1981). An interview with Ralph Tyler [Occasional papers No. 13]. Retrieved May 15, 2004, from http://www.wmich.edu/evalctr/pubs/ops/

Richards, Z. (1892). Historical sketch. History of the National Education Association of the United States: 1857-1891. Washington, DC: National Education Association.

Rose, H., \& Betts, J. R. (2004). The effect of high school courses on earnings. Review of Economics and Statistics, 86(2), 497-513.

Rose, H., \& Betts, J. R. (2001). The link between high school curriculum, college graduation, and earnings: Math matters. San Francisco: Public Policy Institute of California.

Rosenshine, B., \& Meister, C. (1992). The use of scaffolds for teaching higher-level cognitive strategies. Educational Leadership, 49(7), 26-33.

Rugg, H. (1926). Curriculum-making: Points of emphasis. In G.M. Whipple (Ed.), The twenty-sixth yearbook of the national society for the study of education: The 
foundation and technique of curriculum-construction (pp. 147-162).

Bloomington, IL: Public School Publishing Company.

Rutter, M., Maughan, B., Mortimiore, P., Ouston, J., \& Smith, A. (1979). Fifteen thousand hours: Secondary schools and their effects on children. Cambridge, MA: Harvard University Press.

Sakiz, G. (2007). Does teacher affective support matter? An investigation of the relationship among planned teacher affective support, sense of belonging, academic emotions, academic self-efficacy, beliefs, and academic effort in middle school mathematics classroom (Doctoral dissertation, Ohio State University, 2007). Retrieved July 14, 2008, from dissertation \& thesis full database. (Publication No. ATT 3262063)

Sarita, K. (2005, Spring). Use of project-based learning. Afterschool Matters, 4, 2.

Schlafty, P. (2000). Why public schools are being federalized. Retrieved June 2, 2008, from http://www.eagleforum.org/psr/2000/apr00/psrapr2000.html

Schoen, H. L. (1993). Assessment issues from a mathematics education perspective. Retrieved September 25, 2008, from http://www.stemworks.org/Bulletins/ seb93-1.html

Schwarz, R. W. (1979). Light bearers to the remnant. Denominational history textbook for Seventh-day Adventist college classes. Mountain View, CA: Pacific Press.

Seguel, M. L. (1966). The curriculum field: Its formative years. New York: Teacher College Press.

Seigler, R. S. (1991). Children's thinking (2nd ed). Englewood Cliffs, NJ: Prentice-Hall.

Selmanovic, S. (1996). The empirical development of a curriculum on faith development. Unpublished doctoral dissertation, Andrews University, Berrien Springs, MI.

Sergiovanni, T. J., \& Starratt, R. J. (1998). Supervision a redefinition. New York: McGraw-Hill.

Shaw, F. (1966). Changing the curriculum. Review of Educational Research, 36(3), 343-352.

Sherman, H. J., Richardson, L. I., \& Yard, G. J. (2005). Teaching children who struggle with mathematics. Upper Saddle River, NJ: Pearson.

Silberman, C. E. (1970). Crisis in the classroom. New York: Random House. 
Silver, E. A. (1986). Using conceptual and procedural knowledge: A focus on relationships. In J. Hiebert (Ed.), Conceptual and procedural knowledge: The case of mathematics. Hillsdale, NJ: Lawrence Erlbaum.

Silver, E. A. (1987). Foundations of cognitive theory and research for mathematics problem-solving instruction. In A. H. Schoenfled (Ed.), Cognitive science and mathematics education (pp. 33-60). New York: Lawrence Erlbaum.

Silver, E. A. (1998). Improving mathematics in middle school: Lessons from TIMSS and relates research. Retrieved April 19, 2005, from http://www.ed.gov/inits/Mat/silver.html

Silver, E. A. (2000). Improving mathematics teaching and learning: How can principles and standards help? Mathematics Teaching in the Middle School, 6(1), 20-23.

Silver, E. A. (2002). Education research and education policy: Be careful what you wish for! Journal for Research in Mathematics Education, 33(2), 74-77.

Silver, E. A., \& Kenney, P. A. (Eds.) (2000). Results from the Seventh Mathematic Assessment of the National Assessment of Educational Progress. Reston, VA: NCTM.

Silver, H., Strong, R., \& Perini, M. (2000). So each may learn: Integrating learning styles and multiple intelligences. Alexandria, VA: ASCD.

Slavin, R., Karweit, N., \& Madden, N. (1989). Effective programs for students at risk. Boston: Allyn \& Bacon.

Soslau, E. G., \& Yost, D. S. (2007). Urban service-learning: An authentic teaching strategy to deliver a standards-driven curriculum. Journal of Experiential Education, 30(1), 36-53.

Stronge, J.H. (2002). Qualities of effective teachers. Alexandria, VA: Association for Supervision and Curriculum Development.

Sutherland, P. (1992). Cognitive development today: Piaget and his critics. London: Paul Chapman.

Suydan, M. (1990). Curriculum and evaluation standards for mathematics education. ERIC/SMEAC Mathematics Education Digest. Retrieved August 25, 2007, from http://www.ericdigest.org/pre-9215/evaluation.html (ED31963000)

Taba, H. (1962). Curriculum development: Theory and practice. New York: Harcourt, Brace \& World. 
Tanner, D., \& Tanner, L. N. (1990). History of the school curriculum. New York: MacMillan.

Third International Mathematics and Science Study. (1995). Mathematics achievement in the middle school years: IEA's third international math and science report. International Study Center of Boston College. Retrieved August 23, 2006, from http://timss.bc.edu/timss1995/MathB.html

Third International Mathematics and Science Study. (2003). Highlights from the trends in international mathematics and science study: TIMSS 2003. National Center for Educational Statistics. Retrieved November 4, 2008, from http://nces.ed.gov/pubs2005/timss03/index.asp

Thomas, J. W., \& Mergendoller, J. R. (2000). Managing project-based learning: Principles from the field. Paper presented at the meeting of the American Educational Research Association on Creating Knowledge in the 21st Century, New Orleans.

Townsend, L. O. (2003, Spring). Dialogue in philosophy, practice, and evaluation. Afterschool Matters, 2.

Tomlinson, C. A. (2000). Differentiation of instruction in the elementary grades. ERIC Digest. (ERIC Document Reproduction No. ED443572)

Turner, J. C., \& Patrick, H. (2006). Reonceptualizing emotion and motivation to learn in classroom context. Education Psychology Review, 4(4), 377-390.

Tyler, R. (1986). Basic principles of curriculum and instruction. Chicago: University of Chicago Press. (Original work published 1949)

U. S. Congress. (2002). No Child Left Behind Act: A description of state responsibilities. Washington, DC: Council of Chief State School Officers. Retrieved August 10, 2007, from http://www.ccsso.org/publications/index.cfm

U. S. Department of Education. (1997). Mathematics and future opportunities: The importance of mathematics for college entrance. Retrieved September 28, 2008, from http://www.learndoearn.org/For-Educators/Math-and-FutureOpportunites.pdf

Usiskin, Z. (1995). What should not be in the algebra and geometry curriculum of average college-bound students? Mathematics Teachers, 88, 156-164.

Van de Walle, J. A. (2004). Elementary and middle school mathematics: Teaching developmentally ( $2^{\text {nd }}$ ed.). Sydney: Pearson.

Van de Walle, J. \& Folk, S. (2008). Elementary and middle school mathematics: 
teaching developmentally. Second Canadian Edition. Toronto, ON: Pearson Education Canada.

Van Hiele, P. (1986). Structure and insight. Orlando, FL: Academic Press.

Vygotsky, L. S. (1978). Mind in society. Cambridge, MA: Harvard University Press.

Vygotsky, L. S. (1987). Collected works of L. S. Vygotsky, Vol. 1: Problems of general psychology (Norris Minch, Trans.). New York: Plenum.

Warren, C., Brown, P., \& Freudenburg, N. (1999). Evaluation of the New York City Beacon: Summary of Phase 1 findings. New York: Academy for Educational Development.

Watson, F. G. (1963). Research on teaching science. In N. L. Gage (Ed.), Handbook of research on teaching (pp. 1031-1059). Chicago: Rand McNally.

White, E. G. (1882). Early writings. Washington, DC: Review \& Herald

White, E. G. (1903). Education. Mountain View, CA: Pacific Press.

White, E. G. (1911). The great controversy. Phoenix, AZ: Inspiration Books.

White, E.G. (1913). Counsels to teachers, parents, and students. Mountain View, CA: Pacific Press.

White, E. G. (1930). Messages to young people. Nashville, TN: Southern Publishing.

White, E. G. (1952). Education. Boise, ID: Pacific Press.

White, E. G. (1977). Mind, character, and personality. Washington, DC: Review \& Herald.

White, E. G. (1985). Reflecting Christ. Hagerstown, MD: Review \& Herald Publishing Association.

Whitenack, J., \& Yackel, E. (2002). Making mathematical arguments in the primary grades: The importance of explaining and justifying ideas. Teaching Children Math, 8(9), 524-527.

Wilkins, J. L. M., \& Ma, X. (2003). Modeling change in student attitude toward and beliefs about mathematics. The Journal of Educational Research, 97(1), 52-63.

YMCA of the USA. (2001). Afterschool for American teens: A national survey of teens' attitudes and behaviors in the hours after school. Retrieved June 15, 2006, from http://www.ymca.net/pdf/executivesummary.pdf 
Zhao, Y. (2005). Increasing math and science achievement: The best and worst of the east and west. Phi Delta Kappan, 87(3), 219-222. 
VITA 
VITA

\section{Donaldson Washington Williams}

\section{EDUCATION}

Doctor of Philosophy Curriculum \& Instruction - Andrews University Berrien Springs, Michigan, 2008.

Master of Arts in Teaching (MAT) Elementary Education - Andrews University, Berrien Springs, Michigan, 1995.

Bachelor of Science in Teaching (B.Sc.) Elementary Education - West Indies College, Mandeville, Jamaica, 1985.

Three-year Teaching Diploma - West Indies College, Mandeville, Jamaica, 1980.

Certificate \& Diploma in Teaching - University of the West Indies (in collaboration with the Jamaica Joint Board of Teacher Education), 1980, 1985.

CERTIFICATIONS

Certified by North American Division Office of Education with the following endorsements:

- Professional Elementary

- Professional Junior Academy Mathematics

- Professional Junior Academy Religion, and

- Professional Junior Academy General Science

EMPLOYMENT HISTORY

Lake Region Conference: Principal, Fifth-Eight Grade Math and Science Teacher Chicago SDA Elementary School, Chicago, Illinois, 2004 - Present. 
Allegheny West Conference: Ninth \& Tenth Grade Homeroom Teacher, Fifth Tenth Grade Math \& Science Instructor, Vice Principal -Ramah Junior Academy, Cleveland, Ohio, 1995 - 2002.

Principal/Teacher - Ethnan SDA Elementary - Pittsburgh, Pennsylvania, 2002 2004.

New Jersey Conference: Math and Science Instructor - Grades 5-10 - Waldwick SDA Academy, Waldwick, New Jersey, 1994 - 1995.

Allegheny East Conference: Homeroom Teacher - Fourth \& Fifth Grade - Trinity Temple Academy, Hillside, New Jersey, 1991 - 1994.

West Indies Union: Math content \& Methodology Instructor - Teacher Education Department, Northern Caribbean University (formerly, West Indies College) Jamaica, 1980 -1985.

Jamaican Ministry of Education: Math instructor, Tenth grade Program Glengoffe Secondary School \& Oberlin High School, 1985 - 1989.

\section{PROFESSIONAL ACTIVITIES}

1. Coordinated preparation for state recognition of Seventh-day Day Adventist K-12 Schools

2. Coordinated self study procedures for denominational recognition

3. Developed intervention plans for low performing students

4. Experienced in teacher-training, assessment and support

5. Presented at Teaching and Learning (TLC) Conference at Andrews University, July 2004 - Closing the Achievement Gap in Mathematics

6. Presented at Teaching and Learning (TLC) Conference Andrews University, July 2005 - Making of Meaning in Mathematics at the Foundation

7. Participated in research writing group sessions at Andrews University School of Education. 